\title{
Preliminary Assessment of Blending Hanford Tank Wastes
}

\author{
J. G. H. Geeting \\ D. E. Kurath
}

March 1993

Prepared for the U.S. Department of Energy under Contract DE-AC06-76RLO 1830

Pacific Northwest Laboratory

Richland, Washington 99352

\section{MASTER}




\begin{abstract}
A parametric study of blending Hanford tank wastes identified possible benefits from blending wastes prior to immobilization as a high level or low level waste form. Track Radioactive Components data were used as the basis for the single-shell tank (SST) waste composition, while analytical data were used for the double-shell tank (DST) composition. Limiting components were determined using the existing feed criteria for the Hanford Waste Vitrification Plant (HWVP) and the Grout Treatment Facility (GTF). Results have shown that blending can significantly increase waste loading and that the baseline quantities of immobilized waste projected for the sludge-wash pretreatment case may have been drastically underestimated, because critical components were not considered. Alternatively, the results suggest further review of the grout feed specifications and the solubility of minor components in HWVP borosilicate glass. Future immobilized waste estimates might be decreased substantially upon a thorough review of the appropriate feed specifications.
\end{abstract}




\section{Summary}

Pacific Northwest Laboratory (PNL) conducted a preliminary evaluation of the benefits of blending Hanford Site tank waste to be immobilized in the Hanford Waste Vitrification Plant (HWVP) and the Grout Treatment Facility (GTF). Blending was considered because many feeds to the HWVP and the GTF have chemical components that limit the waste loading in both forms to less than its maximum. The basic concept is that a feed high in one component, relative to feed limits, would be mixed with another feed that contains a low level of the same component, producing a blended stream with a lower concentration of said component. The blend could be processed with greater overall waste loading.

This report presents the results of work in which two cases were considered. Case I evaluated all tank waste currently included in the Tank Waste Remediation System (TWRS) planning basis for retrieval and pretreatment prior to immobilization as a high-level waste form [all single-shell tank (SST) waste (149 tanks) and ten double-shell tank (DST) waste types (10 tanks); namely, complexant concentrate (CC), neutralized current acid waste (NCAW), neutralized cladding removal waste (NCRW), and Plutonium Finishing Plant (PFP) waste]. Case II evaluated eight selected tanks: AY-101 (CC waste type), AY-102 (dilute waste type), AZ-101 (NCAW waste type), AZ-102 (NCAW waste type), C-105 (SST), C-106 (SST), SY-101 (CC waste type), and SY-103 (CC waste type). The eight tanks in Case II were selected because they are under consideration for early retrieval and immobilization.

The volumes of immobilized waste were estimated on the basis of sludge-washing flowsheets. The most limiting components were used to determine the allowable waste loading and hence the immobilized volumes. Case I used Track Radioactive Components (TRAC) data as the basis for the SST waste composition, while analytical data were used for the DST waste composition. Case II used analytical data for all tank compositions. In both cases, the limiting components were determined using the existing feed criteria for the HWVP and the GTF. Evaluation of Case II also included the use of the glass feed criteria models from the Compositional Variability Study (CVS) to re-evaluate HWVP loadirg and benefits of blending. Tables S.1 through S.4 summarize the quantity of final waste form estimated for Case I and Case II.

The report is preliminary, and the results should be viewed more qualitatively than quantitatively. Assumed tank compositions, sludge-washing partitioning factors, and uncertainties in some technical aspects of the HWVP and GTF feed criteria all add to quantitative uncertainty. Evaluation will continue as new information becomes available. A computer optimization program is currently being developed which incorporates the CVS modeling and should provide more detailed information on blending a large selection of tank wastes. 


\section{Case I}

For waste to be immobilized in the HWVP, Table S.1 displays a summary of the of the HWVP waste-f)rm production using the HWVP reference feed composition model. The " $25 \mathrm{wt} \%$ load" column is the widely used HWVP baseline for canister estimates. This baseline assumes that the immobilized waste volumes are only dependent on the total mass to be vitrified. The "no blend" and "total blend" columns take into account the HWVP reference feed chemical composition range (without and with the benefit of blending). The "limiting component (total blend)" column displays those components in the "total blend" which limit waste loading due to their high concentration in the feed relative to the limits. The potential benefit of blending is evident by comparison of the volume of glass associated with the bounding option of "no blend" and "total blend." This potential waste reduction, defined as the percent difference between the "no blend" and "total blend," is a measure of the maximum benefits blending may provide. The potential waste reduction is $25 \%$ for the sludge-wash-only case, $66 \%$ for the sludge wash with $\mathrm{PO}_{4}{ }^{3-}$ leach, and $69 \%$ for the sludge wash with $\mathrm{PO}_{4}{ }^{3-}$ and other leach. Note, in looking down the columns, that selected leaching and blending are both integral steps in reducing the waste volume so that it approaches the $25 \mathrm{wt} \%$ load.

The following chemical species from the HLW feed ${ }^{(s)}$ ("no blend" option) exceeded the HWVP reference feed composition: $\mathrm{Al}_{2} \mathrm{O}_{3}, \mathrm{BaO}, \mathrm{CaO}, \mathrm{Cr}_{2} \mathrm{O}_{3}, \mathrm{Fe}_{2} \mathrm{O}_{3}, \mathrm{MnO}_{2}, \mathrm{Na}_{2} \mathrm{O}, \mathrm{NiO}, \mathrm{P}_{2} \mathrm{O}_{5}, \mathrm{SO}_{3}, \mathrm{SiO}_{2}$, $\mathrm{ZrO}_{2}$, Other, $\mathrm{Cl}^{-}, \mathrm{CO}^{3}, \mathrm{NO}_{\mathrm{x}}$, and total organic constituents (TOC). Every tank had at least one HWVP outlier, ${ }^{(b)}$ and no tank's waste contents could be fully loaded (25 wt\%) without blending or further pretreatment. In order to approach the $25 \mathrm{wt} \%$ loading without blending, either pretreatments capable of reducing the concentration of the 17 chemical outliers must be developed or examination of increasing these waste concentrations must be evaluated. Blending can reduce the number of outliers from 17 to $3\left(\mathrm{P}_{2} \mathrm{O}_{5}\right.$, others, and $\left.\mathrm{Al}_{2} \mathrm{O}_{3}\right)$.

Clearly, not all of the outliers will actually be a problem for waste loading in glass, and many of these outliers, in the future, may be inconsequential when reviewed after CVS analysis. $\mathrm{SiO}_{2}$, for example, is a large constituent in glass and compensation might be made in the composition of glass frit. Similarly, $\mathrm{NO}_{\mathrm{x}}$ and TOC may not be a problem in the glass per se but in the off-gas system, which might be engineered to handle larger off-gas rates.

Conversely, $\mathrm{Cr}_{2} \mathrm{O}_{3}, \mathrm{P}_{2} \mathrm{O}_{5}$, and $\mathrm{SO}_{3}$ have serious potential to negatively impact waste loading. CVS modeling uses limits identical to the HWVP reference model for these three components, and a more detailed blending analysis using CVS would certainly flag these components as outliers too.

(a) Note that the feed components are not actually converted to oxides until they are added to the melter.

(b) An outlier is defined as a component outside the specified feed limit. 
Table S.1. Case I Waste Production Summary: HWVP

Quantity of Waste Produced(a)

\begin{tabular}{|c|c|c|c|c|c|}
\hline Pretreatment HWVP & $\begin{array}{l}25 \text { wt \% Load } \\
\text { (canisters) }\end{array}$ & $\begin{array}{l}\text { "No Blend" } \\
\text { (canisters) }\end{array}$ & $\begin{array}{c}\text { "Total } \\
\text { Blend" } \\
\text { (canisters) }\end{array}$ & $\begin{array}{c}\text { Potential } \\
\text { Waste } \\
\text { Reduction }^{(\mathfrak{b})}\end{array}$ & $\begin{array}{c}\text { Limiting } \\
\text { Component } \\
\text { ("total blend") }\end{array}$ \\
\hline Sludge wash (SW) & 34,100 & 267,000 & 200,000 & $25 \%$ & $\overline{\mathbf{P}}$ \\
\hline SW w/P leach ${ }^{(\mathfrak{c})}$ & 28,000 & 139,500 & 47,000 & $66 \%$ & Others $^{(d)}$ \\
\hline SW w/P \& other leach ${ }^{(e)}$ & 27,700 & 117,900 & 36,500 & $69 \%$ & $\mathrm{Al}$ \\
\hline
\end{tabular}

(a) Waste Production from the HWVP is based upon washed sludge from DSTs and SSTs currently included in the TWRS planning basis for retrieval and pretreatment prior to immobilization as a high-level waste form.

(b) (volume from "no blend" - volume from "total blend")/(volume from "no blend")

(c) Fraction of $P$ leached $=0.76$. This value is the required fraction of $P$ that must be removed so that it no longer limits waste loading in the "total blend".

(d) "Other" is defined as fission product elements and minor components.

(e) Fraction of $P$ leached $=0.82$. Fraction of other leached $=0.22$. These are the required fractions of $P$ and other that must be removed so that they no longer limit waste loading.

For waste to be immobilized in the GTF, compare in Table S.2 the "5 M Na load" column, which displays the widely used GTF baseline loading, with the "no blend" and "total blend" columns, which take into account the grout wasie feed acceptance criteria (without and with the benefit of blending). The potential benefit of blending is evident by comparing the volume of grout associated with the bounding options of "no blend" and "total blend." Note, in looking down the columns, that selected leaching and blending are both integral steps in reducing the waste volume so that it approaches the $25 \mathrm{wt} \%$ load.

The following grout feed acceptance criteria were exceeled in the low-level waste (LLW) feed ("no blend" option): $\mathrm{Ca}^{2+}, \mathrm{Ni}^{2+}, \mathrm{Pb}^{2+}, \mathrm{F}^{-}, \mathrm{NO}_{2}^{-}, \mathrm{OH}^{-}, \mathrm{PO}_{4}{ }^{3}, \mathrm{SO}_{4}{ }^{2-}, \mathrm{TOC}, \mathrm{Na}^{+} i$ (total cations), $\mathrm{NO}_{2}{ }^{-}$ $\left.+\mathrm{NO}_{3}{ }^{-}\right) /($total anions), and radiolytic heat content/unit volume. (By definition of the $5 \mathrm{M} \mathrm{Na}$ loading, $\mathrm{Na}$ cannot exceed the limit.) In order to approach the $5 \mathrm{M} \mathrm{Na}$ loading without the aid of blending, either pretreatments capable of reducing the concentration of the 12 different outliers must be developed or the potential for increasing these waste coricentrations must be evaluated. Blending can reduce the number of chemical outliers from 12 to $2\left(\mathrm{~F}, \mathrm{~Pb}^{2+}\right)$.

Again, not all of the GTF outliers should actually be a problem for waste loading in grout, and many of these outliers, in the future, may be inconsequential when reviewed. The current grout feed specifications are based upon three major considerations: a) thermal loading in the grout;

b) regulatory-based limits; and c) past experience. Item a is based on experimental evidence that the 
Table S.2. Case I Waste Production Summary: GTF

Quantity of Waste Produced(a)

\begin{tabular}{|c|c|c|c|c|c|}
\hline GTF & $\begin{array}{l}5 \mathrm{M} \mathrm{Na} \text { Load } \\
\left(\mathrm{m}^{3}\right) \text { grout }\end{array}$ & $\begin{array}{l}\text { "No Blend" } \\
\text { ( } \mathrm{m}^{3} \text { grout) }\end{array}$ & $\begin{array}{l}\text { "Total blend" } \\
\text { (m } \mathrm{m}^{3} \text { grout) }\end{array}$ & $\begin{array}{l}\text { Potential } \\
\text { Waste } \\
\text { Reduction }\end{array}$ & $\begin{array}{l}\text { Limiting } \\
\text { Component } \\
\text { ("total } \\
\text { blend") }\end{array}$ \\
\hline$\overline{\text { Water dilution of } 5 \mathrm{~m} \mathrm{Na}}$ & 473,000 & $3,610,000$ & $1,890,000$ & $\overline{48 \%}$ & $\overline{\mathrm{F}}$ \\
\hline $\begin{array}{l}\text { Water dilution to } 5 \mathbf{M ~ N a} \\
\text { w/F removal }\end{array}$ & 473,000 & $2,036,000$ & $1,113,000$ & $45 \%$ & $\mathrm{~Pb}$ \\
\hline $\begin{array}{l}\text { Water dilution to } 5 \mathrm{M} \mathrm{Na} \\
\mathrm{w} / \mathrm{F} \& \mathrm{~Pb} \text { removal }\end{array}$ & 473,000 & 977,000 & 473,000 & $52 \%$ & $\begin{array}{l}\text { No limiting } \\
\text { component }\end{array}$ \\
\hline
\end{tabular}

(a) Waste production from the GTF is based upon the soluble mass from the SSTs only.

(b) (volume from "no blend" - volume from "total blend")/(volume from "no blend")

grout will have acceptable physical properties when the peak cure temperature is kept below $100^{\circ} \mathrm{C}$. Item $b$ is based on specific regulatory guidance [e.g. land disposal restrictions (LDR) for organic contaminant] or on extrapolation of Extraction Procedure Toxicity (EPTOX) and Toxicity Characteristic Leaching Procedure (TCLP) tests of actual grout formulations to define probable acceptance limits for heavy metals. ${ }^{(a)}$ Item $\mathrm{c}$ is the basis for the remainder of the grout limits, and the specified limit may not be the maximum concentration that can be successfully grouted.

Regulatory limits are the basis for grout feed limitation of the following outliers: $\mathrm{Pb}^{2+}$ and $\mathrm{TOC}$. Without mitigating pretreatment or further evaluation of the regulatory-based limit, these outliers have serious potential to negatively impact waste loading.

\section{Case II}

Table S.3 displays a summary of the HWVP waste-form production of various blend options using both the HWVP reference feed composition model and the CVS model. The HWVP reference model indicates that the potential waste reduction ranges between $29 \%$ and $44 \%$, depending on the pretreatment and blend option chosen. Nearly all the benefits blending may provide in terms of final waste form reduction are gleaned from blend options 1 and 2 (see Table S.3), which blend wastes, by tank, to obtain four and three discrete waste feeds, respectively. Results suggest that a minimum

(a) Hendrickson, D. W. 1991. Grout Treatment Facility Waste Feed Acceptance Criteria. WHC-SD-WM-RD-019, Rev. 1, Westinghouse Hanford Company, Richland, Washington. 
Table S.3. Case II Waste Production Sunmary: HWVP Reference Model and CVS Model

\begin{tabular}{|c|c|c|c|c|}
\hline \multirow[b]{2}{*}{$\begin{array}{c}\text { Waste } \\
\text { Loading } \\
\text { Approach }^{(\mathrm{a})}\end{array}$} & \multicolumn{2}{|c|}{ HWVP Reference Model } & \multicolumn{2}{|c|}{ CVS Model } \\
\hline & Canisters & $\begin{array}{l}\text { Potential } \\
\text { waste } \\
\text { reduction } \\
(\%)\end{array}$ & Canisters & $\begin{array}{c}\text { Potential } \\
\text { waste } \\
\text { reduction } \\
(\%)\end{array}$ \\
\hline \multicolumn{5}{|c|}{ Pretreatment: SW Only } \\
\hline "No blend" & 11,060 & NA & 8,620 & NA \\
\hline Option $1^{(b)}$ & 7,830 & 29 & 7,810 & 9 \\
\hline Option $2^{(c)}$ & 7,580 & 31 & 7,560 & 12 \\
\hline "Total blend" & 7,470 & 32 & 7,470 & 13 \\
\hline \multicolumn{5}{|c|}{ Pretreatment: SW w/Cr Leach } \\
\hline "No blend" & 5,980 & NA & 2,380 & NA \\
\hline Option 1 & 4,210 & 30 & 2,120 & 11 \\
\hline Option 2 & 3,920 & 34 & 2,070 & 13 \\
\hline "Total blend" & 3,360 & 44 & 2,080 & 13 \\
\hline
\end{tabular}

(a) For comparison purposes, the number of canisters that would result from 25 wt\% loading is 2820 .

(b) Blend of tanks SY-101/C-106, SY-103/C-105, AZ-101/AY-101, AZ-102/AY-102, resulting in four waste feeds.

(c) Blend of tanks SY-101/C-106/AZ-102, SY-103/C-105/AY-102, AZ-101/AY-101, resulting in three waste feeds.

blending effort may provide near-maximum benefits to final waste-volume reduction. Note, in looking down the columns, that selected leaching and blending are both integral steps in reducing the waste volume so that it approaches the $25 \mathrm{wt} \%$ load.

The results obtained using the CVS model are similar to those obtained using the reference model. The potential waste reduction is substantially decreased to $9 \%$ to $13 \%$ from $29 \%$ to $44 \%$ as a result of lowering the "no blend" canister estimate to 8,620 in the CVS model from 11,060 in the reference model. CVS model analysis indicates that the benefits of blending in terms of waste production analysis are significant, although lower than that estimated from the HWVP reference model. Again note, in looking down the columns, that selected leaching and blending are both integral steps in reducing the waste volume. 
For waste to be immobilized in the GTF, compare in Table S.4 the " $5 \mathrm{M} \mathrm{Na}$ load" volume estimate, which is the widely used GTF baseline, with the "no blend" and "total blend" volume estimates, which take into account the grout waste feed acceptance criteria (without and with the benefit of blending). The potential benefit of blending is evident by comparing the volume of grout associated with the bounding options of "no blend" and "total blend." Both blend option 1 and the "total blend" result in grout production equal to the $5 \mathrm{M} \mathrm{Na}$ load, eliminating the need for pretreatment beyond that necessary to remove organics, and radiolytic heat generators.

Obviously, waste-form production estimates are highly sensitive to tank chemical composition data and sludge-wash partitioning factors. Comparison of TRAC data with core sample data has shown TRAC to be within an order of magnitude in some components and off by many orders of magnitude in other components. As a result, greater emphasis should be placed on the observed beneficial trends of blending, and less emphasis placed on the actual numbers predicted for immobilized waste volume. Since the process of selecting tank feeds to blend is based upon finding compatible feed compositions, more precise tank characterization data will be required. Tank characterization data should also include experimentally determined component solubility data, as would occur in tank waste pretreatment.

In addition to blending as a method for maximizing the waste loading, the non-regulatory limits for the glass and grout should be reviewed and considered, if possible. For vitrification, consideration should be given to designing experiments with waste simulants high in minor components whose loading is limited by solubility constraints $\left(\mathrm{Cr}_{2} \mathrm{O}_{3}, \mathrm{~F}^{-}, \mathrm{P}_{2} \mathrm{O}_{5}\right.$, and $\left.\mathrm{SO}_{3}\right)$ in an effort to extend these limits.

For grout, considerat:on should be given to designing experiments which test the regulatorybased heavy metal limits, and the limits based simply upon experience.

Table S.4. Case II Waste Production Summary: GTF (post organic destruction and heat-loading limits pretreatment)

\begin{tabular}{|c|c|c|c|}
\hline $\begin{array}{l}\text { Waste Loading } \\
\text { Approach }\end{array}$ & $\begin{array}{l}\text { Grout } \\
\left(\mathrm{m}^{3}\right)\end{array}$ & $\begin{array}{c}\text { Limiting } \\
\text { Component(s) }\end{array}$ & $\begin{array}{c}\text { Potential } \\
\text { Waste } \\
\text { Reduction }\end{array}$ \\
\hline $5 \mathrm{M} \mathrm{Na}$ load & $\overline{31,600}$ & $\overline{\mathrm{NA}}$ & $\overline{\mathrm{NA}}$ \\
\hline "No blend" & 44,600 & $\mathrm{~F}^{-}, \mathrm{Pb}^{2+}, \mathrm{SO}_{4}{ }^{2-}$ & NA \\
\hline "Total blend" & 31,600 & None & $29 \%$ \\
\hline Blend option $1^{(\omega)}$ & 31,600 & None & $29 \%$ \\
\hline
\end{tabular}

(a) Blend of tanks SY-101/C-106, SY-103/C-105, AZ-102/AY-101, AZ-101/AY-102, resulting in four waste feeds. 
Results from this study have shown that although blending can significantly increase waste loading, blending is not a pretreatment step that can replace all other pretreatments being considered. The baseline quantities of immobilized waste projected for sludge-wash cases inay have been drastically underestimated, because critical components were not considered. Alternatively, the results suggest further review of the grout feed specifications and of the solubility of minor components in HWVP borosilicate glass. Future glass and grout volume estimates might be decreased substantially upon a thorough review of the feed specifications. The results of this study suggest that blending, selective leaching, and HWVP glass and GTF grout feed specifications should be evaluated further as an element in the TWRS pretreatment strategy. 


\section{Acknowledgments}

The authors acknowledge the technical efforts and contributions of the following individuals:

P. R. Hrma (PNL) for guidance in frit design and interpretation of CVS model results, R. J. Robertus (PNL) for the use of Ternary Waste Envelope Casement Tool (TWEAT) and interpretation of TWEAT results, and E. H. Randklev (WHC), P. E. Lamont (DOE-RL), and K. P. Brooks (PNL) for investigation of Waste Form Qualification (WFQ). 


\title{
Glossary
}

\author{
BDAT best demonstrated available technology \\ CC complexant concentrate \\ CRWMS Civilian Radioactive Waste Management System \\ CVS Composition Variability Study \\ DOE Department of Energy \\ DST double-shell tank \\ DWPF Defense Waste Processing Facility \\ EA environmental assessment \\ EPTOX Extraction Procedure Toxicity \\ EM Department of Energy Office of Environmental Restoration and Waste Management \\ GTF Grout Treatment Facility \\ HLW high-level waste \\ HWVP Hanford Waste Vitrification Plant \\ LDR land disposal restrictions \\ LFCM Liquid-Fed Ceramic Melter \\ LLW low-level waste \\ MCC-1 a durability test developed by the Materials Characterization Center in which a small \\ monolith of glass is leached for 28 days in deionized water at $90^{\circ} \mathrm{C}$ \\ NCAW neutralized current acid waste \\ NCRW neutralized cladding removal waste
}




$\begin{array}{ll}\text { OCRWM } & \text { Office of Civilian Radioactive Waste Management } \\ \text { PFP } & \text { Plutonium Finishing Plant } \\ \text { PNL } & \text { Pacific Northwest Laboratory } \\ \text { RL } & \text { Department of Energy, Richland Field Office } \\ \text { SRTC } & \text { Savannah River Technology Center } \\ \text { SST } & \text { single-shell tank } \\ \text { SW } & \text { sludge wash } \\ \text { TCLP } & \text { Toxicity Characteristic Leaching Procedure } \\ \text { TOC } & \text { total organic constituents } \\ \text { TRAC } & \text { Track Radioactive Components } \\ \text { TRU } & \text { transuranic } \\ \text { TWEAT } & \text { Ternary Waste Envelope Assessment Tool } \\ \text { WWRS } & \text { Tank Waste Remediation System } \\ \text { WA-SRD } & \text { Waste Acceptance System Requirements Document } \\ \text { WAPS } & \text { Waste Acceptance Product Specifications } \\ \text { Whaste Form Qualification }\end{array}$




\section{Contents}

Abstract $\ldots \ldots \ldots \ldots \ldots \ldots \ldots \ldots \ldots \ldots \ldots \ldots \ldots \ldots \ldots \ldots \ldots \ldots \ldots \ldots \ldots \ldots$

Summary $\ldots \ldots \ldots \ldots \ldots \ldots \ldots \ldots \ldots \ldots \ldots \ldots \ldots \ldots \ldots \ldots \ldots \ldots$

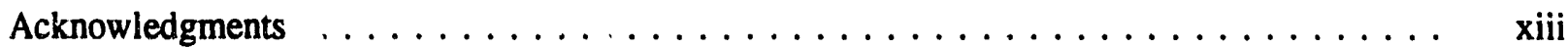

Glossary $\ldots \ldots \ldots \ldots \ldots \ldots \ldots \ldots \ldots \ldots \ldots \ldots \ldots \ldots \ldots \ldots \ldots \ldots \ldots$

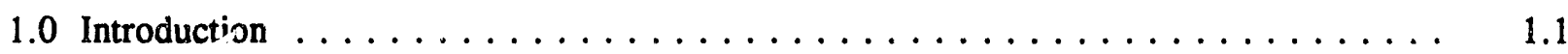

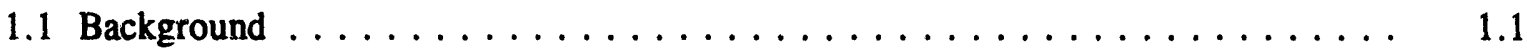

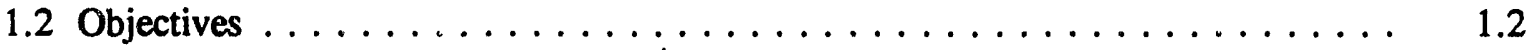

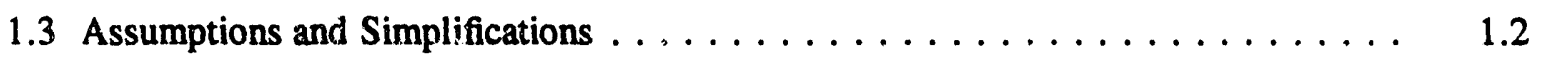

1.4 Approach for This Analysis $\ldots \ldots \ldots \ldots \ldots \ldots \ldots \ldots \ldots \ldots \ldots$

1.4.1 Case I: HWVP Feed Blend Analysis $\ldots \ldots \ldots \ldots \ldots \ldots \ldots \ldots .7$

1.4.2 Case I: GTF Feed Blend Analysis $\ldots \ldots \ldots \ldots \ldots \ldots \ldots \ldots \ldots \ldots$

1.4.3 Case II: HWVP and GTF Feed Blend Analysis $\ldots \ldots \ldots \ldots \ldots \ldots 1.8$

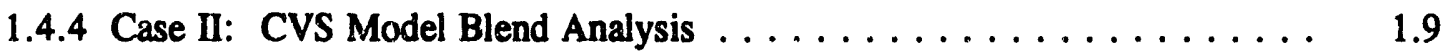

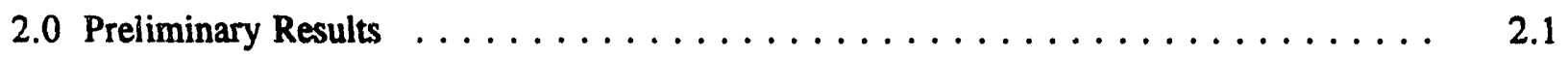

2.1 Case I: Blending HLW Using HWVP Reference Feed Criteria $\ldots \ldots \ldots \ldots \ldots 2.1$

2.1.1 Canister Estimate: Sludge-Wash Pretreatment $\ldots \ldots \ldots \ldots \ldots \ldots .2 .2$

2.1.2 Canister Estimate: Sludge-Wash with Selective Leaching $\ldots \ldots \ldots \ldots .2 .5$

2.1.3 Comparison of HWVP Reference Model with a CVS Model Approximation $\ldots \ldots \ldots \ldots \ldots \ldots \ldots \ldots \ldots \ldots . .5$

2.2 Case I: Blending LLW Using Grout Feed Acceptance Criteria $\ldots \ldots \ldots \ldots \ldots$.

2.2.1 Grout Volume Estimate $\ldots \ldots \ldots \ldots \ldots \ldots \ldots \ldots \ldots \ldots \ldots$

2.3 Case II: Blending HLW Using HWVP Reference Feed Criteria . . . . . . . . . 2.9 
2.4 Case II: Blending HLW Using CVS Modeling $\ldots \ldots \ldots \ldots \ldots \ldots \ldots$

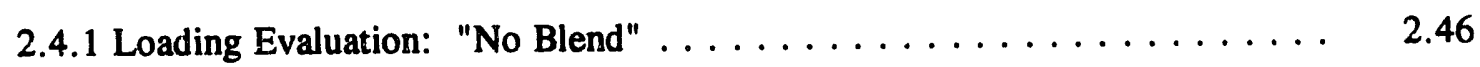

2.4.2 Loading Evaluation: Selected Blends $\ldots \ldots \ldots \ldots \ldots \ldots \ldots \ldots$

2.4.3 Comparison of HWVP Reference Model and the CVS Model . . . . . . 2.51

2.5 Case II: Blending LLW Using Grout Feed Acceptance Criteria . . . . . . . . 2.53

3.0 Discussion $\ldots \ldots \ldots \ldots \ldots \ldots \ldots \ldots \ldots \ldots \ldots \ldots \ldots \ldots \ldots \ldots \ldots \ldots$

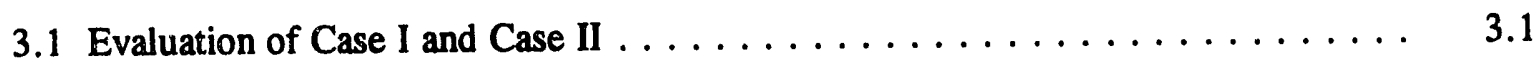

3.2 HWVP Feed Acceptance Criteria $\ldots \ldots \ldots \ldots \ldots \ldots \ldots \ldots \ldots \ldots \ldots \ldots$

3.2.1 Phosphate $\ldots \ldots \ldots \ldots \ldots \ldots \ldots \ldots \ldots \ldots \ldots \ldots \ldots \ldots \ldots$

3.2.2 Chromium $\ldots \ldots \ldots \ldots \ldots \ldots \ldots \ldots \ldots \ldots \ldots \ldots \ldots \ldots \ldots \ldots$

3.3 Grout Feed Acceptance Criteria $\ldots \ldots \ldots \ldots \ldots \ldots \ldots \ldots \ldots \ldots$

3.3.1 Impact on Grout Volume Estimates $\ldots \ldots \ldots \ldots \ldots \ldots \ldots \ldots . \ldots \ldots$

3.4 Benefit to Waste Form Qualification (WFQ) $\ldots \ldots \ldots \ldots \ldots \ldots \ldots$

3.4.1 WFQ Background $\ldots \ldots \ldots \ldots \ldots \ldots \ldots \ldots \ldots \ldots \ldots$

3.4.2 Potential Blending Benefits to WFQ $\ldots \ldots \ldots \ldots \ldots \ldots \ldots \ldots$

3.5 Drawbacks to Blending . . . . . . . . . . 3.6

4.0 Conclusions and Recommendations $\ldots \ldots \ldots \ldots \ldots \ldots \ldots \ldots \ldots \ldots \ldots$

5.0 References $\ldots \ldots \ldots \ldots \ldots \ldots \ldots \ldots \ldots \ldots \ldots \ldots \ldots \ldots \ldots \ldots \ldots \ldots$

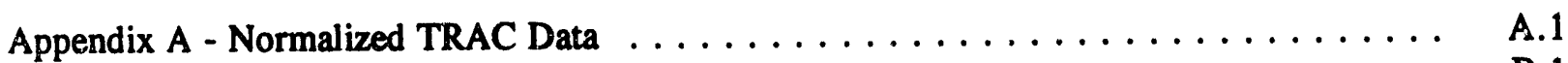

Appendix B - Case I HWVP Tank Composition Data $\ldots \ldots \ldots \ldots \ldots \ldots \ldots \ldots$. . . . . .

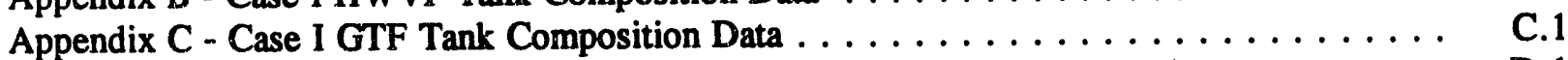

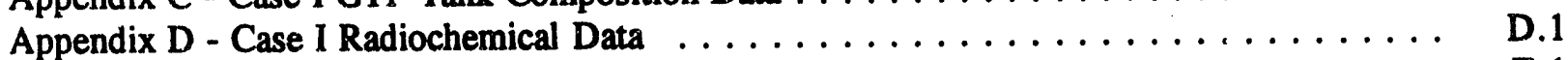

Appendix E - Case II GTF Tank Composition Data $\ldots \ldots \ldots \ldots \ldots \ldots \ldots \ldots \ldots$. . . . . . . . . . . . .

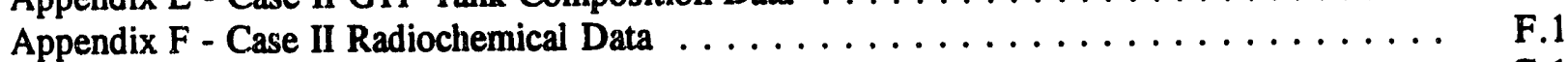

Appendix G - Case II HWVP Tank Composition Data $\ldots \ldots \ldots \ldots \ldots \ldots \ldots \ldots$ G.1 


\section{Figures}

2.1 HWVP Canister Production: Sludge Wash Only $\ldots \ldots \ldots \ldots \ldots$

2.2 HWVP Canister Production: Selective Leaching $\ldots \ldots \ldots \ldots \ldots \ldots \ldots$

2.3 Comparison of HWVP Model with CVS Approximation $\ldots \ldots \ldots \ldots$

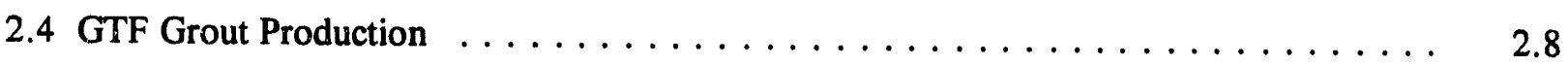

2.5 HWVP Canisters $\operatorname{Re}$ ұuired to Immobilize Various Blend Options $\ldots \ldots \ldots \ldots \ldots$

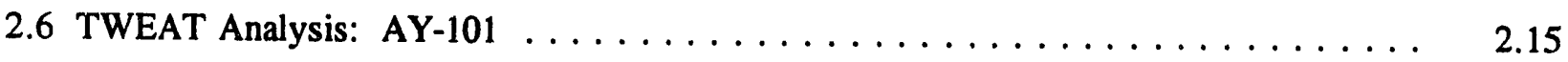

2.7 TWEAT Analysis: $\mathrm{AY}-102 \ldots \ldots \ldots \ldots \ldots \ldots \ldots \ldots \ldots \ldots \ldots$

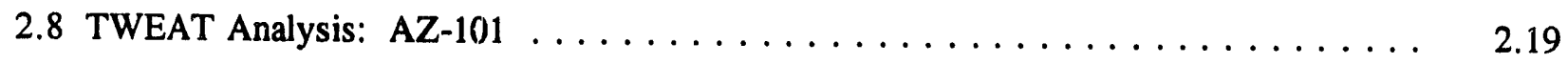

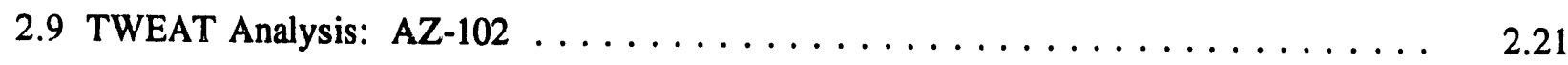

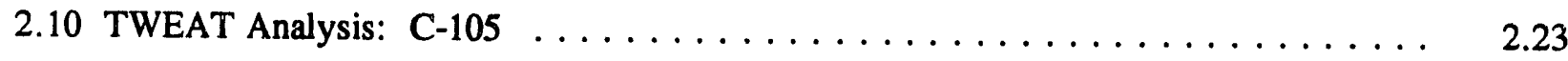

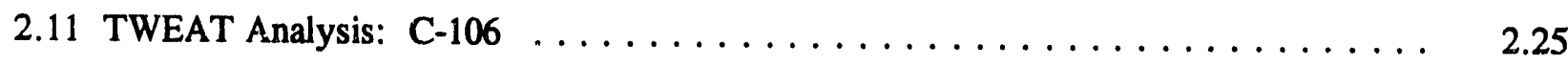

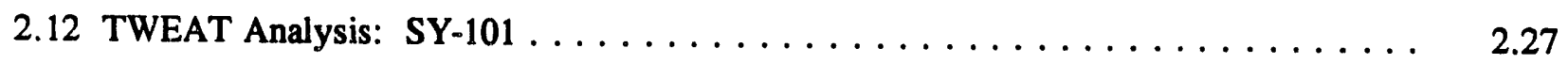

2.13 TWEAT Analysis: SY-103 . . . . . . . . . . . . . . . . . . . . 2.29

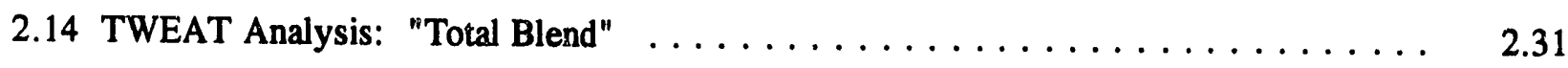

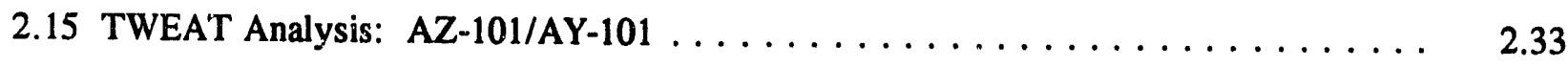

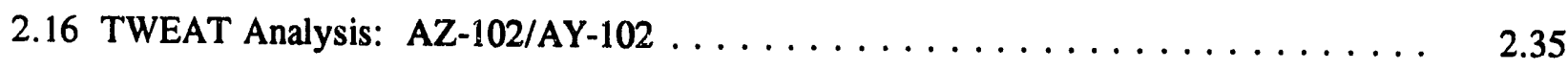

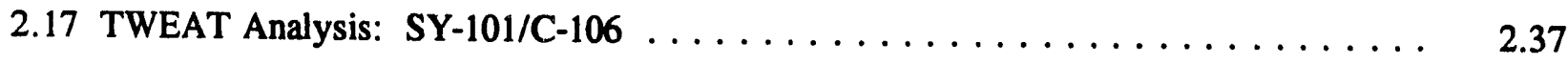

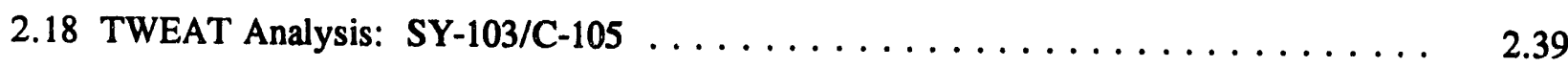

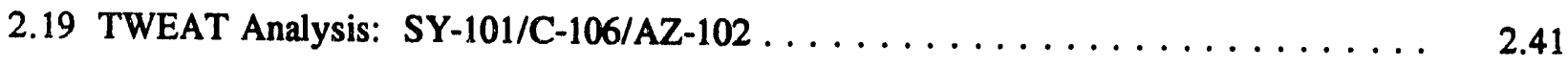

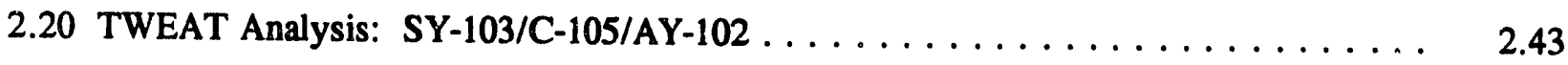

2.21 Waste Loading Estimates for the HWVP Reference and CVS Models . . . . . . . 2.52

2.22 Volume of Grout Required to Immobilize Various Blend Options . . . . . . . . . 2.55 


\section{Tables}

S.1 Case 1 Waste Production Summary: HWVP $\ldots \ldots \ldots \ldots \ldots \ldots \ldots$

S.2 Case I Waste Production Summary: GTF $\ldots \ldots \ldots \ldots \ldots \ldots \ldots \ldots \ldots \ldots$

S.3 Case II Waste Production Summary: HWVP Reference Model and CVS Model ...... vii

S.4 Case II Waste Production Summary: GTF $\ldots \ldots \ldots \ldots \ldots \ldots \ldots$ viii

1.1 Chemical Composition Range for the HWVP Reference Feed $\ldots \ldots \ldots \ldots \ldots \ldots$

1.2 Summary of Grout Feed Acceptance Criteria $\ldots \ldots \ldots \ldots \ldots \ldots$

1.3 Partitioning Factors for SST Waste Sludge-Washing Components $\ldots \ldots \ldots \ldots$

1.4 HWVP Acceptability Criteria for Glass Properties $\ldots \ldots \ldots \ldots \ldots \ldots \ldots$

2.1 HWVP Waste Production Summary $\ldots \ldots \ldots \ldots \ldots \ldots \ldots \ldots \ldots \ldots \ldots$

2.2 HWVP Outliers: Before and After Blending $\ldots \ldots \ldots \ldots \ldots \ldots \ldots$

2.3 GTF Waste Production Summary $\ldots \ldots \ldots \ldots \ldots \ldots \ldots \ldots \ldots \ldots$

2.4 GTF Outliers: Before and After Blending $\ldots \ldots \ldots \ldots \ldots \ldots \ldots \ldots \ldots$

2.5 Waste Production Summary for Selected Tanks: HWVP . . . . . . . . . . . . 2.11

2.6 HWVP Outliers from Selected Hanford Tank Wastes $\ldots \ldots \ldots \ldots \ldots \ldots \ldots$

2.7 HWVP Outliers from Selected Hanford Tank Waste Blends . . . . . . . . . 2.13

2.8 Region of CVS Property Model Validity $\ldots \ldots \ldots \ldots \ldots \ldots \ldots \ldots$

2.9 CVS Waste Loading Summary $\ldots \ldots \ldots \ldots \ldots \ldots \ldots \ldots \ldots \ldots \ldots \ldots$

2.10 GTF Outliers from Selected Hanford Tank Wastes $\ldots \ldots \ldots \ldots \ldots \ldots$

2.11 Selected Tank Waste Production Summary: GTF $\ldots \ldots \ldots \ldots \ldots$ 


\subsection{Introduction}

The Hanford Site has 177 double-shell tanks (DSTs) and single-shell tanks (SSTs) containing radioactive mixed waste that will be remediated. The waste volume in those 177 tanks is approximately $700,000 \mathrm{~m}^{3}$. Current planning calls for the transuranic (TRU) and high-level waste (HLW) fractions to be immobilized by vitrification in the Hanford Waste Vitrification Plant (HWVP), with the resulting waste form taken to an offsite repository, while the low-level wasie (LLW) fraction will be immobilized in a grout waste form at the Grout Treatment Facility (GTF) or in other waste forms for near-surface burial.

\subsection{Background}

Pretreatment alternatives are being studied to reduce the waste volume requiring immobilization in the HWVP. Because of the large variety of chemical constituent concentrations in different tank wastes and the composition limitations embodied in HWVP and GTF feed acceptance criteria, blending tank wastes is being considered. By blending tank wastes, components whose concentrations exceed the established waste feed criteria can be diluted, thereby increasing waste loading. For example, a waste whose phosphate concentrations exceed feed limits may be blended with a waste whose phosphate concentrations are well below limits. If the blend feeds are judiciously chosen, the resultant blend will also have a phosphate concentration below feed limits. In addition to decreased volume of the final waste form, a pretreatment strategy that includes blending will simplify processing due to decreased feed types.

Complexities involved in waste form qualification (WFQ) and in determining a suitable glass frit/ grout-forming material composition for each waste also make blending an attractive alternative. Fewer waste types will result in a simpler WFQ process, and larger volumes of feed will provide more feed continuity for sustained plant operations.

In 1991, Pacific Northwest Laboratory (PNL) $)^{(\infty)}$ examined combinations of simple pretreatment and blending strategies on selected DSTs and SSTs. The results showed that blending wastes enhances HWVP waste volume reduction over that of performing pretreatment alone. This study furthered that work by extending the evaluation to include all SSTs and selected DSTs and examining the subsequent waste loading expected in the HWVP and the GTF.

(a) Pacific Northwest Laboratory is operated for the U.S. Department of Energy by Battelle Memorial Institute under Contract DE-AC06-76RLO 1830. 


\subsection{Objectives}

The objective of this study is to evaluate on a broad scale the magnitude of the potential benefits provided from blending tank wastes.

\subsection{Assumptions and Simplifications}

The following assumptions and simplifications were used in this study:

1. The HWVP feed criteria have been established in the HWVP Technical Data Package, Revision 5. Table 1.1 shows the criteria.

2. The grout feed acceptance criteria have been established by the Grout Treatment Facility Waste Feed Acceptance Criteria. $^{(a)}$ Table 1.2 shows the criteria.

3. The HWVP canisters used for analysis were cylindrical canisters 2 feet in diameter and 10 feet in length, with a mass of $1650 \mathrm{~kg}$.

4. The 122,000 -ppm Na limit given in Table 1.2 corresponds approximately to a $5 \mathrm{M}$ Na concentration in a solution with a specific gravity of 1.0 . In a higher specific gravity solution, 122,000-ppm Na converts to a higher molar Na solution; however, throughout this report the concentration will be referred to as $5 \mathrm{M}$ Na.

5. Assumptions on the solubility of chemicals and radionuclides during the pretreatment sludge wash for SSTs are the same as those used in Systems Engineering Study for the Closure of Single-Shell Tanks (Boomer 1991) and are shown ${ }^{(b)}$ in Table 1.3.

6. Tank availability or retrieval sequencing were not taken into account in the blending analysis.

7. Safety issues that may result from blending incompatible wastes were not examined.

8. Tank wastes were assumed to be thoroughly mixed during the retrieval process.

(a) Hendrickson, D. W. 1991. Grout Treatment Facility Waste Feed Acceptance Criteria. WHCSD-WM-RD-019, Rev. 1, Westinghouse Hanford Company, Richland, Washington.

(b) The $99 \%$ solubility of Na used by Boomer was reduced to $97 \%$. 
Table 1.1. Chemical Compositional Range for the HWVP Reference Feed

\begin{tabular}{|c|c|c|}
\hline \multirow[b]{2}{*}{$\begin{array}{l}\text { Chemical Composition Range Limits } \\
\text { (oxide basis) }\end{array}$} & Minimum & Maximum \\
\hline & \multicolumn{2}{|c|}{$\begin{array}{c}\text { Wt\% of Total Nonvolatile } \\
\text { Oxides }\end{array}$} \\
\hline $\begin{array}{l}\mathrm{Al}_{2} \mathrm{O}_{3} \\
\mathrm{BaO} \\
\mathrm{CaO} \\
\mathrm{CdO} \\
\mathrm{Fe}_{2} \mathrm{O}_{3} \\
\left(\mathrm{La}, \mathrm{Nd}_{2} \mathrm{O}_{3}\right. \\
\mathrm{MnO}_{2} \\
\mathrm{MoO}_{3} \\
\mathrm{Na}_{2} \mathrm{O} \\
\mathrm{NiO} \\
\mathrm{SiO}_{2} \\
\mathrm{TiO}_{2} \\
\mathrm{U}_{3} \mathrm{O}_{8} \\
\mathrm{ZrO}_{2} \\
\mathrm{Cr}_{2} \mathrm{O}_{3} \\
\mathrm{Noble} \text { metals }\left(\mathrm{PdO}, \mathrm{Rh}_{2} \mathrm{O}_{3}, \mathrm{Ru}_{2} \mathrm{O}_{3} \text { ) }\right. \\
\mathrm{P}_{2} \mathrm{O}_{5} \\
\mathrm{SO}_{3} \\
\mathrm{~F}^{-} \\
\text {Fission product elements and minor components }\end{array}$ & $\begin{array}{l}2.0 \\
0.0 \\
0.0 \\
0.0 \\
8.0 \\
0.0 \\
0.0 \\
0.0 \\
4.5 \\
0.0 \\
0.0 \\
0.0 \\
0.0 \\
0.0 \\
0.0 \\
0.0 \\
0.0 \\
0.0 \\
0.0 \\
0.0\end{array}$ & $\begin{array}{r}26.0 \\
20.0 \\
20.0 \\
10.0 \\
60.0 \\
8.0 \\
20.0 \\
8.0 \\
22.0 \\
8.0 \\
17.5 \\
4.0 \\
32.0 \\
40.0 \\
2.0 \\
1.0 \\
4.0 \\
2.0 \\
6.9 \\
5.0(\text { a) }\end{array}$ \\
\hline Volatile Components & \multicolumn{2}{|c|}{$\begin{array}{c}\mathrm{Lb} / 100 \mathrm{lb} \text { of Total Waste } \\
\text { Oxides }\end{array}$} \\
\hline $\begin{array}{l}\mathrm{Cl}^{-} \\
\mathrm{CO}_{3}^{2 \cdot} \\
\mathrm{NO}_{x} \text { (as } \mathrm{NO}_{3}^{-} \text {) } \\
\mathrm{TOC}\end{array}$ & $\begin{array}{l}0.0 \\
2.4 \\
0.0 \\
0.0\end{array}$ & $\begin{array}{r}0.3 \\
30.0 \\
36.0 \\
11.0\end{array}$ \\
\hline \multicolumn{3}{|c|}{ Overall Waste Loading Limits } \\
\hline total nonvol & 0.15 & 0.83 \\
\hline
\end{tabular}

(a) Maximum value for the sum of fission product elements and trace components is $5.0 \mathrm{wt} \%$. 
Table 1.2. Summary of Grout Feed Acceptance Criteria

Feed Component

Organics (ppm)(a)

TOC

Cations/Metais (ppm)

$\mathrm{Ag}^{+}$

$\mathrm{Al}^{3+}$

$\mathrm{As}^{3+}$

$\mathrm{B}^{3+}$

$\mathrm{Ba}^{2+}$

$\mathrm{Ca}^{2+}$

$\mathrm{Cd}^{2+}$

$\mathrm{Cr}^{3+}$

$\mathrm{Cu}^{2+}$

$\mathrm{Fe}^{2+}$

$\mathrm{Hg}^{2+}$

K

$\mathrm{Mg}^{2+}$

$\mathrm{Mn}^{2+}$

$\mathrm{Mo}^{2+}$

$\mathrm{Na}^{+}$

$\mathrm{Ni}^{2+}$

$\mathrm{Pb}^{2+}$

$\mathrm{Se}^{4+}$

$\mathrm{Si}^{4+}$

$\mathrm{Zn}^{2+}$

Anions (ppm) $)^{(0)}$

$\mathrm{Cl}^{-}$

$\mathrm{CO}_{3}{ }^{2-}$

$\mathrm{F}^{*}$

$\mathrm{NO}_{3}^{-}$

$\mathrm{NO}_{2}^{-}$

$\mathrm{OH}^{-}$

$\mathrm{PO}_{4}{ }^{3-}$

$\mathrm{SO}_{4}{ }^{2-}$

Radionuclides $(\mathrm{Ci} / \mathrm{L})^{(\mathrm{d}, \mathrm{e})}$

${ }^{3} \mathrm{H}$

${ }^{14} \mathrm{C}$

${ }^{60} \mathrm{Co}$

${ }^{79} \mathrm{Se}$

${ }^{90} \mathrm{Sr}$
Acceptable Limit

1,556

5,063

20,300

0.15

136

46,154

573

80

21,000

7

1,490

20

11,500

320

3,010

68

122,000

30

12.5

45

502

2,930

5,360

22,920

562

186,000

38,250

34,850

18,430

5,100

$16 \mu \mathrm{Ci} / \mathrm{L}$

0.647

0.1162

80.6

0.2662 
Table 1.2. (contd)

\begin{tabular}{|c|c|}
\hline Feed Component & Acceptable Limit \\
\hline \multicolumn{2}{|c|}{ Radionuclides $(\mathrm{Ci} / \mathrm{L})^{(\mathrm{d}, e)}$ (contd) } \\
\hline${ }^{94} \mathrm{Nb}$ & 120.7 \\
\hline${ }^{99} \mathrm{Tc}$ & 0.2617 \\
\hline${ }^{106} \mathrm{Ru}$ & 0.1855 \\
\hline${ }^{125} \mathrm{Sb}$ & 0.5399 \\
\hline${ }^{129} \mathrm{I}$ & 0.00107 \\
\hline${ }^{134} \mathrm{Cs}$ & 0.1761 \\
\hline${ }^{137} \mathrm{Cs}$ & 0.3718 \\
\hline${ }^{144} \mathrm{Ce}$ & 0.2237 \\
\hline${ }^{237} \mathrm{~Np}$ & Total TRU concentration $<100 \mathrm{nCi} / \mathrm{g}$ \\
\hline \multicolumn{2}{|l|}{${ }^{238} \mathrm{Pu}$} \\
\hline \multicolumn{2}{|l|}{${ }^{241} \mathrm{Am}$} \\
\hline \multicolumn{2}{|l|}{${ }^{244} \mathrm{Cm}$} \\
\hline \multicolumn{2}{|l|}{ Other Parameters } \\
\hline pH (Standard Units) & $>10$ \\
\hline Total Solids (ppm) & $<400,000$ \\
\hline Heat Generators & $<0.37 \mathrm{CsmBa}$ heat equivalents $\mathrm{Ci} / \mathrm{L}$ \\
\hline Density & $<1.4 \mathrm{~kg} / \mathrm{L}$ \\
\hline
\end{tabular}

(a) Total organic constituents should not exceed $3260 \mathrm{mg} / \mathrm{L}$.

(b) Total Na should be greater than $75 \%$ of total cations. Total $\mathrm{Al}$ should be less than $20 \%$ of total cations. Waste limitations for $\mathrm{As}, \mathrm{Ba}, \mathrm{Cd}, \mathrm{Cr}, \mathrm{Pb}$, $\mathrm{Hg}$, Se, and $\mathrm{Ag}$ are based on Extraction Procedure Toxicity (EPTOX) and Toxicity Characteristic Leaching Procedure (TCLP) tests assuming linearity between waste feed concentration and extract concentrations.

(c) Total nitrate-nitrite $\left(\mathrm{NO}_{3}^{-}-\mathrm{NO}_{2}^{-}\right)$should be less than $75 \%$ of total anions. Total chloride-fluoride-hydroxide-carbonate $\left(\mathrm{Cl}^{-}, \mathrm{F}-\mathrm{OH}^{-}, \mathrm{CO}_{3}{ }^{2-}\right)$ should be less than $20 \%$ of total anions.

(d) Performance goal is to limit maximum individual exposure from grout through all pathways to $5 \mathrm{mrem} / \mathrm{yr}$ or $0.8 \mathrm{mrem} / \mathrm{yr}$ from drinking water.

(e) The total mix of radionuclides in the grout feed must be evaluated to assure that the net concentration in CsmBa equivalent curies is $370 / \mathrm{m}^{3}$. The evaluation method is based on the sum of the fractions rule as described in Hendrickson. ${ }^{(n)}$

(a) Hendrickson, D. W. 1991. Radiolytic Heat Loading Calculation Methods for the Hanford Grout Disposal Facility. WHC-SC-WM-TI-455, Rev. 0, Westinghouse Hanford Company, Richland, Washington. 
Table 1.3. Partitioning Factors For SST Waste Sludge-Washing Components

\begin{tabular}{|c|c|c|c|}
\hline Component & $\begin{array}{c}\text { Soluble in } \\
\text { Water Wash } \\
(\%)\end{array}$ & Component & $\begin{array}{c}\text { Soluble in } \\
\text { Water Wash } \\
(\%)\end{array}$ \\
\hline $\mathrm{Ag}$ & 5 & $\mathrm{Si}$ & 1 \\
\hline $\mathrm{Al}$ & 25 & $\mathrm{SO}_{4}$ & 98 \\
\hline B & 50 & $\mathrm{Sr}$ & 1 \\
\hline $\mathrm{Ba}$ & 1 & TOC & 90 \\
\hline $\mathrm{Bi}$ & 25 & $\mathrm{U}$ & 5 \\
\hline $\mathrm{Ca}$ & 5 & $\mathrm{Zn}$ & 10 \\
\hline $\mathrm{Cd}$ & 50 & $\mathrm{Zr}$ & 5 \\
\hline $\mathrm{Cl}$ & 95 & ${ }^{241} \mathrm{Am}$ & 10 \\
\hline $\mathrm{CN}$ & 25 & ${ }^{14} \mathrm{C}$ & 99 \\
\hline Co & 25 & ${ }^{60} \mathrm{Co}$ & 10 \\
\hline $\mathrm{CO}_{3}$ & 90 & ${ }^{137} \mathrm{Cs}$ & 75 \\
\hline $\mathrm{Cr}$ & 10 & ${ }^{129} \mathrm{I}$ & 99 \\
\hline $\mathrm{Cu}$ & 10 & ${ }^{239 / 240} \mathrm{Pu}$ & 2 \\
\hline $\mathrm{F}$ & 95 & ${ }^{90} \mathrm{Sr}$ & 1 \\
\hline $\mathrm{Fe}$ & 1 & ${ }^{90} \mathrm{Tc}$ & 50 \\
\hline $\mathrm{Hg}$ & 1 & $\mathrm{Cm}$ & 1 \\
\hline$K$ & 50 & $\mathrm{Nb}$ & 10 \\
\hline $\mathrm{Mg}$ & 1 & $\mathrm{~Np}$ & 10 \\
\hline $\mathrm{Mn}$ & 5 & $\mathrm{~Pa}$ & 1 \\
\hline $\mathrm{Na}$ & 97 & Pd & 10 \\
\hline $\mathrm{Ni}$ & 10 & $\mathrm{Ra}$ & 1 \\
\hline $\mathrm{NO}_{2}$ & 99 & $\mathrm{Sm}$ & 1 \\
\hline $\mathrm{NO}_{3}$ & 99 & $\mathrm{Sn}$ & 25 \\
\hline $\mathbf{P}$ & 50 & Th & 1 \\
\hline $\mathrm{Pb}$ & 25 & $\mathrm{La}$ & 1 \\
\hline $\mathrm{Se}$ & 99 & & \\
\hline
\end{tabular}

\subsection{Approach for This Analysis}

There are two models that predict waste loading for the HWVP. The first (shown in Table 1.1), called the HWVP reference feed chemical compositional range, simply sets limits on volatile and nonvolatile components expected in the feed. These limits are commonly referred to as "neutralized current acid waste (NCAW) limits" because originally the limits were specified only for that waste type. Because better modeling approaches were not available until recently, these limits were incorporated as the reference. The second model, the Composition Variability Study (CVS), is significantly 
more sophisticated and sets limits based on predicted glass properties and on limits on the solubility of minor components $\left(\mathrm{Cr}_{2} \mathrm{O}_{3}, \mathrm{~F}^{-}, \mathrm{P}_{2} \mathrm{O}_{5}\right.$, and $\left.\mathrm{SO}_{3}\right)$ which are identical to the limits set in the HWVP reference model for the same components.

Ideally, this study would have evaluated all tanks using the CVS model. Instead, all tanks were evaluated using the reference model, and a subset of tanks were evaluated using CVS and then compared with the reference model. Such an analysis should indicate if the trends established using the reference model are valid.

PNL conducted a preliminary evaluation of the benefits of blending Hanford Site tank waste. This report presents the results of work in which two cases were considered. Case I evaluated all tank waste currently included in the Tank Waste Remediation System (TWRS) planning basis for retrieval and pretreatment prior to immobilization as a high-level waste form [all single-shell tank (SST) waste (149 tanks) and 10 double-shell tank (DST) waste types; namely complexant concentrate (CC), NCAW, neutralized cladding removal waste (NCRW), and Plutonium Finishing Plant (PFP) ]. Case II evaluated eight selected tanks: AY-101 (CC waste type), AY-102 (Dilute waste type), AZ-101 (NCAW waste type), AZ-102 (NCAW waste type), C-105 (SST), C-1G5 (SST), SY-101 (CC waste type), and SY-103 (CC waste type). These eight tanks were selected because they are being considered for early retrieval and immobilization. The following sections explain the approach used in the blending evaluation for Case I and Case II.

\subsubsection{Case I: HWVP Feed Blend Analysis}

All DSTs and SSTs currently included in the TWRS planning basis for retrieval and pretreatment prior to immobilization as a HLW form were initially considered as blending candidates. Because of the limited core sample analysis of SSTs, chemical composition data were taken from Track Radioactive Components (TRAC) data (see Appendix A). The chemical composition of the DST waste was taken from analytical data compiled by Lowe. ${ }^{(a)}$ The sludge-wash partitioning factor, which specifies the soluble fraction of each listed constituent, was applied to the composition data. The resultant component quantities were converted to an oxide basis in the form in which they are expected to exist in borosilicate glass.

First, the total mass of the oxides (see Appendix B) was used to determine the HWVP canisters produced with a $25 \mathrm{wt} \%$ waste loading. This case is often used as a baseline case and represents an estimate of the nominal waste loading in an HWVP canister. The data were then compared with the chemical composition acceptance criteria for the HWVP reference feed and the limiting components for each tank were identified. The number of HWVP canisters required to immobilize each tank's waste sludge was determined from the limiting component identified for each tank. The summation of the canisters required to immobilize waste from each tank individually represents the "no blend" case.

(a) Lowe, S. S. 1991. Preliminary Material Balances for the Pretreatment of NCAW, NCRW, PFP, and CC Wastes. WHC-SC-TI-492, Rev. 0, Westinghouse Hanford Company, Richland, Washington. 
The "total blend" case is represented by first summing all the waste sludge constituents and then identifying the number of canisters required to immobilize the limiting component of the blend. The benefits of blending tank wastes (after sludge wash) were then evaluated and compared to the alternative pretreatment approach of blending with leaching of selected components.

\subsubsection{Case I: GTF Feed Blend Analysis}

An approach similar to that used for the HWVP blending analysis was used to evaluate the benefits of blending grout feed. Assuming that any waste mass not vitrified would be sent to grout, a simple mass balance sets the quantity of grout feed (see Appendix C). Radiochemical data is provided in Appendix D. The water dilution necessary to make each tank's $\mathrm{Na}$ concentration $5 \mathrm{M}$ was determined for each tank. In some tanks, without any water addition, the tank's sludge composition was less than $5 \mathrm{M} \mathrm{Na}$. Recognizing that some water was need for retrieval and grout formulation, water volume equal to the waste volurne was added to such tanks. The tanks whose sludge Na concentration was greater than $5 \mathrm{M}$ were diluted with the calculated water volume such that $5 \mathrm{M} \mathrm{Na}$ feed was obtained. An expansion factor of 1.43 and a grout feed specific gravity of 1.3 were assumed in calculating grout volume.

The data were then analyzed against the grout feed acceptance criteria, and the limiting component for each tank was identified. An effective TRU filtering and removal pretreatment was assumed. The volume of grout required to immobilize each tank's grout feed was determined from the limiting component identified for each tank. The summation of the grout volume required to immobilize each tank represents the "no blend" case. The "total blend" case is represented by first summing all the grout feed constituents and then identifying the volume of grout required to immobilize the limiting component of the blend. The benefits of blending grout feeds were then evaluated and compared to the blending of feeds from which selected components were removed.

\subsubsection{Case II: HWVP and GTF Feed Blend Analysis}

Case II feed blend analysis used the same approach as that used for Case I. However, since analytical data were used in Case II for both the solids and supernatant, slight differences exist. Namely, all supernatant in addition to the soluble fraction of the sludge was used as the LLW grout feed (see Appendix E). Radiochemical data are provided in Appendix F. A simple mass balance on the washed sludge determined the composition and mass of the oxides serving as HWVP feed (see Appendix G). Sludge washing partitioning factors were obtained from Lowe for the CC and NCAW waste types. Solubilities for waste types and constituents not given by Lowe, were taken from Table 1.3. Finally, solids and supernatant tank waste volume estimates were obtained from the Tank Farm Surveillance and Waste Status Summary Report for October 1991 (Hanlon 1992). 


\subsubsection{CVS Case II Model Blend Analysis}

The Ternary Waste Envelope Assessment Tool (TWEAT) was used to re-evaluate the eight selected tanks and see what impact the CVS model would have on the blending analysis. TWEAT is designed to visually display the results of the CVS. TWEAT incorporates first-order empirical CVS models fitted to glass and melt properties as a function of composition.

Briefly, ${ }^{(a)}$ the CVS model predicts melt and glass product properties as a function of ten glass components: $\mathrm{SiO}_{2}, \mathrm{~B}_{2} \mathrm{O}_{3}, \mathrm{Na}_{2} \mathrm{O}, \mathrm{Li}_{2} \mathrm{O}, \mathrm{CaO}, \mathrm{MgO}, \mathrm{Fe}_{2} \mathrm{O}_{3}, \mathrm{Al}_{2} \mathrm{O}_{3}, \mathrm{ZrO}_{2}$, and others (all remaining components). As of September 1992, 81 glasses have been tested, with the following properties measured: viscosity, electrical conductivity, glass transition temperature, thermal expansion, crystallinity, and durability, based on the Materials Characterization Center 28-day leach test (MCC-1). Table 1.4 displays taken from Hrma and Piepel, the CVS acceptability criteria for glass properties.

In addition to glass product properties defined as a function of the ten oxides, separate limits are imposed, including crystallinity constraints and constraints on $\mathrm{Cr}_{2} \mathrm{O}_{3}, \mathrm{~F}^{-}, \mathrm{P}_{2} \mathrm{O}_{5}$, and $\mathrm{SO}_{3}$. These latter constraints have limits identical to those defined in the HWVP reference model.

A spreadsheet incorporating first-order CVS empirical models was used to design a four component frit $\left(\mathrm{SiO}_{2}, \mathrm{~B}_{2} \mathrm{O}_{3}, \mathrm{Na}_{2} \mathrm{O}, \mathrm{Li}_{2} \mathrm{O}\right)$ for each waste stream. The idea was to design a frit which, when combined with the waste, would produce a glass with viscosity (at $1150^{\circ} \mathrm{C}$ ) of $6 \mathrm{~Pa} \cdot \mathrm{S}$, electrical conductivity (at $1150^{\circ} \mathrm{C}$ ) of $30 \mathrm{~S} / \mathrm{m}$, satisfactory crystallinity constraints, and minimum boron release based upon MCC-1 models. Because the liquidus temperature model is known to be inaccurate in its current state of development, this property was not used in the design of the frit. ${ }^{(b)}$ Each waste stream composition and associated frit were entered into TWEAT. A recycle stream with set composition was also incorporated into the model. The results are displayed in a ternary diagram with the waste stream, frit, and recycle at the vertices.

Waste loadings were determined using TWEAT in conjunction with both crystallinity constraints and the solubility of minor components constraints $\left(\mathrm{Cr}_{2} \mathrm{O}_{3}, \mathrm{~F}^{-}, \mathrm{P}_{2} \mathrm{O}_{5}, \mathrm{SO}_{3}\right)$.

(a) For a detailed model description, see P. R. Hrma and G. F. Piepel. 1992. Property/Composition Relationships for Hanford Waste Vitrification Plant Glasses--Preliminary Results Through CVS-II Phase 2, PHTD-92-03.01/K897, Pacific Northwest Laboratory, Richland, Washington.

(b) A new model is being developed for liquidus temperature and is expected to be out in the second quarter of FY93. 
Table 1.4. HWVP Acceptability Criteria for Glass Properties

Property

Viscosity at $1150^{\circ} \mathrm{C}$

Electrical conductivity at $1150^{\circ} \mathrm{C}$

Liquidus temperature

Phase separation

Dissolution rate in deionized water ${ }^{(b)}$

Glass transition temperature ${ }^{(\mathrm{d})}$

Devitrification during cooling(t)

Other processability aspects ${ }^{(i)}$
Acceptability Criteria

$$
\begin{aligned}
& 2-10 \mathrm{~Pa} \cdot \mathrm{s} \\
& 18-50 \mathrm{~S} / \mathrm{m}^{(\text {a) }} \\
& \leq 1050^{\circ} \mathrm{C}
\end{aligned}
$$

No liquid-liquid separation in the melter $\leq$ EA glass (TBD) $)^{(\text {) }}$

Descriptive

Descriptive

(a) $\mathrm{S}=$ Siemens $=\mathrm{ohm}^{-1}$. These were the limits used in planning and conducting the CVS up through CVS-II Phase 2. See the discussion in Section 3.2 for an expected revision to these limits.

(b) Earlier versions of the (preliminary) Waste Acceptance Specifications (WAPS) specified an upper limit of $1 \mathrm{~g} / \mathrm{m}^{2}$ - day on normalized releases of sodium, silicon, boron, cesium-137, and uranium-238 averaged over a 28 -day $\mathrm{MCC}-1$ leach test $(\mathrm{A} / \mathrm{V}=$ $\left.10 \mathrm{M}^{-1}\right)$.

(c) The June 1991 revision of WAPS (DOE 1991) specifies that elemental releases of boron, lithium, and sodium be less than that of the Defense Waste Processing Facility (DWPF) Environmental Assessment (EA) glass. Numerical limits foi' the elemental releases have not yet been determined, although preliminary results from the Savannah River Technology Center (SRTC) (Hutson et al. 1992) indicate the EA glass normalized boron release will be in the range of 5 to $10 \mathrm{~g} / \mathrm{m}^{2}$.

(d) The WAPS do not specify an acceptability limit for glass transition temperature $\left(T_{z}\right)$, but they do require that it be reported and that glass producers certify that glass temperature does not exceed $\mathrm{T}_{\mathrm{B}}-100^{\circ} \mathrm{C}$ after initial cooldown.

(e) The WAPS has not set a limit on the amount of crystalline material in the glass, but does require that crystalline material expected to be present be characterized.

(f) The CVS does not address other processability aspects, such as feed requirements to limit foaming and guarantee a stable cold cap that melts at an acceptable rate. Other testing outside of the CVS will address such aspects. 


\subsection{Preliminary Results}

Sections 2.1 and 2.2 discuss results from the Case I analysis, and Sections 2.3 through 2.5 discuss results from the Case II analysis.

\subsection{Case I: Blending HLW Usirg HWVP Reference Feed Criteria}

For waste to be immobilized in the HWVP, Table 2.1 displays a summary of the of the HWVP waste form production using the HWVP reference feed composition model. The "25 wt \% load" column is the widely used HWVP baseline for canister estimate. This baseline assumes that the immobilized waste volumes are only depandent ox the total mass to be vitrified. The "no blend" and "total blend" columns take into account the HWVP reference feed chemical composition range (without and with the benefit of biending). The "limiting component (total blend)" column displays those components in the "total blend" which limit waste loading due to their high concentration in the feed relative to the limits. The potential benefit of blending is evident by comparison of the volume of glass associated with the bounding option of "no blend" and "total blend." This potential waste reduction,

Table 2.1. HWVP Waste Production Summary

\begin{tabular}{|c|c|c|c|c|c|}
\hline \multirow[b]{2}{*}{ Pretreatment HWVP } & \multicolumn{3}{|c|}{ Quantity Waste Produced(a) } & \multirow[b]{2}{*}{$\begin{array}{l}\text { Potential } \\
\text { Waste } \\
\text { Reduction }^{(b)}\end{array}$} & \multirow{2}{*}{$\begin{array}{l}\text { Limiting } \\
\text { Component } \\
\text { "Total } \\
\text { Blend" }\end{array}$} \\
\hline & $\begin{array}{c}25 \text { wt\% } \\
\text { Load } \\
\text { (canisters) }\end{array}$ & $\begin{array}{l}\text { "No Blend" } \\
\text { (canisters) }\end{array}$ & $\begin{array}{c}\text { "Total } \\
\text { Blend" } \\
\text { (canisters) }\end{array}$ & & \\
\hline Sludge wash (SW) & 34,100 & 267,000 & 200,000 & $25 \%$ & $\mathbf{P}$ \\
\hline SW w/P leach ${ }^{(c)}$ & 28,000 & 139,500 & 47,000 & $66 \%$ & Other $r^{(d)}$ \\
\hline SW $w / P$ and other leach ${ }^{(e)}$ & 27,700 & 117,900 & 36,500 & $69 \%$ & $\mathrm{Al}$ \\
\hline
\end{tabular}

(a) Waste produrtion from the HWVP is based upon washed sludge from DSTs and SSTs currently included in the TWRS planning basis for retrie"'al and pretreatment prior to immobilization as a high-level waste form.

(b) (volume from "no blend" - volume from "total blend")/(voiume irom "no blend").

(c) Fraction of $P$ leached $=0.76$. This value is the required fraction of $P$ that must be removed S. that it no longer limits waste loading in the "total blend."

(d) "Other" is defined as fission product elements and minor components.

(e) Fraction of $P$ leached $=0.82$. Fraction of other leached $=0.22$. These are the required fractions of $P$ and other that must be removed so that they no longer limit waste loading. 
defined as the percent difference between the "no blend" and "total blend," is a measure of the maximum benefits blending may provide. The potential waste reduction is $25 \%$ for the sludge wash only case, and $66 \%$ for the sludge wash with $\mathrm{PO}_{4}{ }^{3-}$ leach, and $69 \%$ for the sludge wash with $\mathrm{PO}_{4}{ }^{3-}$ and other leach. Note, in looking down the columns, that selected leaching and blending are both integral steps in reducing the waste volume so that it approaches the $25 \mathrm{wt} \%$ load.

\subsubsection{Canister Estimate: Sludge-Wash Pretreatment}

If all the tank sludges were washed and then disposed of in the HWVP at $25 \mathrm{wt} \%$ loading, approximately 34,100 canisters $(29,600$ from the SSTs and 4,500 from the DSTs) would result. This estimate is lower than previous SST estimates of approximately $34,500,{ }^{(a)}$ even though a $\mathrm{Na}^{+}$solubility of 0.97 instead of 0.99 was assumed. If a $0.99 \mathrm{Na}^{+}$solubility factor is assumed, approximately 31,000 canisters (26,500 from SSTs and 4,500 from DSTs) are cotained.

The normalized Track Radioactive Components (TRAC) data base used in this study is similar to the data base usc $\mathrm{u}^{\text {by }}$ boomer (1991) with the exception of cancrinite ${ }^{(b)}$ (not included in TRAC). Because TRAC assigns waste mass by tank, it was used in this study. However, for comparison purposes, if cancrinite mass is added to the TRAC data base, and using a $0.99 \mathrm{Na}^{+}$solubility, approximately 33,000 canisters result from SSTs. The observed variance demonstrates the obvious dependence of canister estimates on sludge-wash partitioning (solubility) factors and chemical database selection.

Estimates assuming $25 \mathrm{wt} \%$ loading neglect the fact that the borosilicate glass feed criteria, reproduced in Table 1.1, is restrictive in many waste oxides. As graphed in Figure 2.1, many more canisters will be produced if the borosilicate glass limits are followed. If all the washed sludge was disposed of in the HWVP without any blending ("no b'end"), 267,000 canisters would be required. If the washed sludge from all the tanks was blended together ("total blend") after a sludge wash, 200,000 canisters would be produced, limited in $\mathrm{P}_{2} \mathrm{O}_{5}$, others, and $\mathrm{Al}_{2} \mathrm{O}_{3}{ }^{\left({ }^{\circ}\right)}$ The concentrations of $\mathrm{P}_{2} \mathrm{O}_{5}$, others, and $\mathrm{Al}_{2} \mathrm{O}_{3}$ are so high that no amount of blending can reduce these outliers' concentrations to within limits. Thus, canister estimations that neglect the HWVP glass criteria may underestimate canister production by an order of magnitude.

The magnitude of the benefit that blending may provide is bounded by the canisters produced from the "no blend" and "total blend" cases. Logistically, blending all 159 tank waste sludges

(a) Boomer (1991) estimated that 23,000 cylindrical canisters, $2 \mathrm{ft}$ in diameter by $15 \mathrm{ft}$ long, or 34,500 cylindrical canisters, $2 \mathrm{ft}$ in diameter by $10 \mathrm{ft}$ long, would be produced after sludge washing the SST waste (sludge wash A, Integrated Alternative 10). Cylindrical canisters, $2 \mathrm{ft}$ in diameter by $10 \mathrm{ft}$ long, were used in this study.

(b) Known silica additions are assumed to have reacted with aluminates and hydroxides to form cancrinite (assumed to be $2 \mathrm{NaAlSiO}_{4} \cdot 0.52 \mathrm{IaNO}_{3} \cdot 0.68 \mathrm{H}_{2} \mathrm{O}$ ).

(c) $\mathrm{P}_{2} \mathrm{O}_{5}$, others, and $\mathrm{Al}_{2} \mathrm{O}_{3}$ concentrations all exceed the borosilicate glass limit. However, relative to the feed limits, the $\mathrm{P}_{2} \mathrm{O}_{5}$ concentration is aighest and thus sets the volume of HWVP glass. 


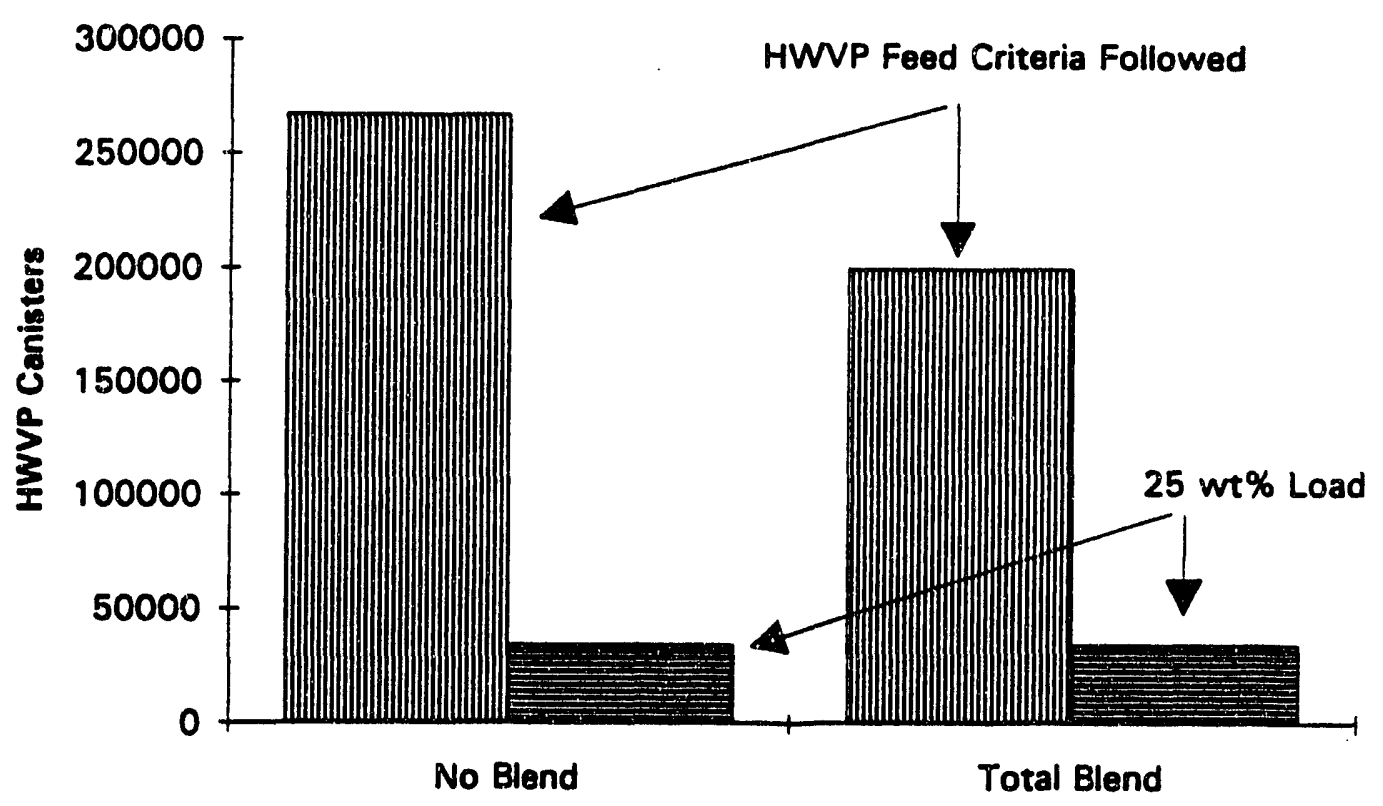

Figure 2.1. HWVP Canister Production: Sludge Wash Only

(149 SSTs and 10 DSTs) is not an option, but by judicious selection of tank blending partners, the "total blend" case may be closely approached. The shape of the a curve, that might connect the set of data points, is unknown. However, Case II analysis (see Sections 2.4 and 2.5) suggests a curve resembling exponential decay.

Table 2.2 shows the number of tanks whose HLW feed exceeded the specified HWVP feed criteria. The following chemical species from the HLW feed(a) ("no blend" option) exceeded the HWVP reference feed composition: $\mathrm{Al}_{2} \mathrm{O}_{3}, \mathrm{BaO}, \mathrm{CaO}, \mathrm{Cr}_{2} \mathrm{O}_{3}, \mathrm{Fe}_{2} \mathrm{O}_{3}, \mathrm{MnO}_{2}, \mathrm{Na}_{2} \mathrm{O}, \mathrm{NiO}, \mathrm{P}_{2} \mathrm{O}_{5}, \mathrm{SO}_{3}, \mathrm{SiO}_{2}$, $\mathrm{ZrO}_{2}$, other, $\mathrm{Cl}, \mathrm{CO}_{3}, \mathrm{NO}_{\mathrm{x}}$, and TOC. Every tank had at least one HWVP outlier, and no tank's waste contents could be fully loaded ( $25 \mathrm{wt} \%$ ) without blending or further pretreatment. In order to approach the $25 \mathrm{wt} \%$ loading without blending, either pretreatments capable of reducing the concentration of the 17 chemical outliers must be developed or examination of increasing these waste concentrations must be evaluated. Since blending can reduce the 17 outliers to $3\left(\mathrm{P}_{2} \mathrm{O}_{5}\right.$, others, and $\left.\mathrm{Al}_{2} \mathrm{O}_{3}\right)$, it is clear that blending can provide great benefit to simple pretreatments.

Clearly, not all of the outliers will actually be a problem for waste loading in glass, and many of these outliers, in the future, may be inconsequential when reviewed after CVS analysis. $\mathrm{SiO}_{2}$, for example, is a large constituent in glass and compensation might be made in the composition of glass frit. Similarly, $\mathrm{NO}_{\mathrm{a}}$ and $\mathrm{TOC}$ may not be a problem in the glass per se, but in the off-gas system which might be engineered to handle larger off-gas rates.

(a) Note that the feed components are not actually converted to oxides until they are added to the melter. 
Table 2.2. HWVP Outliers: Before and After Blending

Number of HLW Feeds (arter sludge wash) Exceeding the Specified HWVP Reference Feed Criteria

\begin{tabular}{|c|c|c|}
\hline & $\begin{array}{l}\text { "No } \\
\text { Blend" }\end{array}$ & $\begin{array}{l}\text { "Total } \\
\text { Blend" }\end{array}$ \\
\hline $\mathrm{Al}_{2} \mathrm{O}_{3}$ & 79 & 1 \\
\hline $\mathrm{BaO}$ & 1 & 0 \\
\hline $\mathrm{CaO}$ & 4 & 0 \\
\hline $\mathrm{CdO}$ & 0 & 0 \\
\hline $\mathrm{Cr}_{2} \mathrm{O}_{3}$ & 25 & 0 \\
\hline $\mathrm{F}^{-}$ & 0 & 0 \\
\hline $\mathrm{Fe}_{2} \mathrm{O}_{3}$ & 7 & 0 \\
\hline $\mathrm{La}_{2} \mathrm{O}_{3}$ & 0 & 0 \\
\hline $\mathrm{MnO}_{2}$ & 6 & 0 \\
\hline $\mathrm{MoO}_{3}$ & 0 & 0 \\
\hline $\mathrm{Pd}, \mathrm{Rh}, \mathrm{Ru}$ & 0 & 0 \\
\hline $\mathrm{Na}_{2} \mathrm{O}$ & 57 & 0 \\
\hline $\mathrm{NiO}$ & 9 & 0 \\
\hline $\mathrm{P}_{2} \mathrm{O}_{5}$ & 62 & 1 \\
\hline $\mathrm{SO}_{3}$ & 5 & 0 \\
\hline $\mathrm{SiO}_{2}$ & 7 & 0 \\
\hline $\mathrm{TiO}_{2}$ & 0 & 0 \\
\hline $\mathrm{U}_{3} \mathrm{O}_{8}$ & 0 & 0 \\
\hline $\mathrm{ZrO}_{2}$ & 3 & 0 \\
\hline Other & 48 & 1 \\
\hline $\mathrm{Cl}^{-}$ & 8 & 0 \\
\hline $\mathrm{CO}_{3}{ }^{2-}$ & 2 & 0 \\
\hline $\mathrm{NO}_{\mathrm{x}}^{-}\left(\right.$as $\left.\mathrm{NO}_{3}\right)$ & 4 & 0 \\
\hline TOC & 6 & 0 \\
\hline
\end{tabular}

(a) Note that the "total blend" has only one HLW feed.

Conversely, $\mathrm{Cr}_{2} \mathrm{O}_{3}, \mathrm{P}_{2} \mathrm{O}_{5}$, and $\mathrm{SO}_{3}$ have serious potential to negatively impact waste loading. CVS modeling uses limits identical to the HWVP reference model for these three components, and a more detailed blending analysis using CVS would certainly flag these components as outliers too.

TRAC data are known to have poor accuracy in representing tank contents, and therefore can only be used to provide an indication of the potential benefits of blending, not reliable quantified predictions. 


\subsubsection{Canister Estimate: Sludge Wash with Selective Leaching}

Significant quantities of $\mathrm{P}$ must be removed so that its concentration no longer limits the waste loading in HWVP glass. Figure $\mathbf{2 . 2}$ has two data points for pretreatment scenarios considered, one for the "no blend" and one for the "total blend" scenario. Starting at the left side of the figure, the left bar represents the sludge-wash-only case. The second bar shows the reduction in caristers that results with leaching a fraction of 0.76 , of $\mathrm{PO}_{4}{ }^{3-}(0.76)$, resulting in both $\mathrm{P}_{2} \mathrm{O}_{5}$ and others ${ }^{(\mathrm{a})}$ being limiting in the "total blend" (i.e., both $\mathrm{P}_{2} \mathrm{O}_{5}$ and others cause the "total blend" to produce 47,000 canisters). Approximately 139,500 canisters result for the "no blend" scenario and 47,000 canisters for the "total blend" scenario. The third bar shows the reduction in canisters that results with removal of both $\mathrm{PO}_{4}{ }^{3-}(0.82)$ and others (0.22). Approximately 117,900 canisters result for the "no blend" case, and 36,500 canisters result for the "total blend" case (limited in $\mathrm{Al}_{2} \mathrm{O}_{3}$ ). The shape of a curve that might connect the sets of data points is unknown. However, since the endpoints of such a curve have already been established, the potential benefit that blending may provide to each pretreatment has also been established.

\subsubsection{Comparison of HWVP Reference Model with a CVS Model Approximation}

The CVS loading trends (refer to Section 2.4) indicate that if a minor component solubility limitation does not restrict waste loading, $25 \mathrm{wt} \%$ loading may reasonably be expected. Thus a decent,

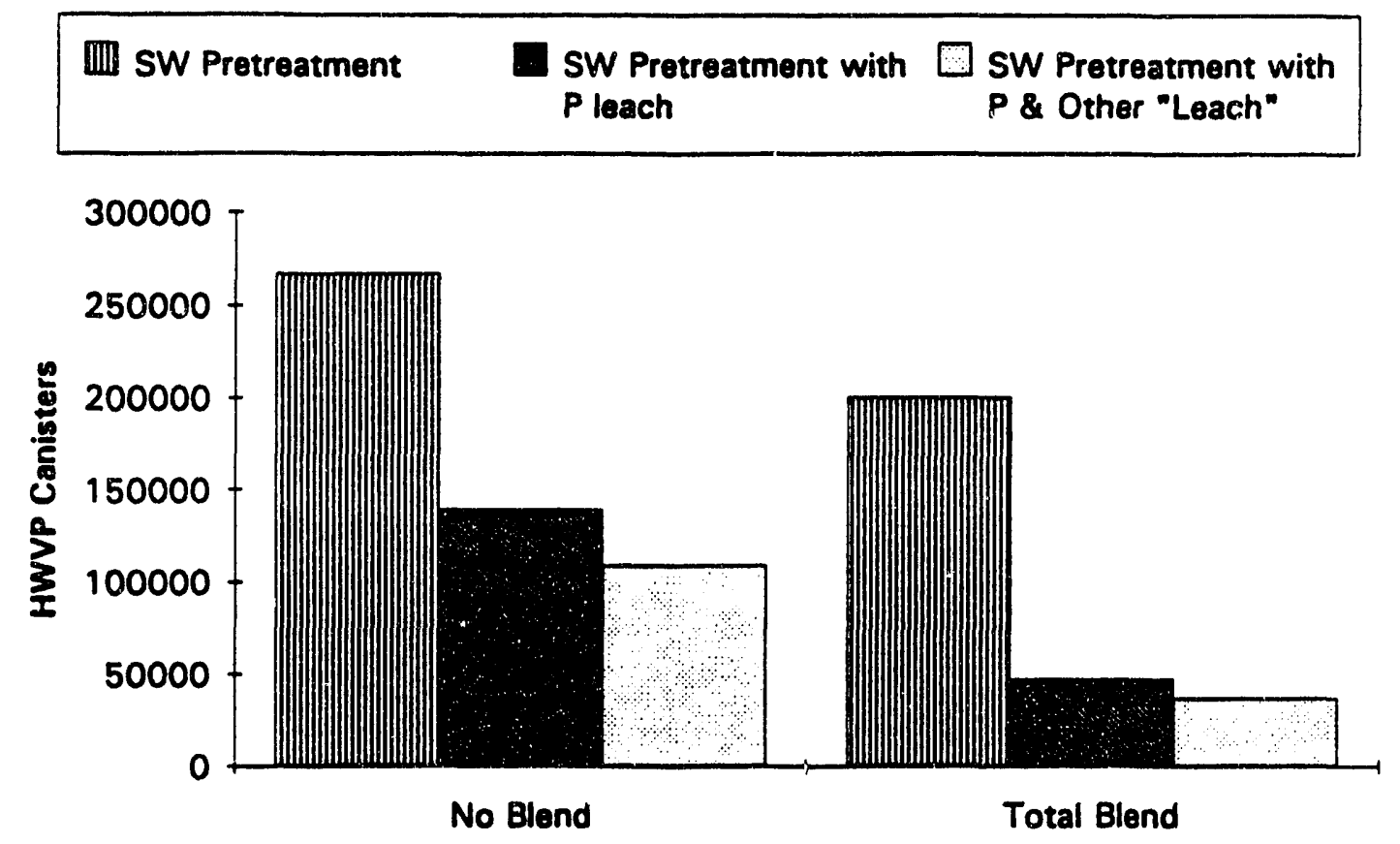

Figure 2.2. HWVP Canister Production: Selective Leaching

(a) "Other" is defined as fission products and minor elements. 
although still conservative, approximation of loading expected from a CVS analysis would disregard all HWVP reference model component constraints with the exception of $\mathrm{Cr}_{2} \mathrm{O}_{3}, \mathrm{~F}, \mathrm{P}_{2} \mathrm{O}_{5}$, and $\mathrm{SO}_{3}$. Any wastes not limited in these components may be loaded to $25 \mathrm{wt} \%$. This loading model will be referred to as the CVS approximation. Thus the CVS approximation is the relaxation of all but four of the HWVP reference model criteria.

Figure 2.3 compares the HWVP reference model and the CVS approximation. Two pretreatments were considered: sludge washing and sludge washing with $\mathrm{PO}_{4}{ }^{3}$ leach. Nctice that the CVS model estimates fewer canisters in the "no blend" but the same number of canisters in the "total blend" scenario. The CVS model approximation estimates fewer canisters in the "no blend" case because not every tank is limited by the solubility of minor components $\left(\mathrm{P}_{2} \mathrm{O}_{5}\right.$ in particular). However, the "total blend" is limited by $\mathrm{P}_{2} \mathrm{O}_{5}$. As a result both the CVS model approximation and the HWVP reference model predict identical quantitites for the "total blend" case.

In the sludge-wash-only pretreatment, both models predict 200,000 canisters for the "total blend," because in both models $\mathrm{P}_{2} \mathrm{O}_{5}$ concentration is limiting. The CVS approximation reduces the "no blend" estimate from 267,000 to 233,000 and as a result the potential waste reduction is reduced to $14 \%$ from $25 \%$.

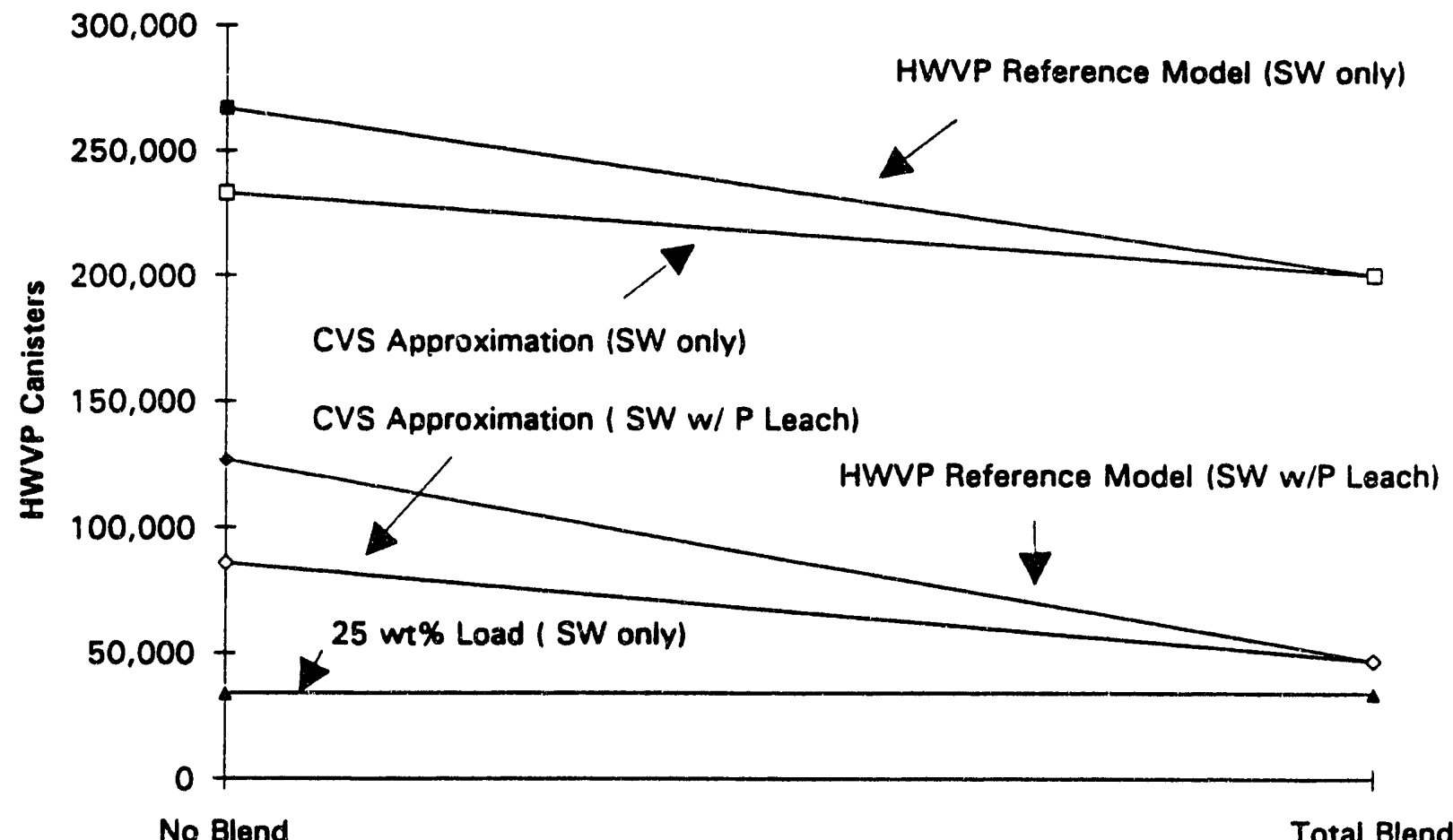

Figure 2.3. Conparison of HWVP Model with CVS Approximation 
For the $\mathrm{PO}_{4}{ }^{3-}$ leach $(0.76)$ pretreatment, the reference model predicts 139,500 canisters, while the CVS approximation estimates 86,000 canisters for the "no blend." In the "total blend" case, both the reference model and CVS approximation estimate 47,000 canisters. The reference model is limited equally in $\mathrm{P}_{2} \mathrm{O}_{5}$ and others, while the CVS approximation is limited in $\mathrm{P}_{2} \mathrm{O}_{5}$. As a result, the potential waste reduction decreases to $45 \%$ from $63 \%$.

Comparison of the HWVP reference model to the CVS approximation indicates that the potential canister reduction predicted by the HWVP model is higher than that predicted by the CVS approximation, simply because the CVS approximation has fewer loading restrictions. Clearly, in both models, blending enhances waste loading.

\subsection{Case I: Blending LLW Using Grout Feed Acceptance Criteria}

Table 2.3 summarizes the GTF waste production expected for SSTs after selected pretreatments and compares the result with the $5 \mathrm{M}$ Na load case. Compare in Table 2.3 the " $5 \mathrm{M}$ Na load" column, which displays the widely used GTF baseline loading, with the "no blend" and "total blend" columns, which take into account the grout waste feed acceptance criteria (without and with the benefit of blending). The potential benefit of blending is evident by comparing the volume of grout associated with the bounding options of "no blend" and "total blend." Note, in looking down the columns, that selected leaching and blending are both integral steps in reducing the waste volume so that it approaches the $25 \mathrm{wt} \%$ load.

Table 2.3. GTF Waste Production Summary

\begin{tabular}{|c|c|c|c|c|c|}
\hline \multirow[b]{2}{*}{ Pretreatment } & \multicolumn{3}{|c|}{ Quantity of Waste Produced ${ }^{(\bullet)}$} & \multirow[b]{2}{*}{$\begin{array}{l}\text { Potential } \\
\text { Waste } \\
\text { Reduction }\end{array}$} & \multirow[b]{2}{*}{$\begin{array}{l}\text { Limiting } \\
\text { Component } \\
\text { "Total Blend" }\end{array}$} \\
\hline & $\begin{array}{c}5 \mathrm{M} \mathrm{Na} \\
\text { Load (m } \\
\text { grout) }\end{array}$ & $\begin{array}{l}\text { "No Blend" } \\
\left(\mathrm{m}^{3} \text { grout }\right)\end{array}$ & $\begin{array}{l}\text { "Total } \\
\text { Blend" (m }{ }^{3} \\
\text { grout) }\end{array}$ & & \\
\hline Water dilution to $5 \mathrm{M} \mathrm{Na}$ & 473,000 & $3,610,000$ & $1,890,000$ & $48 \%$ & $\mathrm{~F}$ \\
\hline $\begin{array}{l}\text { Water dilution to } 5 \mathrm{M} \mathrm{Na} \\
\mathrm{w} / \mathrm{F}^{-} \text {removal }\end{array}$ & 473,000 & $2,036,000$ & $1,113,000$ & $45 \%$ & $\mathrm{Ph} \mathrm{Fb}$ \\
\hline $\begin{array}{l}\text { Water dilution to } 5 \mathrm{M} \mathrm{Na} \\
\mathrm{w} / \mathrm{F}^{-} \& \mathrm{~Pb}^{2+} \text { removal }\end{array}$ & 473,000 & 977,000 & 473,000 & $52 \%$ & $\begin{array}{l}\text { No limiting } \\
\text { component. }\end{array}$ \\
\hline
\end{tabular}

(a) Waste production from the GTF is based upon the soluble mass from the SSTs only.

(b) (volume from "no blend" - volume from "total blend")/(volume from "no blend"). 


\subsubsection{Grout Volume Estimate}

All the waste mass from the SSTs (after a sludge washing) not disposed of in the HWVP was the basis for the grout feed. If all the grout feed from the SSTs were disposed of in the GTF at $5 \mathrm{M} \mathrm{Na}$ loading, $473,000 \mathrm{~m}^{3}$ of grout would be produced. This estimate is lower than published estin:ates (Boomer 1991) because of the differing $\mathrm{Na}^{+}$solubility assumption. If a 0.99 solubility factor were assumed and specific gravity of 1.0 were assumed, $630,000 \mathrm{~m}^{3}$ of grout would be produced. This value agrees with Boomer.

The magnitude of the benefits that blending may provide is bounded by the grout volume produced from the "no blend" and "total blend" data points. Figure 2.4 shows data points for "no blend" and "total blend" for different grout feed scenarios. Starting at the top of the graph, the top line represents the sludge-wash-only case. If all the grout feed for the SSTs were disposed of in the GTF without any blending, $3,610,000 \mathrm{~m}^{3}$ of grout would be produced. If all the grout feed were blended, $1,890,000 \mathrm{~m}^{3}$ of grout (limited in $\mathrm{F}^{*}$ ) would be produced. The second line shows the reduction in volume that results with either actual removal of $\mathrm{F}$ or raising the acceptance limit. Approximately $2,036,000 \mathrm{~m}^{3}$ of grout results for the "no blend" scenario and 1,113,000 $\mathrm{m}^{3}$ of grout for the "total blend" scenario. The third line shows the volume that results with removal of both $\mathrm{F}^{-}$and $\mathrm{Pb}^{2+}$. Approximately $977,000 \mathrm{~m}^{3}$ of grout results for the "no blend" case, and $473,000 \mathrm{~m}^{3}$ of grout results for the "total blend" case, which is equal to the $5 \mathrm{M} \mathrm{Na}$ load.

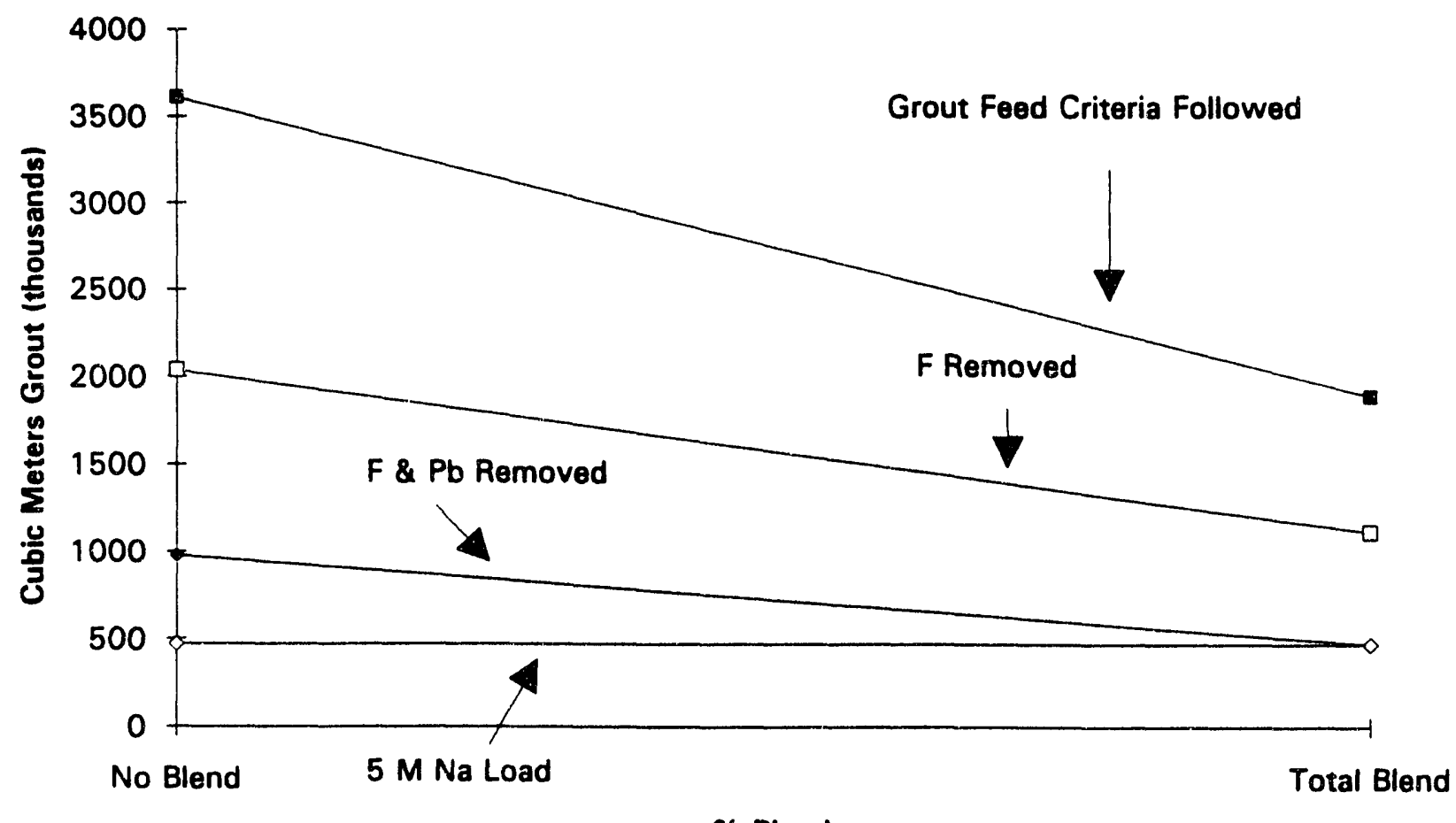

$\%$ Blend

Figure 2.4. GTF Grout Production 
Estimates assuming $5 \mathrm{M} \mathrm{Na}$ loading neglect the fact that the grout feed acceptance criteria, reproduced in Table 1.2, are restrictive in radiolytic heat content and chemical constituent concentrations. Both $\mathrm{F}^{-}$and $\mathrm{Pb}^{2+}$ are listed in the TRAC data base and their concentrations in the grout feed come from applying the solubility factors to the data base. The concentrations of $\mathrm{F}^{-}$and $\mathrm{Pb}^{2+}$ are so high that no amount of blending can reduce these outliers' concentrations to within limits. Thus, grout volume estimates that neglecting the grout feed acceptance criteria may underestimate grout production.

As shown in Table 2.4, out of the 28 constraints considered in the analysis of grout, 12 were exceeded by at least one tank. The following grout feed acceptance criteria were exceeded in the LLW feed ("no blend" option): $\mathrm{Ca}^{2+}, \mathrm{Ni}^{2+}, \mathrm{Pb}^{2+}, \mathrm{F}^{-}, \mathrm{NO}_{2}{ }^{-}, \mathrm{OH}^{-}, \mathrm{PO}_{4}{ }^{3}, \mathrm{SO}_{4}{ }^{2-}, \mathrm{TOC}, \mathrm{Na}^{+} /$(total cations), $\left(\mathrm{NO}_{2}{ }^{-}+\mathrm{NO}_{3}{ }^{-}\right) /$(total anions), and radiolytic heat content/unit volume. (By definition of the $5 \mathrm{M} \mathrm{Na}$ loading, Na cannot exceed the limit.) In order to approach the $5 \mathrm{M} \mathrm{Na}$ loading without the aid of blending, either pretreatments capable of reducing the concentration of the 12 different outliers must be developed or the potential for increasing these waste concentrations must be evaluated. Blending can reduce the number of chemical outliers from 12 to $2\left(\mathrm{~F}, \mathrm{~Pb}^{2+}\right)$.

Again, not all of the GTF outliers should actually be a problem for waste loading in grout, and many of these outliers, in the future, may be inconsequential when reviewed. The current grout feed specifications are based upon three major considerations: a) thermal loading in the grout; b) regulatory limits; and c) past experience. Item $c$ is the basis for many of the grout limits. For example, it certainly may not follow that because the proven "groutability" of $\mathrm{Ca}^{2+}$ is $573 \mathrm{ppm}$, the limit in grout has been established. However, this reasoning is how many of the grout feed specifications were established (excluding regulatory compliance limits).

Regulatory limits are the basis for grout feed limitation of the following outliers: $\mathrm{Pb}^{2+}$ and $\mathrm{TOC}$. Without mitigating pretreatment, these outliers have serious potential to negatively impact waste loading. Twenty-one of the 149 SSTs considered met all the constraints analyzed. There are 42 different categories of tanks which have a unique set of outliers. Of the 42 categories, 16 contain two or more tanks, leaving 26 tanks with a unique outlier set. Most tanks have multiple outliers, and the outliers vary from tank to tank. In order to approach the $5 \mathrm{M} \mathrm{Na}$ loading without the aid of blending, pretreatments must be capable of modifying the concentration of 12 different outliers. Since blending can reduce the number of chemical outliers from 12 (in various combinations in the tanks) to 2 , one must conclude that from this consideration alone, blending would be substantially beneficial to grout.

\subsection{Case II: Blending HLW Using HWVP Reference Feed Criteria}

Table 2.5 summarizes the HWVP canister production of different waste loading approaches examined in Case II. Recall that Case II evaluated eight selected tanks: AY-101 (CC waste type), AY-102 (dilute waste type), AZ-101 (NCAW waste type), AZ-102 (NCAW waste type), C-105 (SST), C-106 (SST), SY-101 (CC waste type), and SY-103 (CC waste type). These eight tanks were selected 
Table 2.4. GTF Outliers: Before and After Blending

\begin{tabular}{|c|c|c|}
\hline \multirow[b]{2}{*}{$\begin{array}{c}\text { Grout Feed Acceptance } \\
\text { Criteria }\end{array}$} & \multicolumn{2}{|c|}{$\begin{array}{l}\text { Number of LLW Feeds } \\
\text { Exceeding the Specified Grout } \\
\text { Feed Acceptance Criteria }\end{array}$} \\
\hline & "No Blend" & $\begin{array}{l}\text { "Total } \\
\text { Blend"(a) }\end{array}$ \\
\hline $\mathrm{Ag}^{+}$ & 0 & 0 \\
\hline $\mathrm{Al}^{3+}$ & 0 & 0 \\
\hline $\mathrm{Ba}^{2+}$ & 0 & 0 \\
\hline $\mathrm{Ca}^{2+}$ & 4 & 0 \\
\hline $\mathrm{Cd}^{2+}$ & 0 & 0 \\
\hline $\mathrm{Cr}^{3+}$ & 0 & 0 \\
\hline $\mathrm{Fe}^{2+}$ & 0 & 0 \\
\hline $\mathrm{Hg}^{2+}$ & 0 & 0 \\
\hline $\mathrm{K}^{+}$ & 0 & 0 \\
\hline $\mathrm{Mn}^{2+}$ & 0 & 0 \\
\hline $\mathrm{Na}^{+}$ & 0 & 0 \\
\hline $\mathrm{Ni}^{2+}$ & 14 & 0 \\
\hline $\mathrm{Pb}^{2+}$ & 8 & 1 \\
\hline $\mathrm{Se}^{4+}$ & 0 & 0 \\
\hline $\mathrm{Si}^{4+}$ & 0 & 0 \\
\hline $\mathrm{Cl}^{-}$ & 0 & 0 \\
\hline $\mathrm{F}^{-}$ & 50 & 1 \\
\hline $\mathrm{NO}_{2}^{-}$ & 9 & 0 \\
\hline $\mathrm{NO}_{3}^{-}$ & 0 & 0 \\
\hline $\mathrm{OH}^{-}$ & 33 & 0 \\
\hline $\mathrm{PO}_{4}^{3-}$ & 6 & 0 \\
\hline $\mathrm{SO}_{4}^{2-}$ & 2 & 0 \\
\hline $\mathrm{CO}_{3}^{2-}$ & 0 & 0 \\
\hline Watts & 13 & 0 \\
\hline TOC & 21 & 0 \\
\hline $\mathrm{Na}^{+}<75 \%$ total cations & 15 & 0 \\
\hline $\mathrm{Al}^{3+}>20 \%$ total cations & 0 & 0 \\
\hline Total $\mathrm{NO}_{\mathbf{x}}>75 \%$ total anions & 58 & 0 \\
\hline
\end{tabular}

(a) Note that the "total blend" has only one LLW feed.

due to their consideration for early retrieval and immobilization. The $25 \mathrm{wt} \%$ loading is the widely used baseline approach which ignores the HWVP feed specifications, and canister estimates are based on the total waste mass. For the eight tanks considered, 2,820 canisters of waste are produced. The "no blend" option takes each tank waste as an individual feed, an approach which results in the worstcase canister production estimate of 11,060 canisters. In contrast to the "no blend" option, the "total blend" option uses as feed a composite of all tank wastes, and results in 7,470 canisters. Thus a $32 \%$ canister reduction may result from blending. 
Table 2.5. Waste Production Summary for Selected Tanks: HWVP

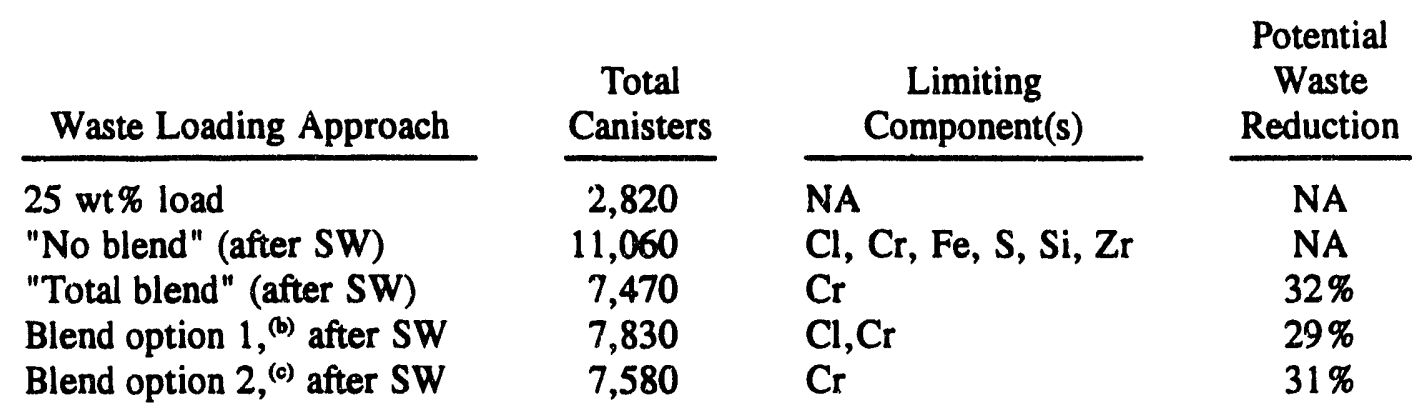

(a) Blend of tanks SY-101/C-106, SY-103/C-105, AZ-101/AY-101, AZ-102/AY-102, resulting in four waste feeds.

(b) Blend of tanks SY-101/C-106/AZ-102, SY-103/C-105/AY-102, AZ-101/AY-101, resulting in three waste feeds.

Blend options 1 and 2 blend wastes, by tank, to obtain four and three discrete waste feeds, respectively. Comparison of the "total blend" case with blend options 1 and 2 shows that the level of effort required to closely approach the optimum ("total blend") case is low. One can see that both blend options 1 and 2 have high potential waste reductions (29\% and $31 \%$, respectively) relative to the "total blend" case after a modest blending effort. Thus, very substantial gains can be made simply by the judicious selection of a few tank blending partners, as shown in Figure 2.5.

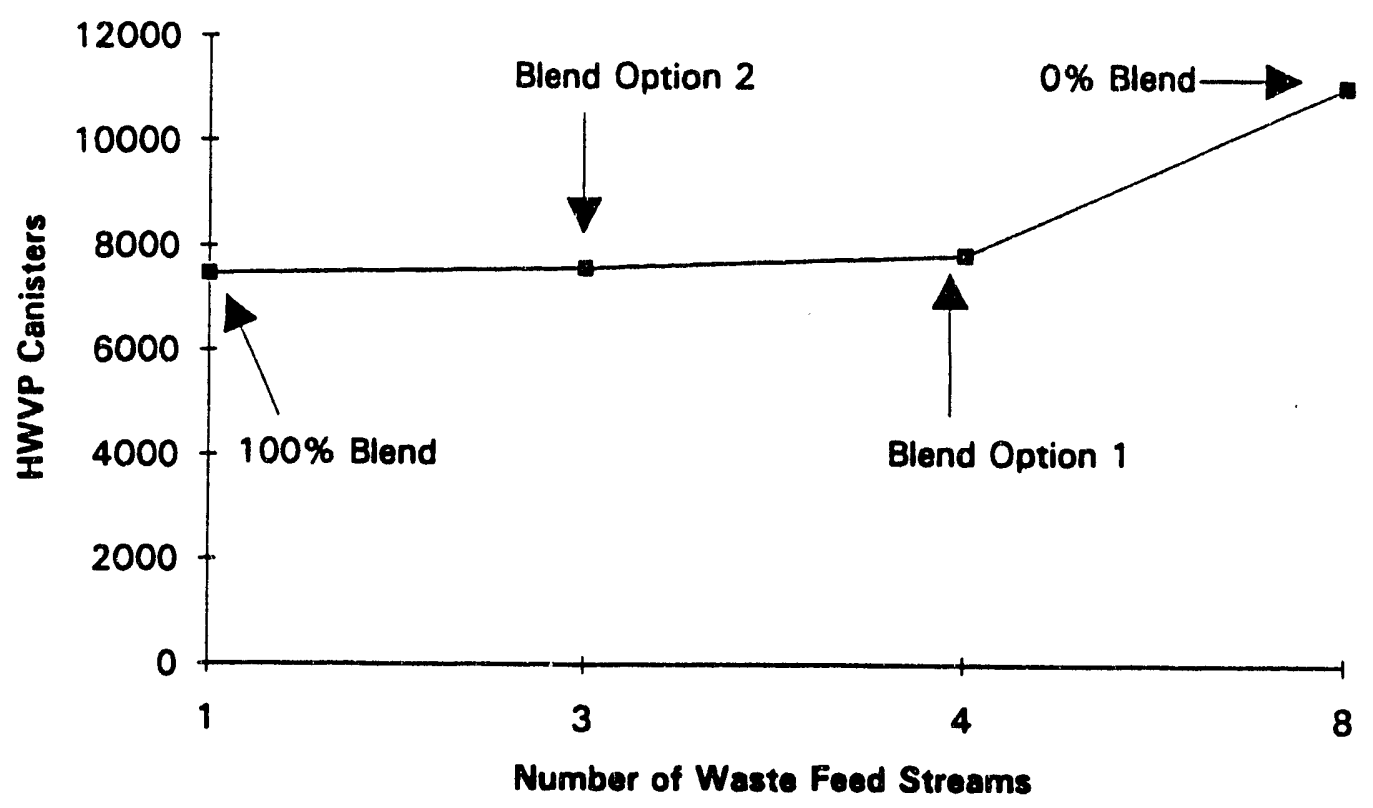

Figure 2.5. HWVP Canisters Required to Immobilize Various Blend Options 
Table 2.6 displays the eight tanks, the HWVP feed constraints considered, and the components whose concentration exceeded the feed limit. A number in a cell indicates the factor by which the component concentration in the feed exceeds the HWVP feed specifications. For example, feed from tank $\mathrm{C}-105$ has an $\mathrm{Ai}_{2} \mathrm{O}_{3}$ concentration 1.4 times the limit. Comparison of the individual tank waste feed to the "total blend" waste feed demonstrates the number of waste oxides that can be diluted to within an acceptable concentration by blending. Before blending, $\mathrm{Al}_{2} \mathrm{O}_{3}, \mathrm{Cr}_{2} \mathrm{O}_{3}, \mathrm{Fe}_{2} \mathrm{O}_{3}, \mathrm{Na}_{2} \mathrm{O}, \mathrm{P}_{2} \mathrm{O}_{5}$, $\mathrm{SO}_{3}, \mathrm{SiO}_{2}, \mathrm{ZrO}_{2}$, other, and $\mathrm{Cl}$ all have concentrations exceeding the $\mathrm{HWVP}$ limit. After blending only $\mathrm{Al}_{2} \mathrm{O}_{3}, \mathrm{Cr}_{2} \mathrm{O}_{3}$, and $\mathrm{SiO}_{2}$ exceed the limits. ${ }^{(a)}$ In this case blending reduced the number of $\mathrm{HWVP}$ outliers from 10 to 3 .

Table 2.6. HWVP Outliers from Selected Hanford Tank Wastes (after SW)

Tank (HWVP feed limit is exceeded by the factor indicated)

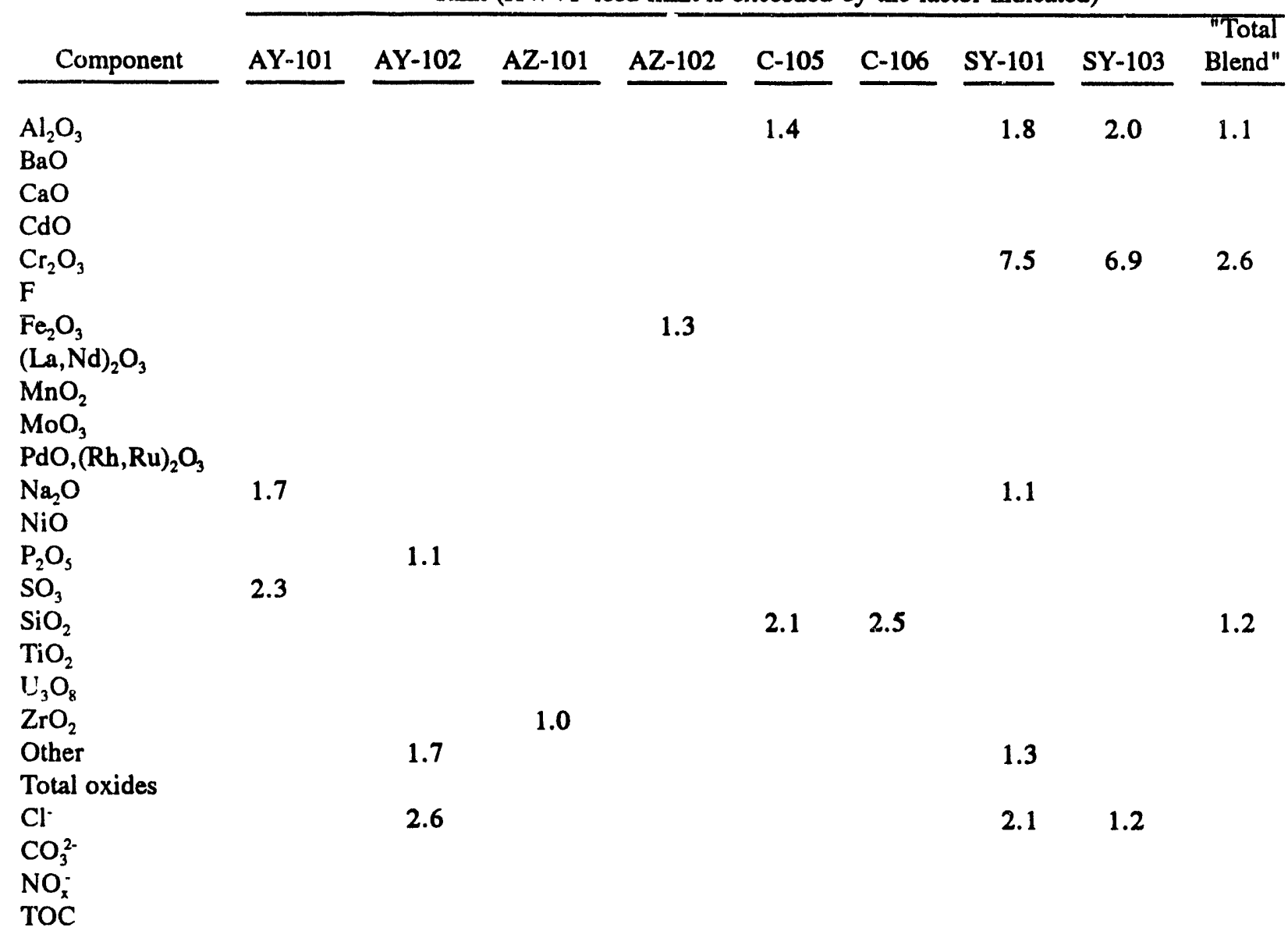

(a) Glass is largely composed of $\mathrm{SiO}_{2}$, and the fact that $\mathrm{SiO}_{2}$ exceeds the limit demonstrates the inadequacy of the HWVP reference model. 
Two blending options were evaluated and compared to the "total blend" case. Blend option 1 mixed waste (by tank) so that four discrete waste types resulted, while blend option 2 mixed waste (by tank) so that three discrete waste types resulted. Obviously, many possible combinations of tanks will result in three and four waste streams. By examining component concentrations, however, the tank combination which produces the fewest canisters was determined. These optimum combinations are shown in Table 2.7, which displays for blend options 1 and 2 the waste feed streams whose concentration exceeds the HWVP constraints. Again a number in the cell indicates the factor by which the component concentration exceeds the HWVP feed specifications. Blend option 1 has six different HWVP outliers $\left(\mathrm{Al}_{2} \mathrm{O}_{3}, \mathrm{Cr}_{2} \mathrm{O}_{3}, \mathrm{Fe}_{2} \mathrm{O}_{3}, \mathrm{SiO}_{2}, \mathrm{Cl}\right.$, others), while blend option 2 has three $\left(\mathrm{Al}_{2} \mathrm{O}_{3}, \mathrm{Cr}_{2} \mathrm{O}_{3}\right.$, and

Table 2.7. HWVP Outliers from Selected Hanford Tank Waste Blends (after SW)

\begin{tabular}{|c|c|c|c|c|c|c|c|}
\hline \multirow[b]{3}{*}{ Component } & \multicolumn{7}{|c|}{ Tank (HWVP limit is exceeded by the factor indicated) } \\
\hline & \multicolumn{4}{|c|}{ Blend Option 1} & \multicolumn{3}{|c|}{ Blend Option 2} \\
\hline & $\begin{array}{c}\text { SY-101 } \\
\text { C-106 } \\
\end{array}$ & $\begin{array}{c}\text { SY-103 } \\
\text { C-105 }\end{array}$ & $\begin{array}{l}\text { AZ-101 } \\
\text { AY-101 }\end{array}$ & $\begin{array}{l}\text { AZ-102 } \\
\text { AY-102 }\end{array}$ & $\begin{array}{c}\text { SY-101 } \\
\text { C-106 } \\
\text { AZ-102 }\end{array}$ & $\begin{array}{l}\text { SY-103 } \\
\text { C-105 } \\
\text { AY-101 }\end{array}$ & $\begin{array}{l}\text { AZ-101 } \\
\text { AY-101 }\end{array}$ \\
\hline $\mathrm{Al}_{2} \mathrm{O}_{3}$ & 1.1 & 1.7 & & & & 1.5 & \\
\hline \\
\hline \multicolumn{8}{|l|}{$\mathrm{CaO}$} \\
\hline \multicolumn{8}{|l|}{$\mathrm{CdO}$} \\
\hline $\mathrm{Cr}_{2} \mathrm{O}_{3}$ & 3.1 & 3.2 & & & 2.6 & 2.8 & \\
\hline \multicolumn{8}{|l|}{$\mathrm{F}$} \\
\hline \multicolumn{8}{|l|}{$\mathrm{Fe}_{2} \mathrm{O}_{3}$} \\
\hline \multicolumn{8}{|l|}{$(\mathrm{La}, \mathrm{Nd})_{2} \mathrm{O}_{3}$} \\
\hline \multicolumn{8}{|l|}{$\mathrm{MnO}_{2}$} \\
\hline \multicolumn{8}{|l|}{$\mathrm{MoO}_{3}$} \\
\hline \multicolumn{8}{|l|}{$\mathrm{PdO},(\mathrm{Rh}, \mathrm{Ru})_{2} \mathrm{O}_{3}$} \\
\hline \multicolumn{8}{|l|}{$\mathrm{Na}_{2} \mathrm{O}$} \\
\hline \multicolumn{8}{|l|}{$\mathrm{NiO}$} \\
\hline \multicolumn{8}{|l|}{$\mathrm{P}_{2} \mathrm{O}_{5}$} \\
\hline \multicolumn{8}{|l|}{$\mathrm{SO}_{3}$} \\
\hline $\mathrm{SiO}_{2}$ & 1.5 & 1.2 & & & 1.3 & 1.1 & \\
\hline \multicolumn{8}{|l|}{$\mathrm{TiO}_{2}$} \\
\hline \multicolumn{8}{|l|}{$\mathrm{U}_{3} \mathrm{O}_{8}$} \\
\hline \multicolumn{8}{|l|}{$\mathrm{ZrO}_{2}$} \\
\hline \multicolumn{8}{|l|}{$\begin{array}{l}\text { Other } \\
\mathrm{Cl}^{-}\end{array}$} \\
\hline $\mathrm{Cl}^{-}$ & & & & 1.1 & & & \\
\hline \multicolumn{8}{|l|}{$\mathrm{CO}_{3}^{2-}$} \\
\hline $\mathrm{NO}_{\mathbf{x}}^{-}$ & & & & & & & \\
\hline TOC & & & & & & & \\
\hline
\end{tabular}


$\mathrm{SiO}_{2}$ ). Blend option 2 collectively has the same outliers as the "total blend" case; however, examining the option 2 waste streams individually reveals that one waste feed stream meets all HWVP constraints, the second waste feed stream is high in $\mathrm{Cr}_{2} \mathrm{O}_{3}$ and $\mathrm{SiO}_{2}$ only, and the outliers from the third waste stream match the "total blend" case. These results accentuate the obvious fact that selected pretreatments (e.g., $\mathrm{Cr}$ leach) may be more efficiently performed before blending because less waste will have to be processed.

\subsection{Case II: Blending HLW Using CVS Modeling}

The CVS models are incorporated into a visual waste loading model called Ternary Waste Envelope Assessment Tool (TWEAT), which calculates glass properties of the chosen waste, frit, and recycle as a function of composition, and displays the results on a ternary diagram. The diagram displays the dependence of glass durability, melt viscosity, and melt electrical conductivity on glass composition. The liquidus model currently used in TWEAT is known to be inaccurate, ${ }^{(a)}$ and although displayed, it was disregarded in the waste loading analysis. In lieu of the liquidus model, crystallinity constraints were used. These were determined on the spreadsheet used to design the frit.

A spreadsheet, designed by Pavel Hrma (PNL), incorporating first-order CVS empirical models was used to design a four-component frit $\left(\mathrm{SiO}_{2}, \mathrm{~B}_{2} \mathrm{O}_{3}, \mathrm{Na}_{2} \mathrm{O}, \mathrm{Li}_{2} \mathrm{O}\right)$ for each waste stream. The idea was to design a frit which when combined with the waste would produce a glass with viscosity (at $1150^{\circ} \mathrm{C}$ ) of $6 \mathrm{~Pa} \cdot \mathrm{S}$, electrical conductivity (at $1150^{\circ} \mathrm{C}$ ) of $30 \mathrm{~S} / \mathrm{m}$, satisfactory crystallinity constraints, and minimum boron release based upon MCC-1 models. Because the liquidus temperature model is known to be inaccurate in its current state of development, this property was not used in the design of the frit. Each waste stream composition and associated frit were entered into TWEAT. A recycle stream with set composition was also incorporated into the model. The results are displayed in a ternary diagram with the waste stream, frit, and recycle at the vertices. The assumed recycle composition follows (weight fraction): $\mathrm{SiO}_{2}-0.4367 ; \mathrm{Na}_{2} \mathrm{O}-0.4253 ; \mathrm{CaO}-0.0030 ; \mathrm{MgO}-0.0032 ; \mathrm{Fe}_{2} \mathrm{O}_{3}-$ $0.0107 ; \mathrm{Al}_{2} \mathrm{O}_{3}-0.0410$; other -0.0801 .

Figures 2.6 through 2.20 show the TWEAT-predicted glass properties. The glass property key is shown at the top of each figure. TWEAT incorporates T liquidus (spinel), viscosity (hi and lo), electrical conductivity (hi and lo), and MCC-1 ( $\mathrm{Si}, \mathrm{B}, \mathrm{Li}$ ) durability models. The model does not consider solubility restrictions of minor components. Since minor components of concern $\left(\mathrm{Cr}_{2} \mathrm{O}_{3}, \mathrm{~F}^{-}, \mathrm{P}_{2} \mathrm{O}_{5}\right.$, and $\mathrm{SO}_{3}$ ) may substantially restrict waste loading, these component concentrations must be examined separately.

(a) A more accurate liquidus temperature model is being designed and is expected to be complete in the second quarter of FY93. 


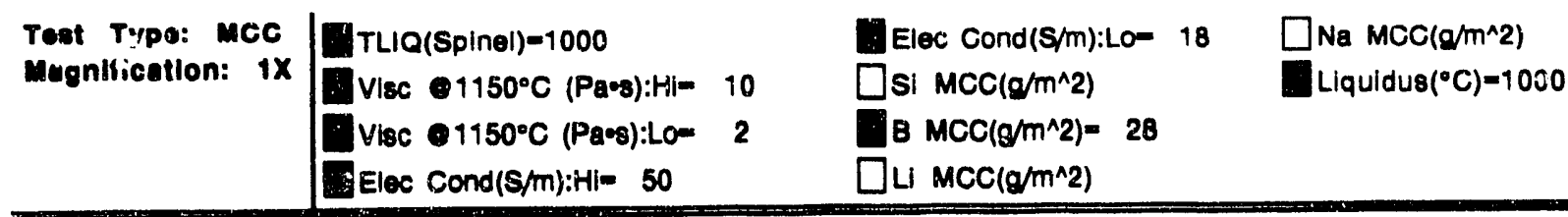

a

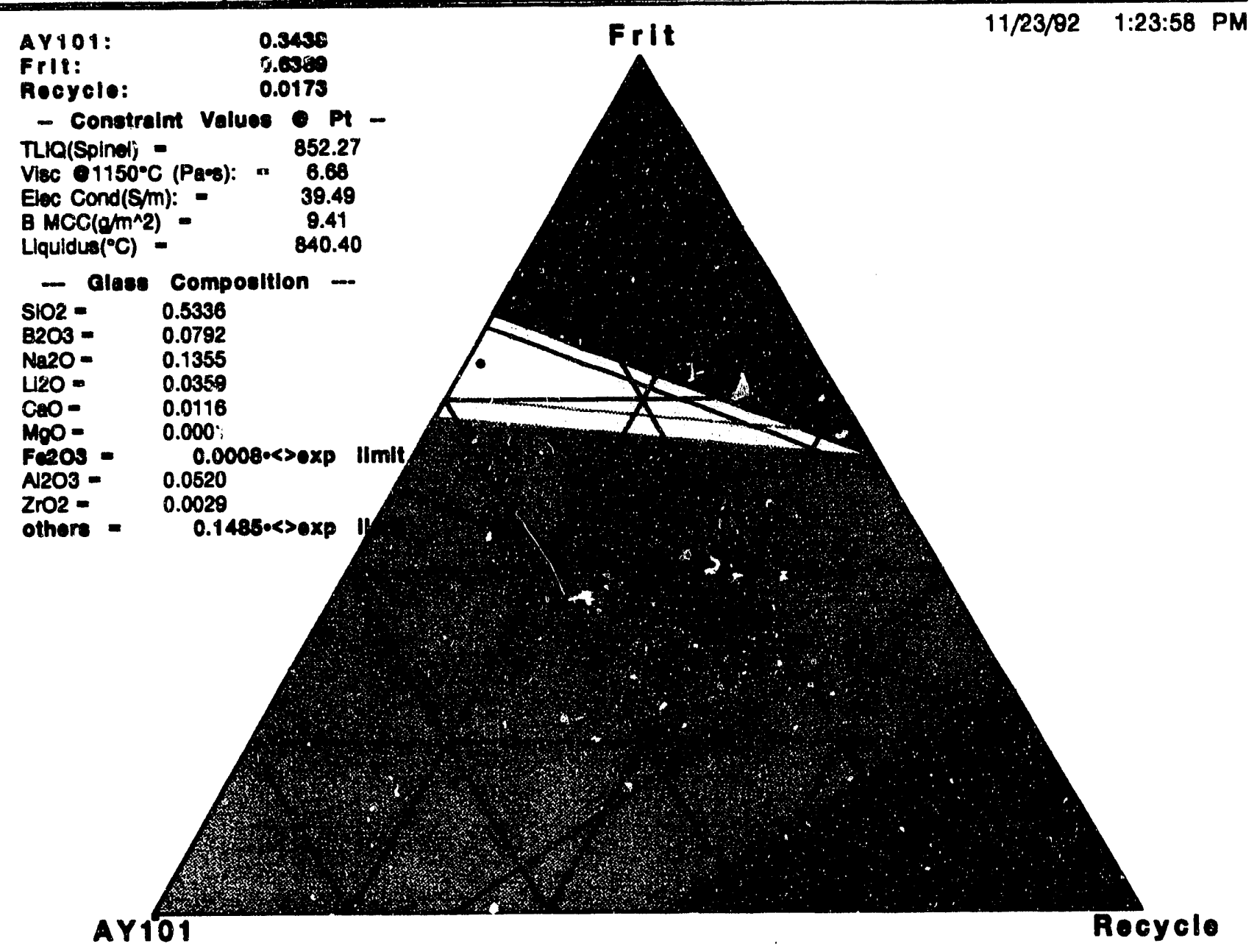

Kigure 2.6. TWEAT Analysis: AY-101 


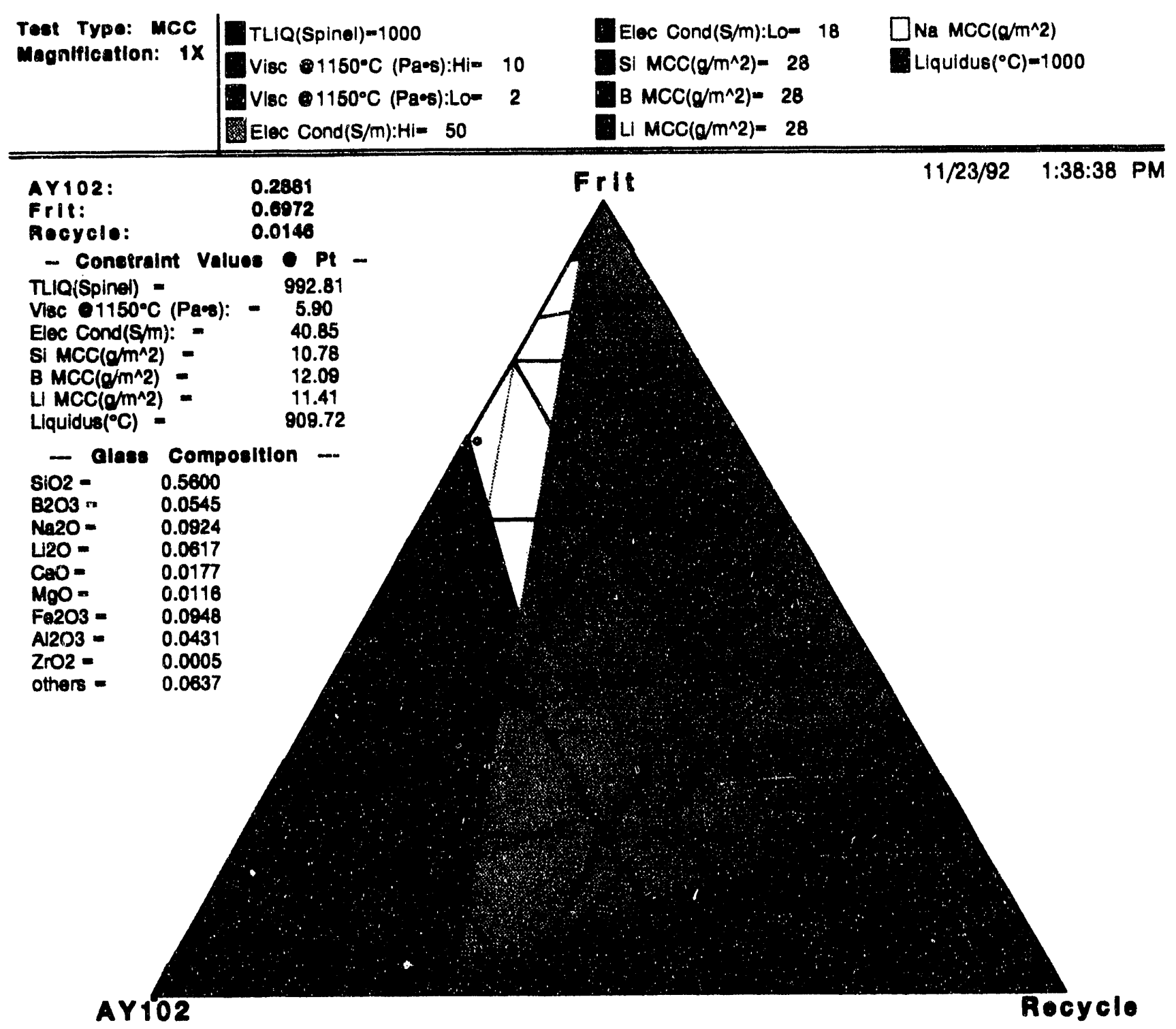

Figure 2.7. TWEAT Analysis: AY-102 


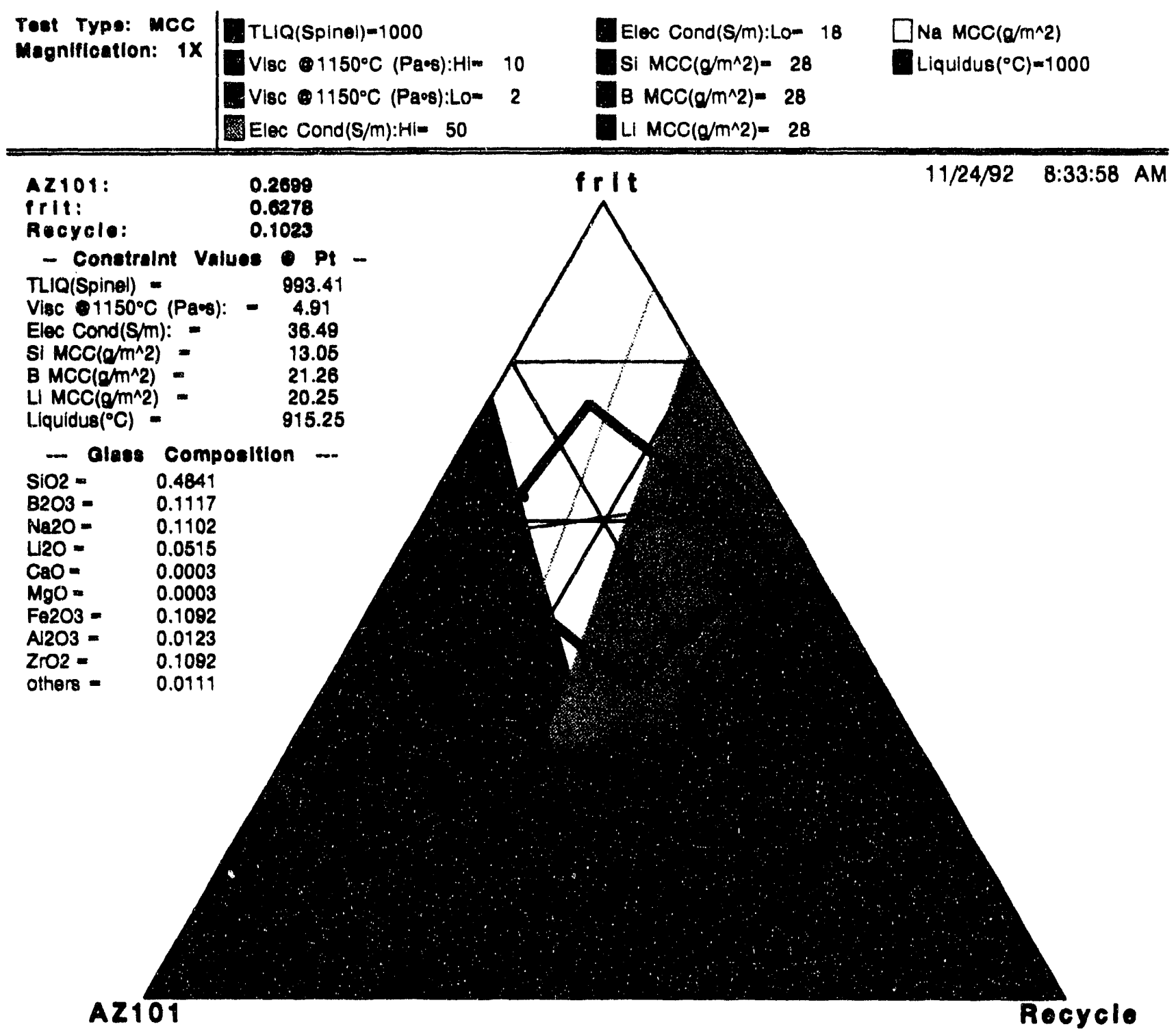

Figure 2.8. TWEAT Analysis: AZ-101 


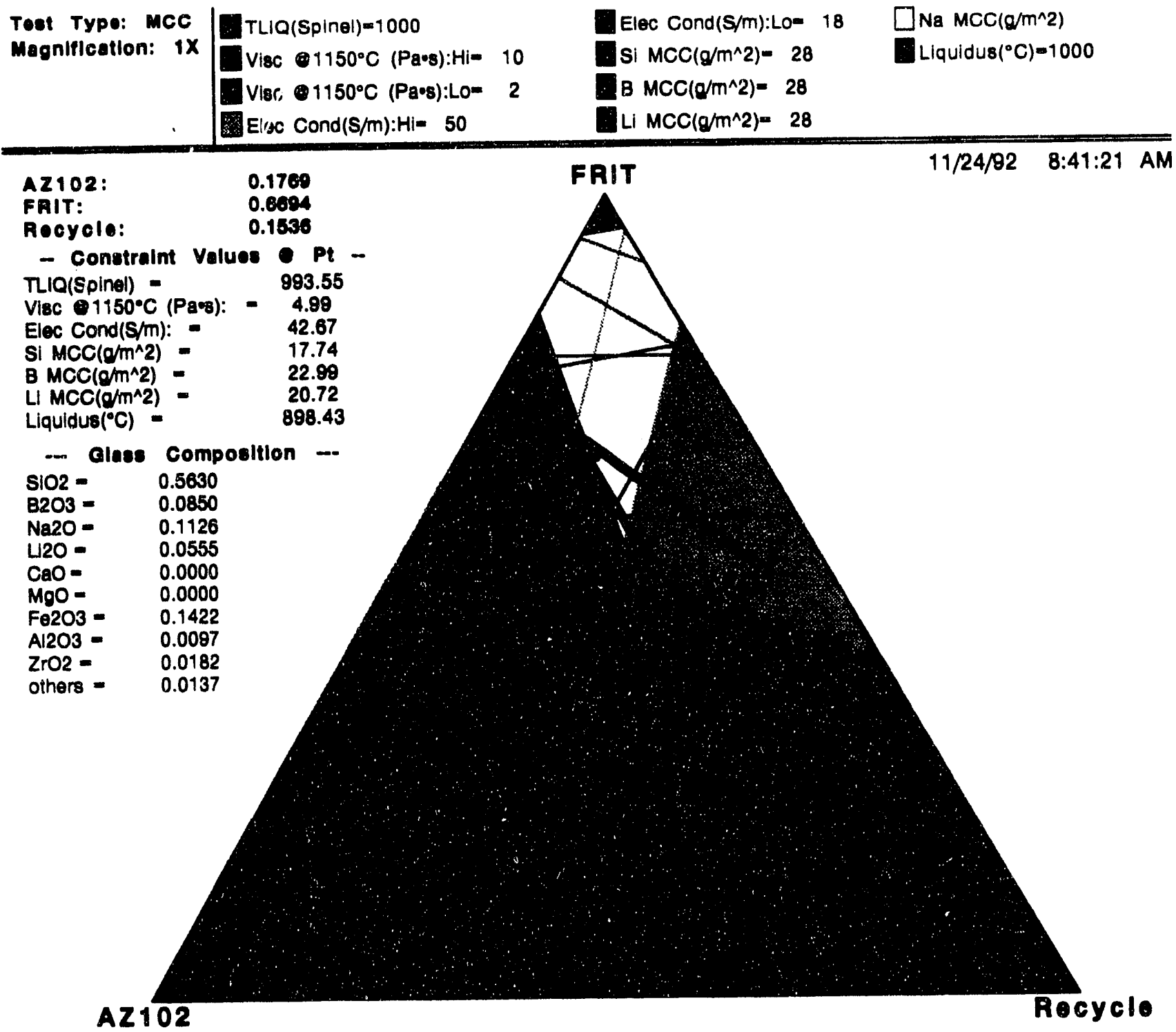

Figure 2.9. TWEAT Analysis: AZ-102 


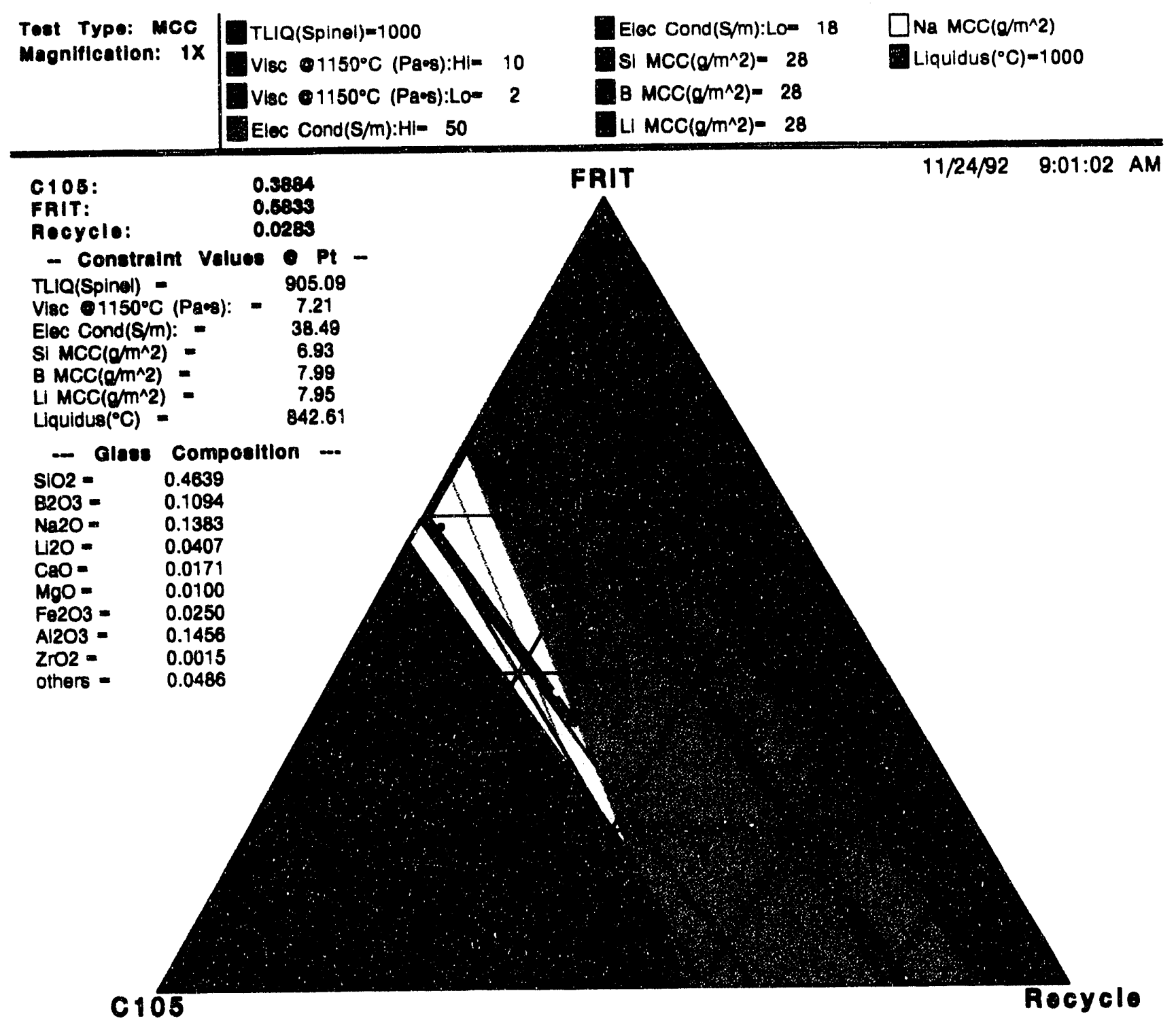

Figure 2.10. TWEAT Analysis: C-105 


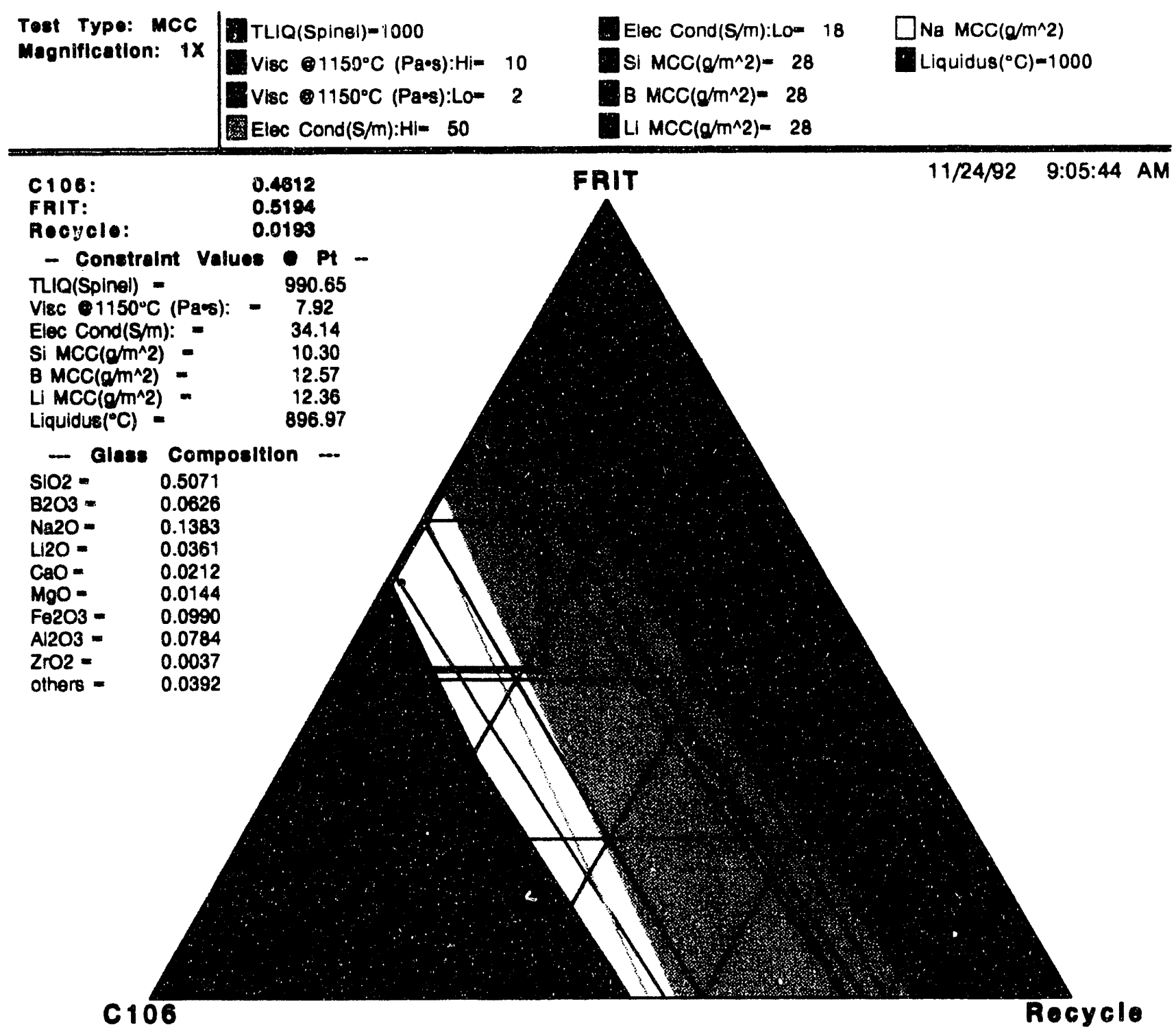

Figure 2.11. TWEAT Analysis: C-106 


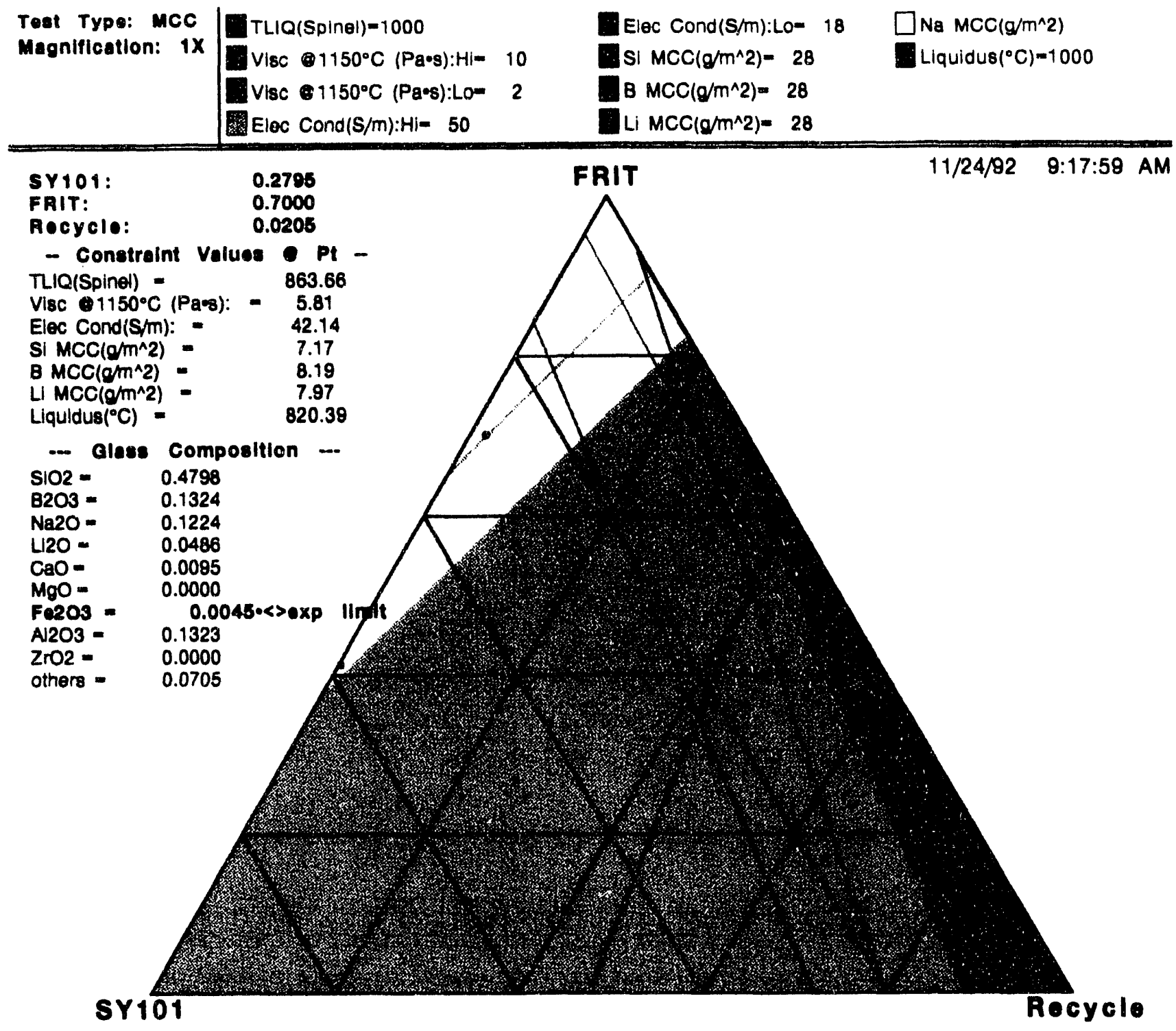

Figure 2.12. TWEAT Analysis: SY-101 


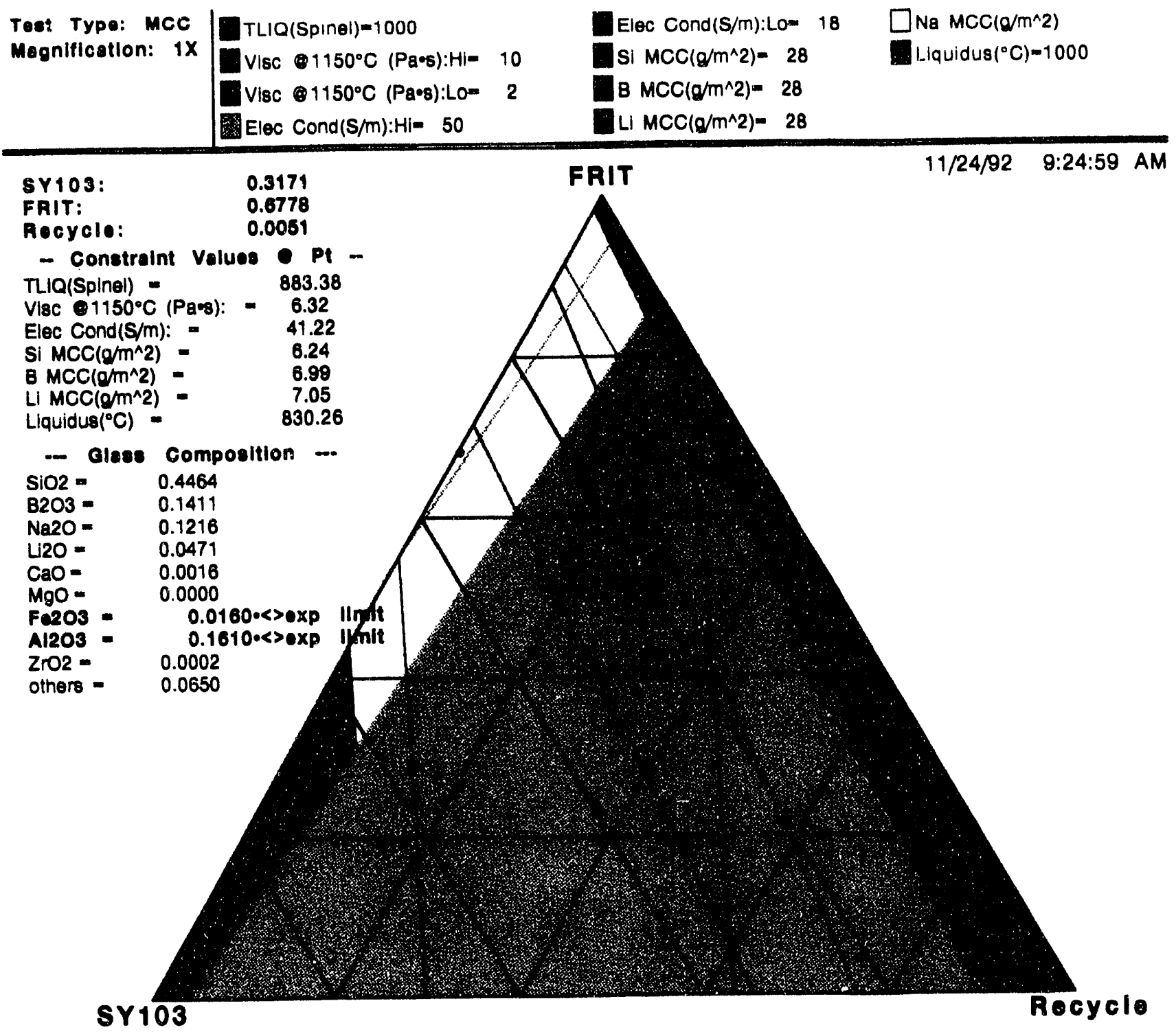

Figure 2.13. TWEAT Analysis: SY-103 


\begin{tabular}{|c|c|c|c|}
\hline \multirow{4}{*}{$\begin{array}{l}\text { Teat Type: MCC } \\
\text { Magnificatlon: } 1 X\end{array}$} & TLIQISp & Elec Cond(S/m):Lo- 18 & ] $\mathrm{Na} M C C\left(a / m^{\wedge} 2\right)$ \\
\hline & Visc $11150^{\circ} \mathrm{C}$ (Paes):HI= 1 & SI $M C C\left(Q / m^{\wedge} 2\right)=28$ & Liquidus $\left({ }^{\circ} \mathrm{C}\right)=1000$ \\
\hline & VIBC $1150^{\circ} \mathrm{C}(\mathrm{Pa} 8): \mathrm{LO}=$ & $\operatorname{MCC}\left(g / m^{\wedge} 2\right)=28$ & \\
\hline & Elec Cond $(S / m): H i=50$ & $4 / \operatorname{MCC}\left(g / m^{\wedge} 2\right)=28$ & \\
\hline
\end{tabular}

c

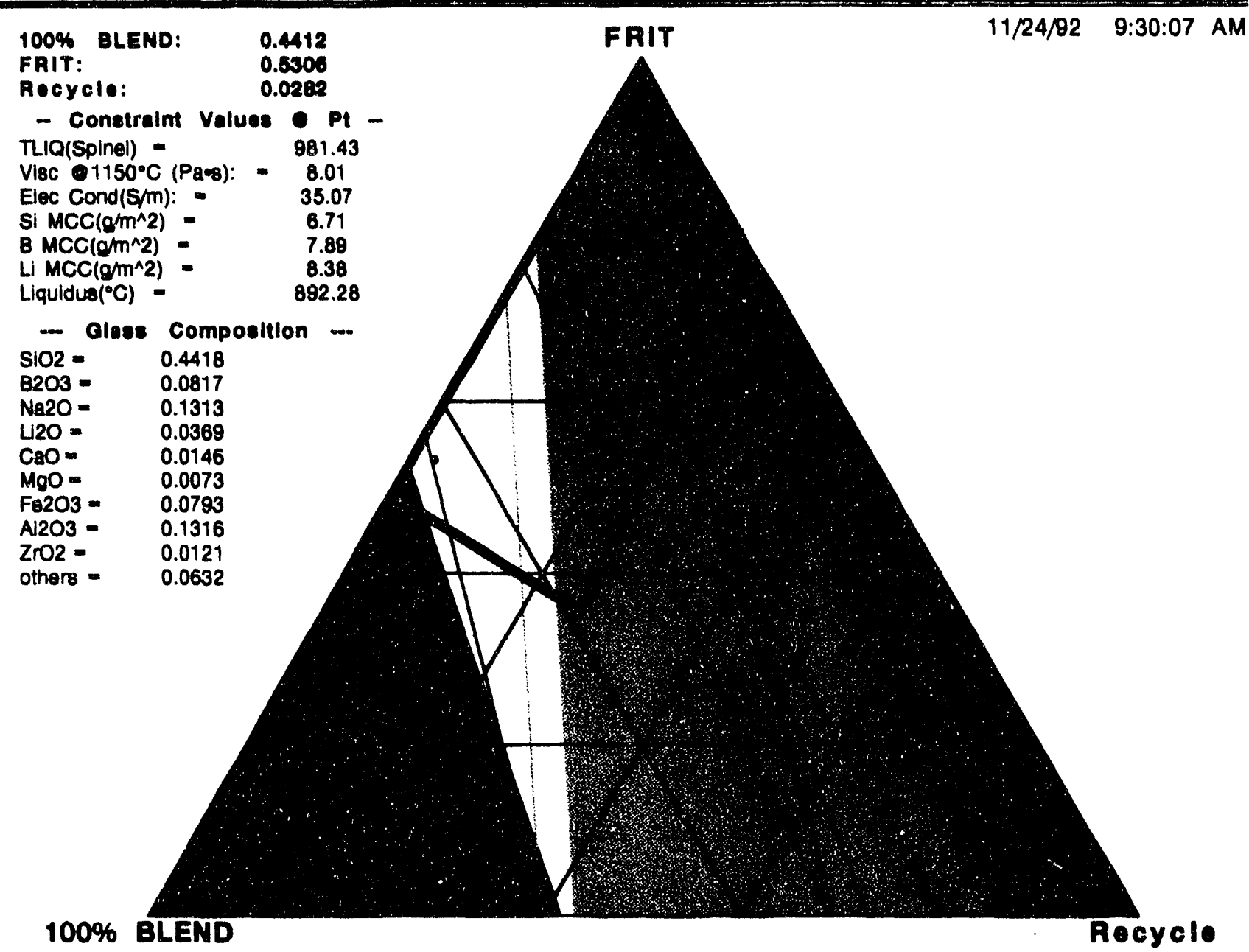

Figure 2.14. TWEAT Analysis: "Total Blend" 


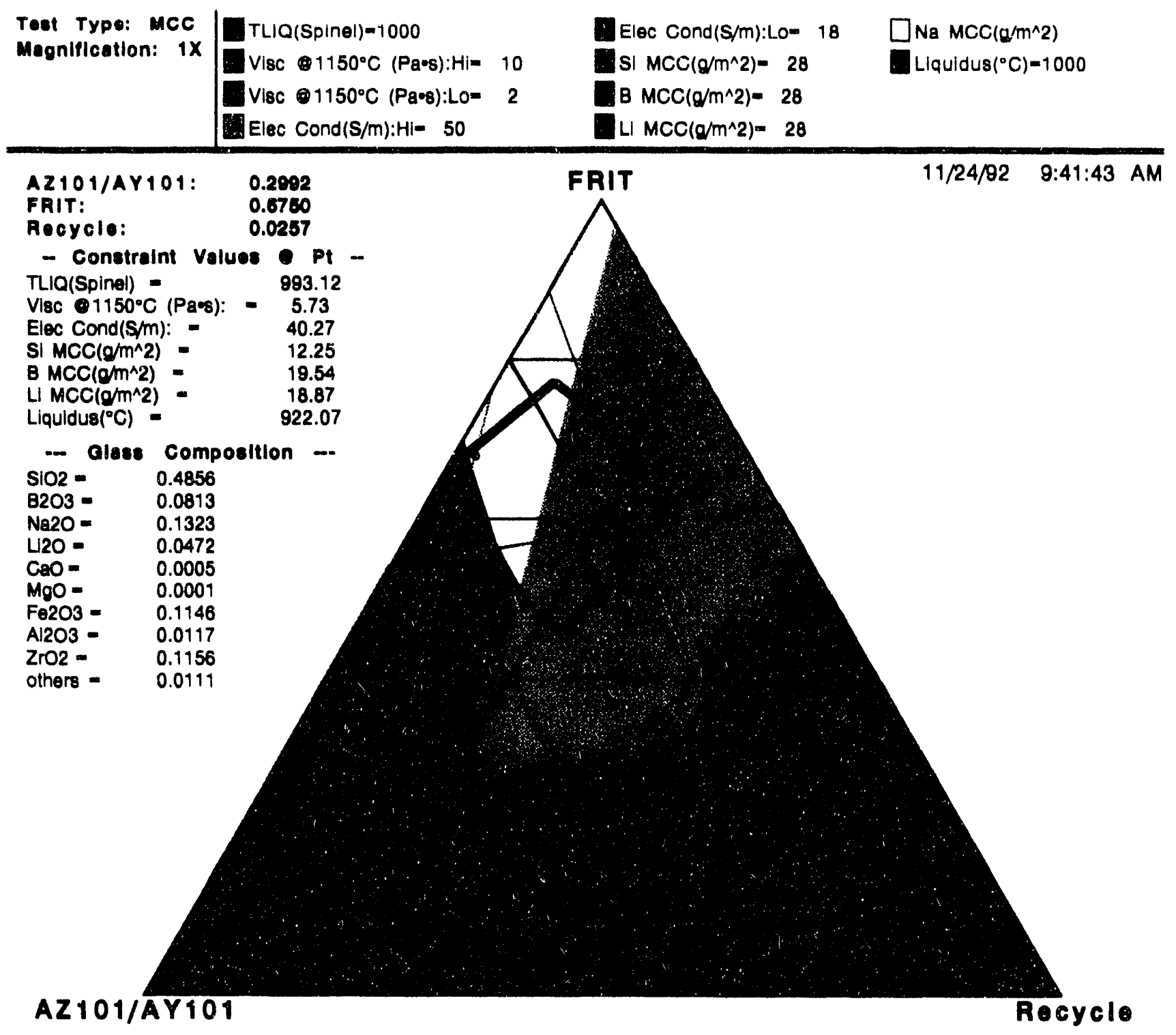

Figure 2.15. TWEAT Analysis: AZ-101/AY-101 


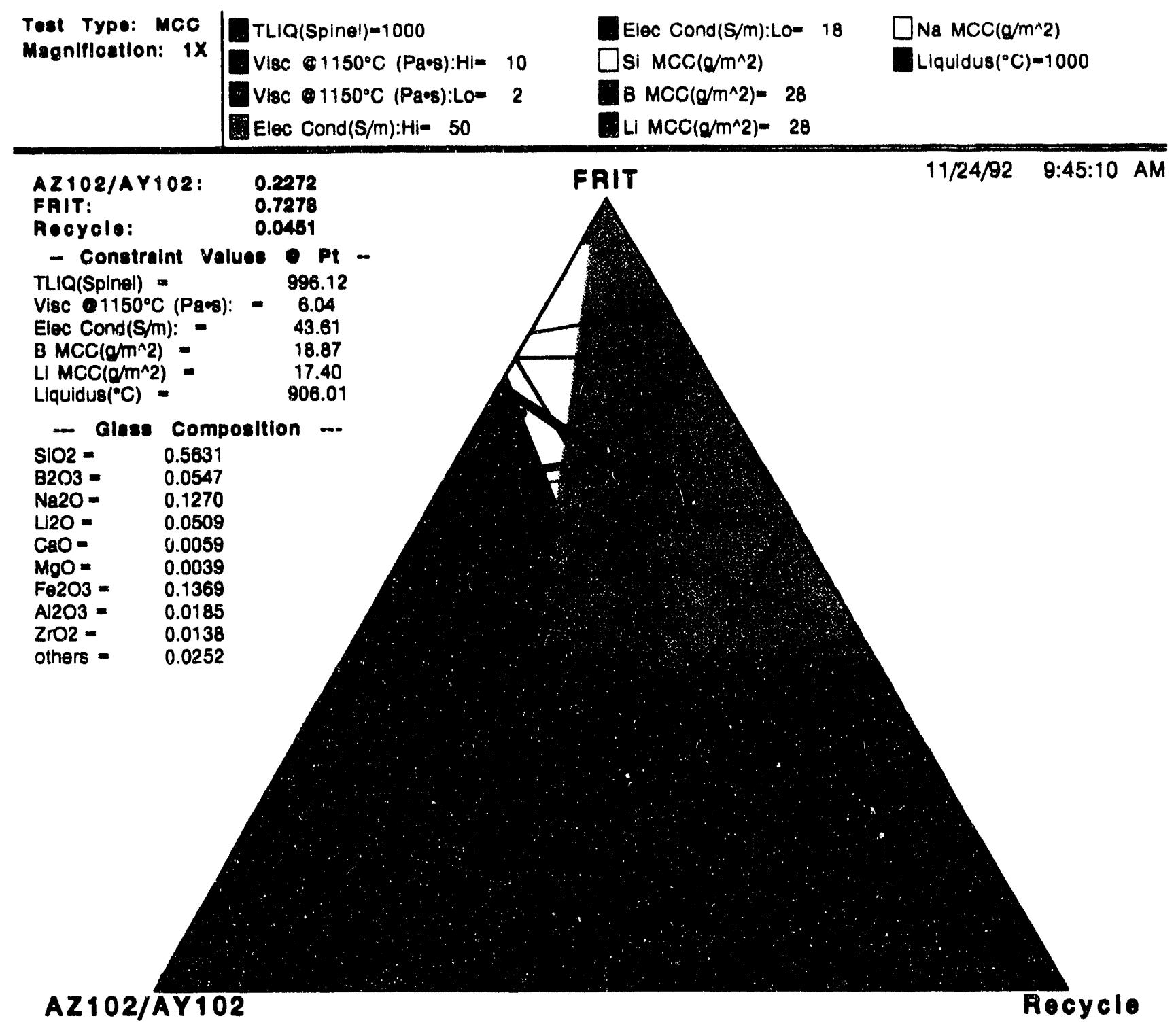

Figure 2.16. TWEAT Analysis: AZ-102/AY-102 


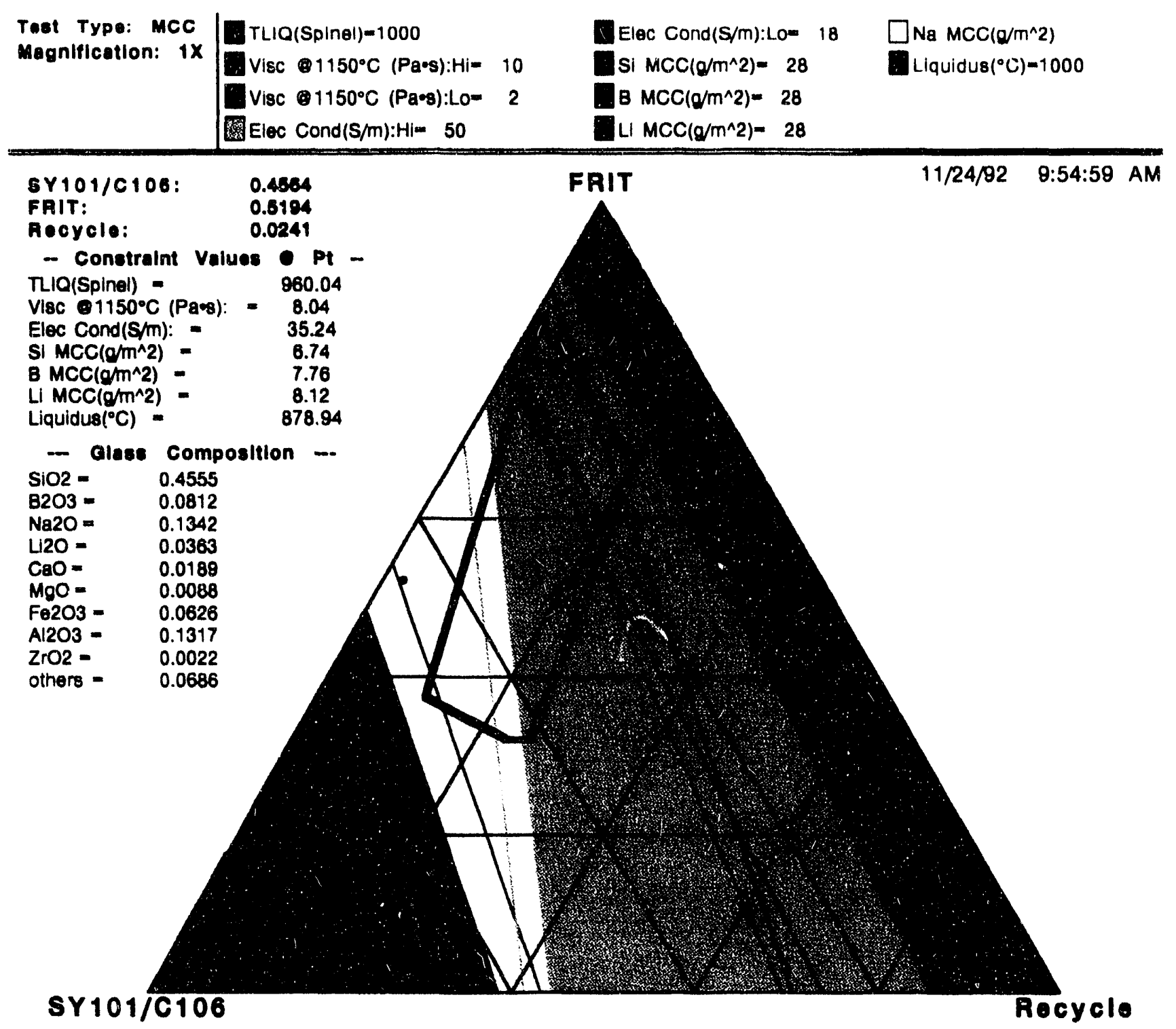

Figure 2.17. TWEAT Analysis: SY-101/C-106 


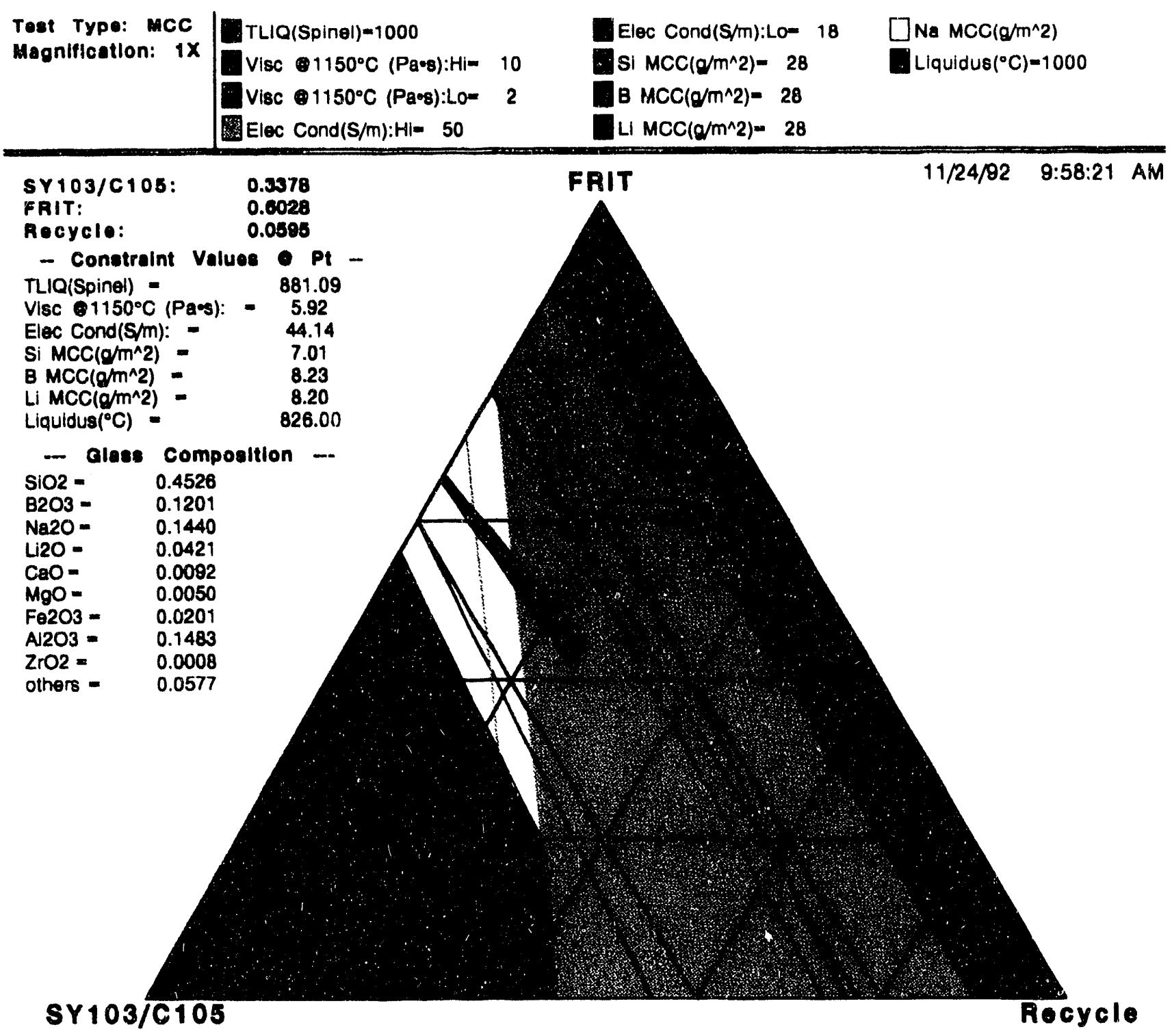

Figure 2.18. TWEAT Analysis: SY-103/C-105 


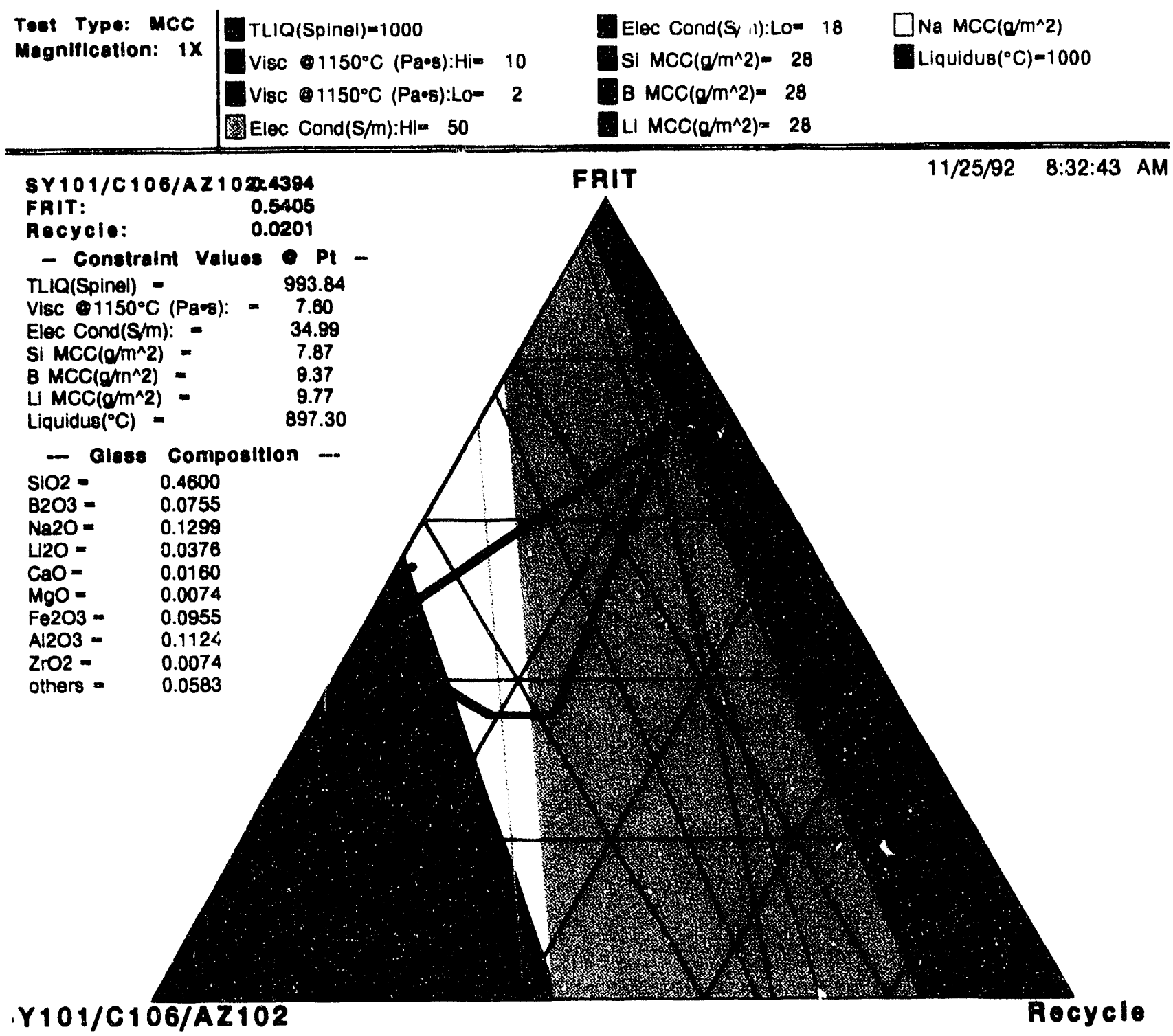

Figure 2.19. TWEAT Analysis: SY-101/C-106/AZ-102 


\begin{tabular}{|c|c|c|c|}
\hline \multirow{4}{*}{$\begin{array}{l}\text { Test Type: MCC } \\
\text { Magniflcation: } 1 X\end{array}$} & $T L I Q($ Spinel) $=1000$ & Elec Cond $(S / m): L o=18$ & ] $\mathrm{Na} \operatorname{MCC}\left(g / m^{\wedge} 2\right)$ \\
\hline & Visc $1150^{\circ} \mathrm{C}$ (Pa-s):Hi= 10 & Si $\operatorname{MCC}\left(8 / \pi^{\wedge} 2\right)=28$ & Llquidus $\left({ }^{\circ} \mathrm{C}\right)=1000$ \\
\hline & Vlsc $1150^{\circ} \mathrm{C}(\mathrm{Pa}-8):$ Lon 2 & $\operatorname{MCC}\left(g / m^{\wedge} 2\right)=28$ & \\
\hline & Elec Cond $(S / m): H i=5 C$ & LI MCC $\left(0 / m^{\wedge} 2\right)=28$ & \\
\hline
\end{tabular}

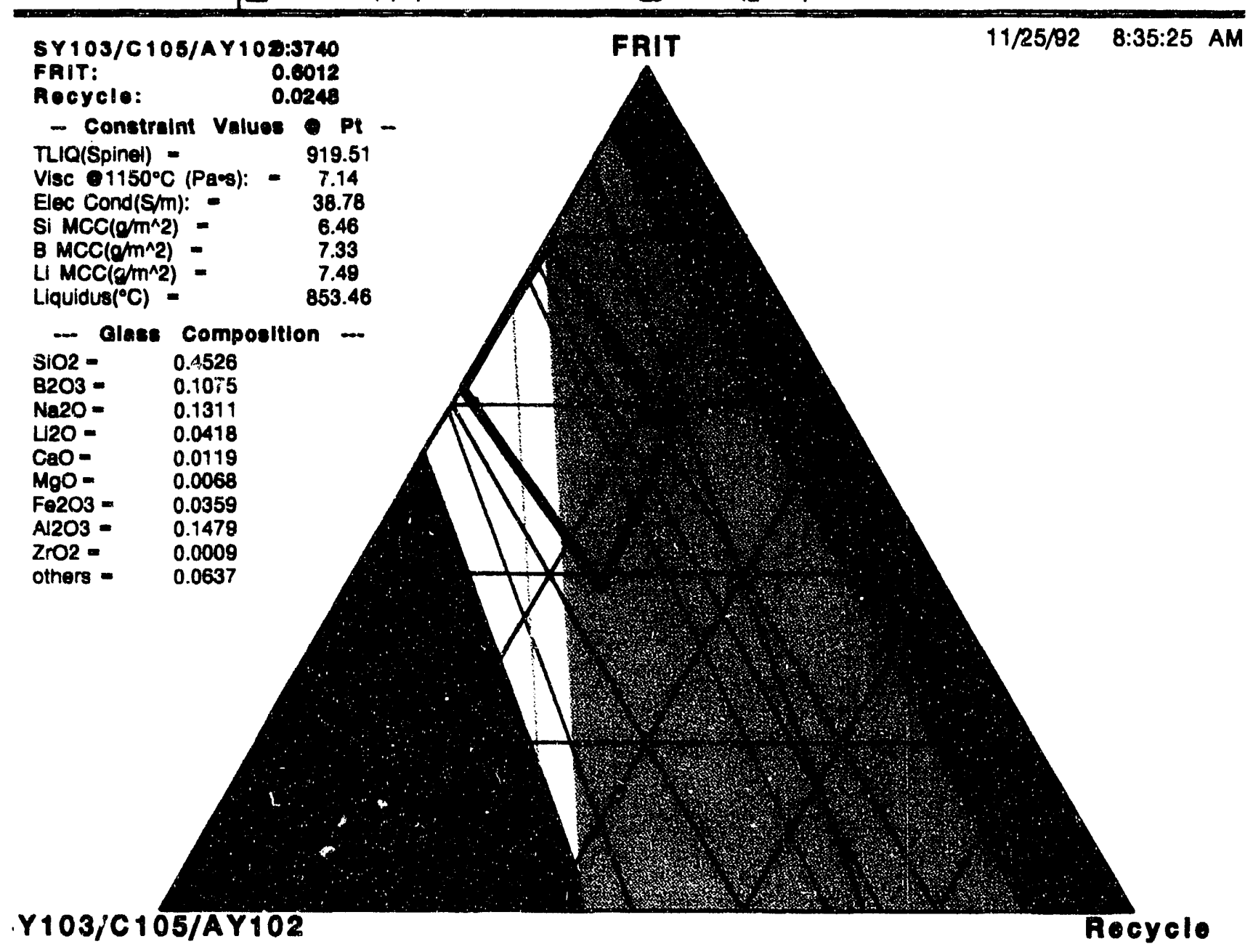

Figure 2.20. TWEAT Analysis: SY-103/C-105/AY-102 
The unacceptable regions in these diagrams are shaded with colors in accordance with the key specified at the top of the diagram. The area within the bold black polygon ${ }^{(a)}$ (if present) defines the region in which the glass models have been experimentally tested and consequently were deemed to be valid. The white space within the polygon (if present) defines the region which satisfies all of the designated criteria. The lightly shaded region (outside of the polygon) defines the region(s) which satisfy all of the designated criteria, yet are outside t'ie model compositions tested to date in the CVS envelope. Table 2.8 displays the compositional enveiupe where CVS has been deemed valid (abstracted from Hrma and Piepel ${ }^{(b)}$ ). In each figure, error bands for each criterion are displayed by a line of the same color as the parent criteria and parallel to the colored unaceptable region. The error band, whose breadth from the unacceptable region depends on the model goodness-of-fit, indicates areas "safe" within two standard deviations of the mean value.

Table 2.8. Region of CVS Property Model Validity

\begin{tabular}{|c|c|c|c|c|c|}
\hline \multicolumn{3}{|c|}{$\begin{array}{c}\text { Individual Mass Fraction } \\
\text { Constraints }\end{array}$} & \multicolumn{3}{|c|}{ Ad Hoc Crystallinity Constraints ${ }^{(\omega)}$} \\
\hline Oxide & $\begin{array}{l}\text { Lower } \\
\text { Bound }\end{array}$ & $\begin{array}{l}\text { Upper } \\
\text { Bound }\end{array}$ & Oxide Ratio or Sum & $\begin{array}{l}\text { Lower } \\
\text { Bound }\end{array}$ & $\begin{array}{l}\text { Upper } \\
\text { Bound }\end{array}$ \\
\hline $\mathrm{SiO}_{2}$ & 0.42 & 0.52 & $\mathrm{SiO}_{2} / \mathrm{Al}_{2} \mathrm{O}_{3}$ & 3.00 & -- \\
\hline $\mathrm{B}_{2} \mathrm{O}_{3}$ & 0.05 & 0.2 & $\mathrm{MgO}+\mathrm{CaO}$ & -- & 0.10 \\
\hline $\mathrm{Na}_{2} \mathrm{O}$ & 0.05 & 0.2 & $\mathrm{Fe}_{2} \mathrm{O}_{3}+\mathrm{Al}_{2} \mathrm{O}_{3}+\mathrm{ZrO}_{2}+$ others & -- & 0.24 \\
\hline $\mathrm{Li}_{2} \mathrm{O}$ & 0.01 & 0.07 & $\mathrm{Al}_{2} \mathrm{O}_{3}+\mathrm{ZrO}_{2}$ & - & 0.16 \\
\hline $\mathrm{CaO}$ & 0 & 0.1 & $\mathrm{MgO}+\mathrm{CaO}+\mathrm{ZrO}_{2}$ & - & 0.18 \\
\hline $\mathrm{MgO}$ & 0 & 0.08 & & & \\
\hline $\mathrm{Fe}_{2} \mathrm{O}_{3}$ & 0.02 & 0.15 & & & \\
\hline $\mathrm{Al}_{2} \mathrm{O}_{3}$ & 0 & 0.15 & & & \\
\hline $\mathrm{ZrO}_{2}$ & 0 & 0.1 & & & \\
\hline Others & 0.01 & 0.1 & & & \\
\hline
\end{tabular}

(a) This table is preliminary at this point and is based on the range of glasses studied in CVS-I and up through CVS-II Phase 2. Changes to a few individual component bounds and possibly other changes are anticipated based on CVS-II Phase 3.

(a) The black polygon would not display for Figure 2.7 (tank AY-102), although the chosen composition was within the CVS valid envelope. Likewise, the shape of the polygon in Figure 2.19 (blend SY-101/C-106/AZ-102) incorrectly represents the CVS valid envelope. The composition chosen, although displayed outsid, the polygon, is within the CVS valid envelope. The TWEAT program is still under review. Further work should rectify these graphical display errors.

(b) Hrma, P. R. and G. F. Piepel. 1992. Property/Composition Relationships for Hanford Waste Vitrification Plant Glasses-Preliminary Results Through CVS-II Phase 2, PHTD-92-03.01/K897, Pacific Northwest Laboratory, Richland, Washington. 
The black point was placed in the region felt to be close to the "maximum" waste loading, although deviations from the point may occur in the final waste loading analysis. The "constraint values at Pt" show the glass property's predicted values where the "point" is located within the region. The "glass composition" section of the figures displays the glass composition (which includes waste, frit, and recycle) at the black point. If the black point was outside of the CVS valid envelope, the components violating the envelope show up in bold followed by $"<>\exp$ limit." For example, Figure 2.6 (tank AY-101) glass composition section indicates that the Fe concentration is low and the "others" concentration is high relative to the CVS valid envelope.

Note that the percent recycle varies in Figures 2.6 through 2.20. Realistically, the percent recycle would not vary substantially from the nominal $3 \%$. The fact that in the figures it does fluctuate is an artifact of the frit design. The frit designed for the waste included four components $\left(\mathrm{SiO}_{2}, \mathrm{~B}_{2} \mathrm{O}_{3}\right.$, $\mathrm{Na}_{2} \mathrm{O}, \mathrm{Li}_{2} \mathrm{O}$ ). Ideally, the frit design would also include $\mathrm{Fe}_{2} \mathrm{O}_{3}$ and "others." As a result, in waste feed cases that have low $\mathrm{Fe}_{2} \mathrm{O}_{3}$ and "others" concentrations, the recycle was allowed to "float" and resulted in higher than ideal recycle. It should be kept in mind that the high recycle is not actually proposed.

\subsubsection{Loading Evaluation: "No Blend"}

This section frequently refers to Figures 2.6 through 2.20 and describes the waste loading estimates for each tank as made by TWEAT. These estimations are tempered by both the crystallinity constraints and the constraints on the solubility of minor components $\left(\mathrm{Cr}_{2} \mathrm{O}_{3}, \mathrm{~F}^{-}, \mathrm{P}_{2} \mathrm{O}_{5}, \mathrm{SO}_{3}\right)$. Table 2.9 summarizes the waste loading results and displays mass, and primary and secondary loading limits, by tank or blending option. The secondary loading limitations were displayed for information purposes.

AY-101. Based upon the TWEAT analysis, there is no composition that is within the envelope studied in the CVS $\mathrm{m}$-el because of the low content of Fe (approximately 0.008 in the glass) and high "others" content (approximately 0.1485 in the glass). Because of the low Fe and high "others" contents, the CVS may not correctly predict the glass properties, and caution must be used in interpreting the expected waste loading. However, because Fe is known to have so little effect on durability, it is expected that a lower Fe content will have little effect. The composition of "others" is mostly U, and it is known that $U$ has little effect on durability. Therefore, based upon extrapolation of the properties examined in TWEAT, one may expect $39 \%$ waste loading (see Figure 2.6). Crystallinity constraints limit loading to $37 \%$, while solubility of sulfate may limit loading to $11 \%$.

In summary, loading is limited to $11 \%$ because of the high $\mathrm{SO}_{3}$ content. If the problem of a high $\mathrm{SO}_{3}$ content can be overcome, 37\% loading is realistic. Recommendations include conducting experiments with a high-SO ${ }_{3}$ waste simulant to assess processability of the glass. Tank AY-101 waste is a good waste for blending with a low-sulfur-content waste.

AY-102. TWEAT analysis indicates loadings of $29 \%$ are possible within the region of acceptability (see Figure 2.7). Crystallinity constraints limit waste loading to $29 \%$, while the $\mathrm{P}_{2} \mathrm{O}_{5}$ constraint 
Table 2.9. CVS Waste Loading Summary

\begin{tabular}{|c|c|c|c|c|c|c|c|c|}
\hline Tank & $\begin{array}{c}\text { Oxide Mass } \\
\text { (g) } \\
\end{array}$ & $\begin{array}{c}\text { Loading } \\
\text { Limit }^{(0)} \\
\text { (primary) } \\
\end{array}$ & $\begin{array}{l}\text { Loading } \\
\text { Limit }^{(\star)} \\
\text { (second- } \\
\text { ary) } \\
\end{array}$ & $\begin{array}{c}\text { Primary } \\
\text { Limitation }^{(b)} \\
\end{array}$ & $\begin{array}{c}\text { Secondary } \\
\text { Limitation }^{(b)} \\
\end{array}$ & $\begin{array}{l}\text { Cans } \\
\text { (pri- } \\
\text { mary) }\end{array}$ & $\begin{array}{c}\text { Cans } \\
\text { (sec- } \\
\text { ondary) }\end{array}$ & $\begin{array}{c}\text { Probable } \\
\text { Canisters }^{\left({ }^{()}\right)}\end{array}$ \\
\hline AY-101 & $2.32 E+06$ & 0.108 & 0.37 & $\mathrm{SO}_{3}$ & Cry & 13 & 4 & 4 \\
\hline$A Y-102$ & $5.98 \mathrm{E}+07$ & 0.236 & 0.29 & $\mathrm{P}_{2} \mathrm{O}_{5}$ & Cry & 154 & 125 & 125 \\
\hline$A Z-101$ & $4.82 E+07$ & 0.270 & 0.32 & Cry & $\begin{array}{l}\text { Dur } \\
\text { (MCC/Li) }\end{array}$ & 108 & 91 & 108 \\
\hline$A Z-102$ & $8.37 \mathrm{E}+07$ & 0.180 & 0.25 & EC & Cry & 282 & 203 & 282 \\
\hline$C-105$ & $2.07 E+08$ & 0.370 & 0.39 & Cry & Visc (hi) & 339 & 322 & 339 \\
\hline$C-106$ & $3.67 E+08$ & 0.327 & 0.42 & $\mathrm{P}_{2} \mathrm{O}_{5}$ & Cry & 680 & 530 & 530 \\
\hline SY-101 & $2.35 E+08$ & 0.033 & 0.30 & $\mathrm{Cr}_{2} \mathrm{O}_{3}$ & Cry, EC (hi) & 4,277 & 475 & 475 \\
\hline SY-103 & $1.65 \mathrm{E}+08$ & 0.036 & 0.30 & $\mathrm{Cr}_{2} \mathrm{O}_{3}$ & Cry & 2,770 & 333 & 333 \\
\hline Total & & & & & & 8,623 & 2,082 & 2,196 \\
\hline "Total blend" & $1.17 \mathrm{E}+09$ & 0.095 & 0.34 & $\mathrm{Cr}_{2} \mathrm{O}_{3}$ & Cry & 7,475 & 2,082 & 2,082 \\
\hline \multicolumn{9}{|l|}{ Blend Option 1} \\
\hline AZ-101/AY-101 & $5.05 \mathrm{E}+07$ & 0.280 & 0.33 & Cry & $\begin{array}{l}\text { Model } \\
\text { bounds }\end{array}$ & 109 & 93 & 109 \\
\hline AZ-102/AY-102 & $1.44 \mathrm{E}+08$ & 0.240 & 0.26 & $\begin{array}{l}\text { Model } \\
\text { bounds }\end{array}$ & Cry & 362 & 334 & 334 \\
\hline SY-101/C-106 & $6.02 \mathrm{E}+08$ & 0.082 & 0.37 & $\mathrm{Cr}_{2} \mathrm{O}_{3}$ & Cry & 4,444 & 986 & 986 \\
\hline SY-103/C-105 & $3.72 \mathrm{E}+08$ & 0.078 & 0.34 & $\mathrm{Cr}_{2} \mathrm{O}_{3}$ & Cry & 2,898 & 663 & 663 \\
\hline Total & $1.17 \mathrm{E}+09$ & & & & & 7,814 & 2,076 & 2,093 \\
\hline \multicolumn{9}{|l|}{ Blend Option 2} \\
\hline $\begin{array}{l}\overline{S Y-101 / C-106 /} \\
\text { AZ-102 }\end{array}$ & $6.86 \mathrm{E}+08$ & 0.094 & 0.35 & $\mathrm{Cr}_{2} \mathrm{O}_{3}$ & Cry & 4,445 & 1,187 & 1,187 \\
\hline $\begin{array}{l}\text { SY }-103 / C-105 / \\
\text { AY }-102\end{array}$ & $4.32 E+08$ & 0.087 & 0.33 & $\mathrm{Cr}_{2} \mathrm{O}_{3}$ & Cry & 3,008 & 793 & 793 \\
\hline AZ-101/AY-101 & $5.05 E+07$ & 0.280 & 0.33 & Cry & $\begin{array}{l}\text { Model } \\
\text { bounds }\end{array}$ & 109 & 93 & 109 \\
\hline Total & $1.17 \mathrm{E}+09$ & & & & & 7,562 & 2,073 & 2,090 \\
\hline
\end{tabular}

(a) Mass fraction of waste in glass.

(b) $\mathrm{Cry}=$ crystallinity constraint, $\mathrm{EC}=$ electrical conductivity, Visc $=$ viscosity, Dur $=$ durability.

(c) Estimate of canisters resulting if solubility of minor component constraints are overcome.

limits loading to $24 \%$. Because of the high $\mathrm{P}_{2} \mathrm{O}_{5}$ concentration, caution should be used; however, the $1 \% \mathrm{P}_{2} \mathrm{O}_{5}$ limit is felt to be conservative, and $29 \%$ loading limited by the crystallinity constraint is felt to be realistic.

In summary, tank $A Y-102$ waste is a good waste for blending with a low $\mathrm{P}_{2} \mathrm{O}_{5}$ content waste; however, loading of this waste alone is limited to $24 \%$.

AZ-101. TWEAT analysis indicates waste loadings of 32\% are possible (see Figure 2.8). Because tank AZ-101 waste has a low concentration of "others," $10 \%$ recycle was used to fall within 
the CVS experimental envelope. The crystallinity constraint limits loading to $27 \%$ due to the relatively high concentrations of $\mathrm{Fe}$ and $\mathrm{Zr}$. This waste contains no loading restrictions due to minor components, and overall has acceptable glass properties.

In summary, waste loadings of $27 \%$ may be obtained.

AZ-102. TWEAT analysis indicates waste loadings of $18 \%$ are possible, ignoring the liquidus model constraint (see Figure 2.9). Again, tank AZ-102 waste has low concentration of "others" and a very high concentration of $\mathrm{Fe}$. In order to obtain a glass within the CVS experimental envelope, $13 \%$ recycle was used to raise the concentration of "others." The durability is within the acceptable limit as indicated by the MCC-1 models. Waste loadings can be improved by blending with a low-Fe waste. This waste contains no loading restrictions due to minor components. The crystallinity constraint limits loading to $25 \%$.

In summary, waste loadings of $18 \%$ can be obtained.

C-105. TWEAT analysis indicates waste loadings of $39 \%$ are acceptable, limited both by the viscosity limit (high) and the experimental compositional envelope (see Figure 2.10). Crystallinity constraints limit loading to $37 \%$. The glass has a relatively high $\mathrm{Al}_{2} \mathrm{O}_{3}$ concentration, but is within limits. Tank C-105 waste contains no loading restrictions due to minor components.

In summary, waste loadings of $37 \%$ are realistic.

C-106. TWEAT analysis indicates waste loadings of $46 \%$ are possible, limited by the viscosity limit (high) (see Figure 2.11). Crystallinity constraints limit loading to $42 \% . \mathrm{P}_{2} \mathrm{O}_{5}$ concentration, however, further restricts loading to $33 \%$. Again biscause the limit is felt to be conservative, $42 \%$ loading may be realistic. Conducting experiments with high $\mathrm{P}_{2} \mathrm{O}_{5}^{-}$content waste to obtain definitive limit on loading is recommended.

In summary, waste loadings are limited to $33 \%$.

SY-101. TWEAT analysis indicates that "no blend" exists that would provide a glass composition within the CVS envelope. Designing a frit that included Fe would alleviate this problem. However, it is felt that the CVS model may be extrapolated to lower-Fe-content glasses. Again, caution must be exercised because the models may not correctly predict property values. Ignoring the low Fe content, TWEAT predicts waste loading of $30 \%$, limited by high electrical conductivity (see Figure 2.12). The crystallinity limit also indicates $30 \%$ is the maximum waste loading. $\mathrm{Cr}_{2} \mathrm{O}_{3}$ concentration in the waste is very high and limits loading to $3 \%$. Because there is so little Fe in the glass, little $\mathrm{Cr}$ would dissolve. This may or may not be a problem. $\mathrm{Cr}_{2} \mathrm{O}_{3}$ limits are conservative estimates of the solubility of $\mathrm{Cr}_{2} \mathrm{O}_{3}$ in glass. It is unknown if $\mathrm{Cr}_{2} \mathrm{O}_{3}$ would cause problems in the melter; it would not cause any corrosion problems or electrical conductivity problems. Inclusions in the glass may not degrade durability. Therefore, a high- $\mathrm{Cr}_{2} \mathrm{O}_{3}$ waste must be tested before drawing conclusions. 
In summary, until high- $\mathrm{Cr}_{2} \mathrm{O}_{3}$ wastes are tested experimentally, it seems prudent to adhere to the set limit of $0.5 \% \mathrm{Cr}_{2} \mathrm{O}_{3}$ in glass. Therefore, loading is limited to $3 \%$. If the $\mathrm{Cr}_{2} \mathrm{O}_{3}$ problem can be overcome through pretreatment or engineering, $30 \%$ waste loading is realistic.

SY-103. Tank SY-103 is similar in composition to tank SY-101. Both are very high in $\mathrm{Cr}_{2} \mathrm{O}_{3}$ and low in Fe. Tank SY-103 exceeds the $\mathrm{Al}_{2} \mathrm{O}_{3}$ limit in the region which satisfies all of the CVS criteria (with the exception of low $\mathrm{Fe}$ ). $\mathrm{Al}_{2} \mathrm{O}_{3}$ concentration in this region is 0.16 and the limit is 0.15 , so again, assuming the CVS models may be extrapolated, TWEAT indicates that $38 \%$ waste loading is possible (see Figure 2.13). However, crystallinity limits loading to $30 \%$, and the high $\mathrm{Cr}_{2} \mathrm{O}_{3}$ further limits loading to $4 \%$.

In summary, until the high- $\mathrm{Cr}_{2} \mathrm{O}_{3}$ wastes are tested experimentally, it seems prudent to adhere to the set $\mathrm{Cr}_{2} \mathrm{O}_{3}$ limit and restrict loading of tank SY-103 to 4\%. If the $\mathrm{Cr}_{2} \mathrm{O}_{3}$ problem can be overcome, $30 \%$ loading is realistic.

\subsubsection{Loading Evaluation: Selected Blends}

\section{"Total Blend"}

The "total blend" alleviates all of the problems present in individual tank wastes, with the exception of high concentrations of $\mathrm{Cr}_{2} \mathrm{O}_{3}$, which cannot be blended to be within acceptable concentrations without considering other tank wastes to blend. The $\mathrm{Fe}, \mathrm{Al}_{2} \mathrm{O}_{3}$, and "others," which were outside CVS model envelope in certain tanks, all fall within the envelope in the "total blend." Furthermore, $\mathrm{SO}_{3}$ and $\mathrm{P}_{2} \mathrm{O}_{5}$, which limited waste loading in individual tanks, are not a problem in the blend. The acceptable composition envelope is very large and allows a great deal of latitude in selecting waste:frit:recycle ratios.

TWEAT analysis indicates that $44 \%$ waste loading is possible, limited by high viscosity constraints (see Figure 2.14). Crystallinity constraints limit loading of the blend to $34 \%$, while $\mathrm{Cr}_{2} \mathrm{O}_{3}$ further restricts loading to $9 \%$. Based upon the significant impact of $\mathrm{Cr}_{2} \mathrm{O}_{3}$ on waste loading and the uncertainty of the effects of high concentrations of $\mathrm{Cr}_{2} \mathrm{O}_{3}$, a study should be made to assess the limit.

In terms of glass canister estimates, separately the eight tanks would require 8,620 cans for immobilization of the waste. The blend, however, would require only 7,470 , representing a $13 \%$ decrease in the number of canisters required.

In summary, loading is restricted to $9 \%$ due to a high concentration of $\mathrm{Cr}_{2} \mathrm{O}_{3}$. If the $\mathrm{Cr}_{2} \mathrm{O}_{3}$ problem can be addressed, $34 \%$ waste loading of the blend is realistic.

\section{Blend Option 1}

AZ-101/AY-101. The blend of tanks AZ-101 and AY-101 favors the waste loading over treating each waste individually. Not only is the $\mathrm{SO}_{3}$ problem alleviated in tank $\mathrm{AY}-101$, but the waste compo- 
sition of the blend falls within the CVS envelope, giving more credibility to the model-predicted glass values. Tank AZ-101, which had poor durability, also benefits from the blend as evidenced by increased durability. Notice how the acceptable composition region is severely restricted by the electrical conductivity (hi) error band (see Figure 2.15).

In terms of glass canister estimates, separately the two tanks would require 121 cans for immobilization of the waste. The blend, however, would require only 109, representing a $10 \%$ decrease in the number of canisters required.

AZ-102/AY-102. The blend of tanks AZ-102 and AY-102 favors the waste loading over treating each waste individually. Not only is the $\mathrm{P}_{2} \mathrm{O}_{5}$ problem alleviated in tank AY-102, but the blend has a lower concentration of Fe and a high concentration of "others" (see Figure 2.16).

In terms of glass canister estimates, separately the two tanks would require 436 cans for immobilization of the waste. The blend, however, would require only 362 , representing a $17 \%$ decrease in the number of canisters required.

SY-101/C-106. The blend of tanks SY-101 and C-106 favors the waste loading over treating each waste individually. Not only is the Fe problem alleviated in tank SY-101, but the waste composition of the blend falls within the CVS envelope, giving more credibility to the model-predicted glass values. The blend also reduces the concentration of $\mathrm{Cr}_{2} \mathrm{O}_{3}$ (see Figure 2.17).

In terms of glass canister estimates, separately the two tanks would require 4,957 cans for immobilization of the waste. The blend, however, would require only 4,444 , representing a $10 \%$ decrease in the number of canisters required.

SY-103/C-105. The blend of tanks SY-103 and C-105 favors the waste loading over treating each waste individually. The blend alleviates the low $\mathrm{Fe}$ and high $\mathrm{Al}_{2} \mathrm{O}_{3}$ problem present in tank SY-103. Because of this, the waste composition of the blend falls within the CVS envelope, giving more credibility to the model-predicted glass values. The blend also reduces the concentration of $\mathrm{Cr}_{2} \mathrm{O}_{3}$ (see Figure 2.18).

In terms of glass canister estimates, separately the two tanks would require 3,109 cans for immobilization of the waste. The blend, however, would require only 2,898 , representing a $7 \%$ decrease in the number of canisters required.

\section{Blend Option 2}

SY-101/C-106/AZ-102. The only improvement to be gained by blending tank AZ-102 waste with waste from tanks SY-102 and C-106 is a greater dilution of $\mathrm{Cr}_{2} \mathrm{O}_{3}$, which improves the overall waste loading (see Figure 2.19). Separately the three tanks would require 5,239 cans for immobilization of the waste. The three-tank blend, however, would require only 4,445 , representing a $15 \%$ decrease in the number of canisters required. Notice that the blend of SY-101/C-106 results in 4,444 
canisters. Tank AZ-102 may be blended with those two tanks, a net increase of only one canister. This is an artifact of the limitation of waste loading due to $\mathrm{Cr}_{2} \mathrm{O}_{3}$.

SY-103/C-105/AY-102. The addition of tank AY-102 to the blend of tanks SY-103 and C-106 increases the acceptable composition envelope overlay on the ternary diagram, allowing more latitude in selection of waste:frit:recycle ratios (see Figure 2.20). The addition of Tank AY-102 also provides a greater dilution of $\mathrm{Cr}_{2} \mathrm{O}$, which can improve the overall waste loading. Separately the three tanks would require 3,263 cans for immobilization. The three-tank blend, however, would require only' 3,008 , representing an $8 \%$ decrease in the number of canisters required.

AZ-101/AY-101. This is the same blend presented in option 2.

\subsubsection{Comparison of HWVP Reference Model and the CVS Model}

Figure 2.21 displays a comparison between the HWVP reference model and the CVS model for the two pretreatments of sludge washing and sludge washing with a $\mathrm{Cr}$ leach. Examination of the estimated canisters assuming the HWVP limits with the CVS limits is interesting. The two estimates are very close for obvious reasons. In both cases, the loading criterion based upon solubility of minor components $\left(\mathrm{Cr}_{2} \mathrm{O}_{3}, \mathrm{P}_{2} \mathrm{O}_{5}, \mathrm{~F}\right.$, and $\left.\mathrm{SO}_{3}\right)$ forces lower waste loadings than could otherwise be expected. Since the loading criteria for minor components are the same in both models, and since there is a relatively large concentration of minor components in the tanks examined, the number of estimated canisters is very similar.

The biggest difference in canister estimates between the two models occurs with "no blending" (eight waste streams, as depicted in Figure 2.21). In the reference model all eight tanks are limited in loading because of outliers (the major outlier, of course, is $\mathrm{Cr}_{2} \mathrm{O}_{3}$ ), and the model estimates production of 11,060 canisters. Looking at the "no blend" case using CVS limits, five of eight tank wastes are limited by minor component constraints. Only tanks AZ-101, AZ-102, and C-105 have minor component concentrations that are within limits. Because of the enhanced loading of these tanks, the CVS model predicts production of 8,620 canisters, or $22 \%$ fewer canisters than estimated by the HWVP model.

The differences between the two model canister estimates become very slight when examining the blending options. The canister estimate for the "total blend" (one waste stream as depicted in Figure 2.20) are identical, because in both models loading is limited by the $\mathrm{Cr}_{2} \mathrm{O}_{3}$ concentration. In blend option 1, where tanks are blended in pairs, three of four blends in the HWVP model have chemical outliers, resulting in 7,830 canisters. Of the three tanks with outliers, two are limited by $\mathrm{Cr}_{2} \mathrm{O}_{3}$. Similarly, in the CVS model two of four blends are limited by $\mathrm{Cr}_{2} \mathrm{O}_{3}$, resulting in a similar canister estimate of 7,810 canisters, representing $0.3 \%$ fewer canisters than that estimated by the HWVP model. In blend option 2, the results are similar. The NCAW model estimates 7,580 canisters, while the CVS model estimates 7,560 canisters. In both models two of three blends are limited by $\mathrm{Cr}_{2} \mathrm{O}_{3}$. Finally, in the "total blend," both streams are limited by the same $\mathrm{Cr}_{2} \mathrm{O}_{3}$ constraint, and therefore provide identical estimations of 7,470 canisters. 


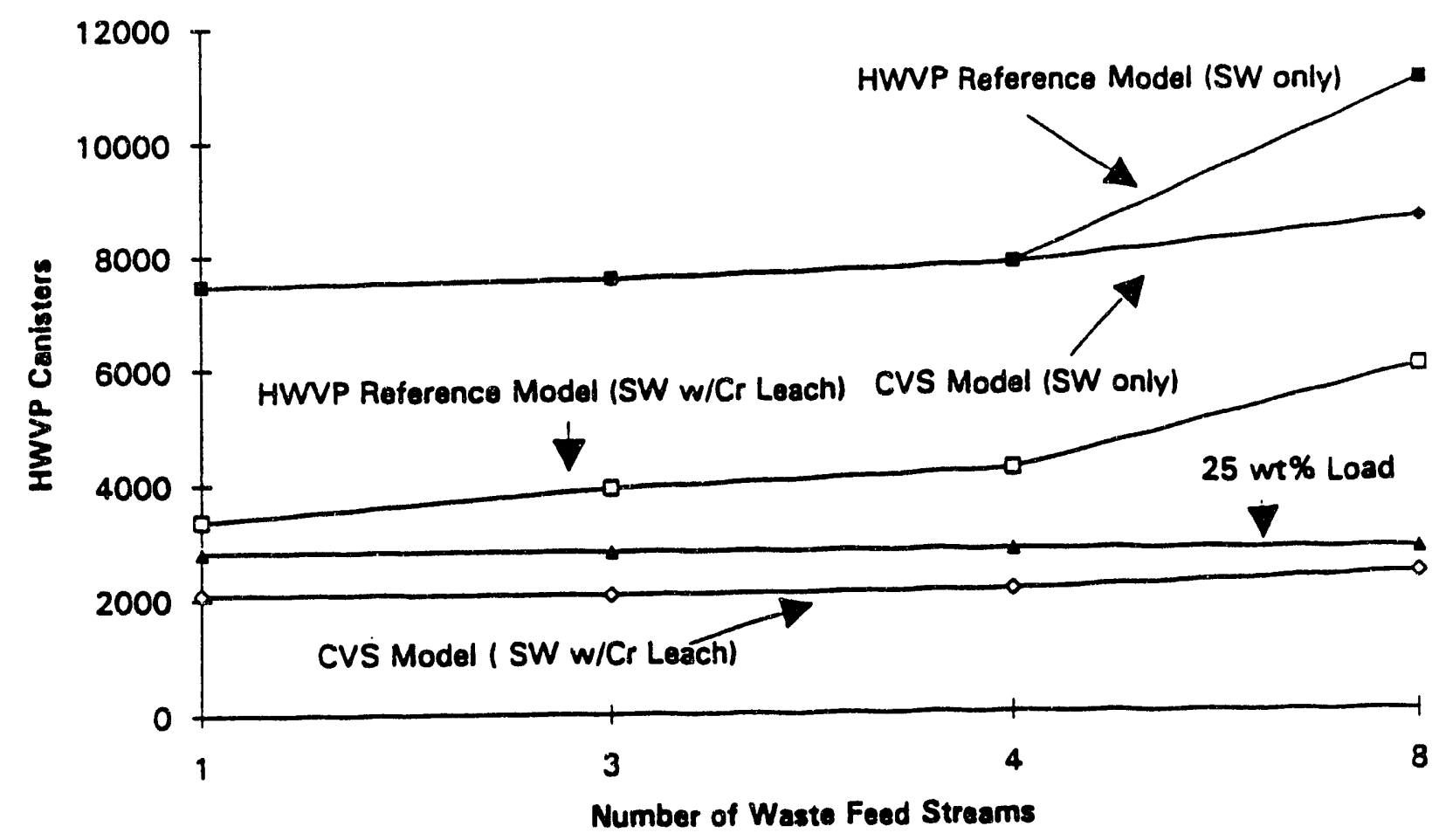

Figure 2.21. Waste Loading Estimate for the HWVP Reference and CVS Models

$\mathrm{A} \mathrm{Cr}_{2} \mathrm{O}_{3}$ leach significantly reduces canister estimates in both models. With the aid of blending, the HWVP model closely approaches the $25 \mathrm{wt} \%$ load. The CVS model estimates better than $25 \mathrm{wt} \%$ loading, even for the "no blend" case.

For the CVS waste loadings, assuming that the solubility of minor components can be overcome either through pretreatment or by relaxing the limit, greatly reduces the canister estimate. The "no blend" would result in 2,200 canisters if the solubility of minor components criteria were overcome, representing an average waste loading of $32 \%$. The "total blend" case further improves waste loading: 2,080 canisters are estimated, representing an additional 5\% reduction over the "no blend" case. Estimates for blend options 1 and 2 are very similar to the "total blend" case and 2,090 canisters are estimated.

Analysis indicates that the CVS model provides lower canister estimates than does the HWVP model. Because of the strong influence of minor components on waste loading in both models, the two models predicted similar results after blending because of the overwhelming presence of $\mathrm{Cr}_{2} \mathrm{O}_{3}$. Clearly, blending can decrease the estimated number of canisters as based on either model and should be considered as a pretreatment step. 


\subsection{Case II: Blending LLW Using Grout Feed Acceptance Criteria}

Table 2.10 displays the eight tanks, the grout feed acceptance criteria considered, and the components whose concentration exceeded the grout feed limit. A number in a cell indicates the factor by which the component concentration in the feed exceeds the HWVP feed specifications. Comparison of the individual tank waste feed to the "total blend" waste feed demonstrates the number of waste components that can be diluted to within an acceptable concentration by blending. Before blending, $\mathrm{Al}^{3+}$, $\mathrm{B}^{3+}, \mathrm{Ca}^{2+}, \mathrm{Cd}^{2+}, \mathrm{Cu}^{2+}, \mathrm{Ni}^{2+}, \mathrm{Pb}^{2+}, \mathrm{Si}^{4+}, \mathrm{Cl}^{-}, \mathrm{F}^{-}, \mathrm{SO}_{4}{ }^{2-}, \mathrm{CO}_{3}{ }^{2-}, \mathrm{TOC}$, and radiolytic heat content all

Table 2.10. GTF Outliers from Selected Hanford Tank Wastes

Tank (grout feed acceptance criteria are exceeded by the factor indicated)

AY-101 AY-102 AZ-101 AZ-102 C-105 C-106 SY-101 SY-103 Total

$\mathrm{Ag}$

$\mathrm{Al}$

B

$\mathrm{Ba}$

$\mathrm{Ca}$

$\mathrm{Cd}$

$\mathrm{Cr}$

$\mathrm{Cu}$

$\mathrm{Fe}$

$\mathrm{Hg}$

K

$\mathrm{Mg}$

$\mathrm{Mn}$

Mo

$\mathrm{Na}$

$\mathrm{Ni}$

$\mathrm{Pb}$

$\mathrm{Se}$

$\mathrm{Si}$

$\mathrm{Zn}$

$\mathrm{Cl}$

$\mathrm{F}$

$\mathrm{NO}_{2}$

$\mathrm{NO}_{3}$

$\mathrm{OH}$

$\mathrm{PO}_{4}$

$\mathrm{SO}_{4}$

$\mathrm{CO}_{3}$

TOC

Heat

\section{7}

$3.3 \quad 1.1$

$2.0 \quad 1.5$

1.2

$\begin{array}{ll}4.1 & 1.8\end{array}$

$\begin{array}{lrr}1.4 & 14.2 & 3.6\end{array}$

1.1

$5.4 \quad 13.9$

14.2

$3.4 \quad 3.0$

4.3

$2.0 \quad 19.5$

$16.9 \quad 4.0$

$\begin{array}{ll}1.1 & 3.9\end{array}$

1.3

$\begin{array}{ll}15.8 & 19.3\end{array}$

$2.6 \quad 2.2$

2.2

7.6

21.7

6.5

14.3

12.8

6.3

2.6

4.0 
have concentrations exceeding the grout feed acceptance criteria. After blending, TOC and radiolytic heat content exceeded the limits. In this case, blending reduced the number of GTF outliers from 14 to 2 .

Effective organic destruction and radiolytic heat removal pretreatments were assumed. Therefore, the TOC and heat limits were disregarded. Table 2.11 summarizes the grout volume production of different waste loading approaches. The $5 \mathrm{M}$ Na load ignores the GTF feed specifications and the grout volume estimate is a product of total $\mathrm{Na}$ mass. For the eight tanks considered, $31,600 \mathrm{~m}^{3}$ of grout is produced. The "no blend" option takes each tank waste as an individual feed, an approach which results in the highest volume $\left(44,600 \mathrm{~m}^{3}\right)$ of grout. In contrast, the "total blend" case uses as feed a composite of all tank wastes (after pretreatment), resulting in $31,600 \mathrm{~m}^{3}$ of grout. Blending all the waste, for any specified pretreatment, results in the least quantity of final waste form if the grout feed specifications are adhered to. Comparison of the "total blend" case with blend option 1 (which consists of four waste types produced from the following blends: SY-103/C-105, SY-101/C-106, $\mathrm{AZ}-102 / \mathrm{AY}-101$, and AZ-101/AY-102) shows that the level of blending effort required to reach the optimum case is low. It can be seen that blend option 1 has a potential waste reduction of $29 \%$, matching the "total blend" grout volume production of $31,553 \mathrm{~m}^{3}$. Again, very substantial gains can be made simply by judicious selection of a few tank blending partners, as shown in Figure 2.22.

Table 2.11. Selected Tank Waste Production Summary: GTF (post-organic destruction and heat-loading pretreatments)

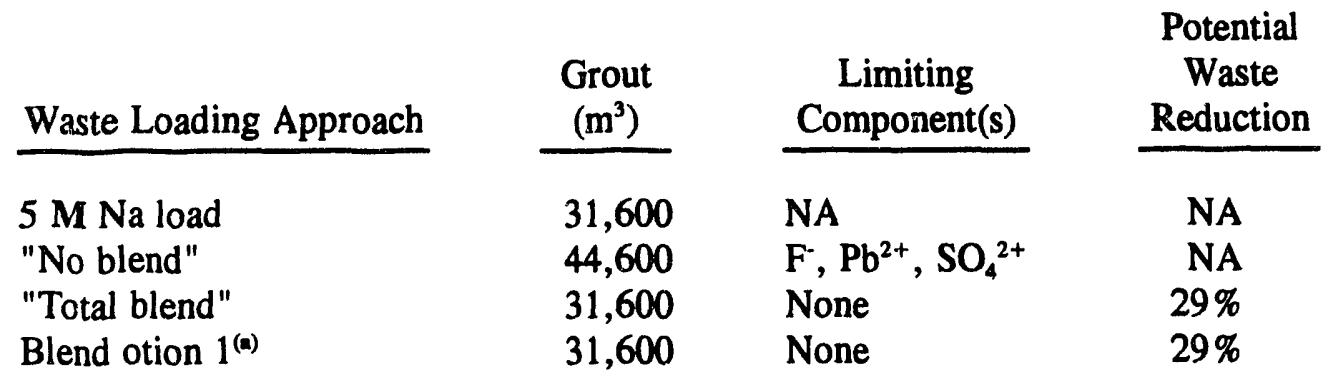

(a) Blend of tanks SY-101/C-106, SY-103/C-105, AZ-102/AY-101, AZ-101/AY-102, resulting in four waste feeds. 


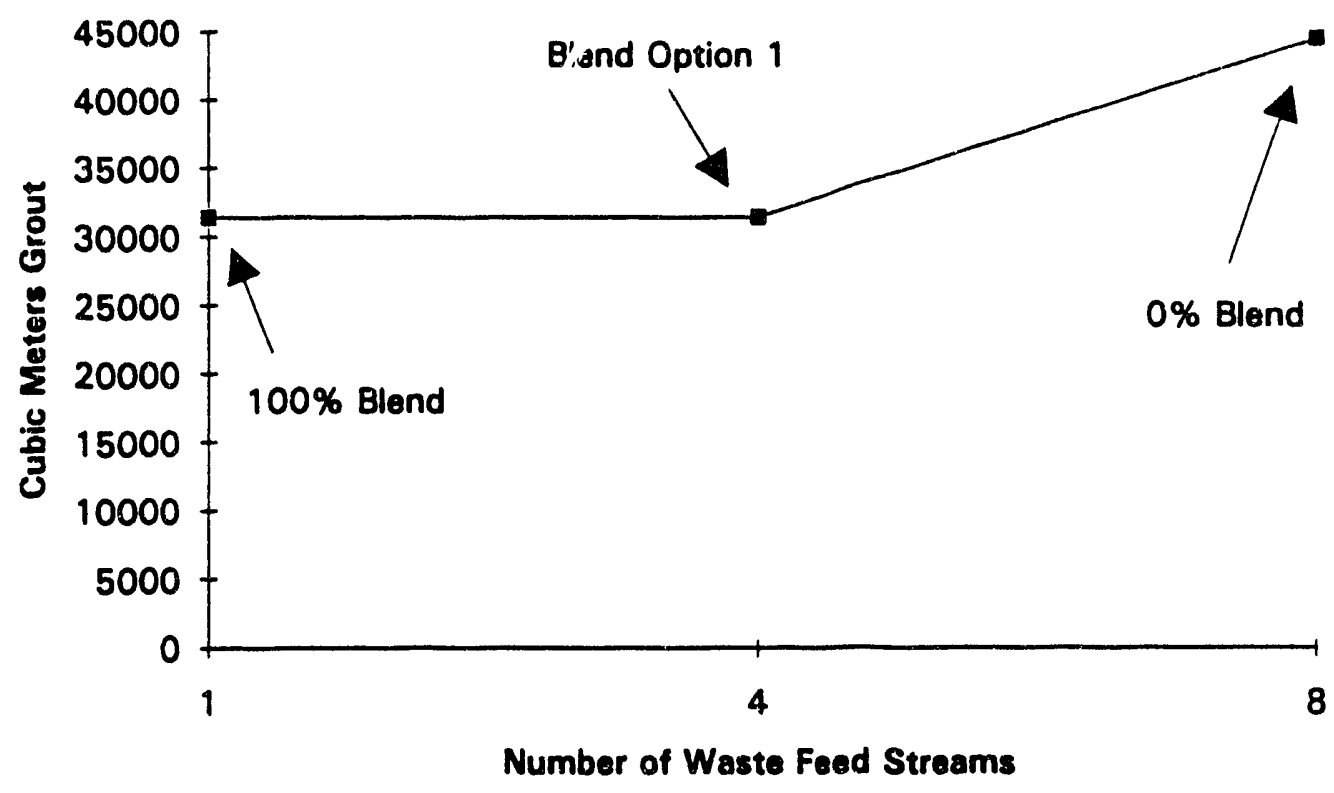

Figure 2.22. Volume of Grout Required to Immobilize Various Blend Options 


\subsection{Discussion}

\subsection{Evaluation of Case I and Case II}

The benefits of blending were assessed in two case studies. The first case involved most of the tanks and demonstrated the potential benefits blending may provide in terms of decreasing the estimated final waste form and reducing the demand for pretreatment. Case I was so large that without the aid of a computer model, or more time, the benefits of blending could not all be examined.

For example, the maximum reduction delta between the "no blend" and "total blend" scenarios was established in Case I, but it was not established how much effort, in terms of blending, would be required to approach the maximum reduction delta. Case II, which considered only six DSTs and two SSTs, was smaller and more manageable. It demonstrated that near maximum benefit in terms of potential waste reduction could be gleaned from minimal blending effort.

Another issue that was difficult to tackle in Case I was whether the CVS model would predict trends similarly to the HWVP model. Would CVS analysis support the trends established by the HWVP reference model, or would it provide its own trends and insight into the blending issue? Case II was analyzed using the CVS criteria and the results from the analysis were compared to the HWVP reference criteria. The results clearly demonstrated that the same trends were evident in both models. The potential waste reduction, although smaller, was evident in the CVS model evaluation. Also, high blending efficiency was achieved with minimal blending effort.

A significant result was the similar number of canister estimate made by both models. This is an artifact of the identical limits on the solubility of minor components, which dominated the restrictions in waste loading. The fact that minor components so greatly restricted loading in Case II led to the "CVS approximation" used in Case I, which only restricted waste loading based upon the limits of $\mathrm{Cr}_{2} \mathrm{O}_{3}, \mathrm{~F}, \mathrm{P}_{2} \mathrm{O}_{5}$, and $\mathrm{SO}_{3}$. If tank wastes were not limited in these components, then $25 \mathrm{wt} \%$ loading should be achievable. This somewhat conservative loading model again predicted canister estimate close to that those estimated by the HWVP reference model. Although the HWVP reference model has been shown to be inadequate, its canister predictions are nevertheless similar to CVS canister predictions because of the dominating effect of the restrictions on minor components.

\subsection{HWVP Feed Acceptance Criteria}

The good agreement of the CVS model analysis with the HWVP reference model indicates that the HWVP reference limits should provide similar qualitative trends and reveal the possible benefits of blending, even though the reference model may be quantitatively misleading. Evaluation of Case $I$ and Case II revealed that two major outliers-- $\mathrm{P}_{2} \mathrm{O}_{5}$ and $\mathrm{Cr}_{2} \mathrm{O}_{3}$--cause severe loading restrictions in both 
models. Further examination of waste simulants with high concentrations of $\mathrm{P}_{2} \mathrm{O}_{5}$ and $\mathrm{Cr}_{2} \mathrm{O}_{3}$ is recommended. The following subsections discuss relevant individual constituent limitations ${ }^{(a)}$ that are of special interest. The information in these subsections was largely abstracted from Kurath. ${ }^{(b)}$

\subsubsection{Phosphate}

The $1 \mathrm{wt} \% \mathrm{P}_{2} \mathrm{O}_{5}$ waste limit ( $4 \mathrm{wt} \%$ in the feed) will restrict overall loading of the blended wastes to much below $25 \mathrm{wt} \%$. Previous review in the Hanford Waste Vitrification Risk Assessment Final Report (Miller et al. 1991) indicates that there is low to moderate risk in assuming that the $\mathrm{P}_{2} \mathrm{O}_{5}$ limit can be raised to $2.5 \mathrm{wt} \%$ ( $10 \mathrm{wt} \%$ in the feed). Even small amounts of $\mathrm{P}_{2} \mathrm{O}_{5}(<0.5 \mathrm{wt} \%$ feed) are apparently immiscible in silicate melts on the molecular scale. It is the coalescence of the immiscible phases into droplets that can create potential problems. The droplets have been observed to form a "scum" on the surface of the melter that reduces the throughput of the melter significantly. The presence of calcium and, to a lesser extent, rare earths, promotes droplet formation. Glasses containing 4.58, 3.8, and 3.14 wt\% $\mathrm{P}_{2} \mathrm{O}_{5}(18.3,15.2$, and $12.6 \mathrm{wt} \%$ in the feed), but no $\mathrm{CaO}$, have been successfully processed in PNL melters. Calcium and rare earths are only minor constituents of DST wastes. Thus with low to moderate risk, DST waste glass containing up to $2.5 \mathrm{wt} \% \mathrm{P}_{2} \mathrm{O}_{5}(10 \mathrm{wt} \%$ in the feed) can be processed safely in the HWVP.

\subsubsection{Chromium}

That the $0.5 \mathrm{wt} \% \mathrm{Cr}_{2} \mathrm{O}_{3}$ guidance limit for NCAW glass ( $2 \mathrm{wt} \%$ in the feed) should also apply to other waste glasses is a judgment based on the following factors:

- Laboratory tests showed that solubility of chromium in NCAW glass is about $0.7 \mathrm{wt} \%$ $\mathrm{Cr}_{2} \mathrm{O}_{3}(2.8 \mathrm{wt} \%$ in the feed). At higher concentrations, chromium begins to precipitate as a spinel.

- Melter runs with about $0.2 \mathrm{wt} \% \mathrm{Cr}_{2} \mathrm{O}_{3}(0.8 \mathrm{wt} \%$ in the feed $)$ at PNL and the Defense Waste Processing Facility (DWPF) show no spinel; melter runs with 1.3 to $1.6 \mathrm{wt} \% \mathrm{Cr}_{2} \mathrm{O}_{3}$ (5.2 to $6.4 \mathrm{wt} \%$ in the feed) all show spinel.

- Most of the spinel remains suspended in the glass and ends up in the canister. The problem is that a fraction of the spinel (perhaps 5\%) has been observed to settle to the melter floor.

(a) This section describes composition limits of the overall glass. The corresponding feed composition is four times the glass composition.

(b) Kurath, D. E., et al. 1991. Intermediate Processing Approaches to the Pretreatment of Selected Double- and Single-Shell Tank Waste. Prepared for Westinghouse Hanford Company by Pacific Northwest Laboratory, Richland, W.ashington. 
- The collection of spinel on the melter floor raises another issue: How soon will enough spinel accumulate on the melter floor to cause problems, and how severe will the problems be? Two kinds of problems have been encountered: 1) melter plugging and 2) potential hot spots at the melter floor. A melter at Savannah River became inoperable because of spinel accumulation. The spirel probably for med while the melter idled at a low temperature, a condition that accentuates the formation of spinel. Hot spots at the melter floor may have been observed in the Liquid-Fed Ceramic Melter (LFCM) at PNL, but the evidence that they were due to chromium is unclear. Monofrax K3, the refractory material to be used for the HWVP melter walls and bottom, is a chrome spinel, but some spinels or spinel relatives are known to have a much lower resistivity.

Some concern has also been expressed abou : the effect of spinels on the quality of the product glass. Testing has shown that spinels have only a minor effect on leachability (Bibler 1983; Bickford and Jantzen 1986; Zhu et al. 1986). Thus, the justification for the chromium concentration limit must be based solely on the potential for chromium to create operational problems in the melter. Although the evidence is not completely clear, the $0.5 \mathrm{wt} \% \mathrm{Cr}_{2} \mathrm{O}_{3}$ concentration limit in the glass seems a prudent precaution.

\subsection{Grout Feed Acceptance Criteria}

Not all of the GTF outliers should actually be a problem for waste loading in grout, and many of these outliers, in the future, may be incc asequential when reviewed. The current grout feed specifications are based upon three major considerations: a) thermal loading in the grout, b) regulatorybased limits, and c) past experience. The information in this subsection was largely abstracted from Hendrickson. ${ }^{(a)}$

Item $a$ is based on experimental evidence that one of the most critical parameters that affects the acceptability of the grouted waste is the max mum cure ternperature. The grout should have acceptable physical properties when the peak cure temperature is kept below $100^{\circ} \mathrm{C}$.

Item $b$ is based on limitations imposed by regulatory limits. Land Disposal Restrictions (LDR) limit the concentration of specific wastes in the waste stream and identify constituents for which pretreatment may be necessary. Organic contaminant restrictions under LDR must be met, as grouting is not currently an acceptable treatment for these constituents. See Hendrickson ${ }^{(a)}$ for constituent listing. Note that this study did not consider individual organic limits as these data were not included in the data base used.

(a) Hendrickson, D. W. 1991. Grout Treatment Facility Waste Feed Acceptance Criteria. WHCSD-WM-RD-019 Rev. 1, Westinghouse Hanford Company, Richland, Washington. 
The concentrations of toxic metals ( $\mathrm{Ag}, \mathrm{As}, \mathrm{Ba}, \mathrm{Cd}, \mathrm{Cr}, \mathrm{Hg}, \mathrm{Pb}, \mathrm{Se}$ ) in the waste feed are limited by the need to show compliance with Toxicity Characteristic Leaching Procedure (TCLP) testing, as solidification and stabilization is the preferred treatment option for these contaminants. The limits stated in the grout feed specifications were based on Extraction Procedure Toxicity (EPTOX) and TCLP tests of actual grout formulations to define probable acceptance limits. The processes of EPTOX or TCLP leaching were assumed to follow a linear trend and the recommended limits for the toxic metals were calculated from the observed test ratios (measured concentration in waste feed:measured concentration in EPTOX/TCLP extractant). This assumption is considered to be conservative because the leachate concentration of individual metal species are expected to be governed by solubility limits at a given $\mathrm{pH}$ rather than by initial inventory.

Specification for some elements that are expected to be present in the waste feed $(\mathrm{Be}, \mathrm{Bi}, \mathrm{Ce}, \mathrm{La}$, $\mathrm{Li}, \mathrm{Nd}, \mathrm{Pd}, \mathrm{Sb}, \mathrm{Ta}, \mathrm{Ti}, \mathrm{U}, \mathrm{V}, \mathrm{W}, \mathrm{CN}, \mathrm{Np}, \mathrm{Pu}, \mathrm{Am}$, and $\mathrm{Cm}$ ) could not be defined because of insufficient data. Analyses of waste constituents in product grouts will be used to define acceptance criteria for those constituents currently identified as "To Be Determined" (TBD), and to refine acceptance criteria for other constituents.

Item $\mathrm{c}$ is based on past experience, and a specified limit may not be the maximum concentration that can be successfully grouted.

\subsubsection{Impact on Grout Volume Estimates}

In Case $\mathrm{I}$, both $\mathrm{F}$ and $\mathrm{Pb}$ are chemical outliers in grout. Fluorine's acceptance limit of $562 \mathrm{ppm}$ is based upon past experience. Grout has been successfully produced with a $F$ feed content of $562 \mathrm{ppm}$. Clearly, the fact that $562 \mathrm{ppm}$ of $\mathrm{F}$ can be grouted does not exclude higher concentrations of this component in the feed. However, this assertion will have to be experimentally tested. If the $F$ limit were increased to the point that the $\mathrm{F}$ concentration was no longer limiting, the $\mathrm{Pb}$ concentration would become limiting. The "total blend" lower bound would be reduced to $1,113,000 \mathrm{~m}^{3}$ from $1,890,000 \mathrm{~m}^{3}$. This value, however, is still 2.4 times higher than the volume estimate assuming $5 \mathrm{M}$ Na loading.

The limit for $\mathrm{Pb}(12.5 \mathrm{ppm})$ is a regulatory-based limit obtained from an experimental ratio of the measured $\mathrm{Pb}$ concentration in the feed:the measured concentration in the EPTOX extractant. The method assumed the leachate concentration will vary linearly with $\mathrm{Pb}$ inventory in the feed. This definition of a probable acceptance limit is conservative for two reasons: first, because the leachate concentration of an individual metal species is expected to be governed by solubility at a given $\mathrm{pH}$ rather than by initial inventory; second, because the EPTOX test (which is no longer the preferred test) produces higher toxic metal concentrations in the leachate than does the TCLP test (which is now the preferred test). One of the primary differences between the two tests is the fact that acetic acid is added to maintain $\mathrm{pH}$ during the EPTOX test. In contrast, the TCLP procedure uses a single batch addition of acetic acid which is buffered upon contact with the grout. Thus, even assuming a linear trend in the leachate with initial inventory, the $12.5-\mathrm{ppm}$ limit for $\mathrm{Pb}$ is conservative and could probably be increased. 
If the $\mathrm{Pb}$ limit can be increased, the $5 \mathrm{M}$ Na limit is achievable because there are no other chemical outliers preventing full loading in the "total blend." Clearly, blending will be required for any simple pretreatment scenario to approach the $5 \mathrm{M}$ Na loading for grout volume production.

To obtain more realistic grout volume estimates, the grout feed acceptance criteria should be critically examined to expand the feed acceptance envelope, thus maximizing LLW loading.

\subsection{Benefit to Waste Form Qualification (WFQ)}

This section describes the background and potential benefits of tank waste blending to the program for qualifying vitrified Hanford defense HLW for acceptance into the Civilian Radioactive Waste Management System (CRWMS) in accordance with the Waste Acceptance System Requirements Document (WA-SRD) to be issued by the DOE Office of Civilian Radioactive Waste Management (OCRWM).

\subsubsection{WFQ Background}

In order to ensure that the vitrified HLW from Hanford (and from DOE's other two HLW vitrification projects) meets the applicable WA-SRD requirements, the DOE Office of Environmental Restoration and Waste Management (EM) has recently drafted Waste Acceptance Production Specifications (WAPS). These specifications include requirements derived from the WA-SRD in the following five areas: (1) waste form, (2) canister, (3) canistered waste form, (4) listed hazardous waste determination, and (5) quality assurance (including nonconformance notification) requirements.

Compliance with the WAPS will require substantial waste sampling, analysis, and reporting for each "waste type" to be fed to the vitrification plant. The WAPS defines waste type as "The waste material fed to each vitrification facility that can be assumed to remain relatively constant in composition and properties for an extended period of time." Therefore, the number of waste types that are subject to the WAPS could be impacted by proposed blending schemes. The WAPS that include sampling, analysis, and reporting specifications explicitly or implicitly tied to a "waste type" are summarized as follows:

Waste Form Specifications:

- chemical composition, projected and measured, including range and uncertainty

- radionuclide inventory, projected and measured, including range and uncertainty

- $\quad$ PCT (a short term "leach" test), projected and measured, including uncertainty; all with respect to a reference standard

- phase stability (glass transition temperature and time-temperature-transformation diagram). 
Canistered Waste Form Specifications:

- heat generation rate

- dose rate (gamma and neutron)

- chemical compatibility (glass and canister)

- subcriticality.

Listed Hazardous Waste Determination:

- Hazardous chemical and element content analysis

- Possible TCLP testing [may be exempt under best demonstrated available technology (BDAT)].

\subsubsection{Potential Blending Benefits to WFQ}

As described in the HWVP Waste Form Qualification Program Plan (Randklev 1993), the WFQ program for each waste type will be a multi-million dollar, multi-year effort. Therefore, substantial savings might be achieved in WFQ as a result of blending schemes that reduce the number of waste types subject to the specifications listed in the preceding section. For example, reducing the number of waste types should simplify the data base required for development of a predictive model for defining acceptable glass-forming frit and final glass compositions for compliance. However, the actual impacts cannot be quantitatively projected at this time.

\subsection{Drawbacks to Blending}

The benefits of blending have been outlined. However, there also may be some drawbacks to blending. Blending tank wastes would require significant capital expense to develop a system(s) that could blend solid wastes and soluble wastes. Blending a soluble LLW fraction in a GTF feed-staging tank should lead to few problems; however, blending the HLW fraction in a solid or slurry form may require more elaborate mixing equipment and testing to ensure consistency and homogeneity. Feed staging tank(s) would have to be filled with blend feed approximately 18 months in advance to properly characterize the waste feed and to determine the glass frit/grout-forming material composition. To avoid gaps in waste form production, multiple feed-staging tanks would be required. These are necessary so that while one tank is providing feed, the other tanks can be refilled with the blend feed. The number of tanks required depends on the size of the blends (in terms of mass), the time required for WFQ, and the waste form production rate of the HWVP and GTF. 
Blending may also require more analytical samples for waste characterization. In order to determine which tanks could be beneficially blended, a detailed waste characterization would be required for each contributing tank waste. Once the wastes have been blended, further samples may be required to ensure waste composition and homogeneity.

Blending grout feed has different implications than does blending HWVP feed. The feed criteria considered in blending HWVP feed are process limitations, not regulatory limitations. The difference between process and regulatory limits is that blending chemical concentrations is acceptable for process feed limits but is unacceptable for regulatory feed limits. Process limits are set to ensure the quality of the final waste form or to prevent the expected capacity of a processor from being exceeded (e.g., HWVP off-gas processing). Process limits may be overcome if an engineering solution can be developed. Thus, blending HWVP feed results in a more concentrated waste product of suitable quality that is within regulatory guidelines. In contrast, the grout feed acceptance criteria are a combination of process and regulatory limitations. For example, the total content of radiolytic heat generators is based on a process limit, while the total TRU concentration is based on a regulatory limit. Blending grout feed to address a process limitation may also lead to the dilution of a regulatory-based limit. For example, a feed with a high TRU content and considered to be unacceptable for grout might be blended with a feed acceptable for grout, producing a blend that also may be acceptable for grout. However, this approach is not acceptable from a regulatory standpoint. This example emphasizes the need to consider the effects from a process-based alteration on the regulatory limits. 


\subsection{Conclusions and Recommendations}

The benefits of blending tank wastes in terms of reducing the final waste form are substantial. The data examined showed that blending may substantially decrease HWVP and GTF production, compared with the same pretreatment without blending. Blending can reduce the number of HWVP outliers from 17 to 3 and the number of GTF outliers from 12 to 2 . The good agreement of the CVS model analysis to the HWVP reference model indicates that the HWVP reference limits should provide similar qualitative trends and reveal the possible benefits of blending, even though the reference model may be quantitatively misleading.

Case II showed that nearly all the benefits that blending may provide in terms of final waste-form volume reduction are gleaned from blend options 1 and 2, which blend wastes, by tank, to obtain four and three discrete waste feeds, respectively. Results suggest that a minimum blending effort may provide near maximum benefit to final waste-volume reduction.

HWVP canister production estimates, which assume $25 \mathrm{wt} \%$ loading and ignore the feed criteria, significantly underestimate final waste-form volume. Both the HWVP reference model and the CVS model have constraints, which limit loading below $25 \mathrm{wt} \%$. CVS is exploring an acceptable HWVP feed composition envelope of 10 waste components known to affect glass processing requirements. However, the two components $\mathrm{P}_{2} \mathrm{O}_{5}$ and $\mathrm{Cr}_{2} \mathrm{O}_{3}$, which have been shown in this study to limit waste loading below $25 \mathrm{wt} \%$, need further research. Experimental evidence suggests that more $\mathrm{P}_{2} \mathrm{O}_{5}$ can be loaded in glass in concentrations greater than either model allows. It is not clear whether the $\mathrm{Cr}_{2} \mathrm{O}_{3}$ limit may be raised without exploring higher temperature glasses. Therefore, it is recommended that the limits of the solubility of minor components $\left(\mathrm{Cr}_{2} \mathrm{O}_{3}, \mathrm{~F}, \mathrm{P}_{2} \mathrm{O}_{5}\right.$, and $\left.\mathrm{SO}_{3}\right)$, particularly both $\mathrm{P}_{2} \mathrm{O}_{5}$ and $\mathrm{Cr}_{2} \mathrm{O}_{3}$, be examined in order to establish definitive loading limits for these limiting oxides.

Grout production estimates which assume $5 \mathrm{M} \mathrm{Na}$ loading and ignore the grout feed acceptance criteria significantly underestimate grout volume production. The data examined indicate that $\mathrm{F}^{-}$and $\mathrm{Pb}^{2+}$ and, in some instances, TOC, $\mathrm{SO}_{4}{ }^{2-}$, and radiolytic heat content limit waste loading. In order to maximize waste loading, it is recommended that the limits be examined to expand the feed acceptance envelope.

Blending may also provide benefits in terms of WFQ. It is not possible at this time to quantify the savings related to WFQ; however, the potential savings in terms of cost and schedule appear to be significant.

Obviously, waste-form production estimates are highly sensitive to tank chemical composition data and sludge wash partitioning factors. Comparison of TRAC data with core sample data has shown TRAC to be within an order of magnitude in some components and off by many orders of magnitude in other components. As a result, greater emphasis should be placed on the observed beneficial trends of blending, and less emphasis placed on the actual numbers predicted for immobilized waste volume. Since the process of selecting tank feeds to blend is based upon finding compatible feed compositions, 
more precise tank characterization data will be required. Tank characterization data should also include experimentally determined component solubility data as would occur in tank waste pretreatment.

Results from this study have shown that although blending can significantly increase waste loading, blending is not a pretreatment step that can replace all other pretreatments being considered. The baseline quantities of immobilized waste projected for sludge-wash cases may have been drastically underestimated, because critical components were not considered. Alternatively, the results suggest further review of the grout feed specifications, and of the solubility of minor components in HWVP borosilicate glass. Future glass and grout volume estimates might be decreased substantially upon a thorough review of the appropriate feed specifications. The results of this study suggest that blending, selective leaching, and HWVP glass and GTF grout feed specifications should be evaluated further as an element in the TWRS pretreatment strategy. 


\subsection{References}

Bibler, N. E. 1983. Characterization of Borosilicate Glass Containing Savannah River Plant Radioactive Waste. II. Microstructure and Durability. DP-MS-82-111, Savannah River Laboratory, Aiken, South Carolina.

Bickford, D. F., and D. M. Jantzen. 1986. "Devitrification of Defense Nuclear Waste Glasses: Role of Insolubles." Journal of Non-Crystalline Solids 84(1-3):299-307.

Boomer, K. D. 1991. Systems Engineering Study for the Closure of Single-Shell Tanks. WHC-EP0405, Westinghouse Hanford Company, Richland, Washington.

Hanlon, B. M. 1992. Tank Farm Surveillance and Waste Status Summary Report for October 1991. WHC-EP-0182-43, Westinghouse Hanford Company, Richland, Washington.

Hutson, N. D., C. M. Jantzen, and D. C. Beam. 1992. "A Pilot Scale Demonstration of the DWPF Process Control and Product Verification Strategy," in "Proceedings of the Third International Conference on High Level Radioactive Waste Management," American Nuclear Society, New York, pp 525-532.

Miller, W. C., D.W. Hamilton, L. K. Holton, and J. W. Bailey. 1991. Hanford Waste Vitrification Systems Risk Assessment - Final Report. WHC-EP-0421, Westinghouse Hanford Company, Richland, Washington.

Randklev, E. H. 1993. Hanford Waste Vitrification Plant Project Waste Form Qualification Program Plan. WHC-EP-0522, Westinghouse Hanford Company, Richland, Washington.

U.S. Department of Energy. 1991. "Waste Acceptance Preliminary Specifications for Vitrified HighLevel Waste Forms, June 1991, Office of Civilian Radioactive Waste Management, U.S. Department of Energy, Washington, D.C.

Zhu, Bing-Fu, D. E. Clark, L. L. Hench, and G. G. Wicks. 1986. "Leaching Behavior of Nuclear Waste Inhomogeneities." Journal of Non-Crystalline Solids 80(1-3):324-334. 


\title{
Appendix A
}

\author{
Normalized TRAC Data
}


-

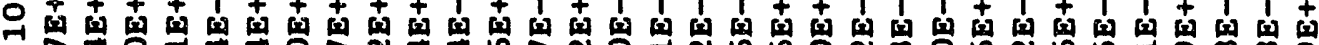

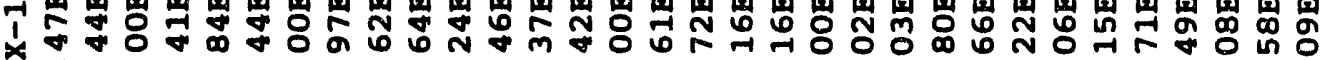

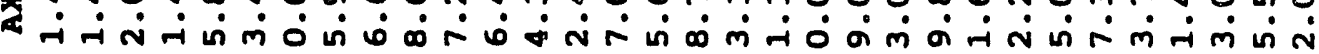

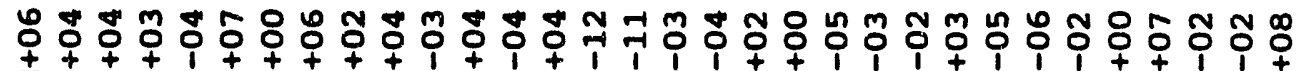

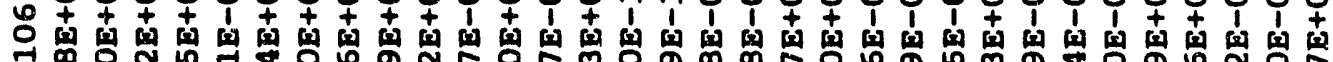

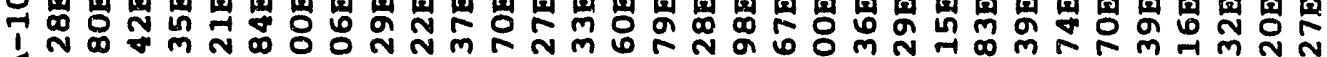

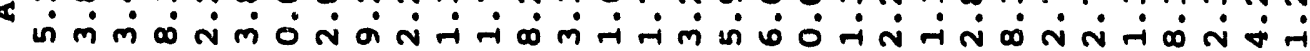

눙 운

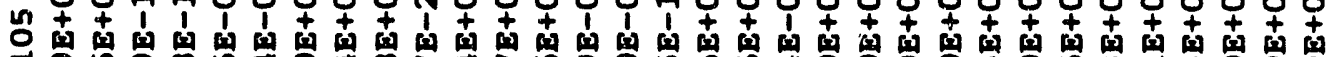

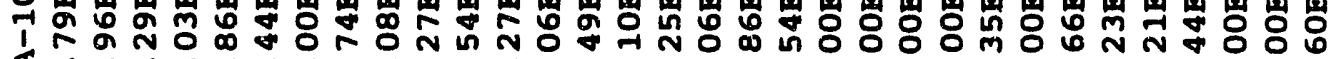

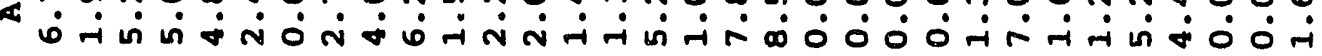

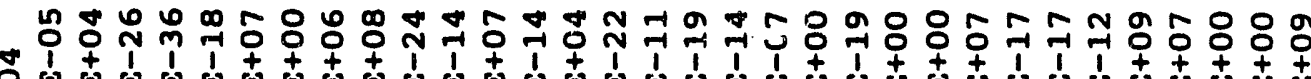

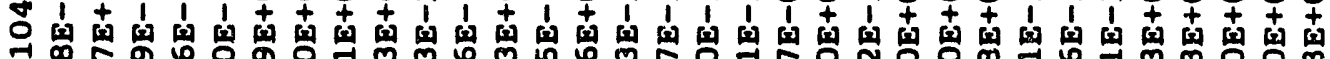

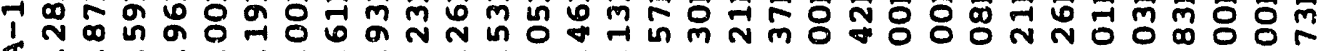

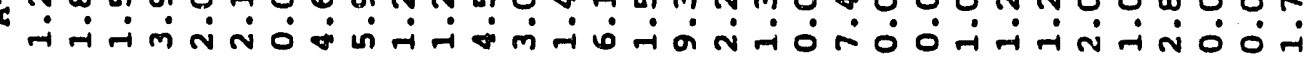

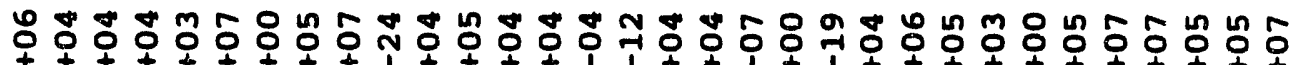

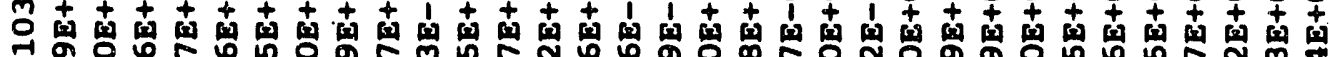
1

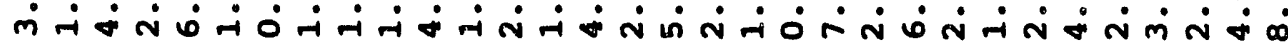

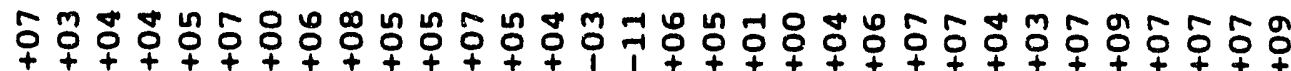

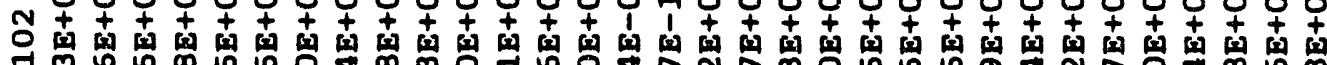

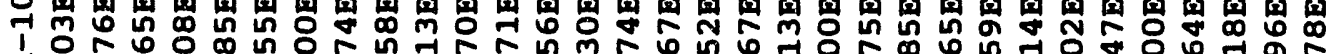

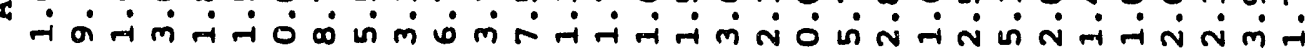

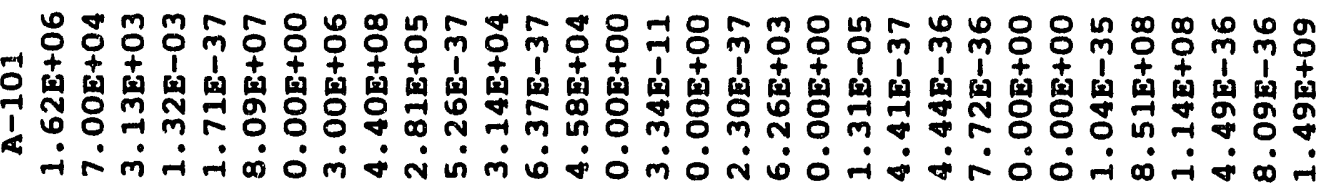

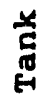

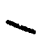

焉 *

A.1 


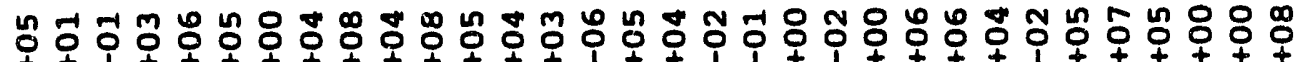

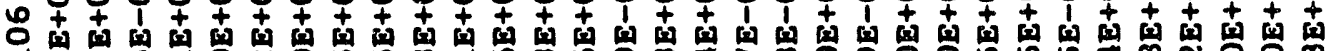

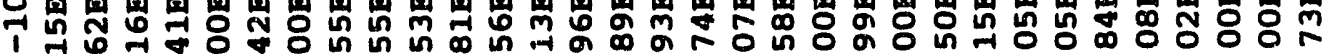
बि

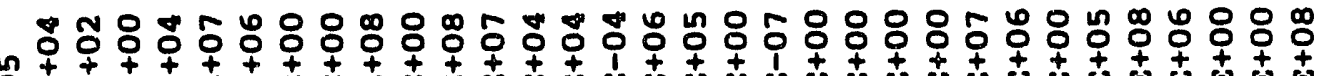

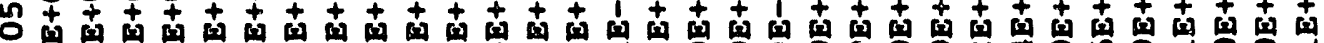

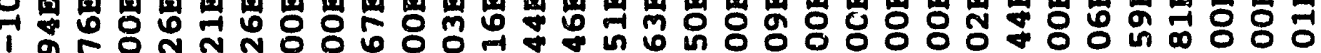
m

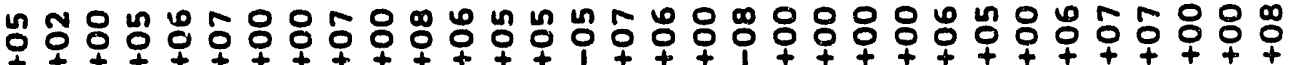

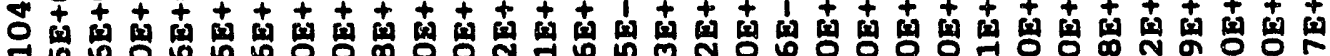

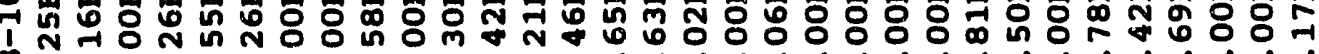

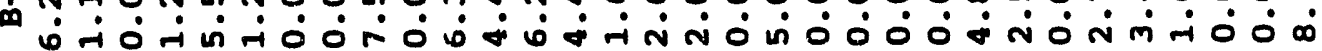

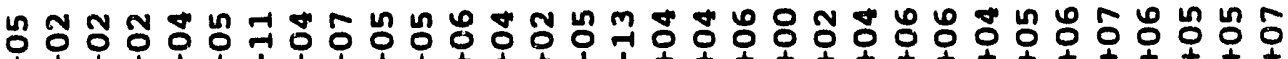

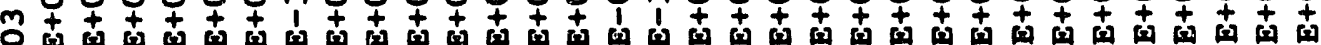

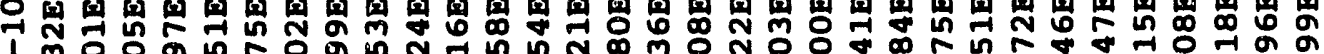

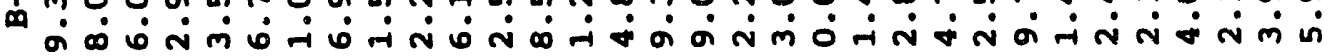

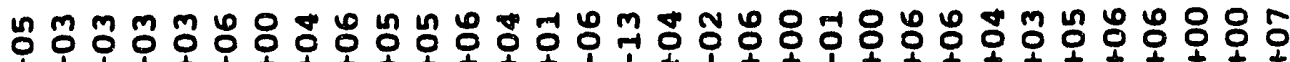

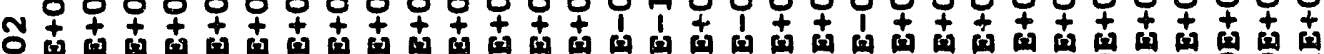

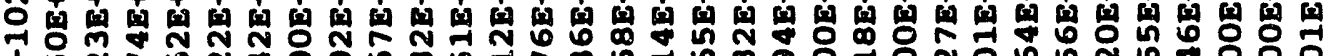
J

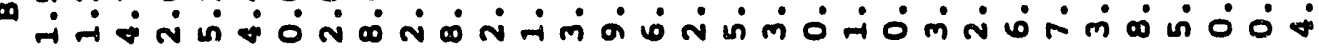

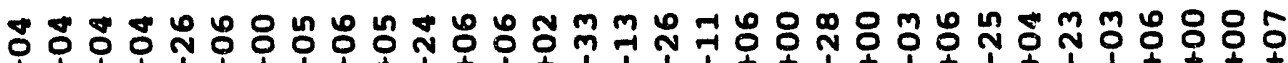

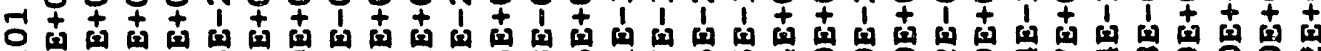

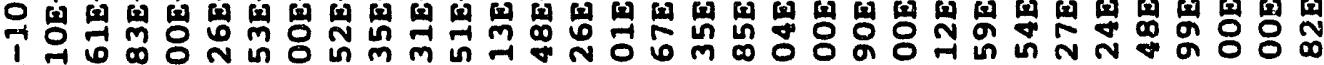

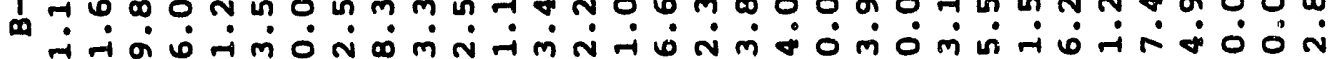

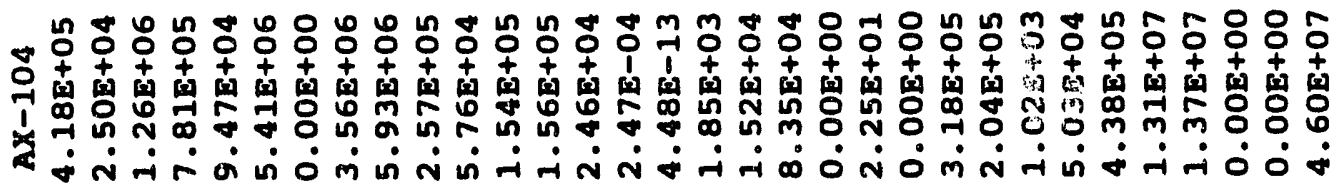

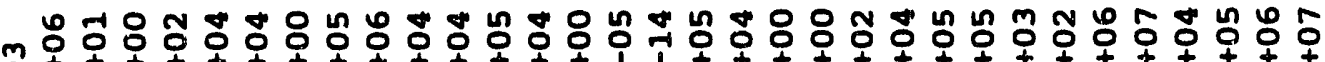

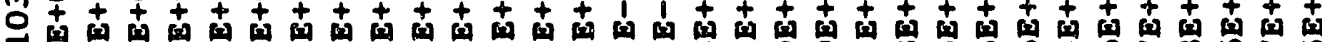

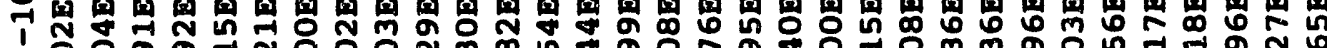

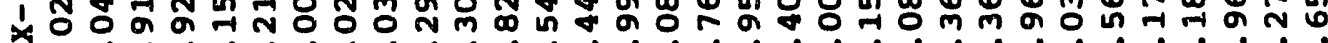

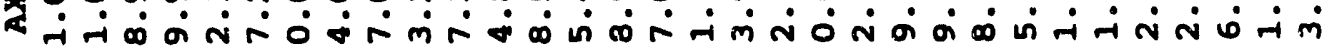

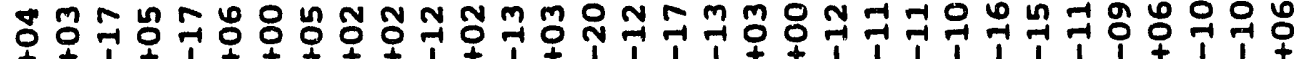

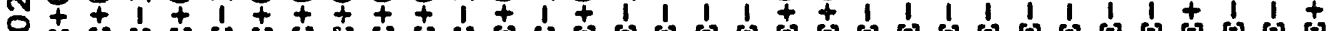

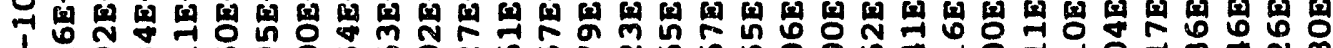
1 مु

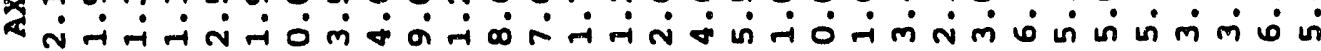




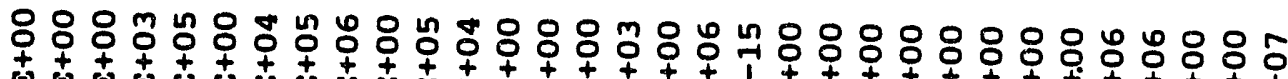

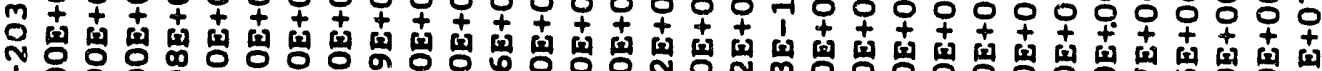

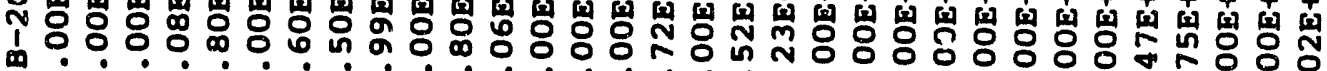
ல்

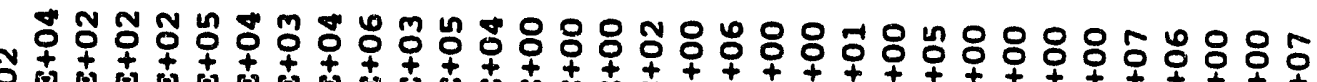

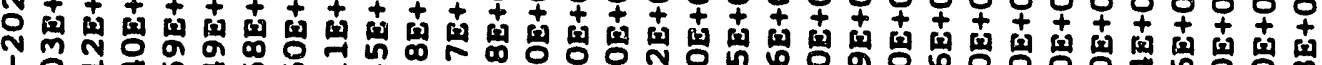

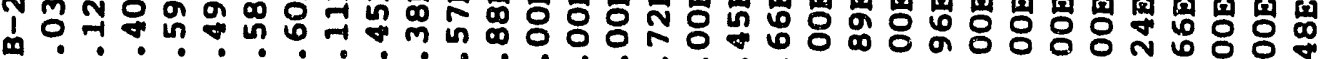
ن

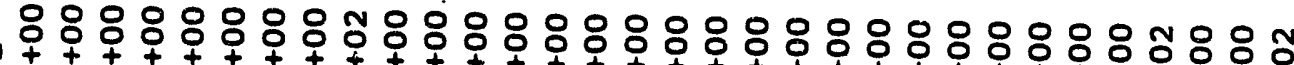

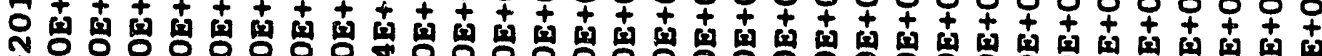

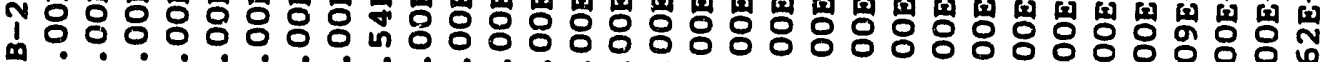

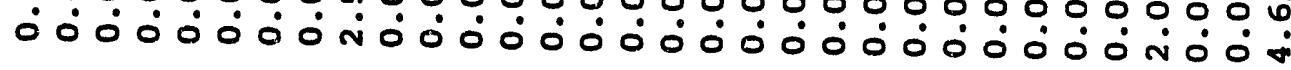

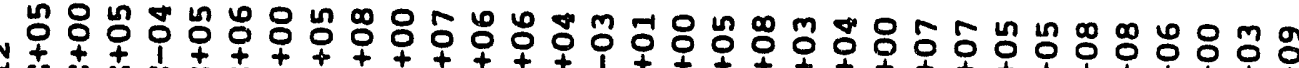

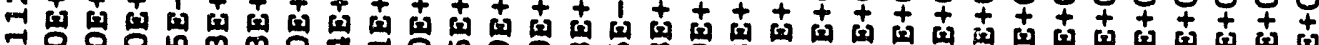

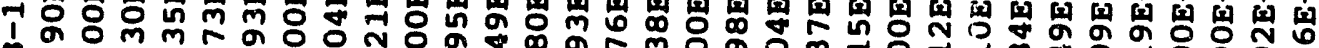
mं

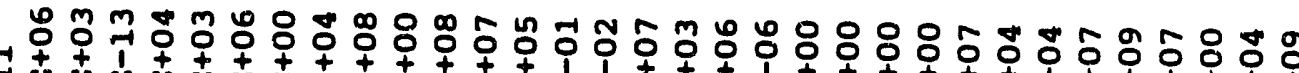

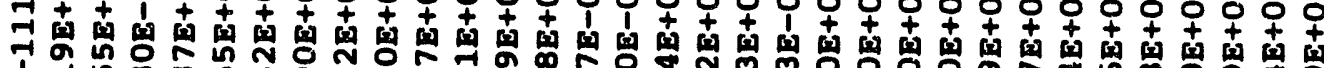

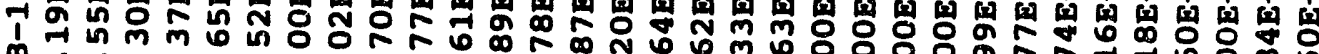

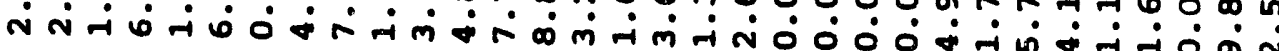

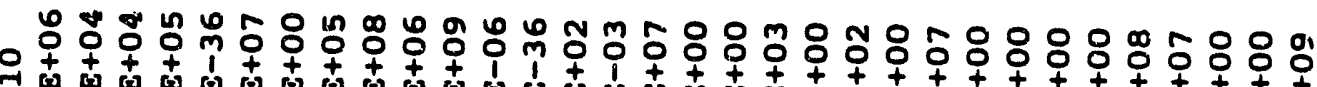

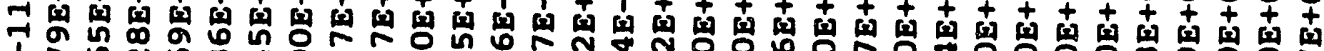

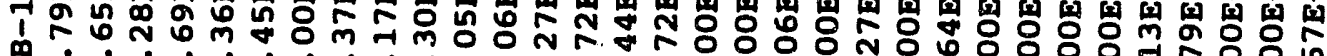
Nं

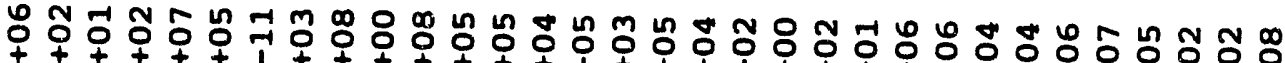

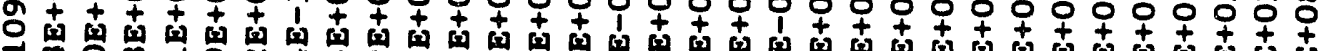

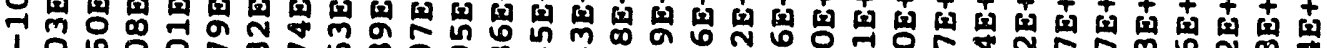
向

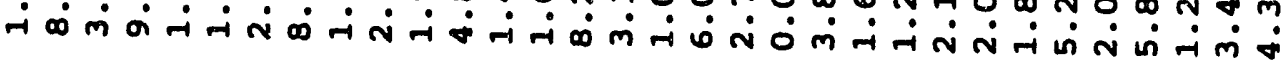

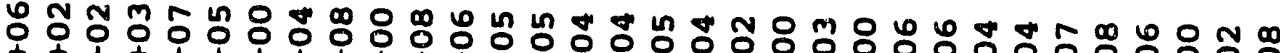

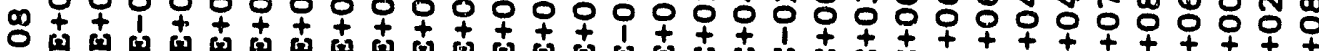

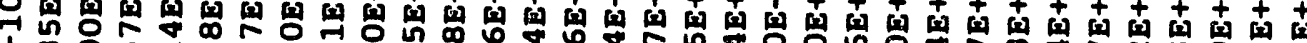
1 $m$ ○ in

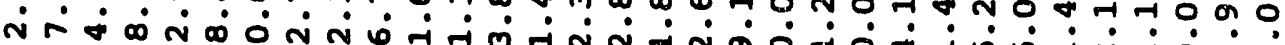

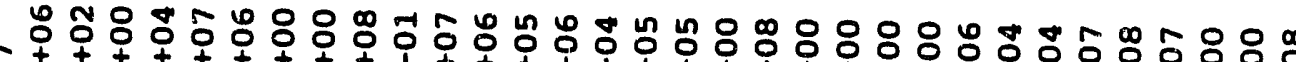

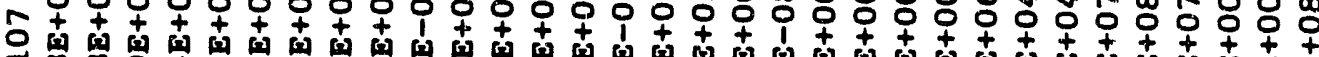

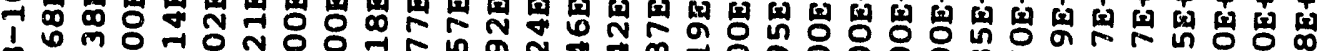

- ON Na 0 D 


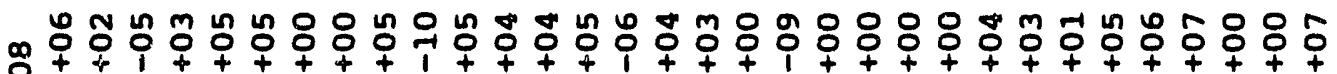

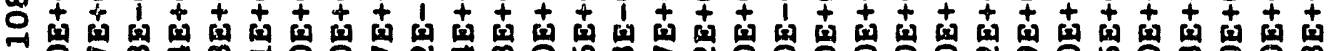
I융

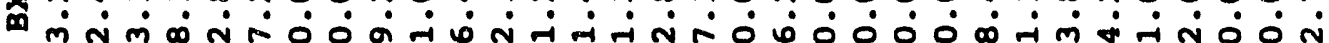

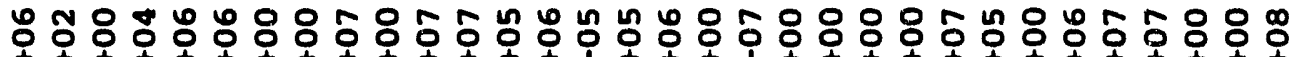

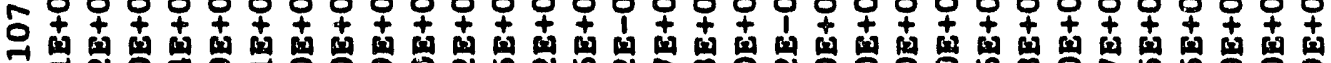
1

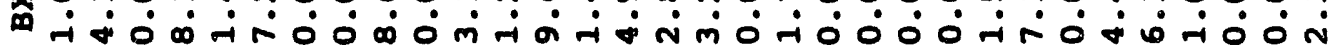

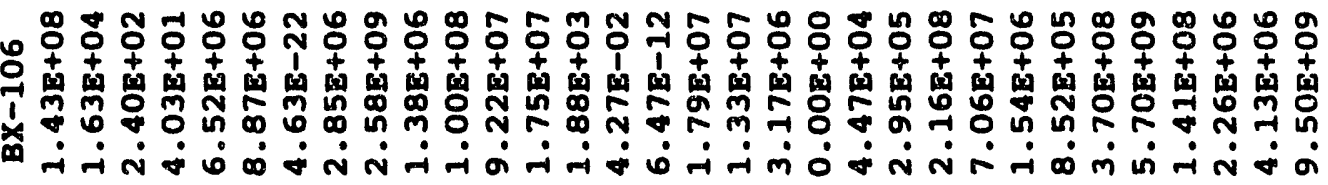

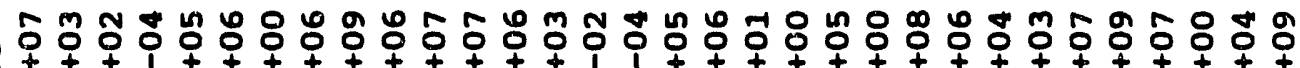

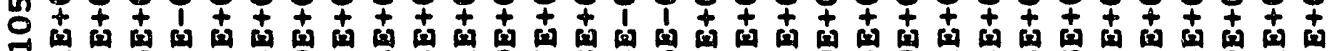

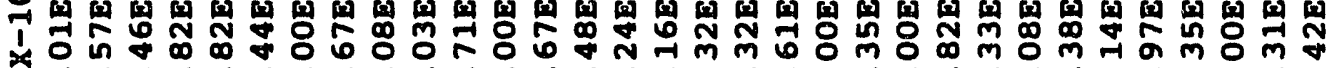

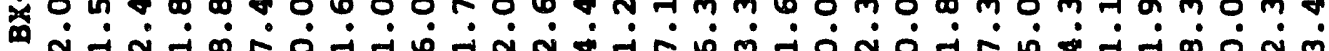

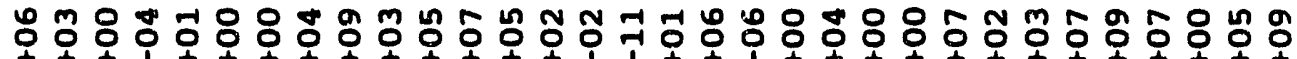

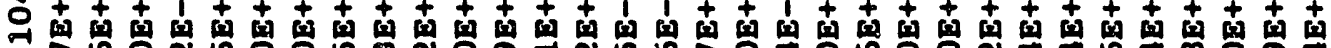

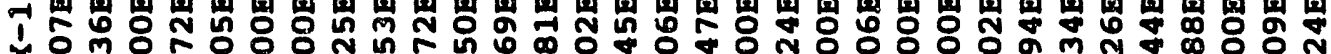
甾 的品

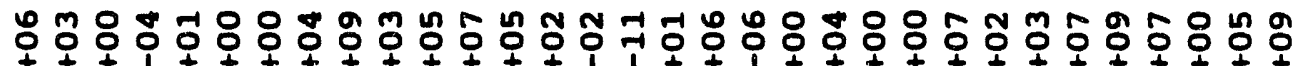

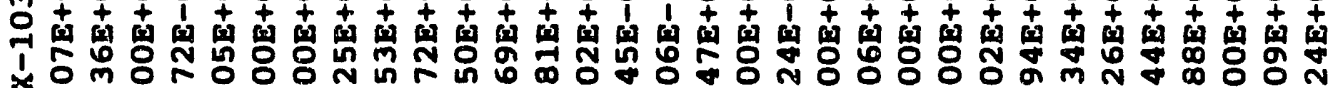

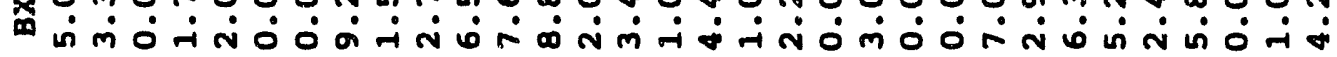

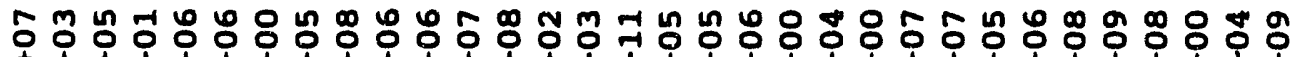
列 +1

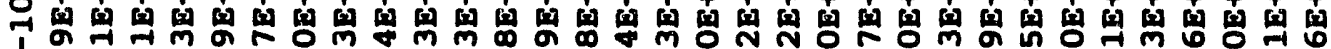
\

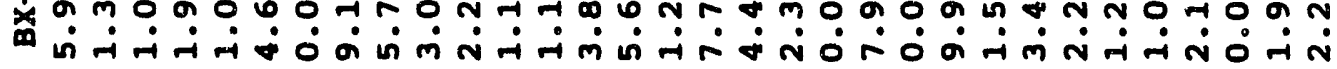

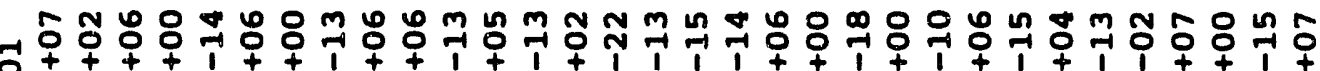

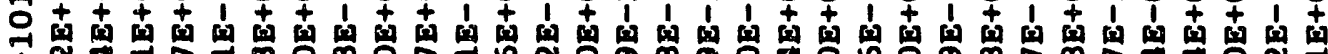

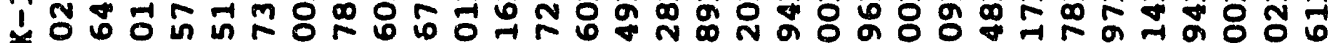

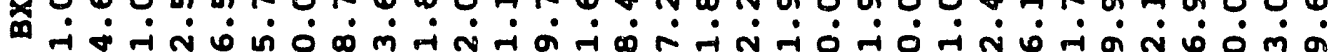

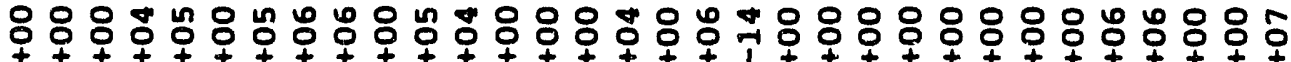

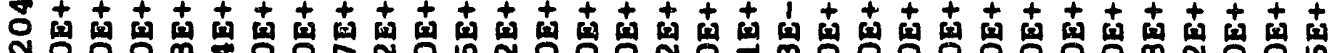

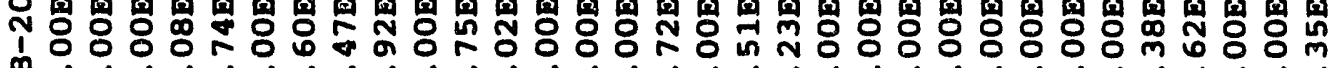

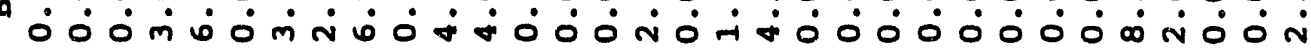




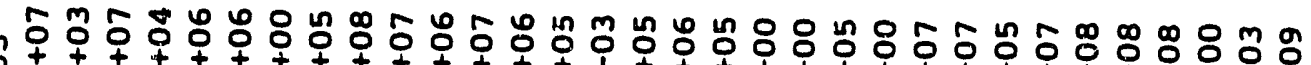

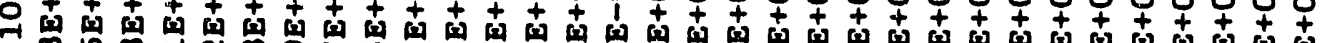

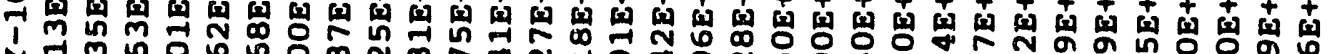
خ

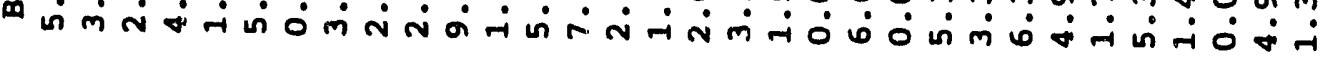

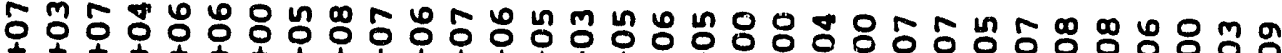

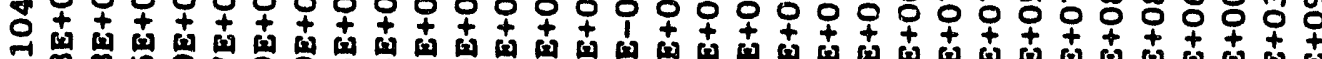

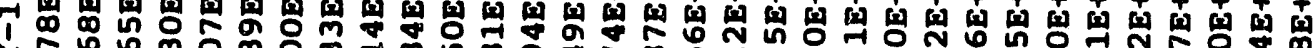

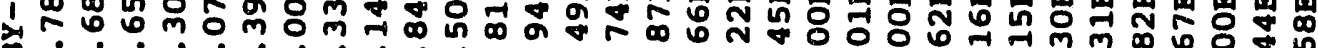

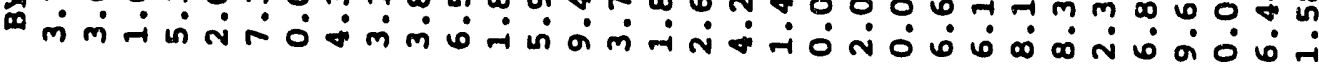

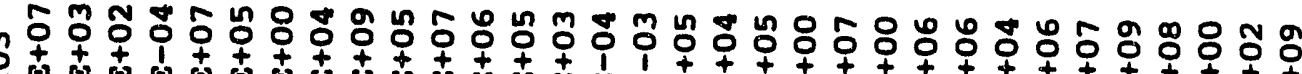

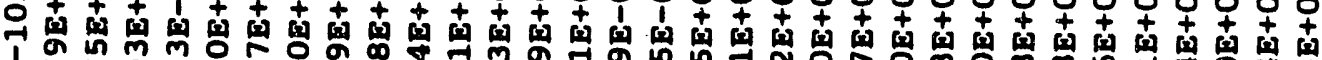

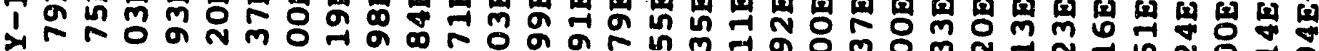

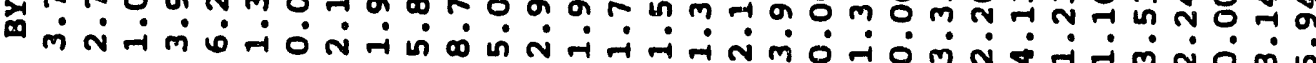

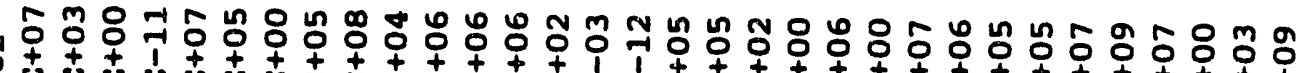

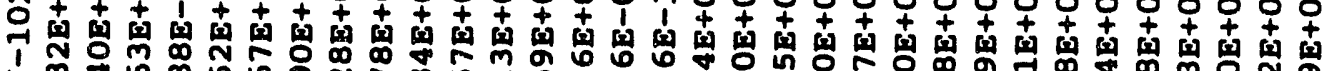
1

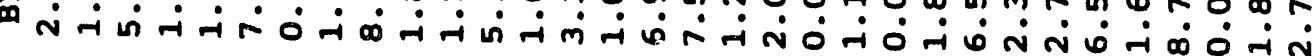

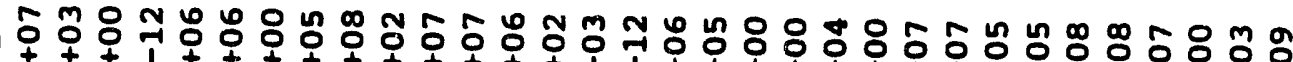

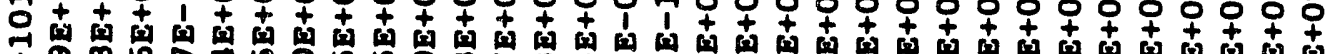

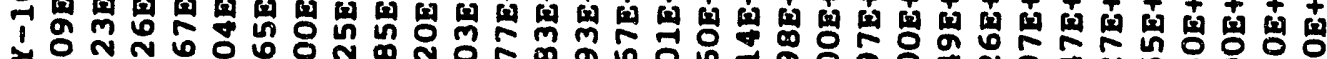

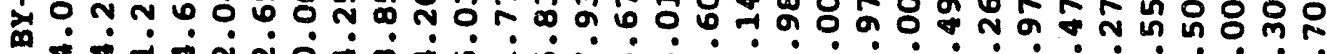

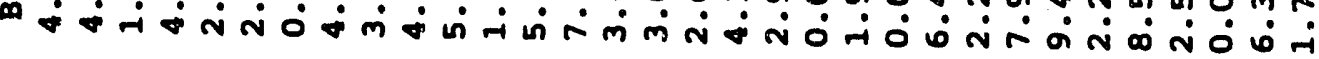

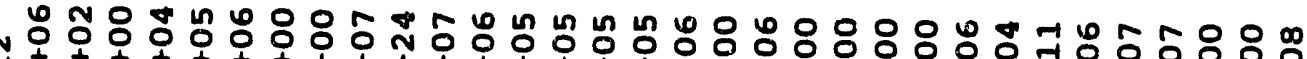

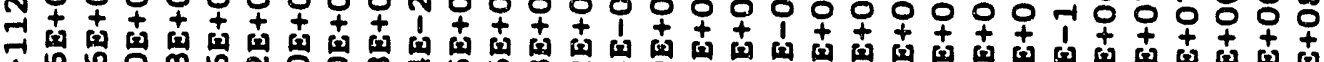

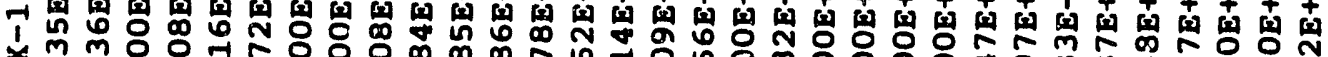
甾

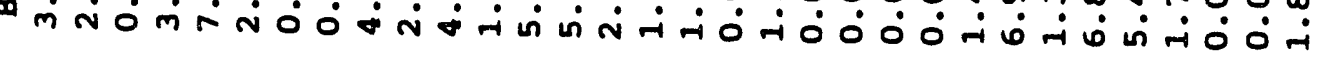

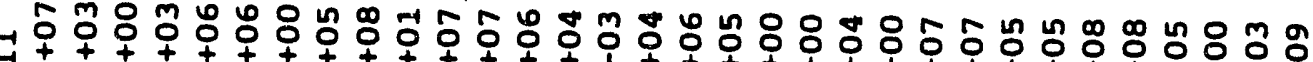

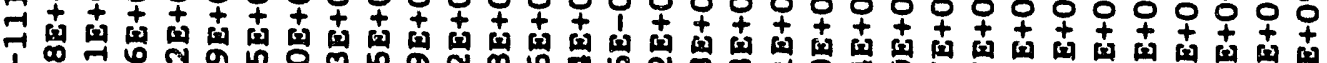

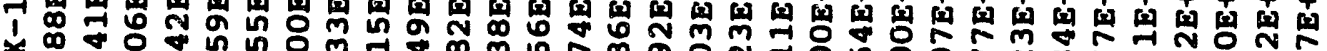

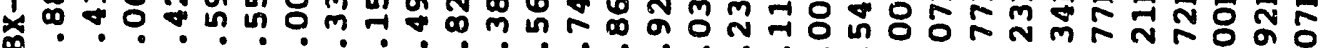

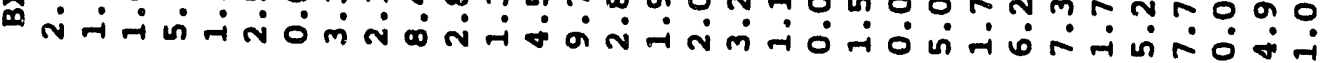

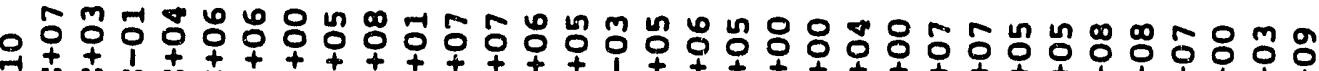

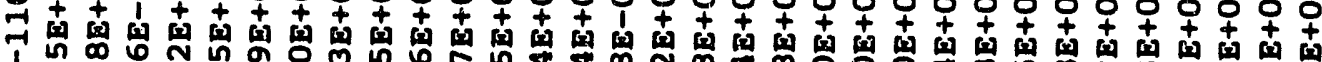

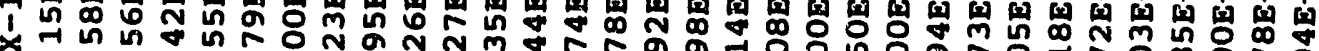

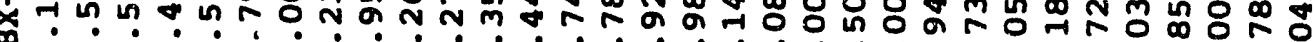

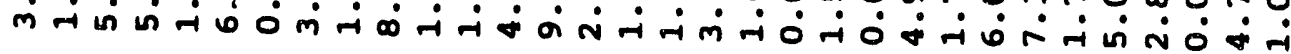

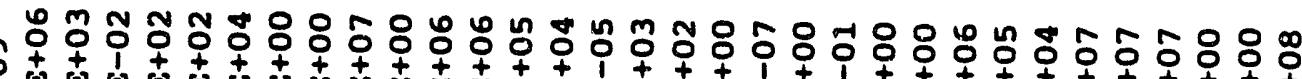

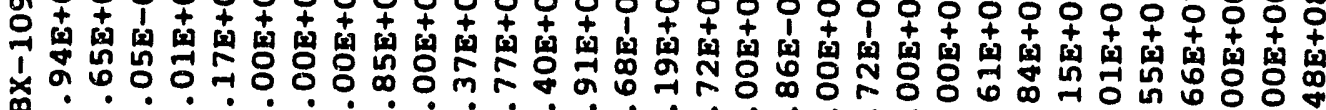

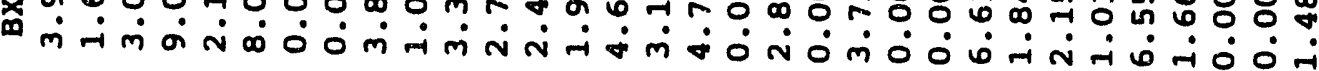




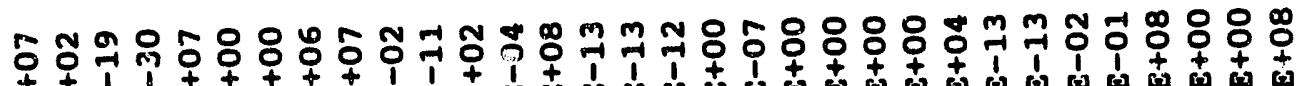

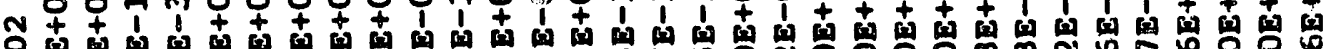

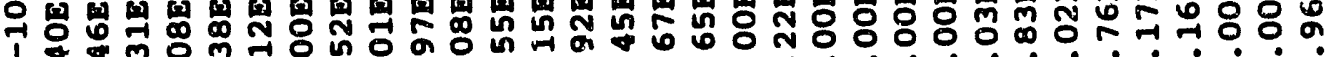

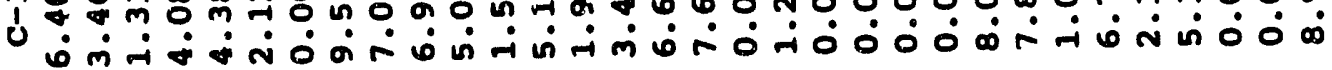

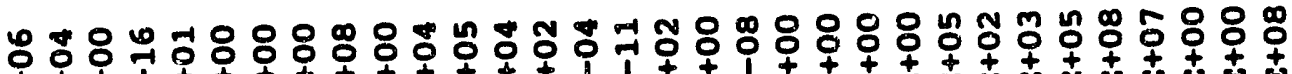

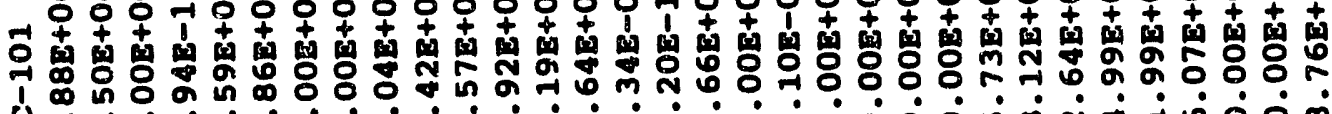

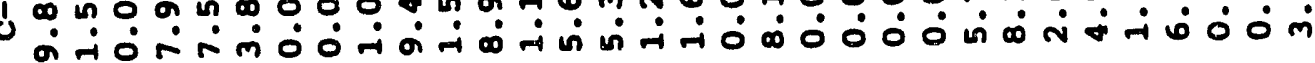

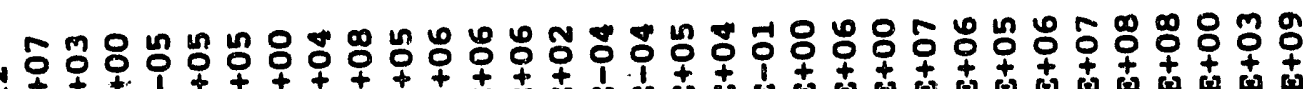

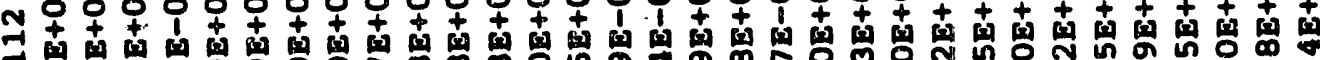

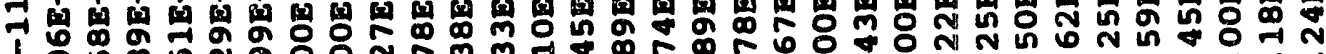

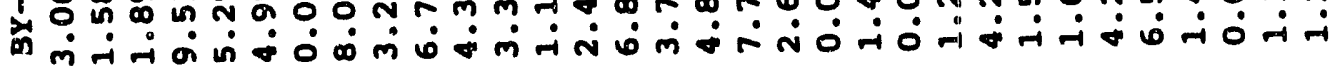

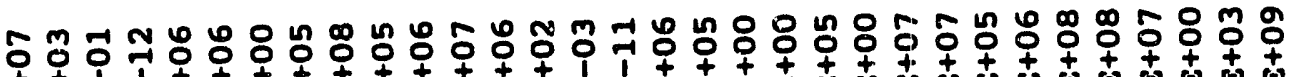

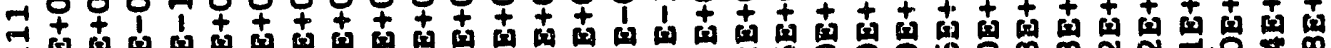

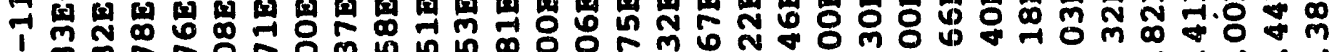

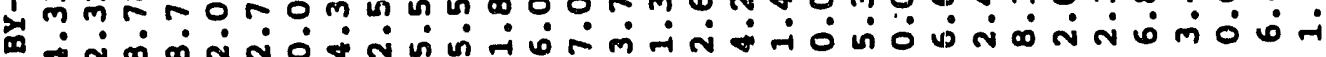

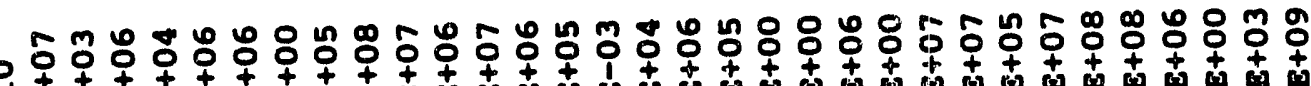

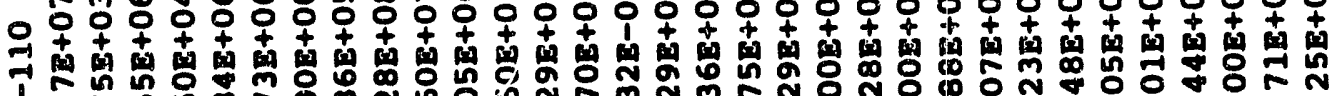

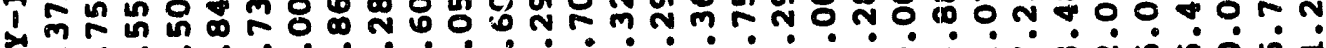

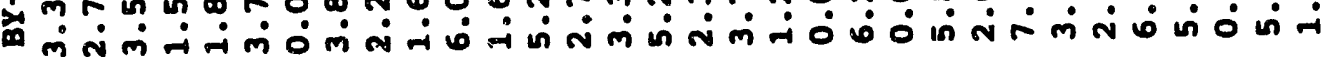

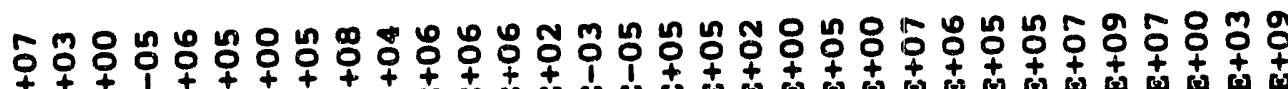

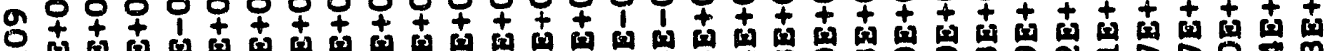

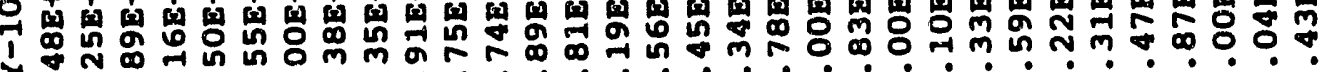

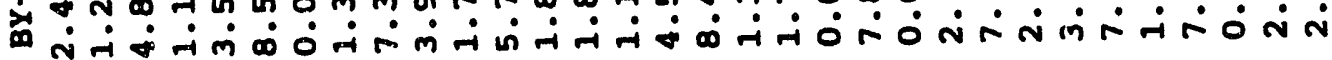

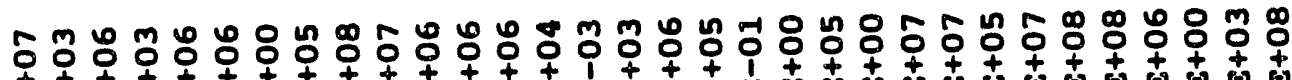

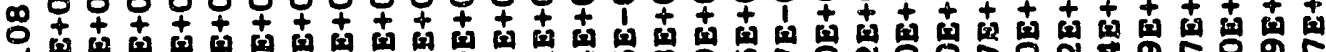

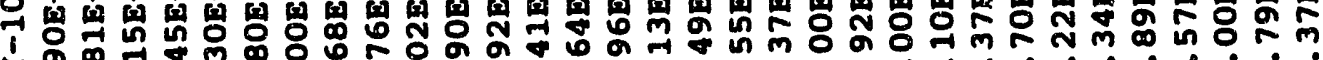
留

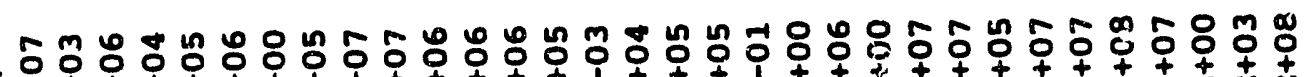

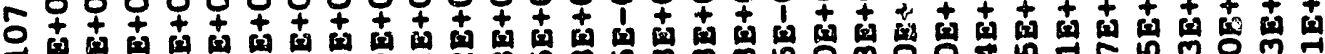

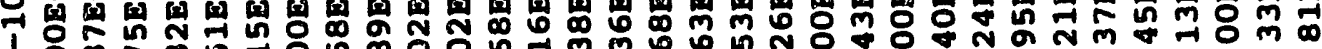

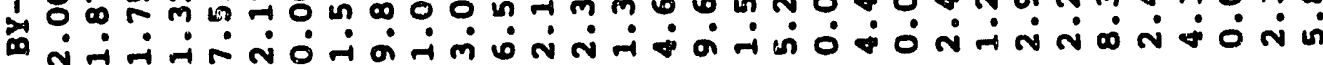

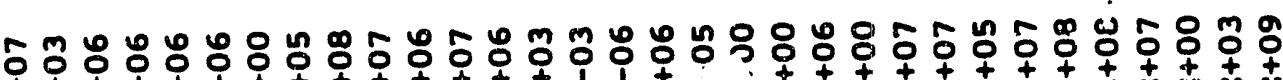

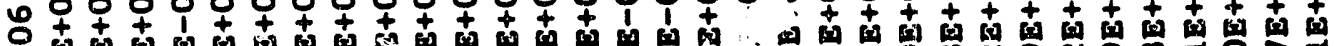

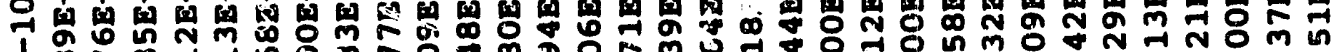
1

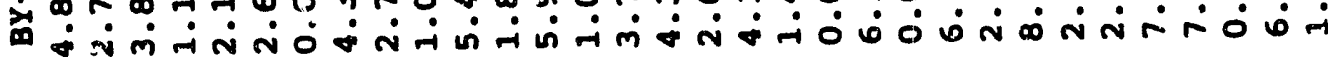




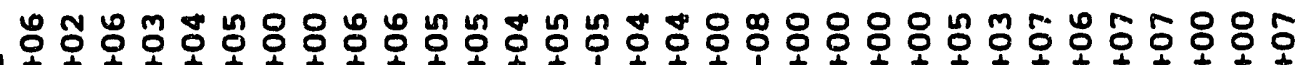

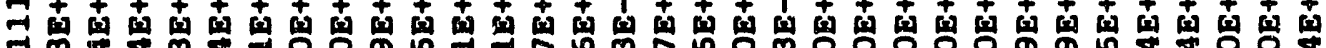

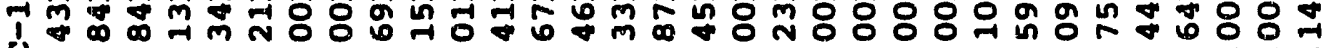

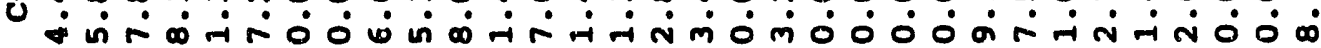

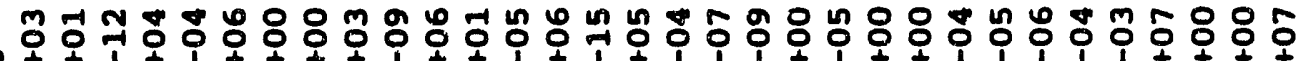

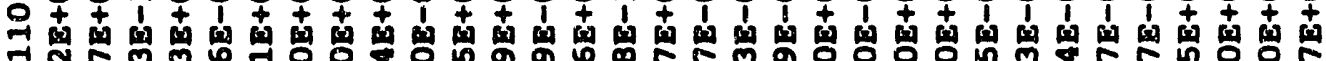

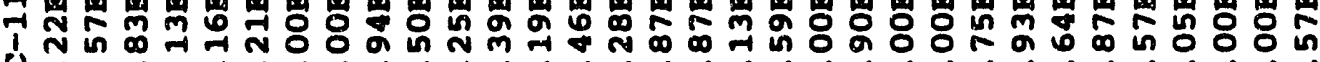

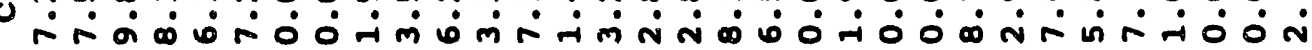

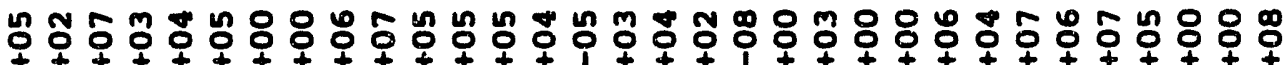

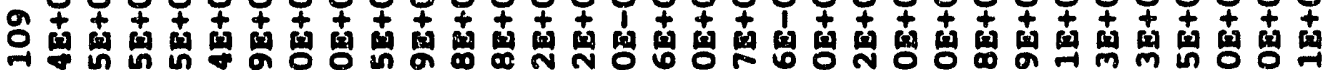

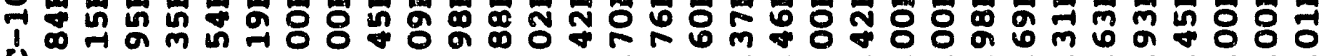

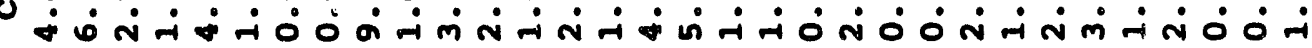

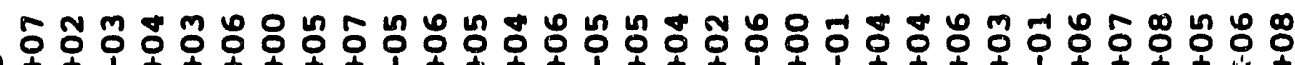

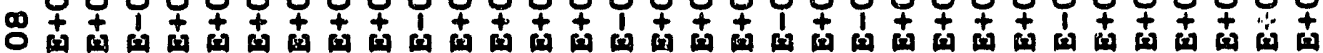

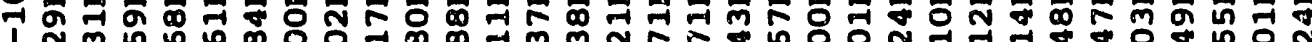
ช ง त

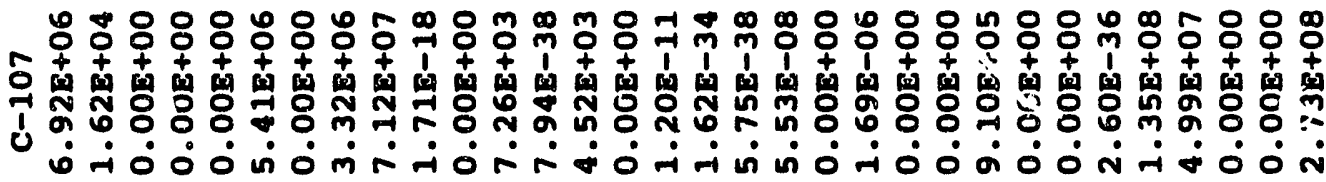

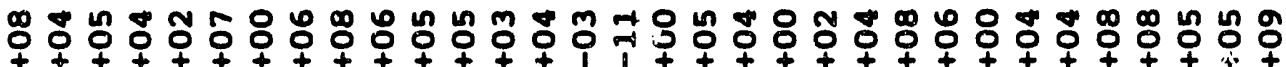

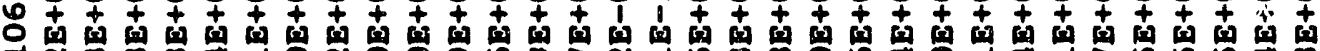

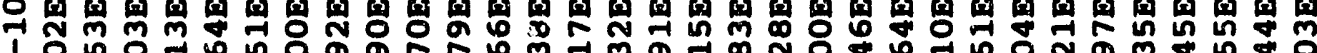

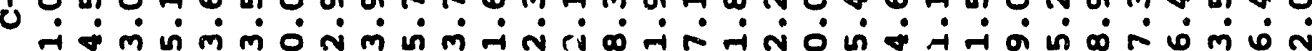

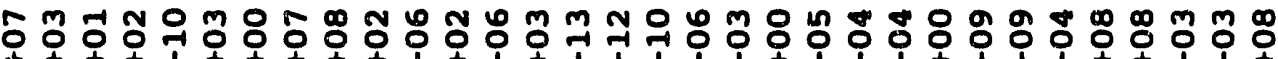

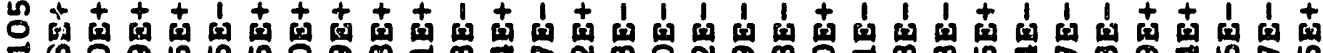

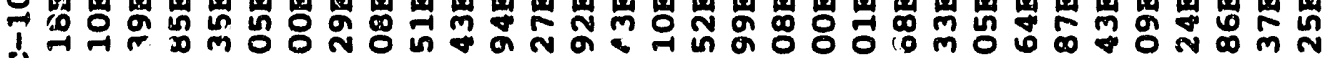

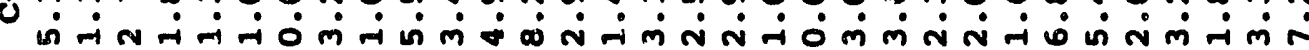

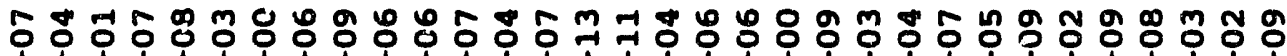
* ot+

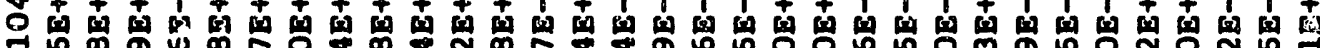
1

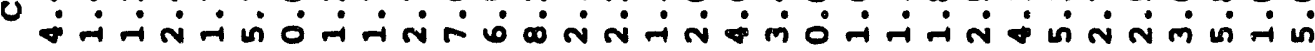

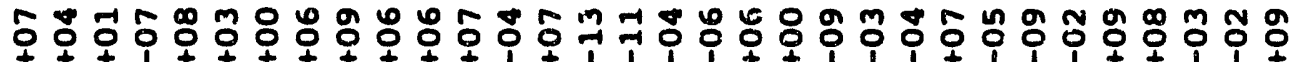

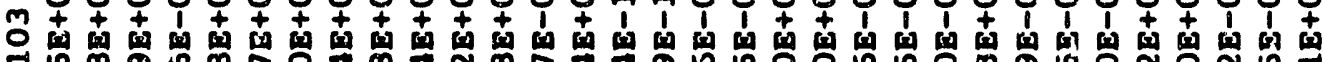
1 U 


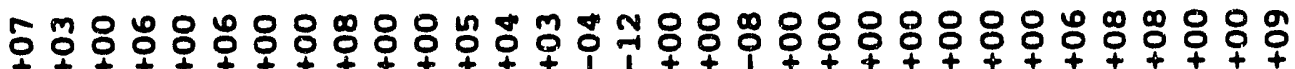

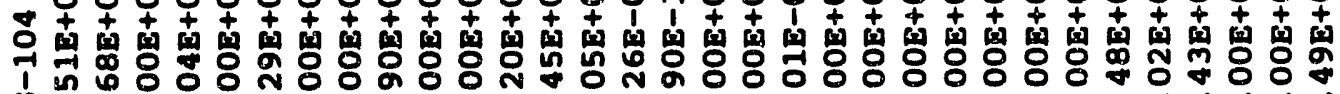

की

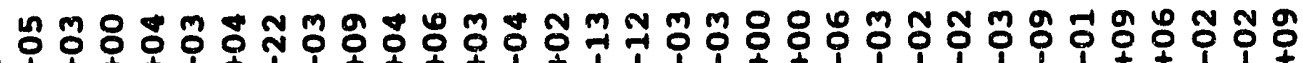

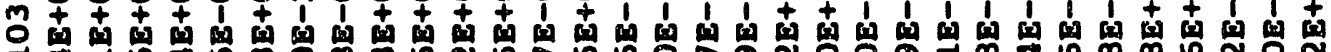

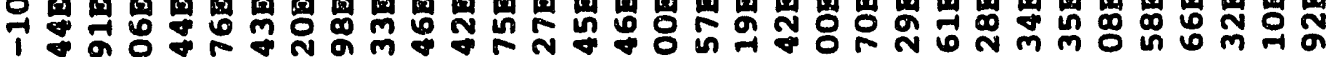

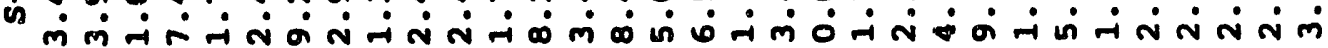

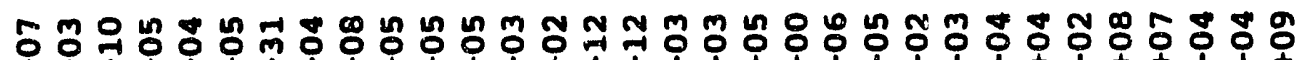

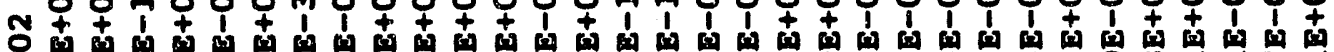

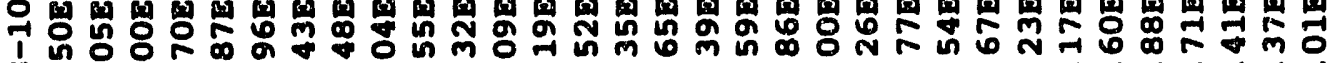

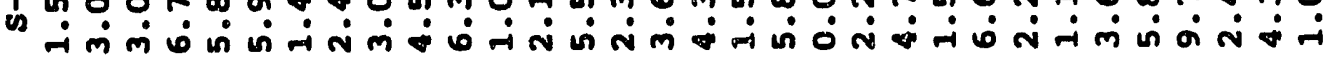

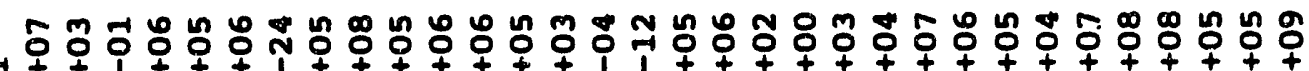

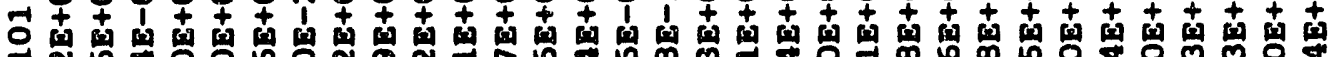

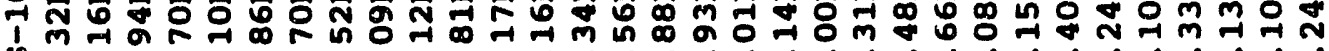

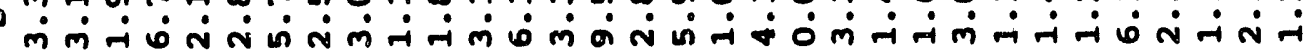

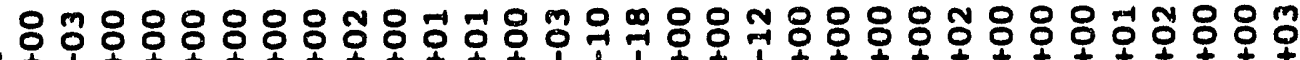

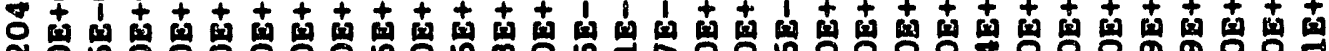

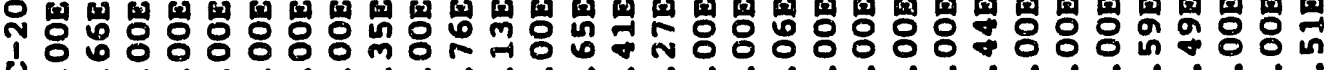

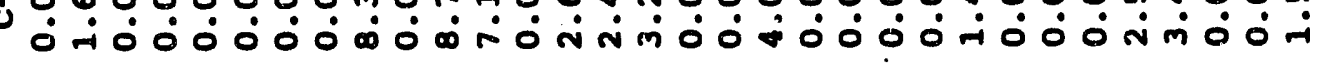

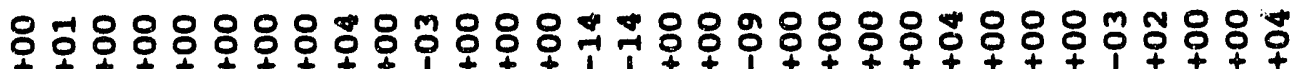

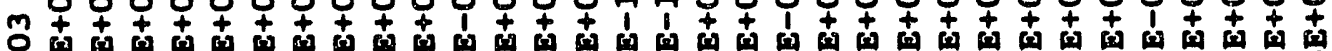

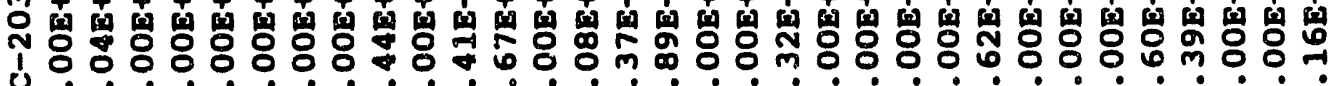

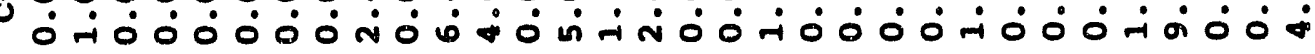

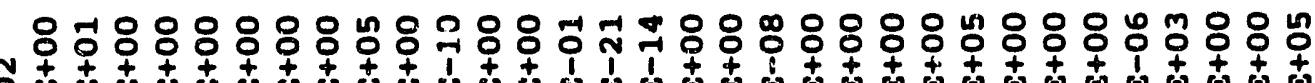

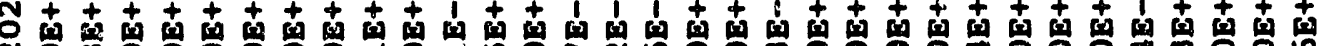

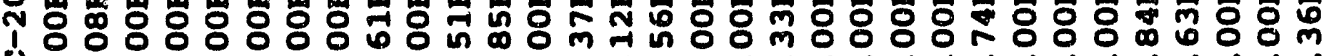

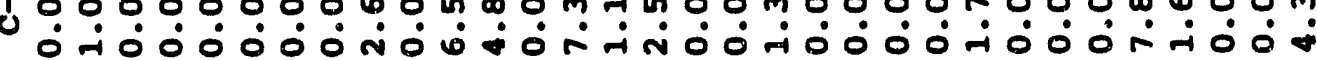

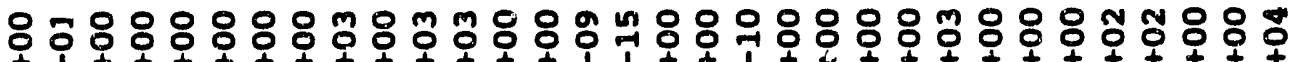

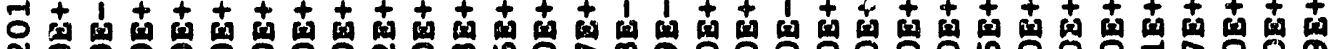

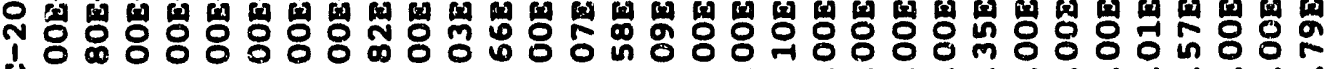

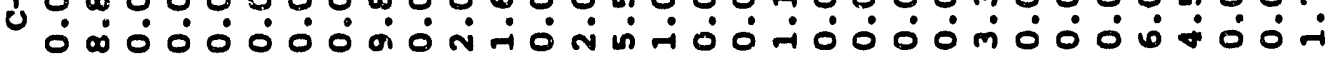

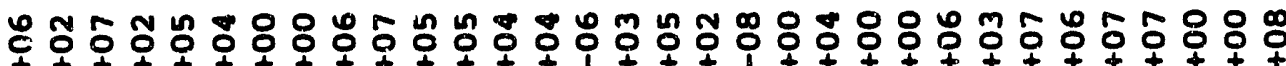
n t

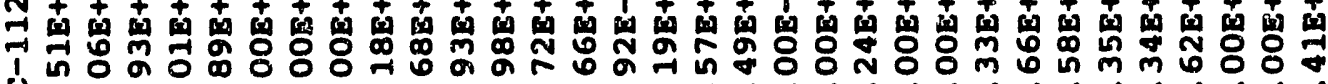

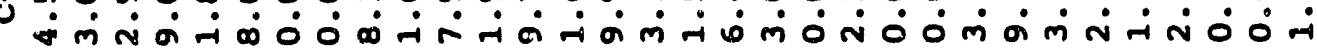



-

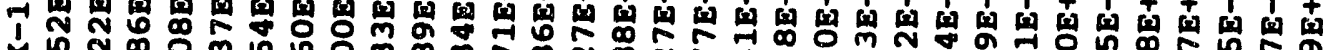

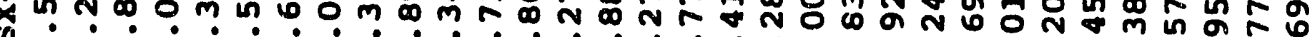

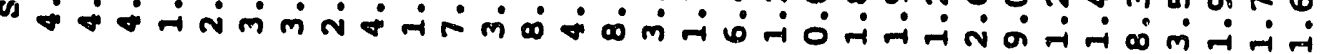

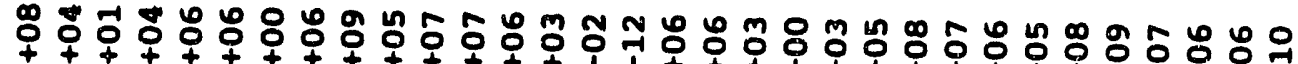

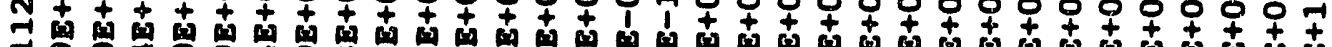

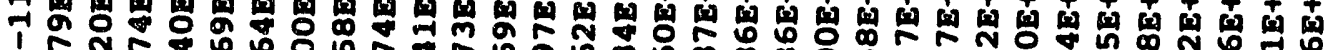
ต - न

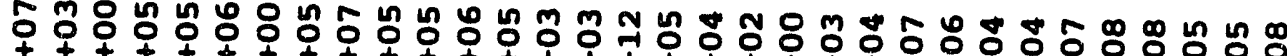

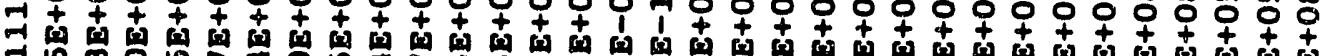

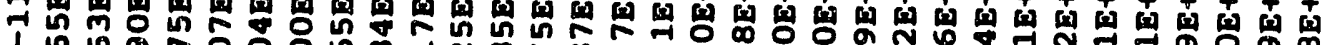
的 Un

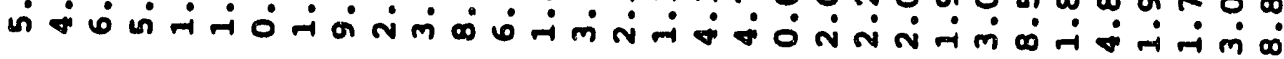

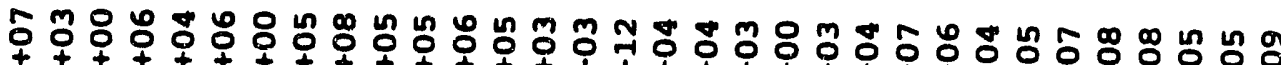

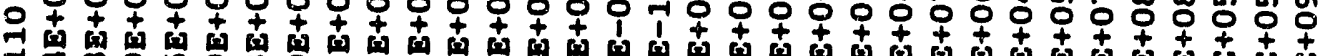

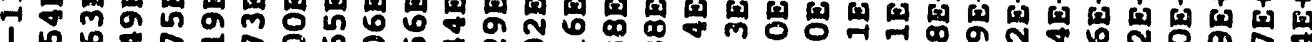
ต ?

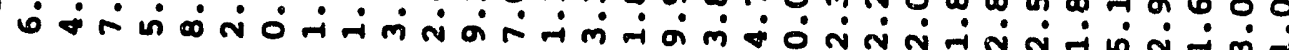

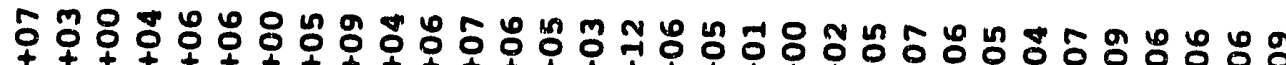

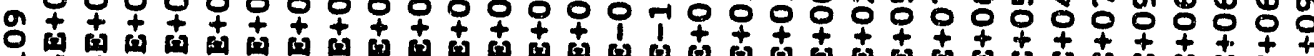

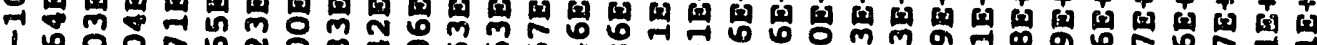
ம

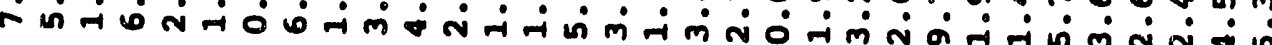

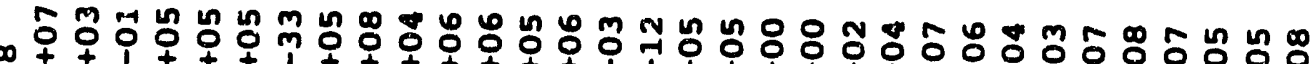

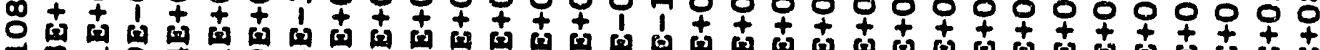

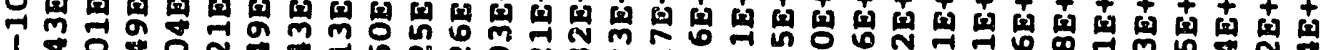

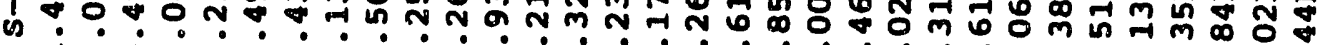

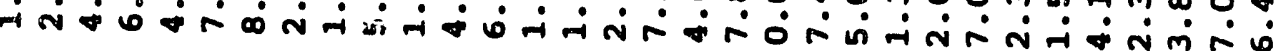

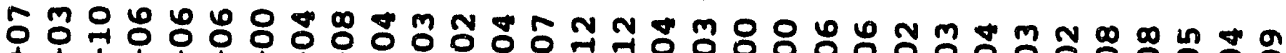

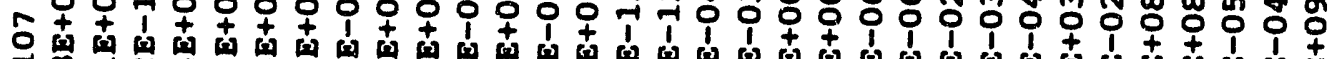

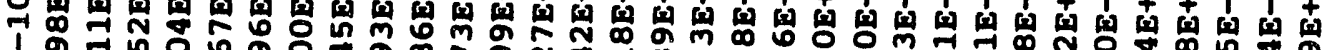
ต ด ?

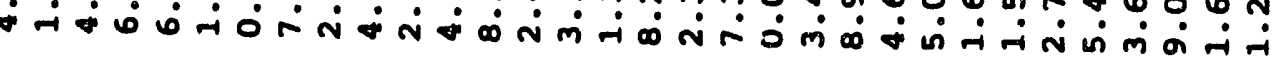

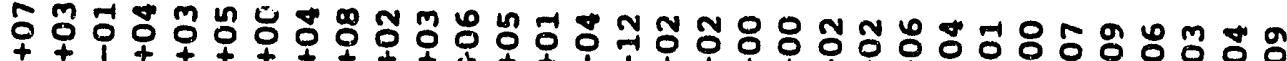

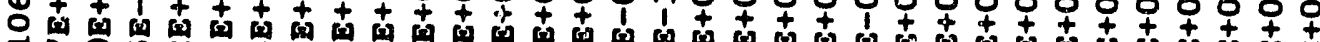

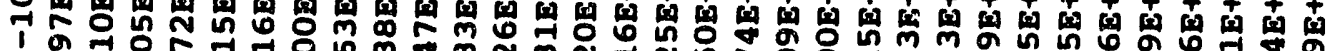

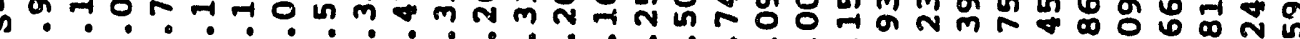

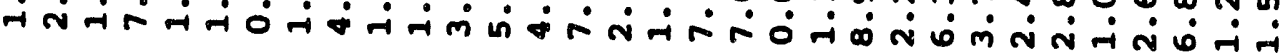

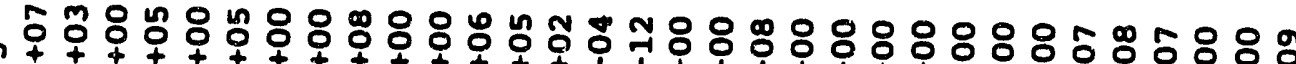

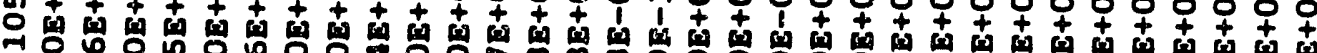

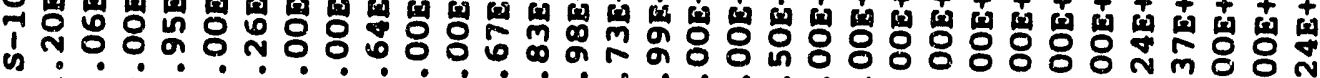

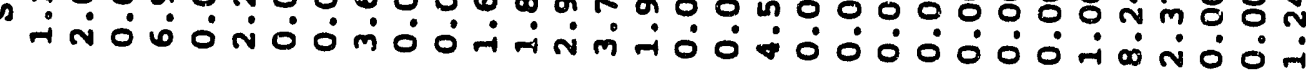




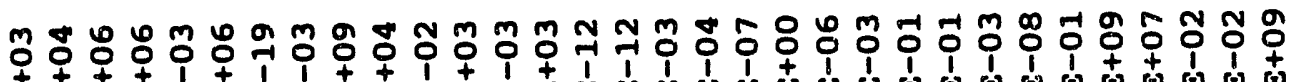

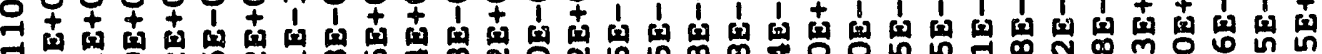

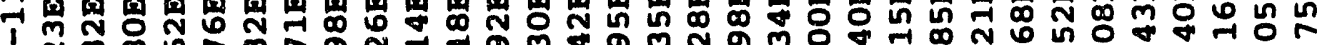
xतm

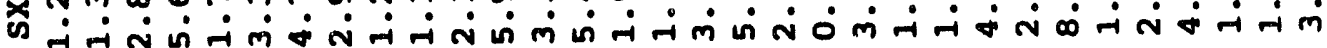

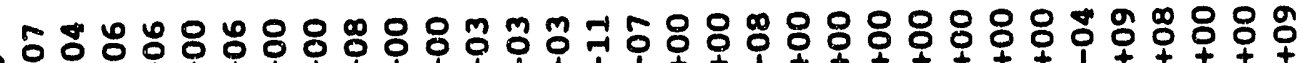

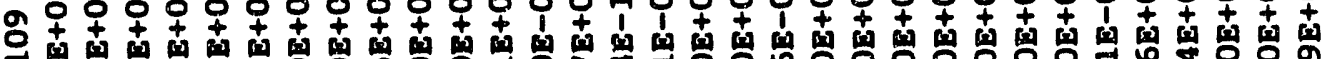

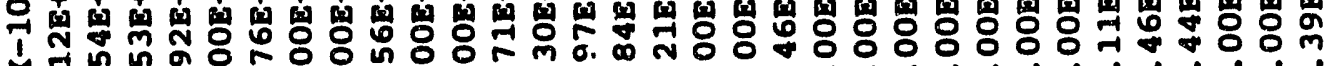
希

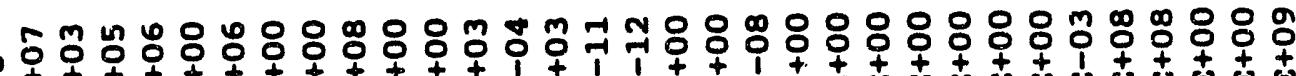

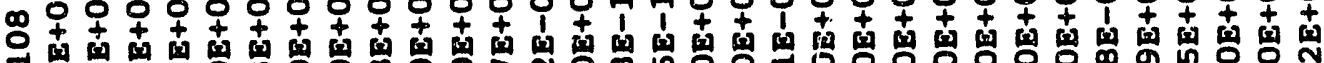

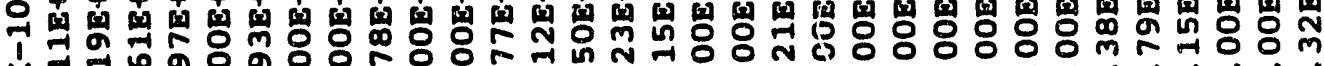
希

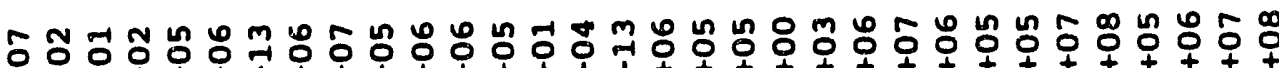

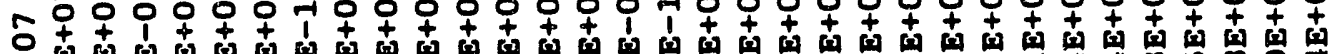

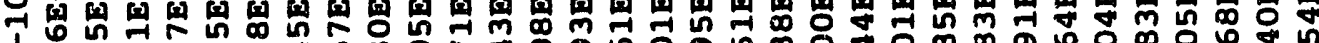

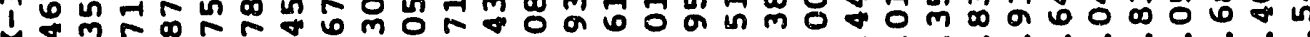

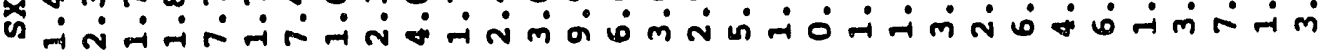

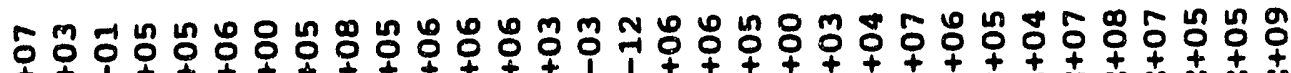

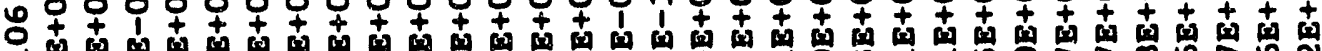

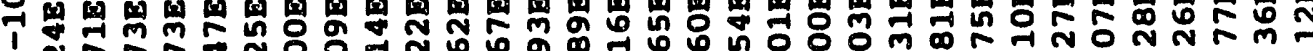
$x$ ㄱ.

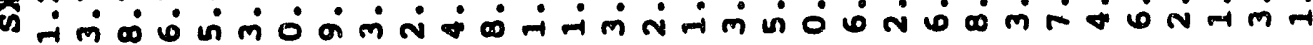

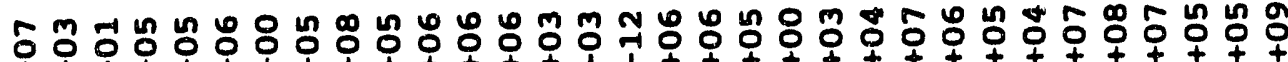
n t

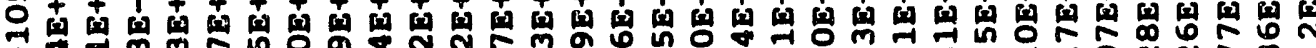

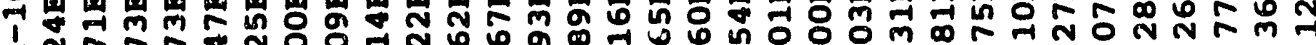

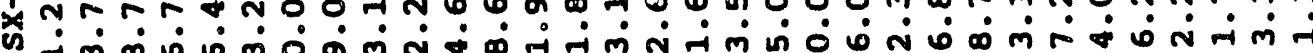

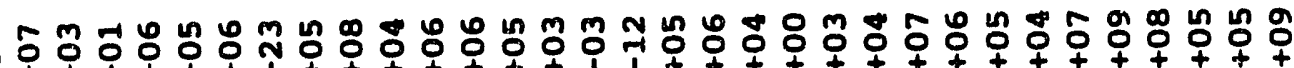

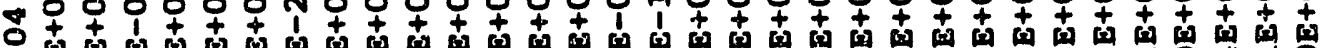

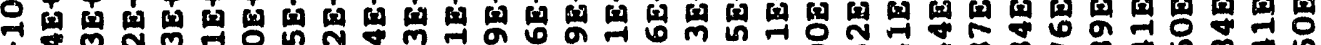

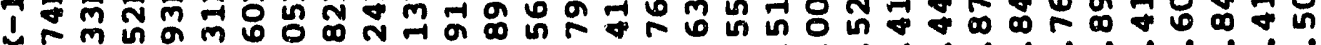

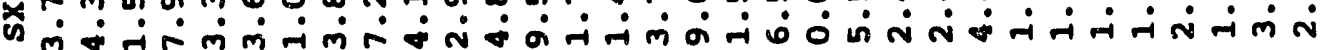

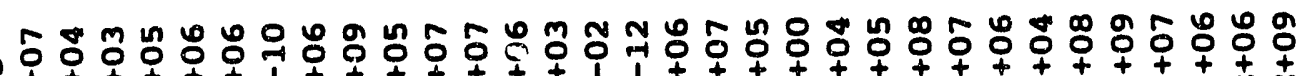

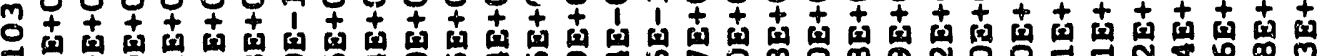

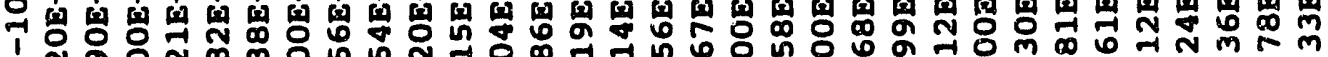
1

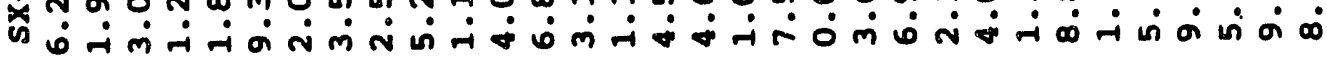

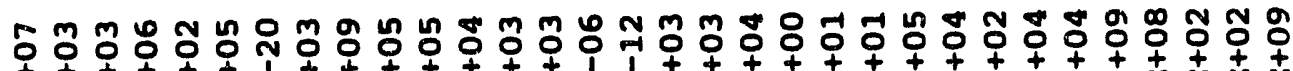

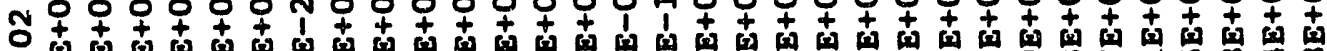

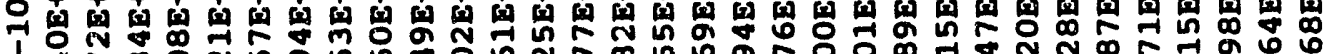
$x+\pi m 0$ n

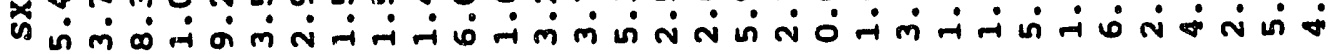




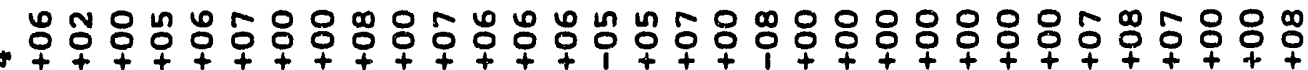

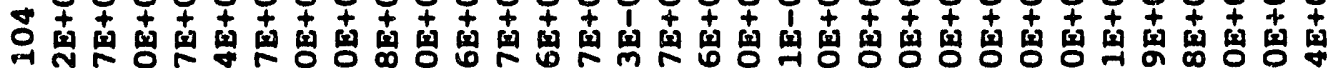

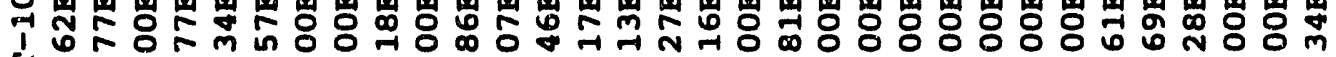

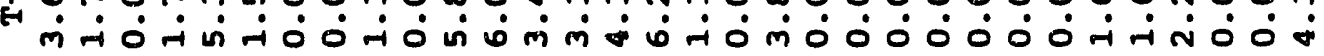

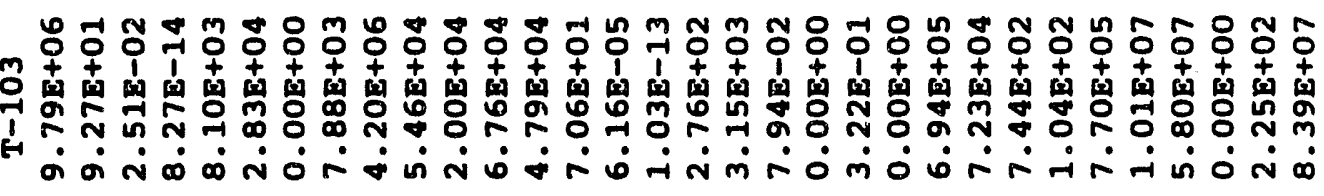

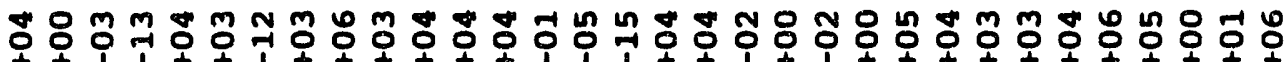

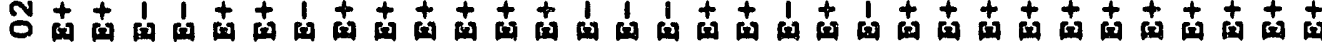

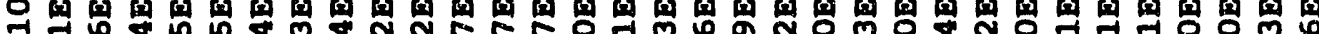

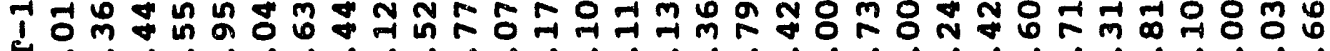

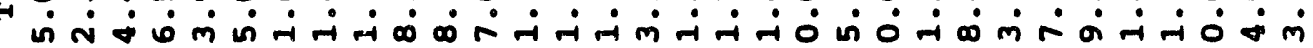

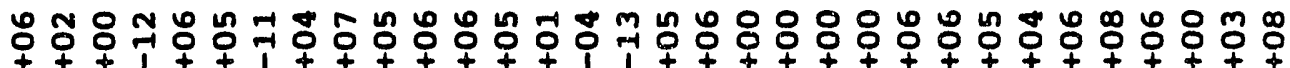

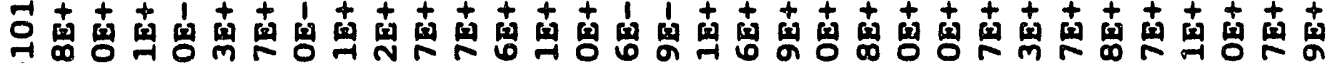

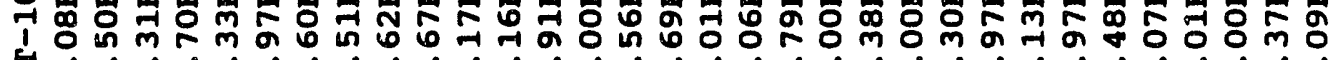

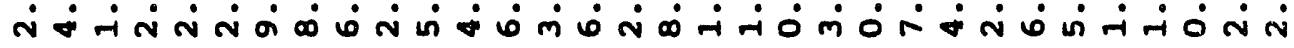

ケ网 nit

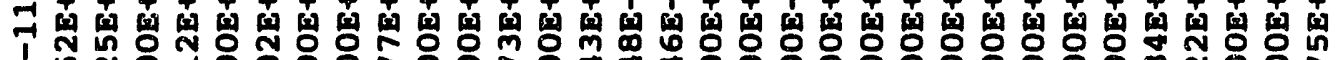

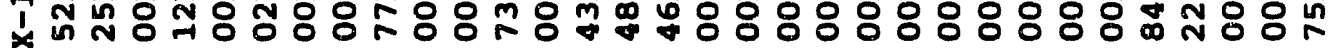

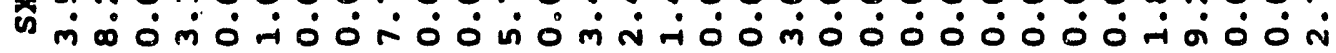

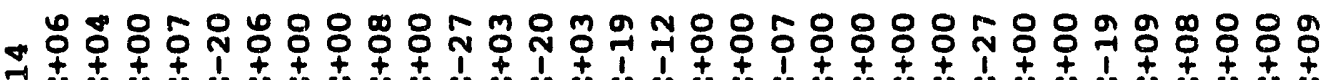

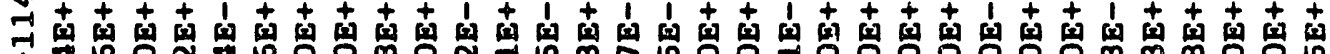

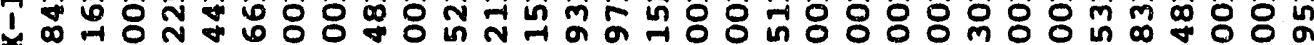
冈ّ

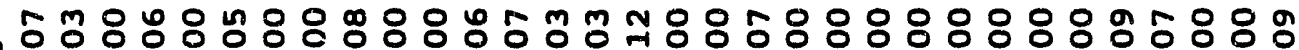

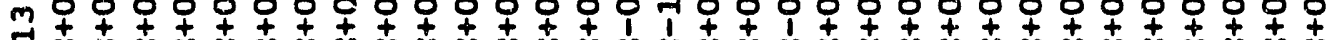

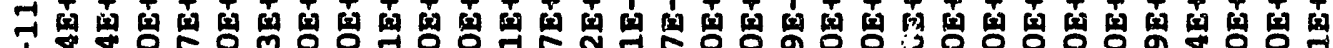
๖

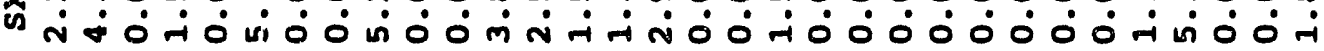

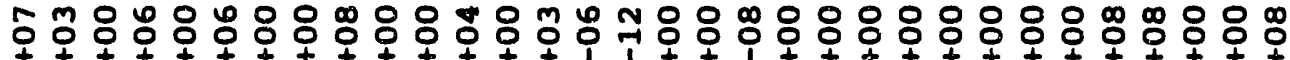

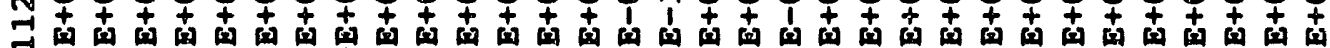

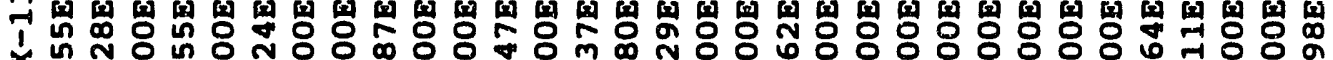

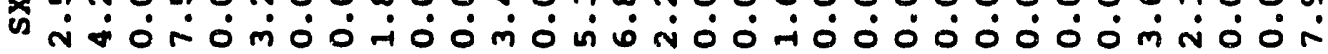

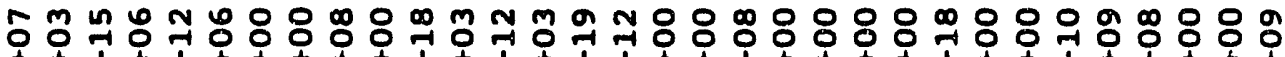

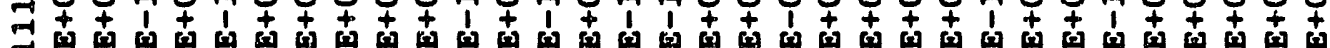

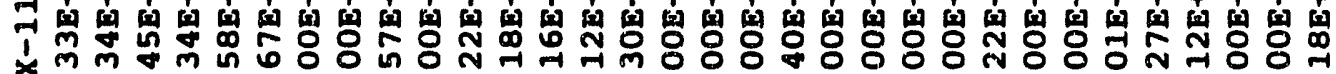
ॠ 


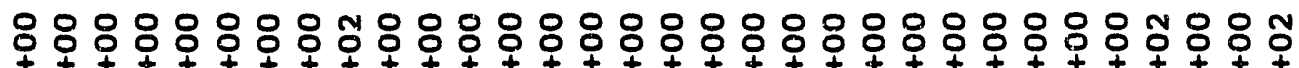

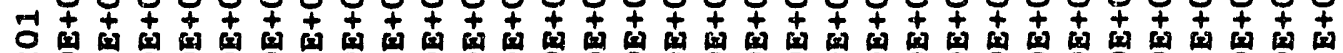

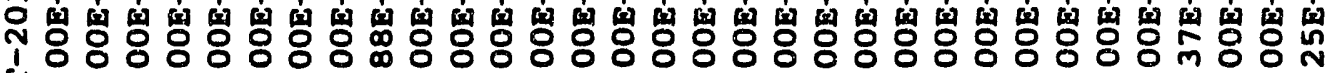
-

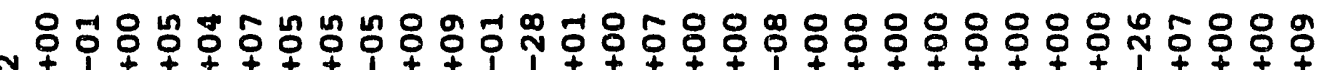
工 二 1008m N W

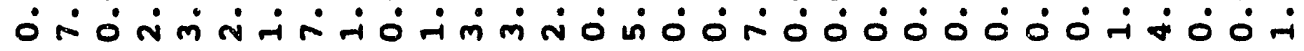

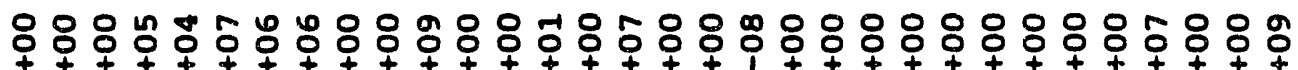

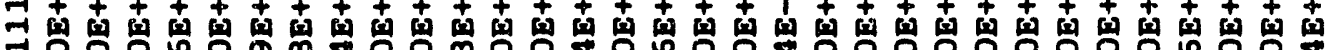

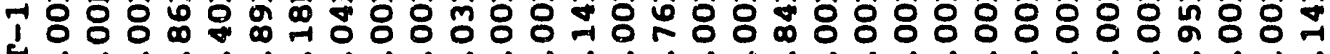

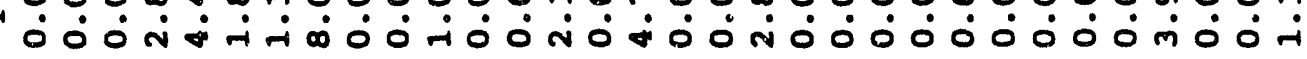

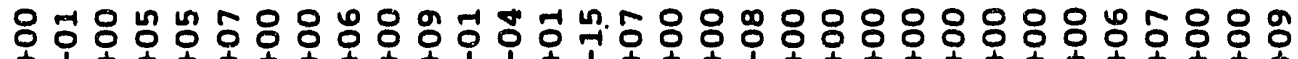

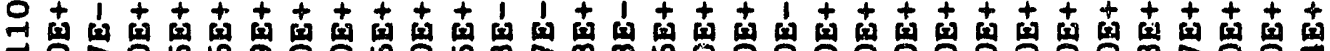

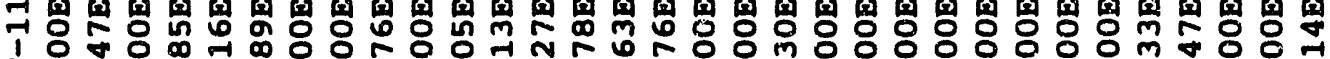

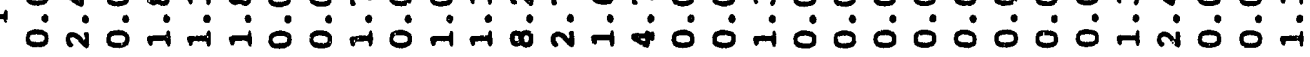

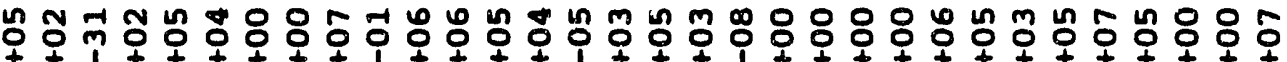

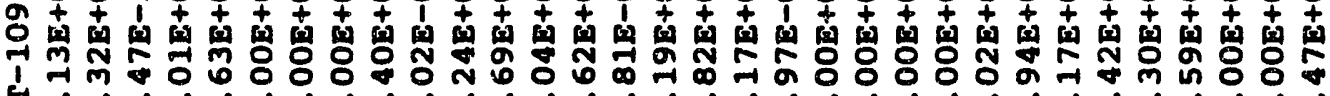
N

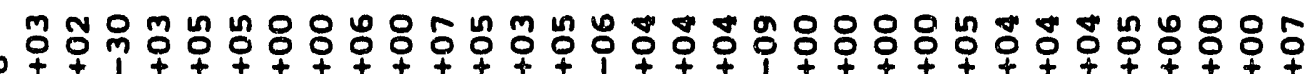

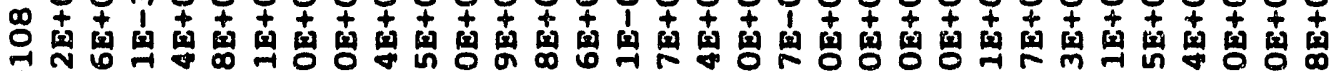
I

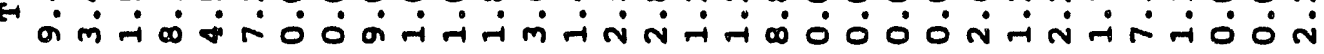

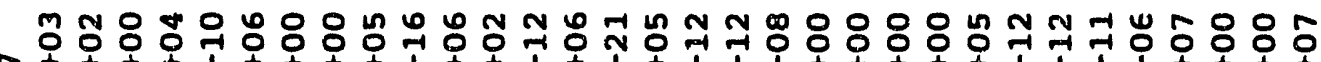

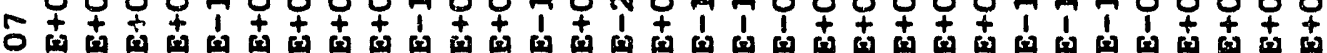

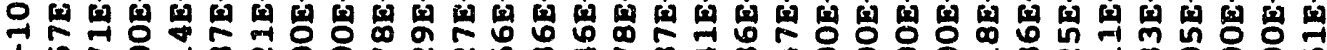
m n

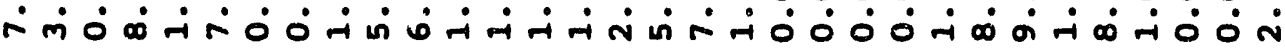

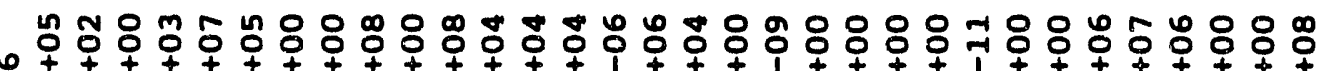

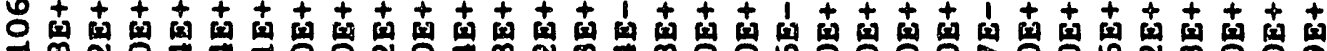
I

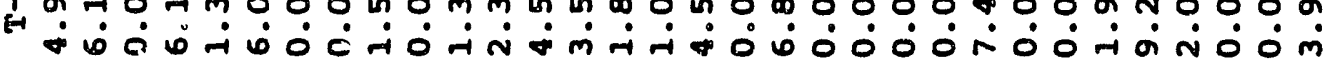

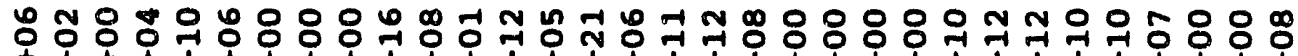

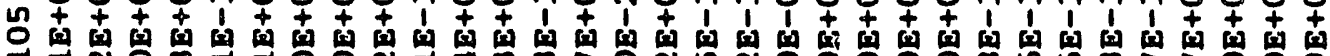

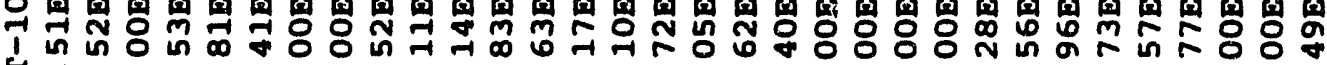

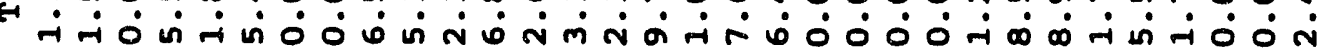




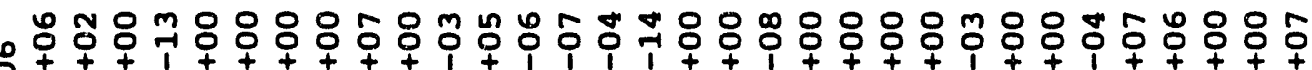

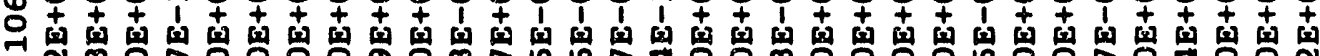
I स

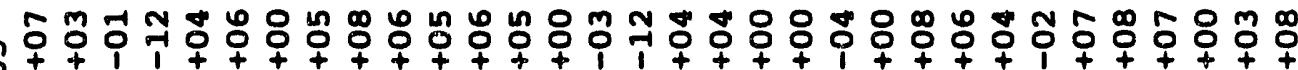

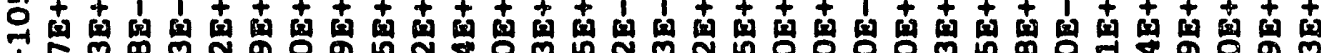
1츄.

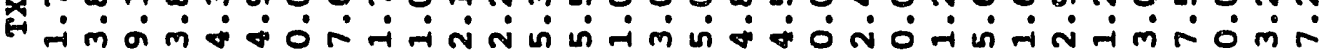

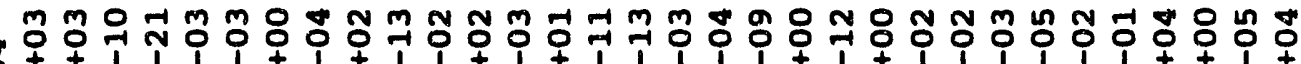

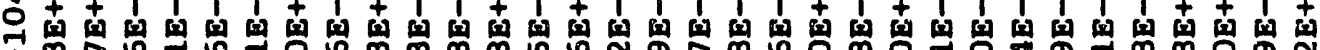

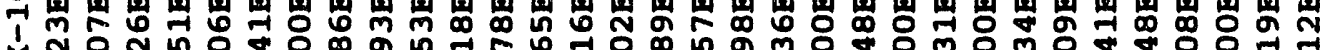
*

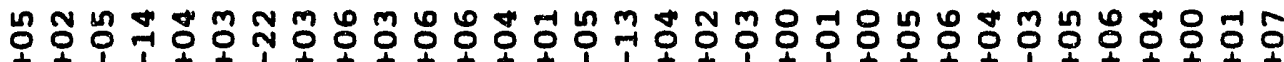
m t $11+t+1+t+t+1$

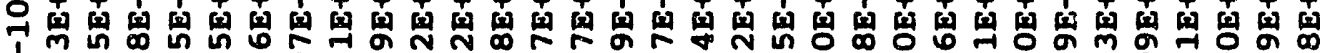
1

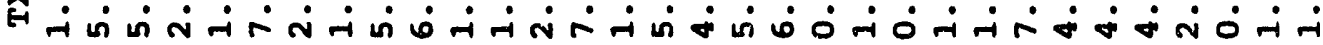

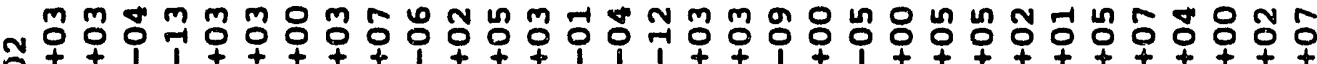

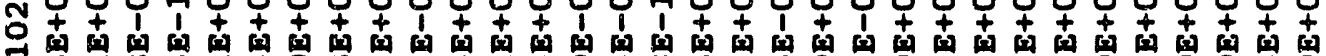

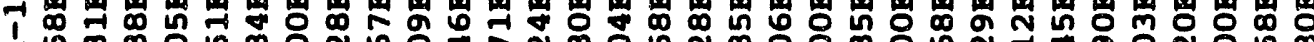
$x$ ๓

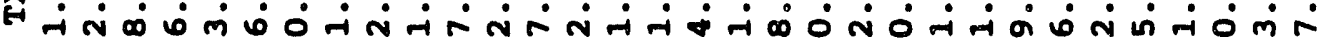

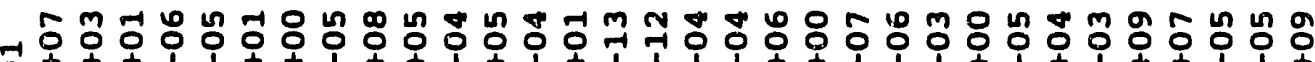

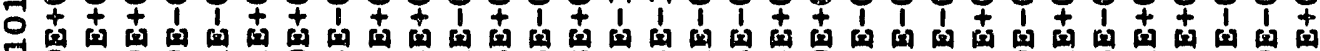

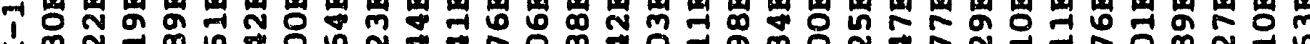
শ. H n

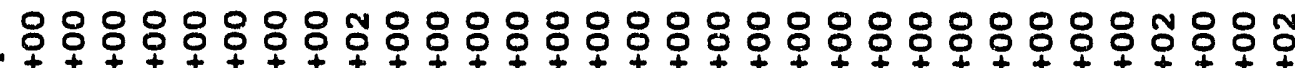

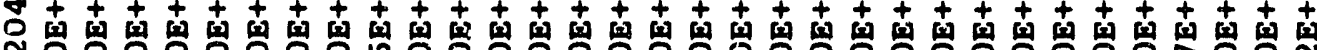

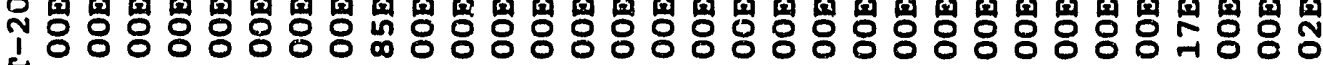

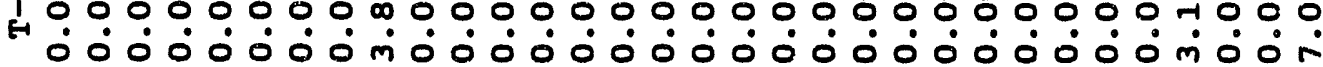

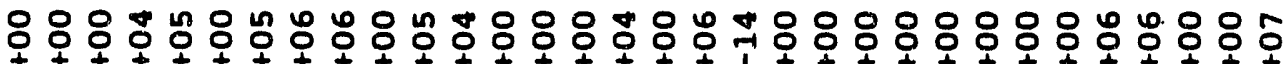

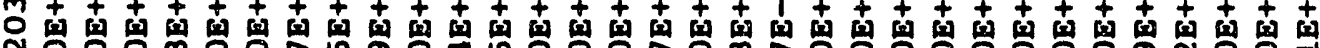

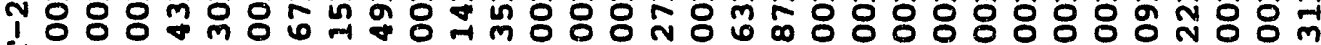

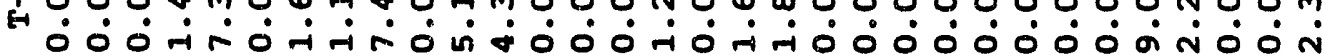

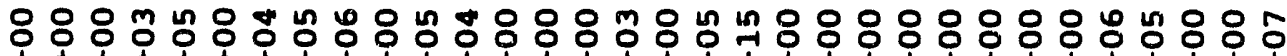

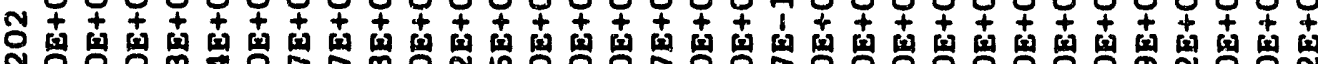

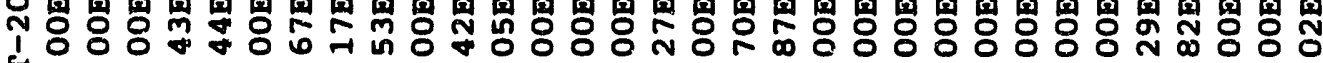

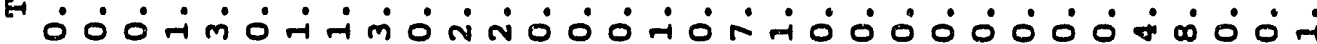




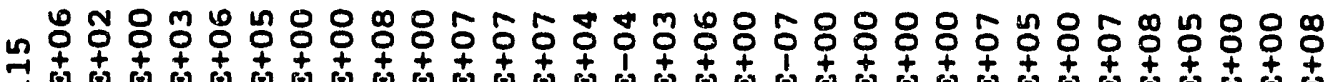

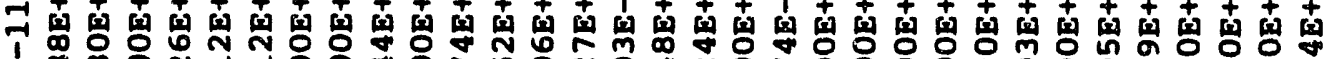

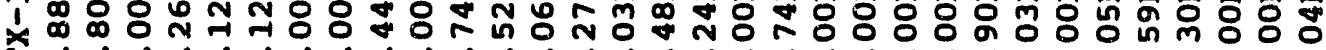

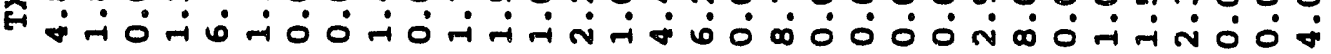

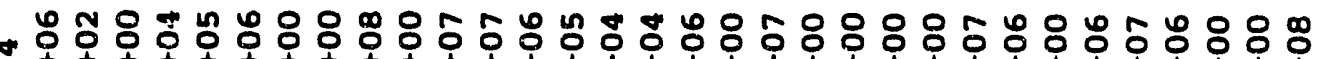

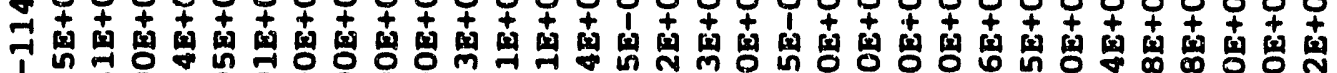

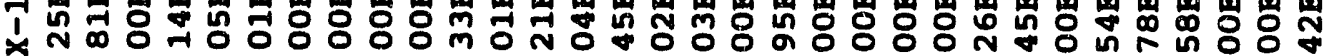

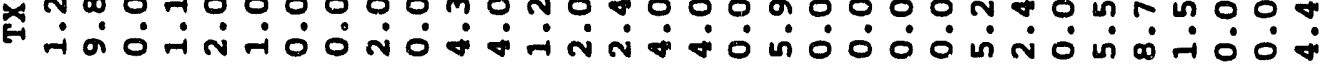

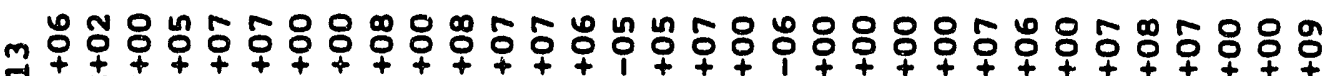

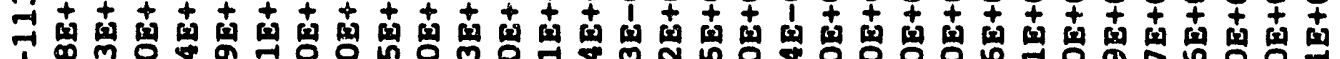

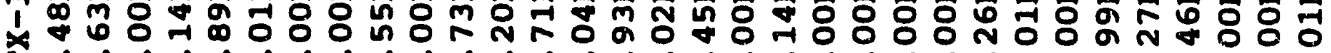

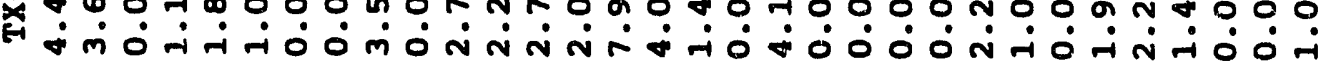

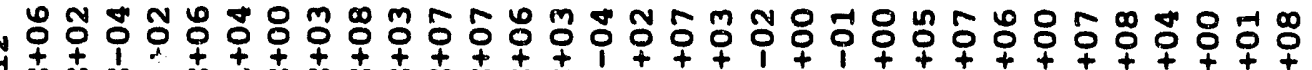

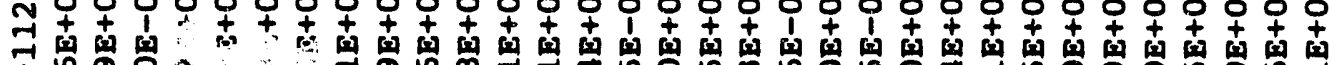

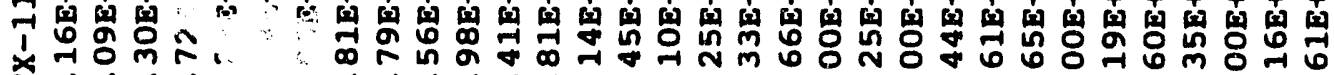

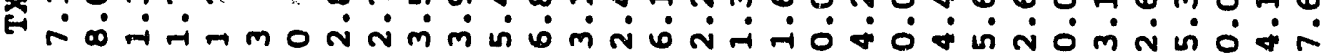

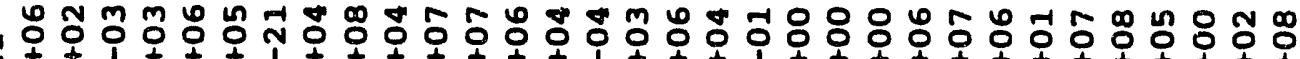

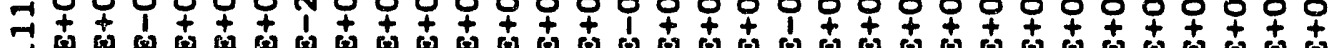

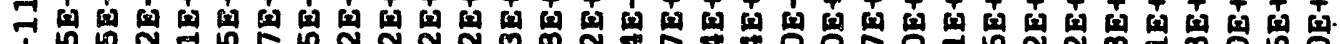

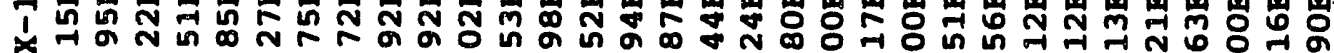

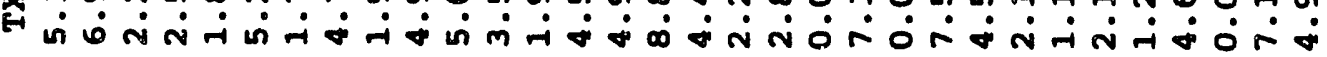

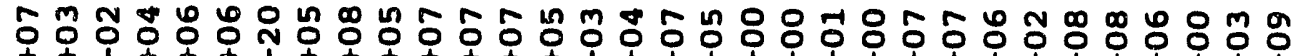

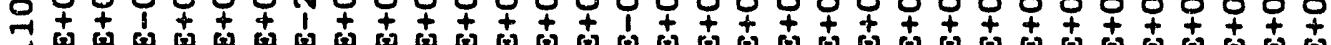

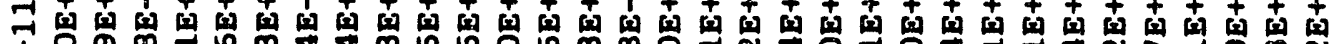
1

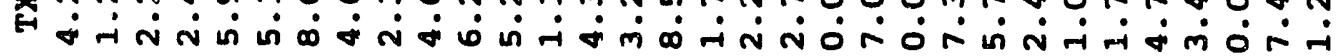

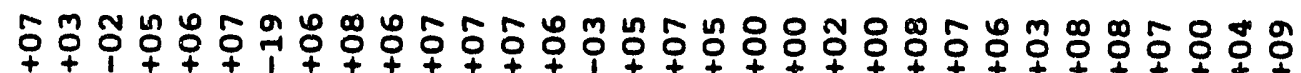

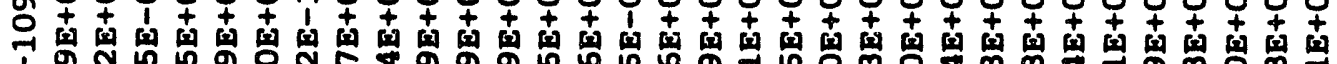
1

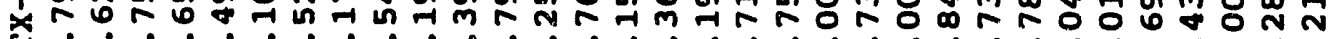

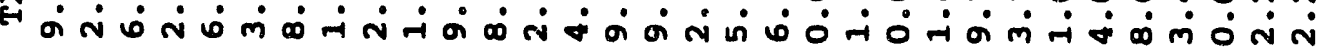

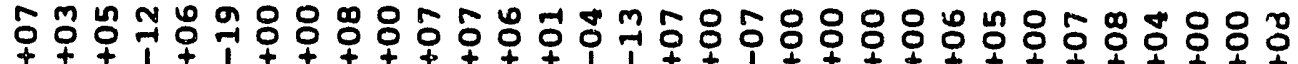

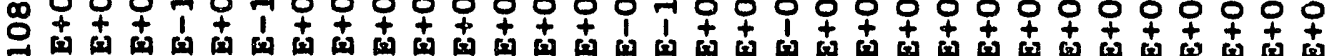

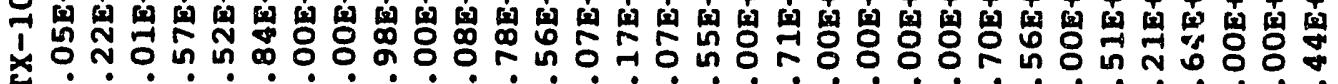

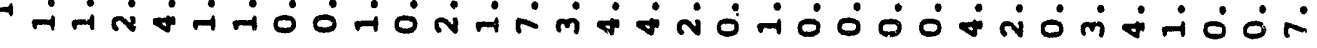

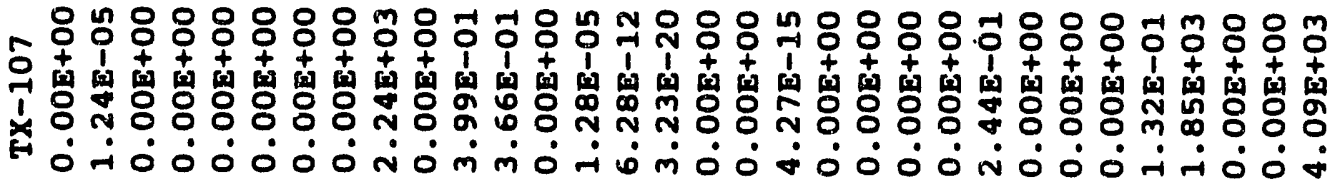




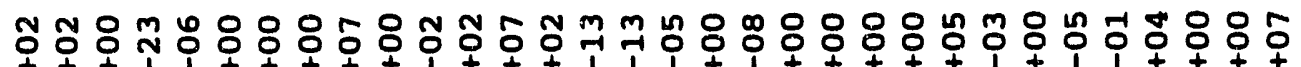

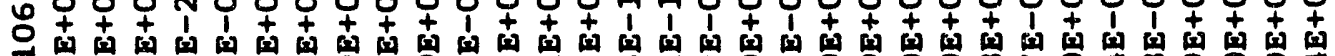

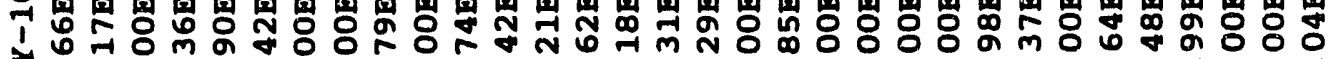

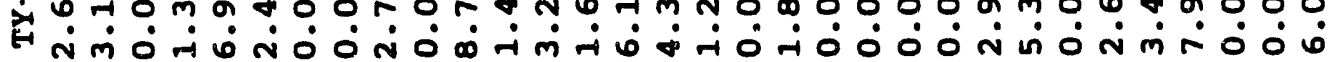

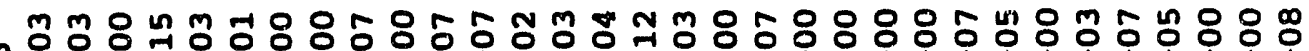

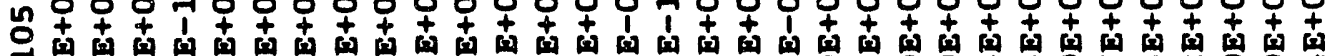

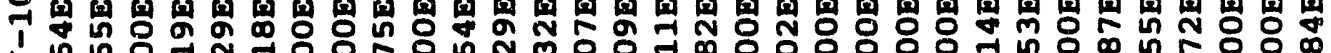

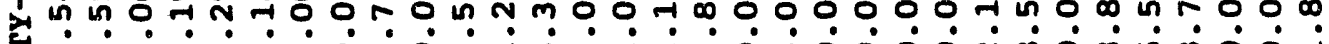

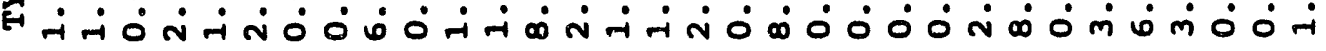

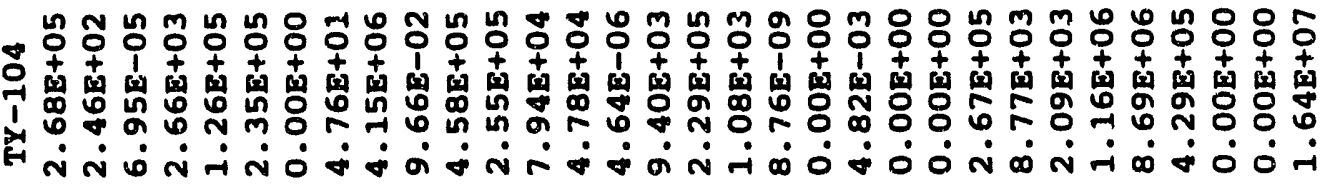

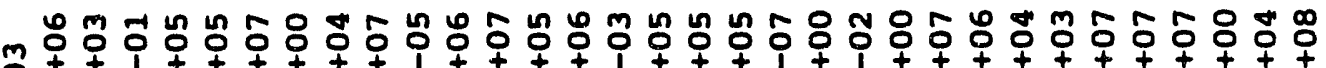

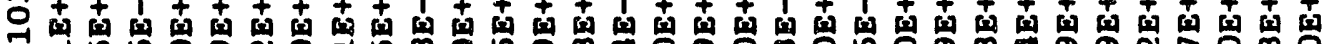
1

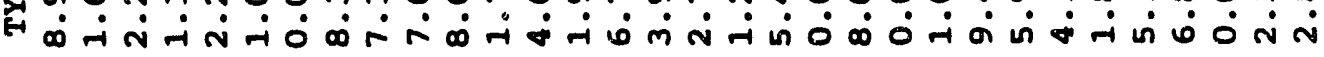

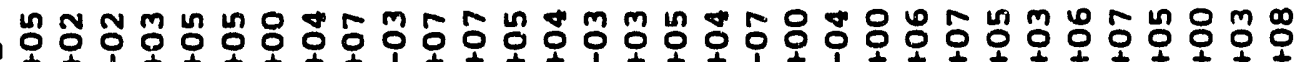

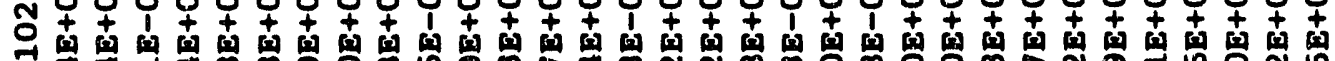

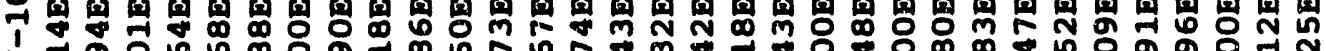

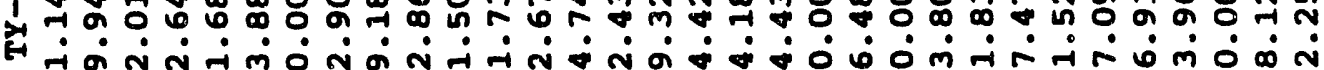

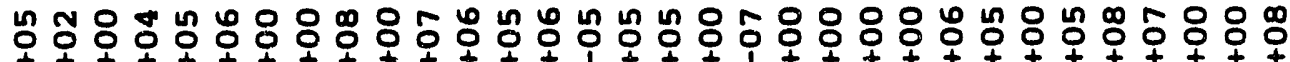

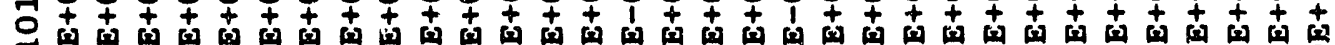
1

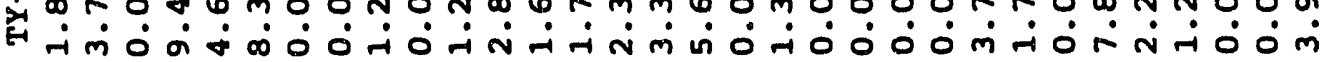

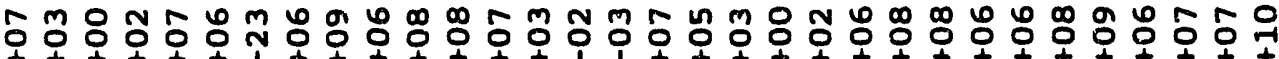

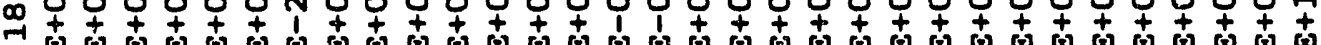

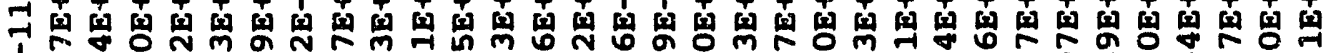

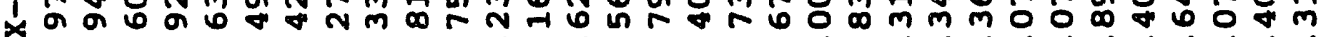
* $\dot{0}$ ó

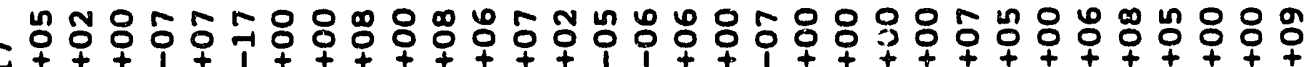

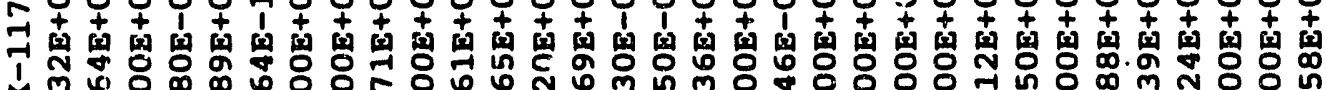

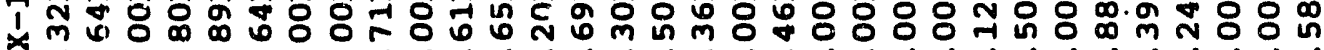

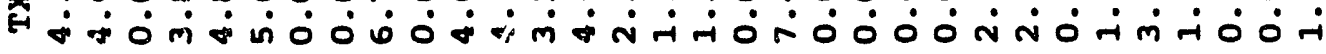

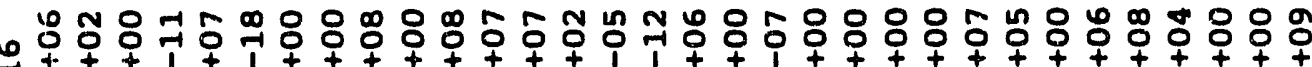

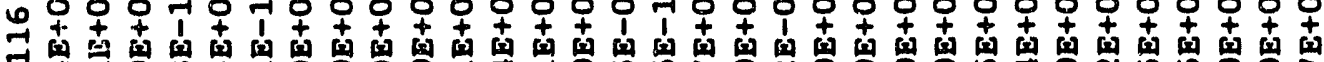
1 * 


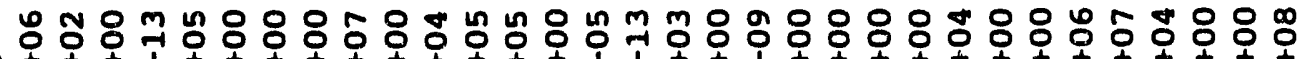

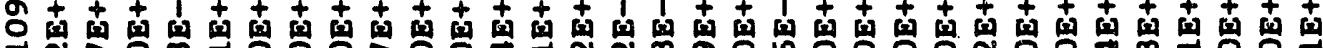

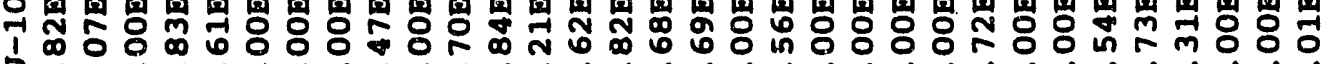

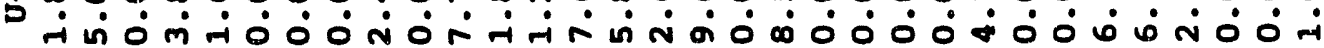

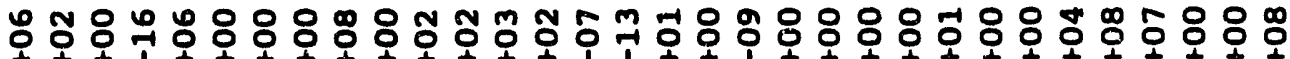

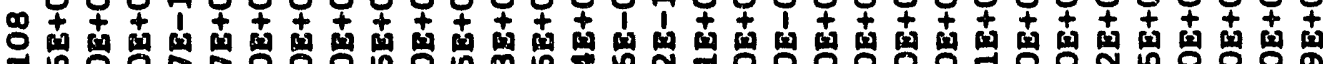

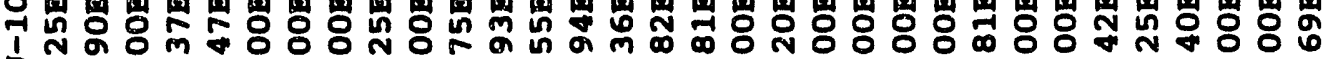
-

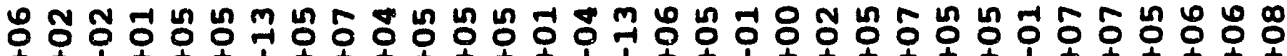

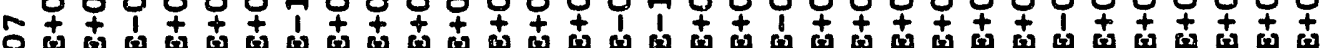

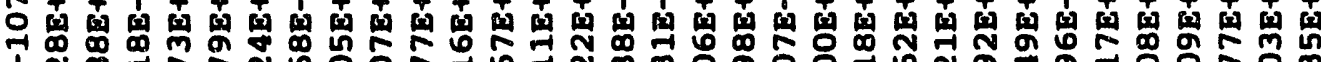

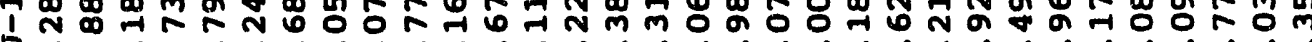

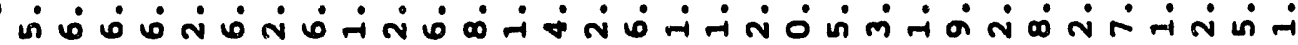

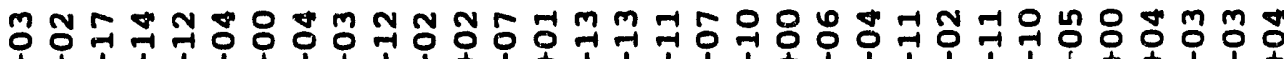

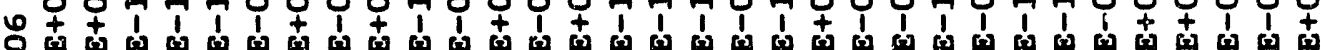

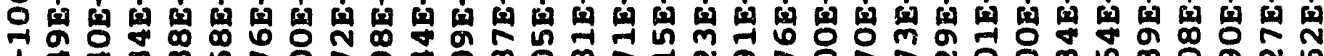
1 \$ m

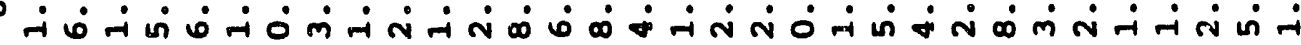

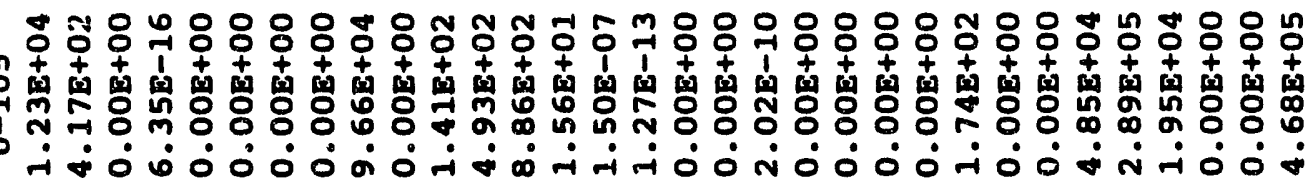

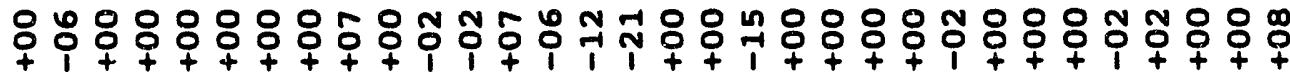

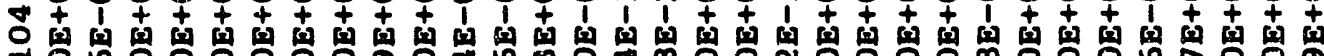

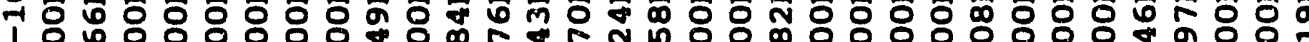
>

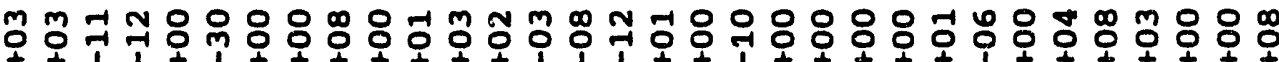

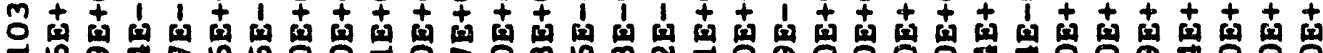

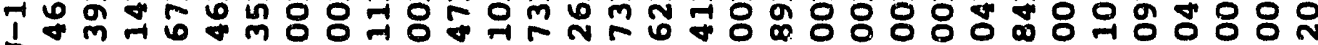

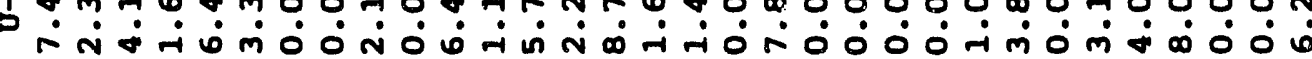

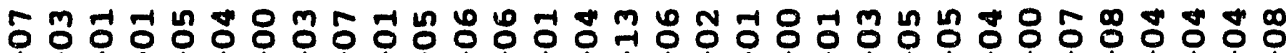
N t

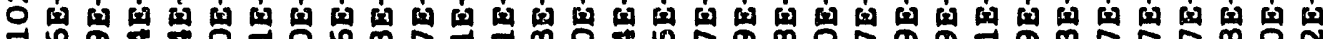

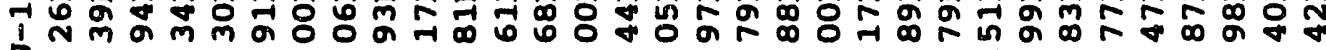

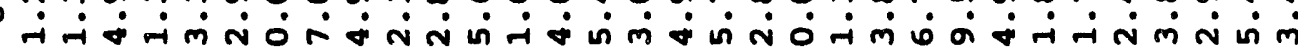

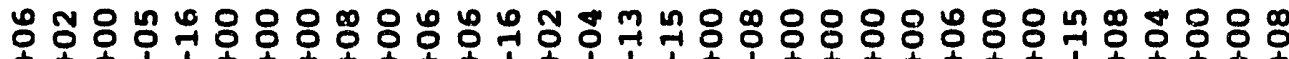

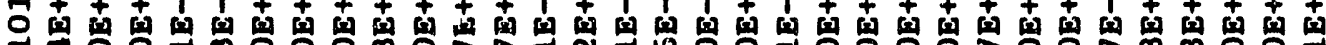
ᄀ

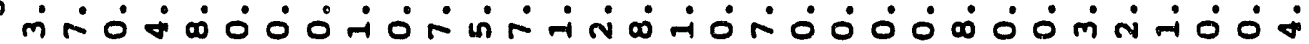




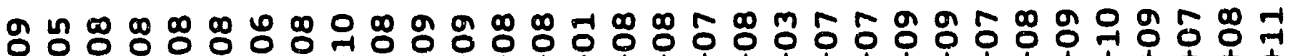

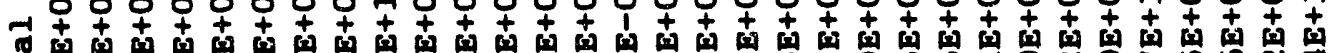

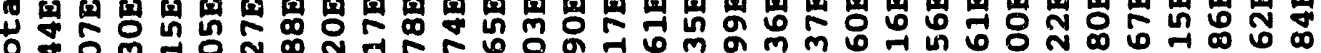

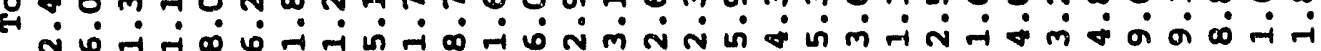

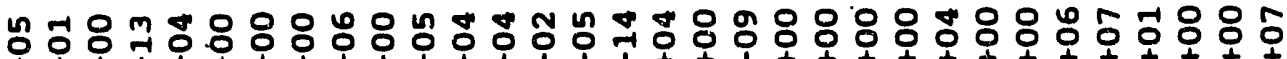

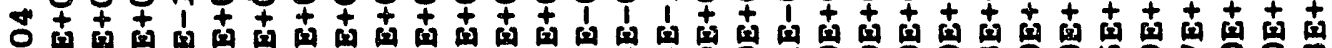

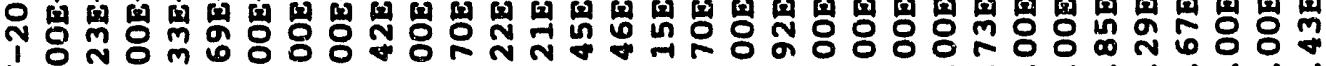

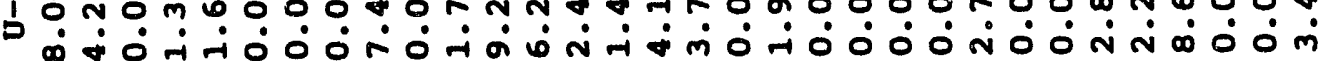

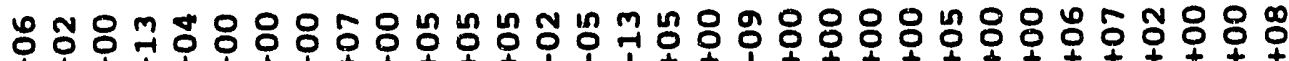

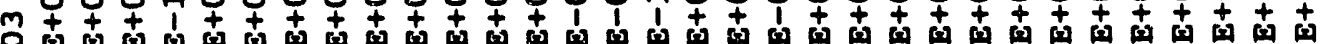

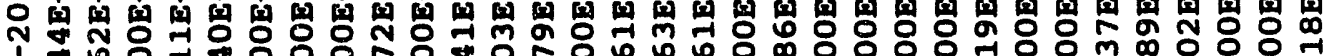
b

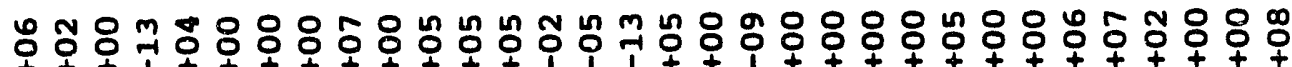

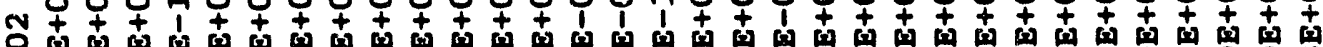

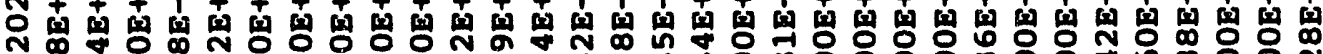
1

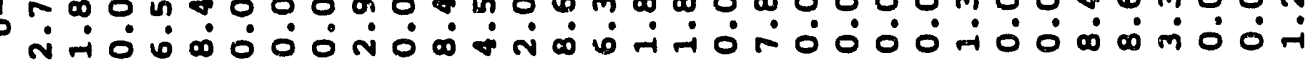

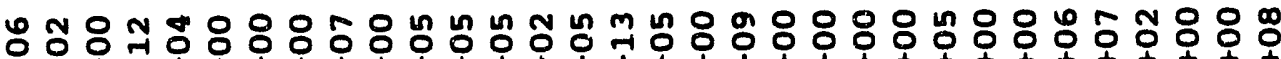

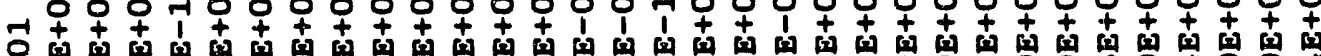

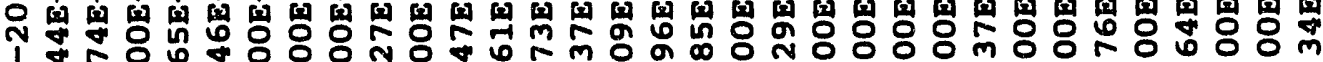

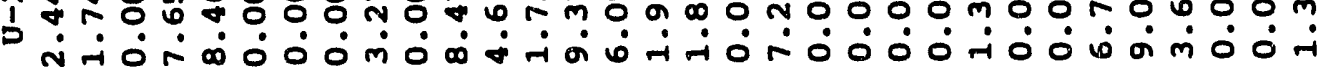

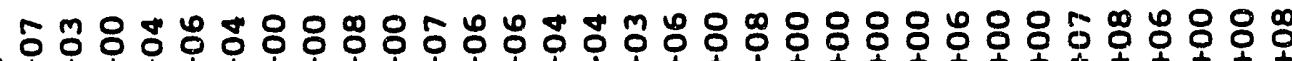

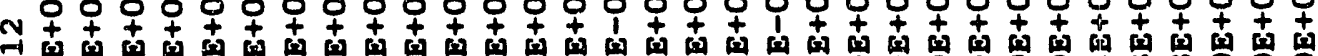

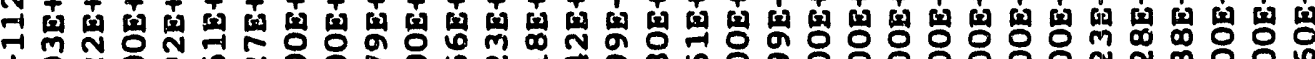
\ 0 N

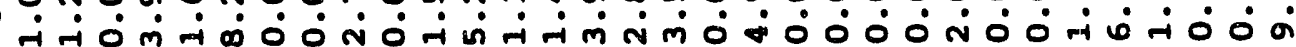

赵 -

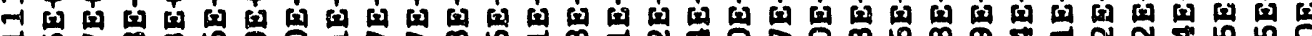

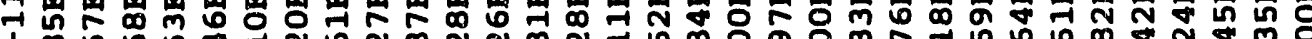

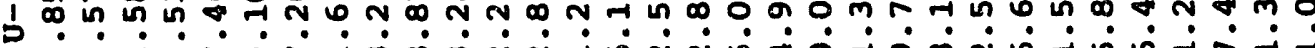

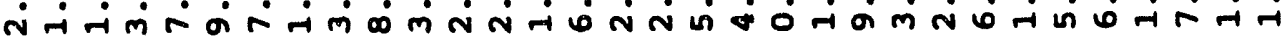

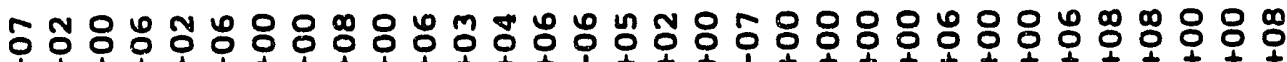

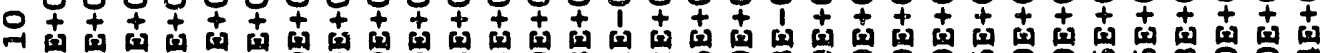

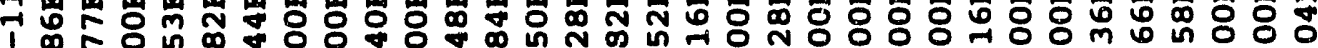
b 


\section{Appendix B}

\section{Case I HWVP Tank Composition Data}




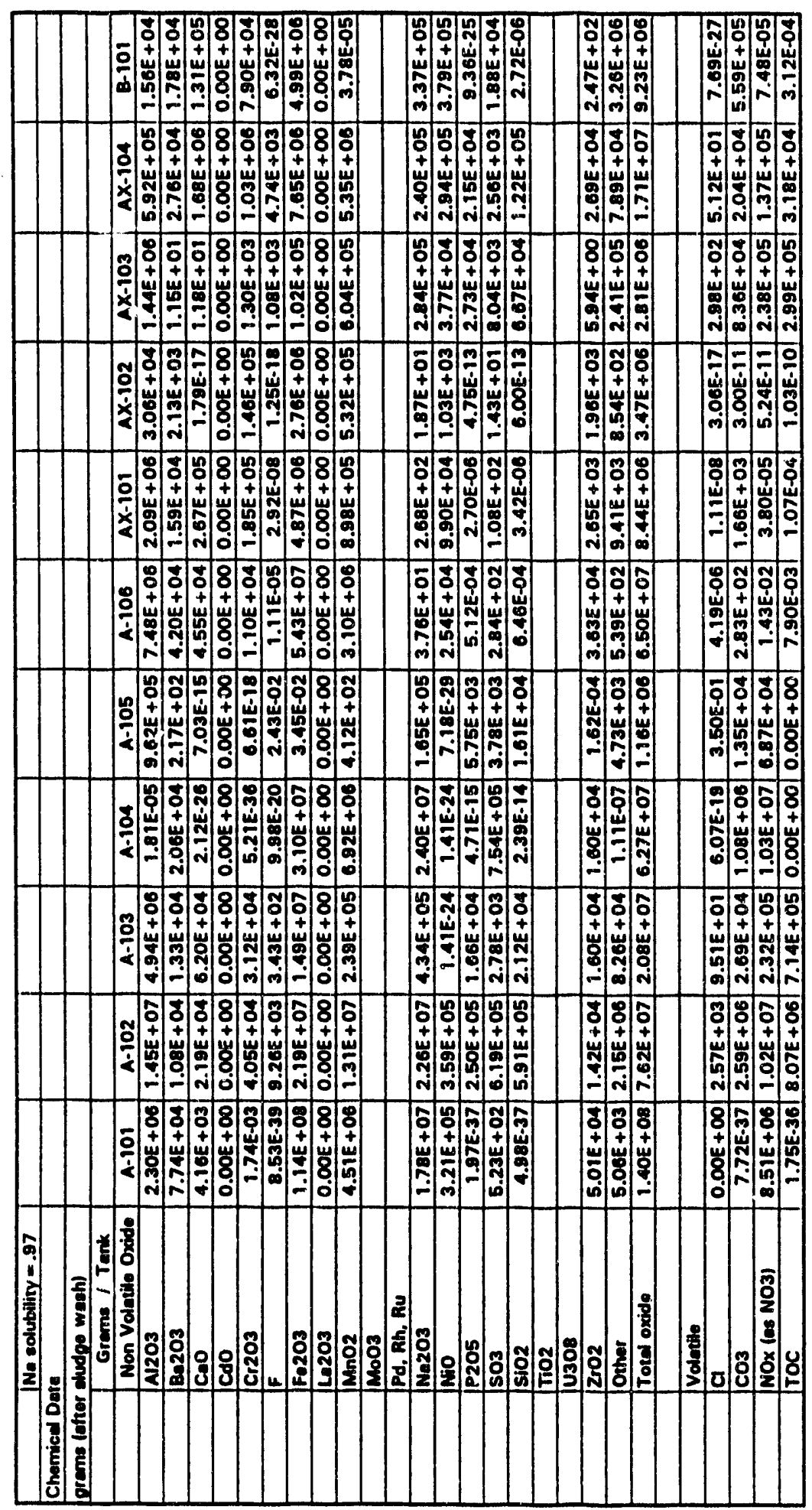

B. 1 


\begin{tabular}{|c|c|c|c|c|c|c|c|c|c|c|c|c|c|c|c|c|}
\hline & (ְ) & $\mid$\begin{tabular}{c|c}
8 & \\
+ \\
+ \\
0 \\
0 \\
0
\end{tabular} & 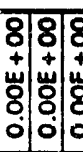 & & 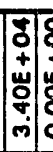 & 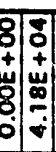 & & 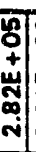 & & $\mid \begin{array}{c}0 \\
0 \\
+ \\
w \\
0 \\
0 \\
0\end{array}$ & \begin{tabular}{|l|}
8 \\
+ \\
\\
\\
0
\end{tabular} & $\left|\begin{array}{l}8 \\
+ \\
+ \\
0 \\
8 \\
0\end{array}\right|$ & 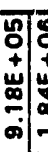 & & $\left|\begin{array}{l}8 \\
+ \\
4 \\
0 \\
8 \\
0\end{array}\right|$ & 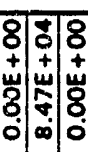 \\
\hline & 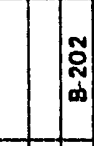 & 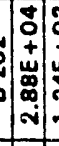 & 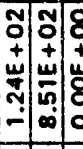 & & 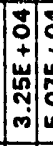 & 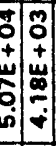 & \begin{tabular}{|c|} 
\\
0 \\
+ \\
$w$ \\
0 \\
0 \\
$\dot{0}$ \\
\end{tabular} & \begin{tabular}{|c|} 
\\
0 \\
+ \\
$\vdots$ \\
\\
0 \\
0
\end{tabular} & & $\mid \begin{array}{c}1 \\
0 \\
+ \\
w \\
\vdots \\
0 \\
0\end{array}$ & 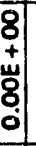 & \begin{tabular}{|l|}
8 \\
+ \\
4 \\
8 \\
0 \\
0
\end{tabular} & 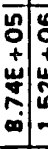 & & 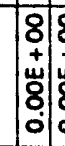 & 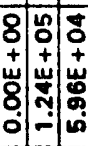 \\
\hline & W & 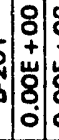 & 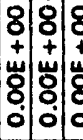 & & $\mid \begin{array}{ll}8 & 1 \\
+ \\
w \\
0 \\
0 \\
0\end{array}$ & & $\begin{array}{c}8 \\
+ \\
\\
\\
0 \\
0\end{array}$ & $\begin{array}{c}- \\
0 \\
+ \\
\\
0 \\
\vdots \\
-\end{array}$ & 8 & $\mid \begin{array}{l}8 \\
+ \\
\\
8 \\
0\end{array}$ & $\begin{array}{l}\mathbf{y} \\
\mathbf{8} \\
0\end{array}$ & $\mid \begin{array}{c}8 \\
+ \\
+ \\
\\
8 \\
0 \\
0\end{array}$ & 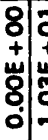 & & 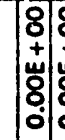 & \begin{tabular}{l|l|l}
8 & 8 & 8 \\
+ & + & + \\
$w$ & 4 & 4 \\
8 & 8 & 8 \\
$\circ$ & 0 & 0
\end{tabular} \\
\hline & $\frac{5}{d}$ & 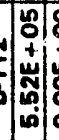 & 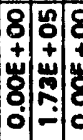 & 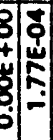 & 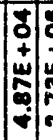 & 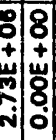 & \begin{tabular}{|c|}
0 \\
0 \\
$\vdots$ \\
$\mu$ \\
0 \\
0 \\
0
\end{tabular} & 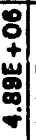 & 5 & \begin{tabular}{|c|c|} 
\\
0 \\
$\vdots$ \\
\hdashline \\
\hdashline \\
\hdashline
\end{tabular} & 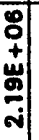 & 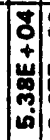 & 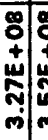 & & 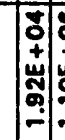 & 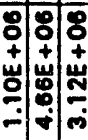 \\
\hline & $\bar{t}$ & $=\left|\begin{array}{c|c}0 \\
0 \\
+ \\
y \\
0 \\
\dot{m}\end{array}\right|$ & 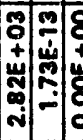 & 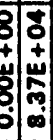 & 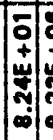 & & \begin{tabular}{|c|} 
\\
+ \\
+ \\
\\
0 \\
0 \\
0
\end{tabular} & & 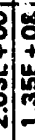 & & $\begin{array}{c}0 \\
0 \\
+ \\
\vdots \\
0 \\
0 \\
0\end{array}$ & 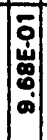 & & & $\left|\begin{array}{c}0 \\
0 \\
+ \\
w \\
w \\
0 \\
\infty \\
\infty\end{array}\right|$ & 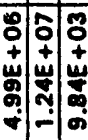 \\
\hline & $\frac{\rho}{\frac{O}{\omega}}$ & 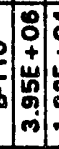 & 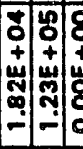 & 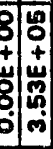 & $\left|\begin{array}{c|c}0 \\
0 \\
0 \\
\dot{b} \\
0 \\
0\end{array}\right|$ & & 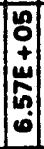 & 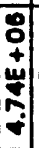 & $\mid \begin{array}{l}0 \\
0 \\
0 \\
0 \\
0\end{array}$ & & 命 & $\begin{array}{c}0 \\
0 \\
+ \\
4 \\
0 \\
0 \\
0 \\
10\end{array}$ & 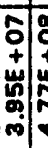 & & \begin{tabular}{l|}
8 \\
+ \\
+ \\
वे \\
0 \\
0
\end{tabular} & 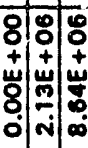 \\
\hline & $\frac{\partial}{\phi}$ & 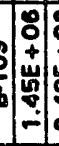 & 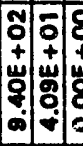 & 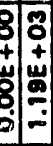 & 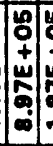 & & 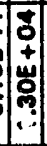 & 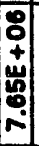 & 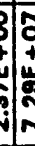 & $\mid \begin{array}{l}0 \\
0 \\
+ \\
0 \\
0 \\
\infty \\
\end{array}$ & \begin{tabular}{l|}
0 \\
$\vdots$ \\
$\vdots$ \\
0 \\
0 \\
-
\end{tabular} & 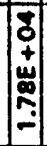 & 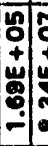 & & \begin{tabular}{c|c}
0 & \\
$\vdots$ \\
+ \\
$m$ \\
0 \\
0
\end{tabular} & 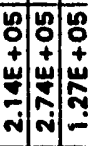 \\
\hline & $\frac{0}{\omega}$ & 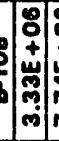 & 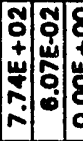 & 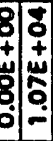 & $\mid$\begin{tabular}{ll}
8 \\
$\vdots$ \\
\hdashline \\
\hdashline
\end{tabular} & & \begin{tabular}{|c|}
0 \\
+ \\
+ \\
0 \\
0 \\
$\vdots$ \\
\end{tabular} & 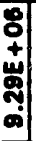 & 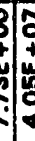 & & \begin{tabular}{l|} 
\\
$\vdots$ \\
+ \\
\\
\\
0 \\
0
\end{tabular} & 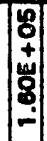 & \begin{tabular}{|c|c} 
& 0 \\
$\vdots$ & 0 \\
4 \\
0 \\
0 \\
$ن$ \\
$ن$
\end{tabular} & & 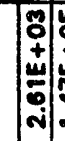 & 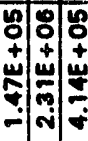 \\
\hline & $\frac{8}{\infty}$ & $\left|\begin{array}{c}0 \\
0 \\
+ \\
4 \\
0 \\
0 \\
\infty \\
0\end{array}\right|$ & 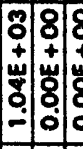 & 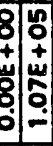 & $\mid \begin{array}{c}|c| \\
0 \\
+ \\
\\
0 \\
0\end{array}$ & & $\begin{array}{l}8 \\
+ \\
4 \\
8 \\
0\end{array}$ & 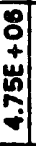 & $\begin{array}{l}n \\
\vdots \\
\vdots \\
\vdots \\
n\end{array}$ & & $\mid \begin{array}{c}0 \\
\\
+ \\
\vdots \\
0 \\
0 \\
0 \\
0\end{array}$ & 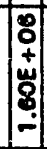 & 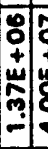 & & 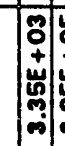 & 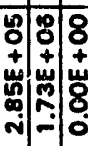 \\
\hline & $\frac{0}{6}$ & : & 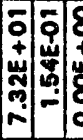 & \begin{tabular}{c|c|}
8 & 0 \\
+ & 0 \\
& + \\
& 4 \\
0 & 0 \\
0
\end{tabular} & $\left|\begin{array}{l}0 \\
0 \\
+ \\
0 \\
0 \\
0\end{array}\right|$ & & 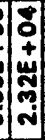 & \begin{tabular}{l|} 
\\
8 \\
+ \\
4 \\
0 \\
0 \\
0
\end{tabular} & 5 & & 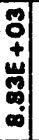 & $\left|\begin{array}{c}0 \\
0 \\
+ \\
w \\
\vdots \\
0 \\
0\end{array}\right|$ & 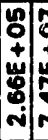 & & 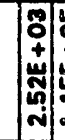 & 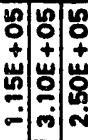 \\
\hline & 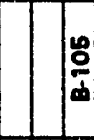 & 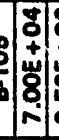 & 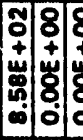 & \begin{tabular}{l|l}
8 & 0 \\
+ & 0 \\
\\
\\
\\
0
\end{tabular} & \begin{tabular}{|c|c} 
\\
0 \\
$\vdots$ \\
$\vdots$ \\
0 \\
0
\end{tabular} & & \begin{tabular}{|l}
8 \\
+ \\
4 \\
8 \\
0 \\
0
\end{tabular} & 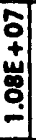 & $\begin{array}{l}3 \\
4 \\
5\end{array}$ & & $\mid$ & $\left|\begin{array}{c}0 \\
\vdots \\
+ \\
\vdots \\
0 \\
\vdots \\
\vdots\end{array}\right|$ & 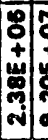 & & 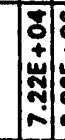 & 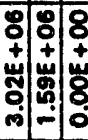 \\
\hline & 中 & 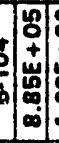 & 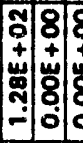 & \begin{tabular}{c|c}
8 & 0 \\
+ & 0 \\
& + \\
& 0 \\
0 & 0 \\
\end{tabular} & $\mid \begin{array}{l}0 \\
0 \\
\vdots \\
0 \\
0 \\
0\end{array}$ & & $\begin{array}{l}8 \\
+ \\
4 \\
8 \\
0 \\
0\end{array}$ & $\begin{array}{l} \\
\\
+ \\
4 \\
0 \\
0 \\
\infty\end{array}$ & 5 & & 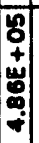 & 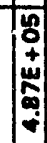 & 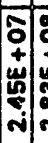 & & 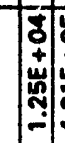 & 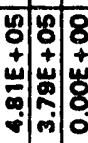 \\
\hline & & 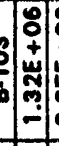 & 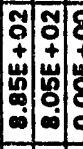 & 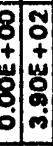 & $\mid \begin{array}{l}0 \\
0 \\
\vdots \\
0 \\
0 \\
-1\end{array}$ & & & $\begin{array}{l}0 \\
0 \\
+ \\
4 \\
0 \\
0 \\
0\end{array}$ & & $\mid \begin{array}{l}0 \\
0 \\
0\end{array}$ & $\left.\mid \begin{array}{l}\dot{\omega} \\
\vdots \\
0 \\
0\end{array}\right]$ & 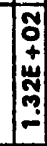 & 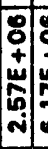 & & 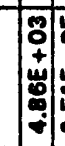 & 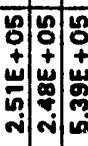 \\
\hline & $1^{\infty}$ & 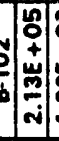 & 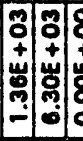 & 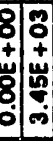 & $\mid \begin{array}{c}0 \\
0 \\
⿱ \\
w \\
0 \\
0\end{array}$ & 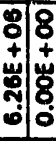 & & 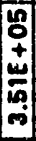 & & & & $\begin{array}{l}\sigma \\
\\
+ \\
\omega \\
0 \\
0 \\
0\end{array}$ & 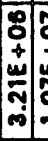 & & 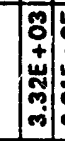 & 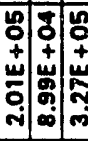 \\
\hline
\end{tabular}

B.2 


\begin{tabular}{|c|c|c|c|c|}
\hline & ( & No: & 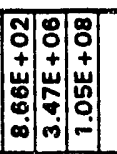 & 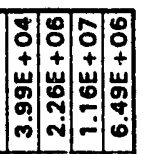 \\
\hline & 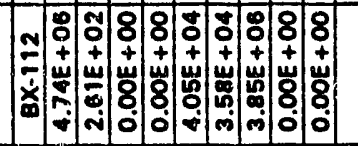 & 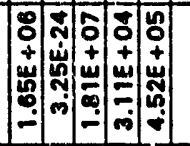 & 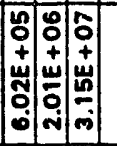 & 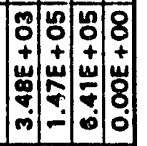 \\
\hline & 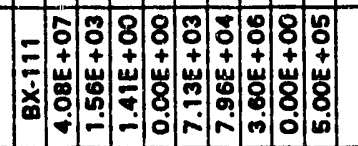 & 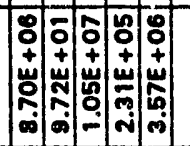 & 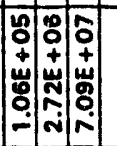 & 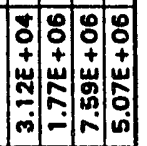 \\
\hline & 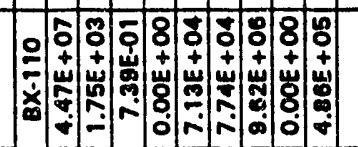 & 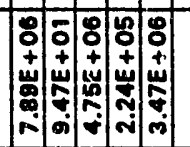 & 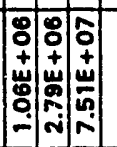 & 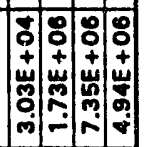 \\
\hline & 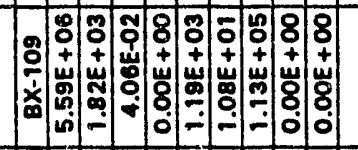 & 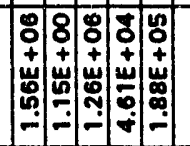 & 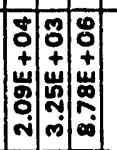 & 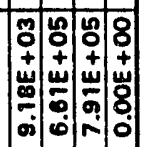 \\
\hline & 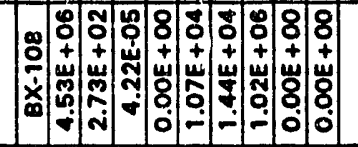 & 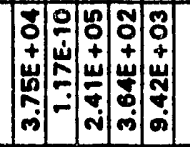 & 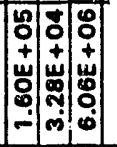 & 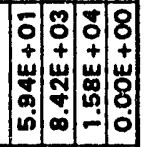 \\
\hline & 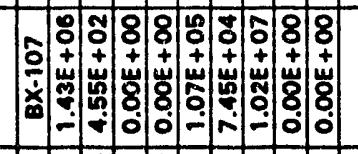 & 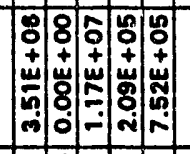 & 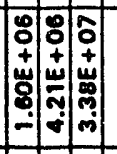 & 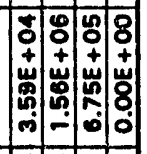 \\
\hline & : & 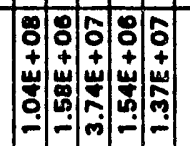 & 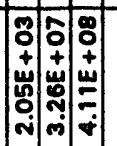 & 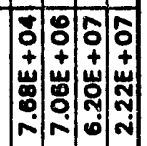 \\
\hline & 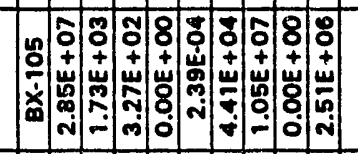 & 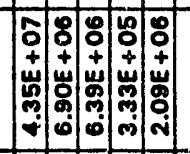 & 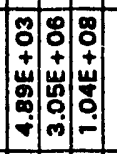 & 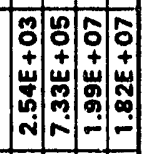 \\
\hline & 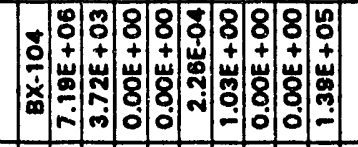 & 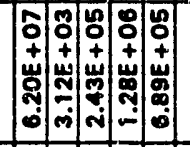 & 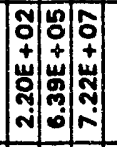 & 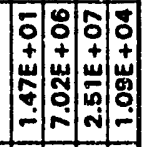 \\
\hline & 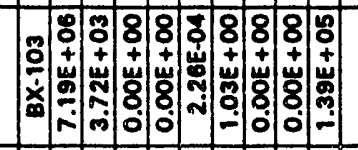 & 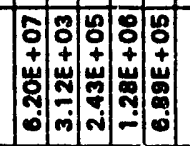 & 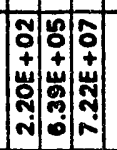 & 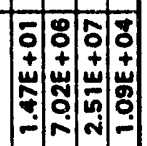 \\
\hline & 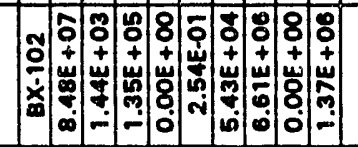 & 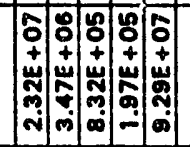 & 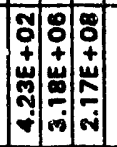 & 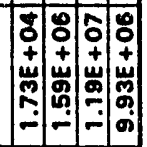 \\
\hline & 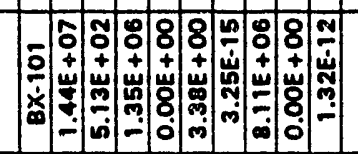 & 列: & 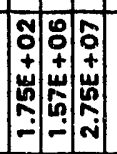 & 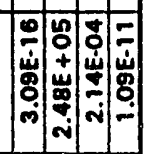 \\
\hline & 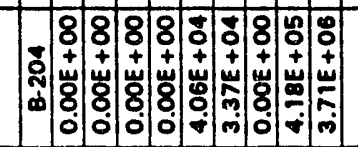 & 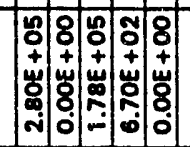 & 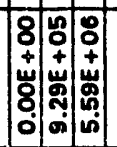 & 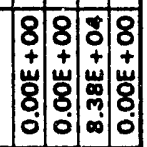 \\
\hline
\end{tabular}

B. 3 


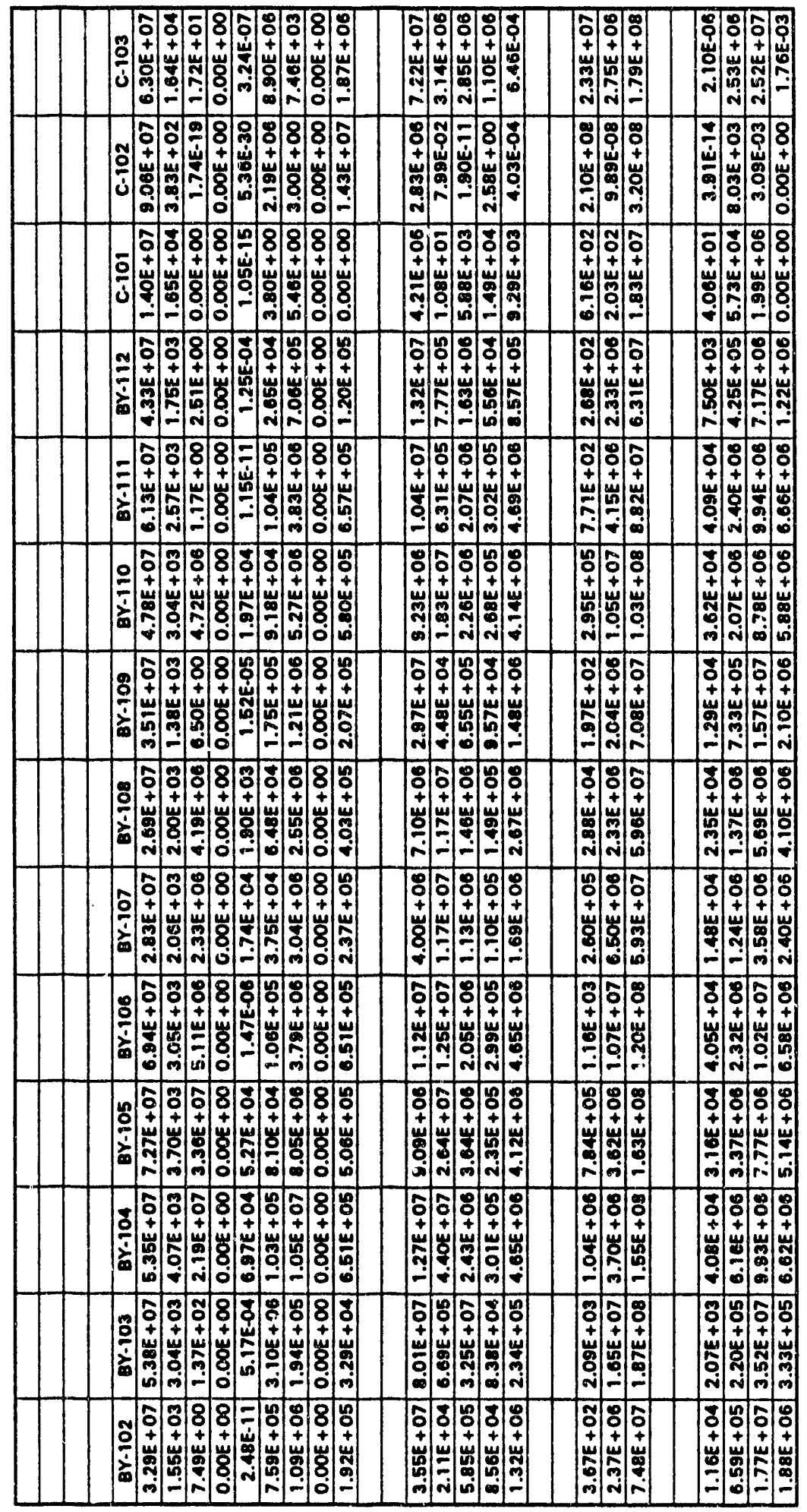

\section{B.4}




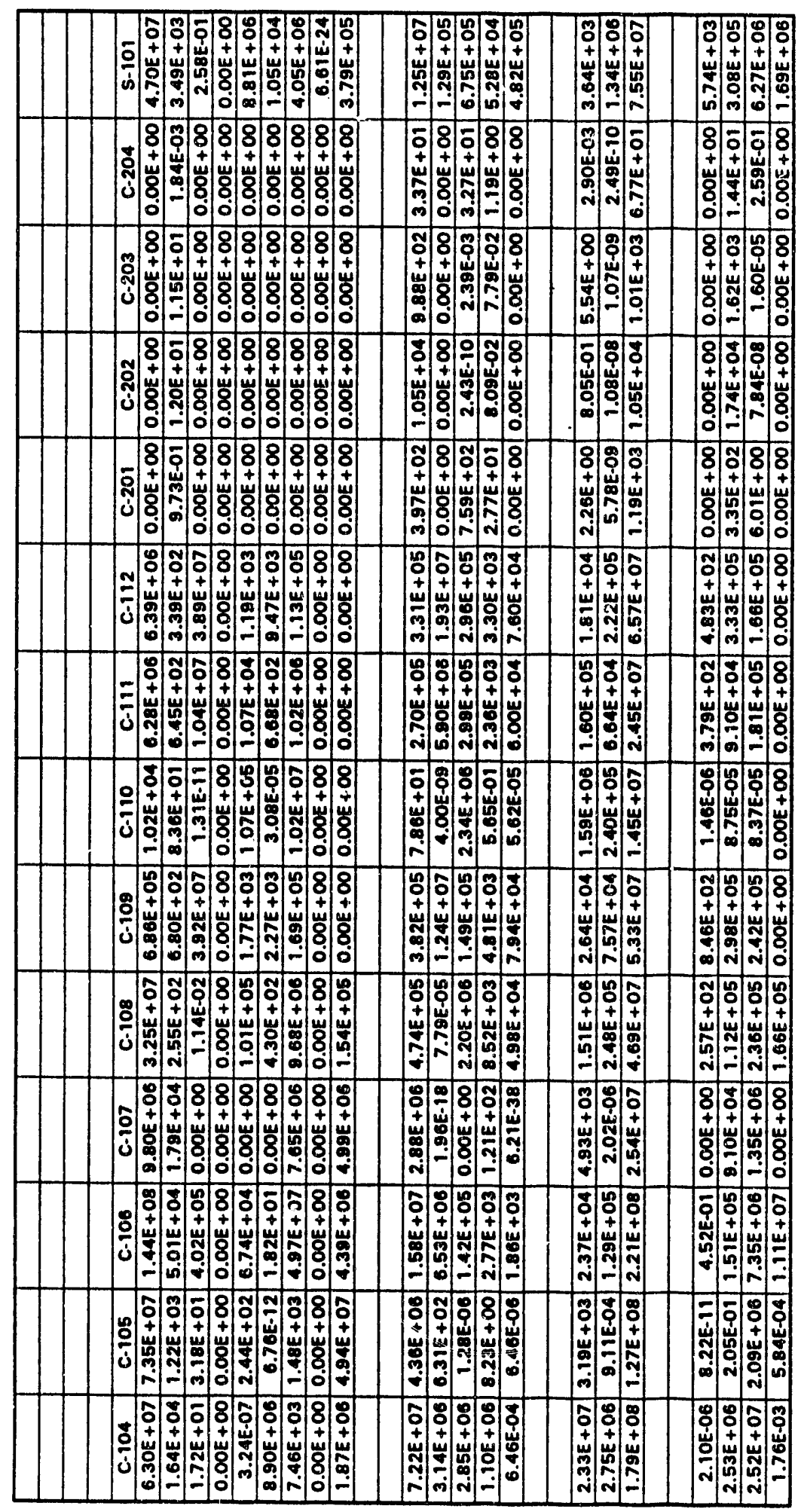

B. 5 


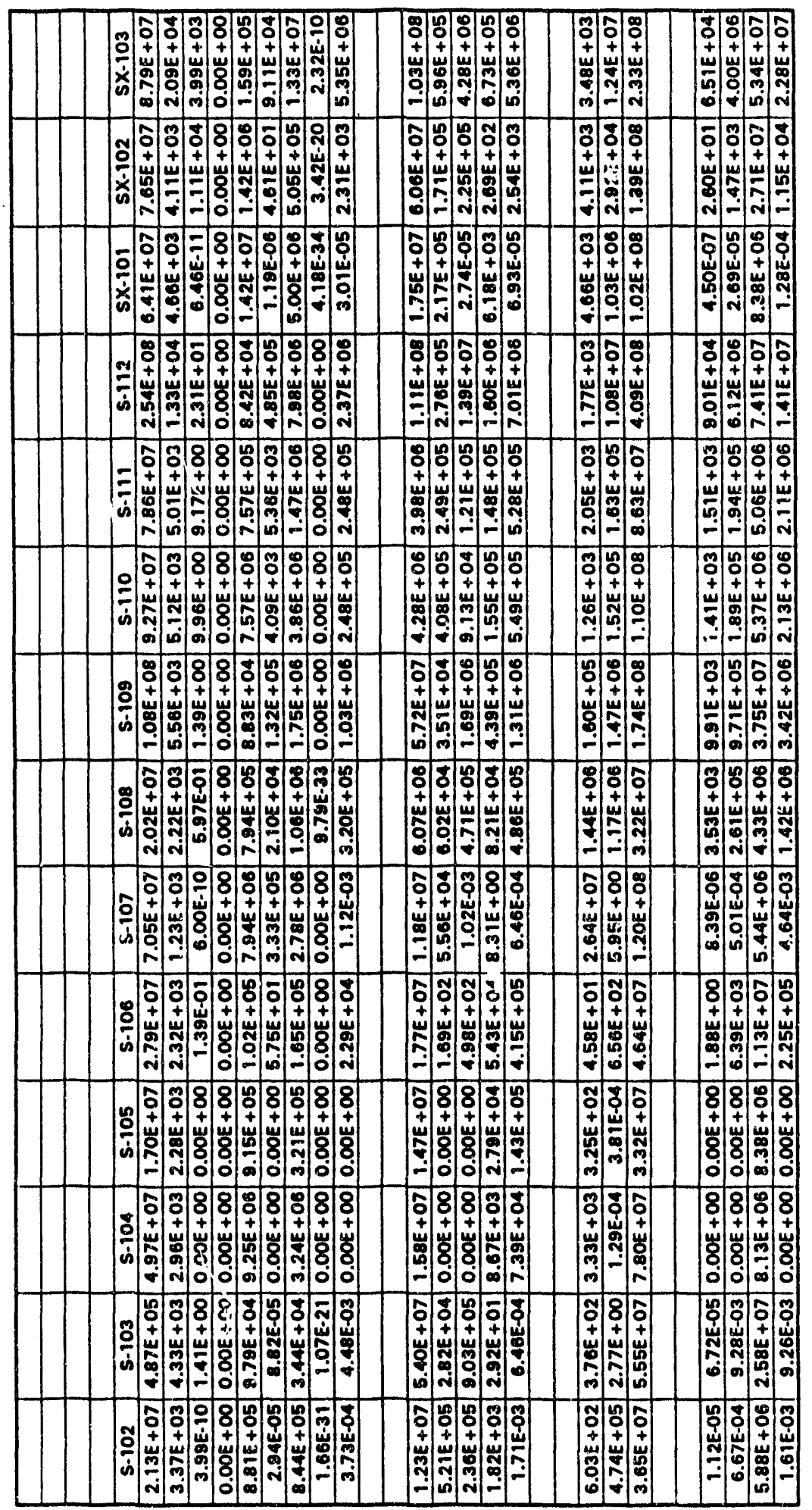

B. 6 


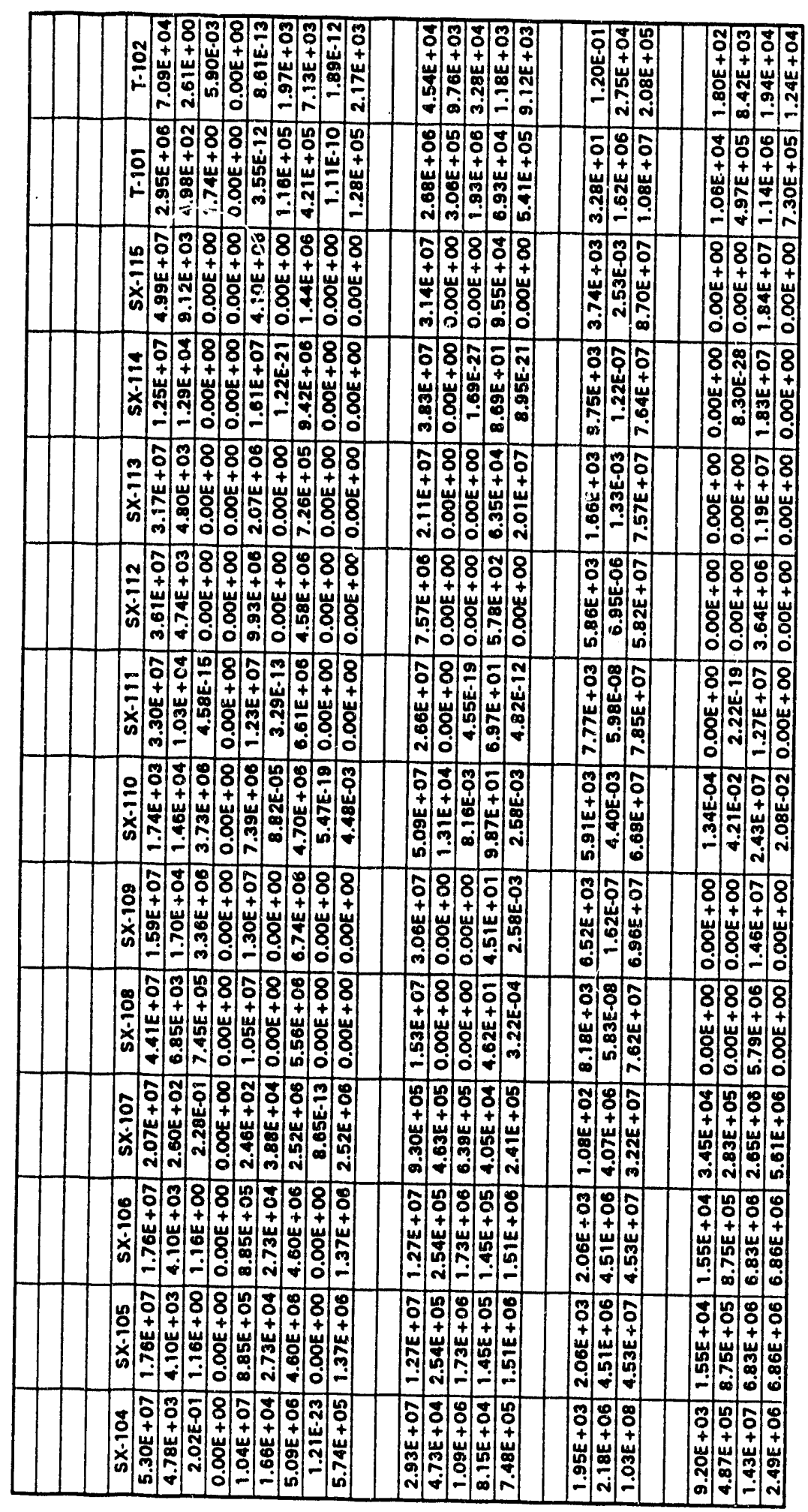

B. 7 


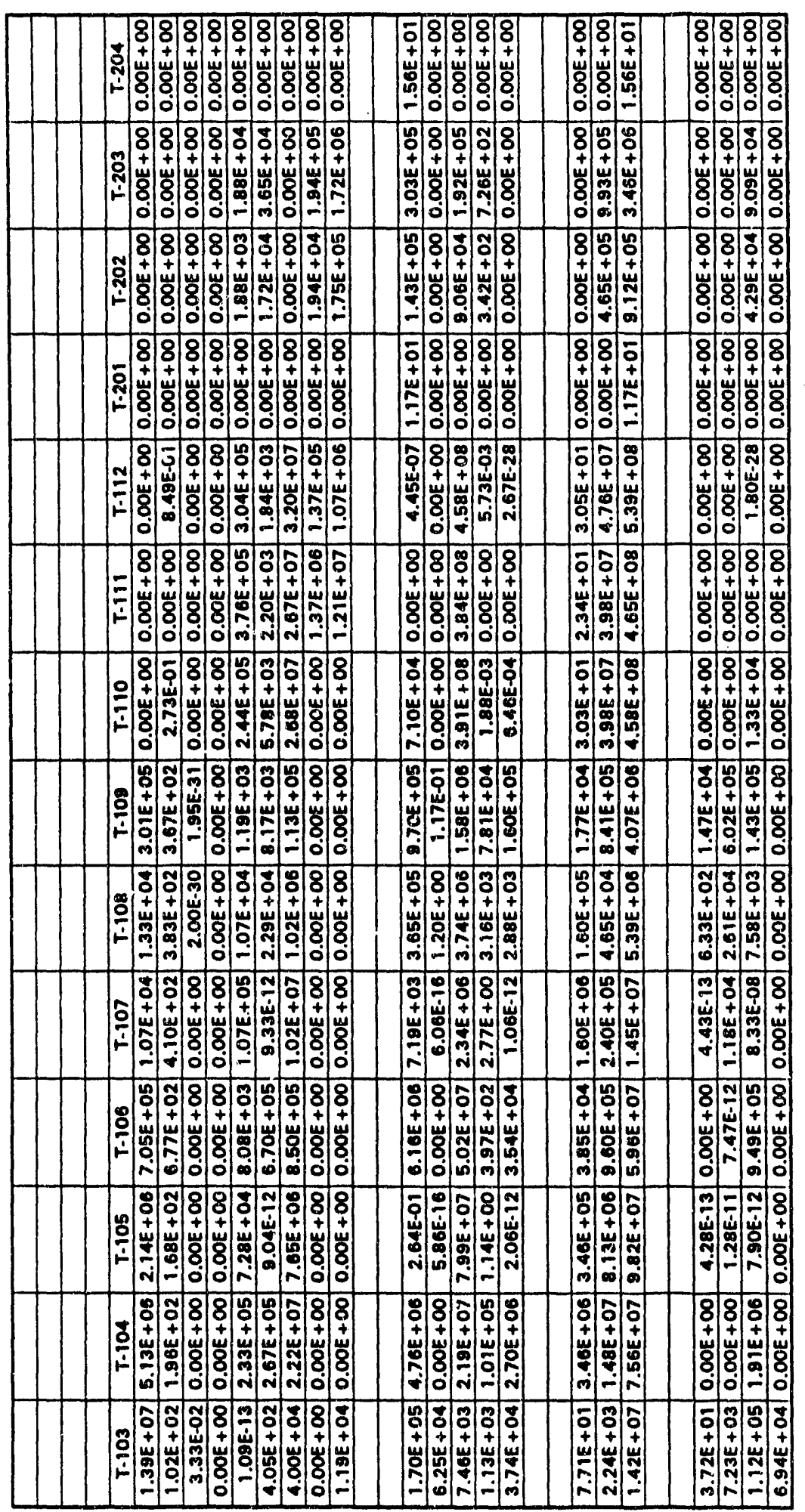

B. 8 


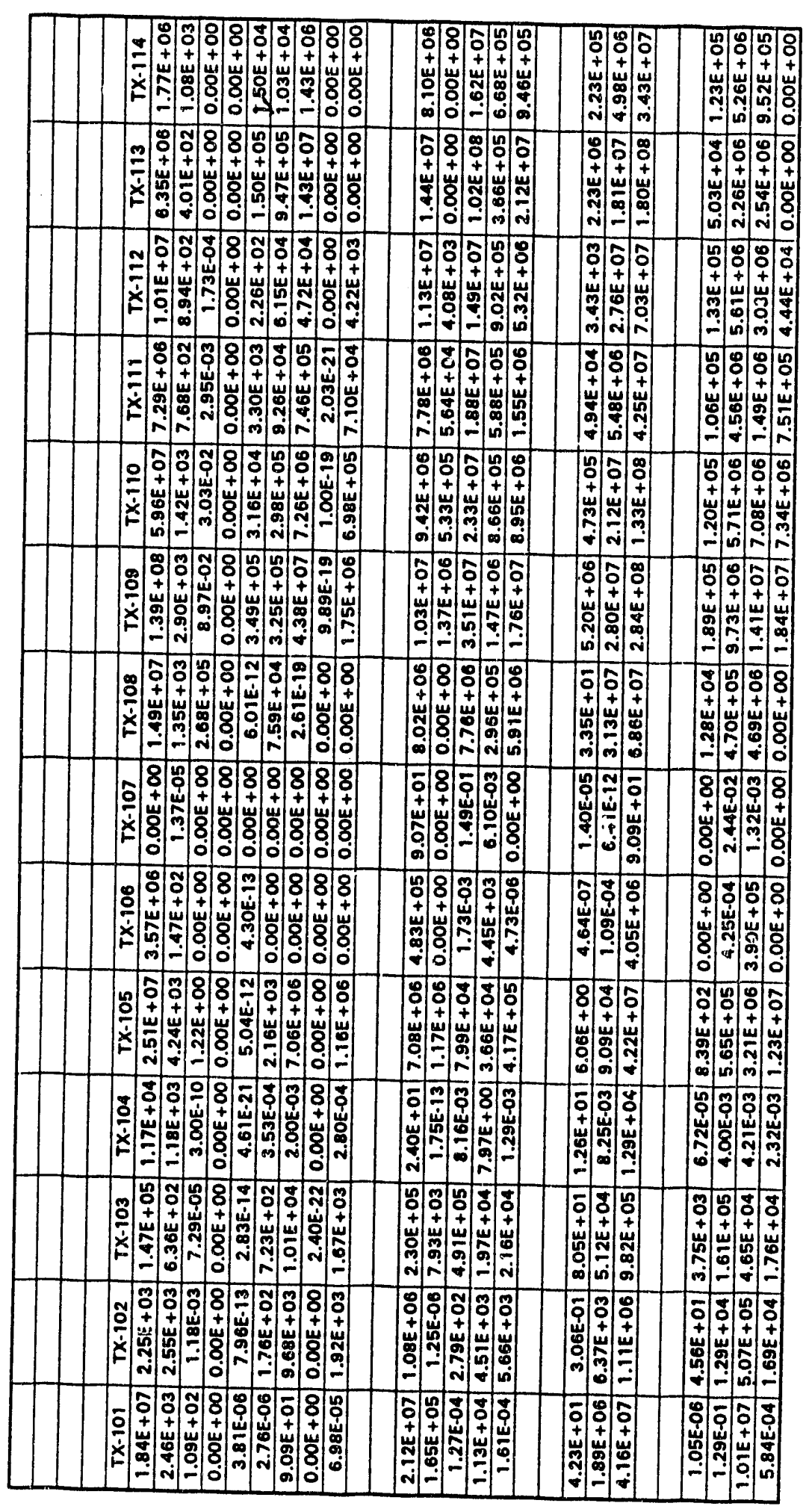

B. 9 


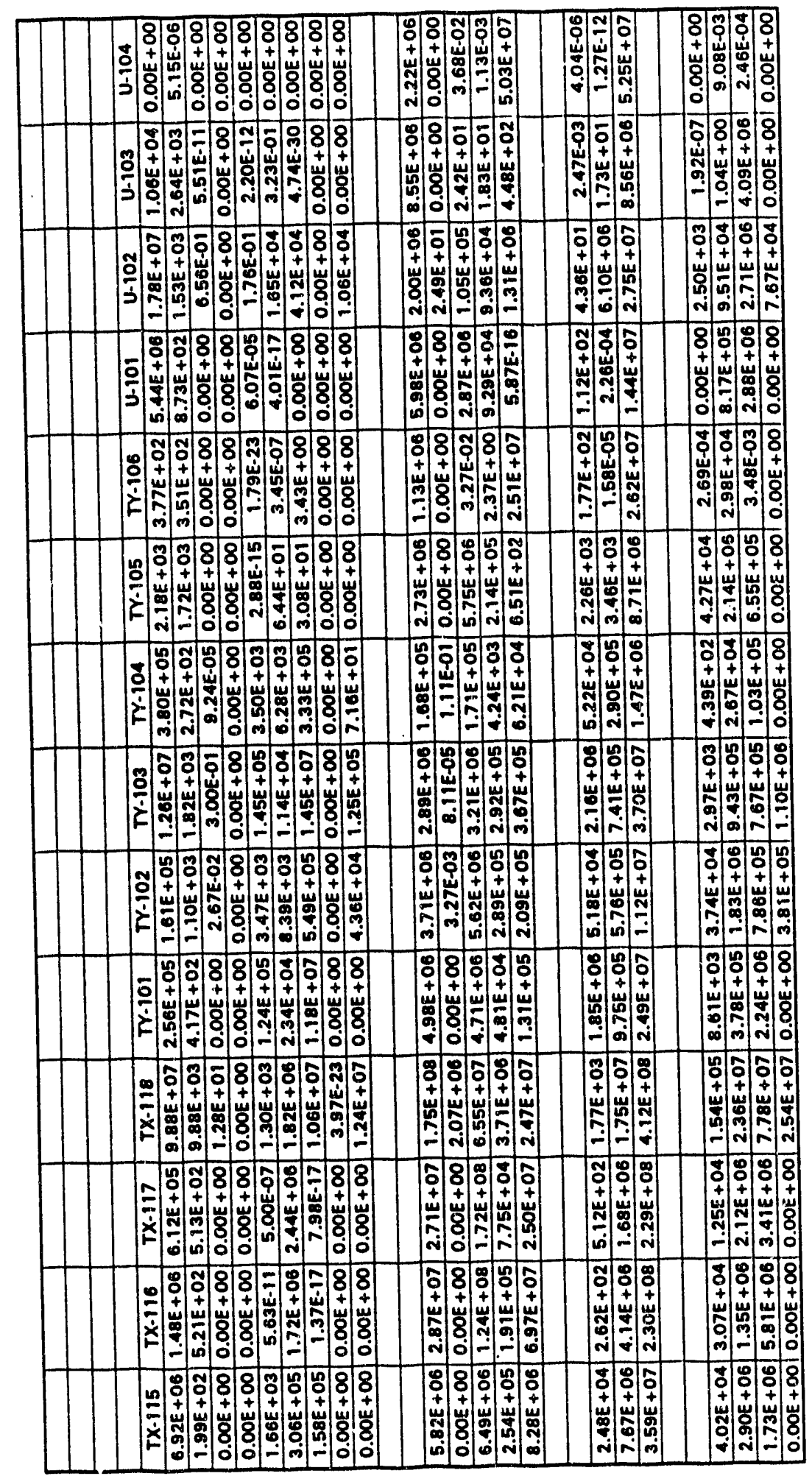

B. 10 


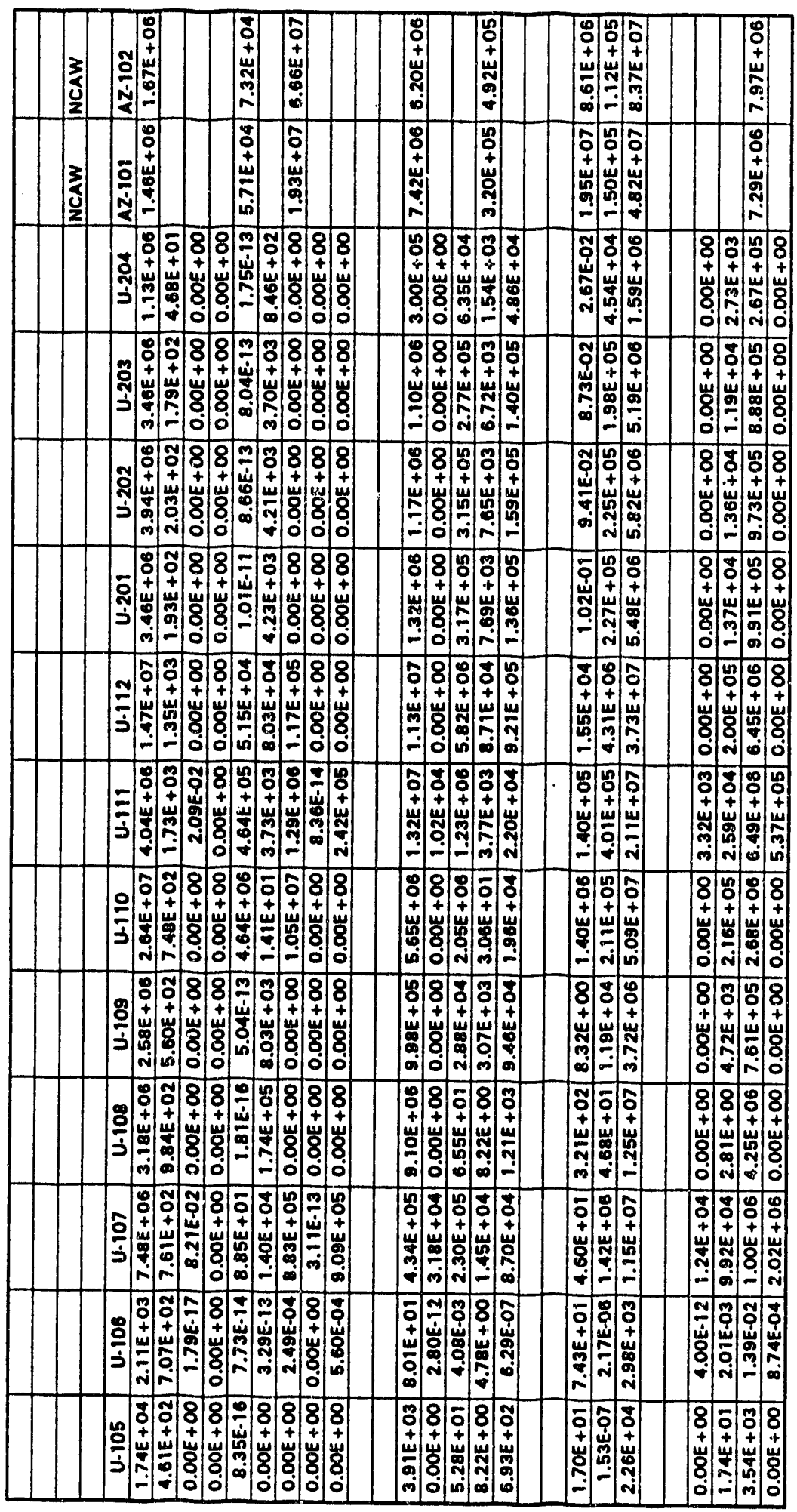

B. 11 


\begin{tabular}{|c|c|c|c|c|c|}
\hline C.20 & 0.8 & D-10 & $D \cdot 12$ & B-68 & \\
\hline PFP & CC East & CC West & CC West & NCRW & \\
\hline & & SY-101 & SY.103 & & Totel \\
\hline $1.14 E+08$ & $1.03 E+08$ & $1.10 E+08$ & $1.02 E+08$ & $2.65 E+07$ & $3.92 E+09$ \\
\hline $0.00 E+00$ & $5.79 E+05$ & & $2.20 E+03$ & $5.86 E+05$ & $1.82 E+08$ \\
\hline $1.08 E+07$ & $8.47 \varepsilon+06$ & $1.23 E+08$ & $1.05 E+06$ & $1.96 E+06$ & $1.97 E+08$ \\
\hline $1.54 E+06$ & & & & $0.00 E+00$ & $1.54 E+06$ \\
\hline $3.20 E+07$ & $1.17 E+07$ & $3.40 E+05$ & $2.17 E+07$ & $6.10 E+08$ & $2.23 E+08$ \\
\hline $1.74 E+06$ & $8.63 E+05$ & $3.26 E+05$ & $1.77 E+05$ & $1.11 E+07$ & $5.42 E+07$ \\
\hline $4.78 E+07$ & $3.41 E+07$ & & $7.31 E+08$ & $3.99 E+06$ & $1.07 E+09$ \\
\hline $7.43 E+05$ & $4.63 E+08$ & & $1.56 E+05$ & $2.23 E+06$ & $9.93 E+06$ \\
\hline $1.93 E+07$ & $1.56 E+07$ & & $2.85 E+06$ & $1.59 E+08$ & $2.20 E+08$ \\
\hline $2.12 E+05$ & $6.81 E+08$ & & $7.52 E+05$ & $5.20 E+04$ & $7.83 E+06$ \\
\hline $1.91 E+08$ & & & & $2.33 E+05$ & $2.14 E+06$ \\
\hline $5.55 E+07$ & $8.93 E+07$ & $5.03 E+07$ & $4.27 E+07$ & $1.62 E+08$ & $2.51 E+09$ \\
\hline $1.15 E+06$ & $5.68 E+08$ & $1.23 \varepsilon+08$ & $6.25 E+05$ & $5.08 E+05$ & $2.13 E+08$ \\
\hline $3.17 E+07$ & $1.81 E+06$ & $2.19 E+00$ & $8.57 E+05$ & $0.00 E+00$ & $3.30 E+09$ \\
\hline $9.65 E+08$ & $2.16 E+08$ & $7.80 E+05$ & $3.51 E+05$ & $1.31 E+06$ & $4.26 E+07$ \\
\hline $7.30 E+06$ & $6.25 E+07$ & & $3.51 E+08$ & $2.46 E+07$ & $5.70 E+08$ \\
\hline $3.65 E+05$ & & & & $2.81 E+05$ & $0.26 E+05$ \\
\hline $2.50 E+O B$ & 0 & $7.608+04$ & & $2.66 E+07$ & $2.92 E+07$ \\
\hline $7.38 E+05$ & $6.50 E+02$ & & & $3.93 E+08$ & $7.38 E+08$ \\
\hline $2.03 E+07$ & $5.30 E+08$ & $6.88 E+08$ & $2.34 E+06$ & $5.26 E+08$ & $9.71 E+08$ \\
\hline $3.60 E+08$ & $3.52 E+08$ & $1.68 E+08$ & $1.86 E+08$ & $6.68 E+08$ & $1.41 E+10$ \\
\hline & & & & & \\
\hline $7.72 E+05$ & $1.18 E+06$ & $1.25 E+06$ & $8.23 E+05$ & $0.00 E+00$ & $6.02 E+06$ \\
\hline $1.61 E+07$ & 0 & 은 & 0 & $6.68 E+05$ & $1.78 E+08$ \\
\hline $1.79 E+07$ & $0.00 E+00$ & $0.00 E+00$ & $0.00 E+00$ & $1.40 E+06$ & $1.07 E+08$ \\
\hline $0.00 E+00$ & 0 & & 0 & $0.00 E+00$ & $2.83 E+08$ \\
\hline
\end{tabular}

B. 12 


\section{Appendix C}

Case I GTF Tank Composition Data 


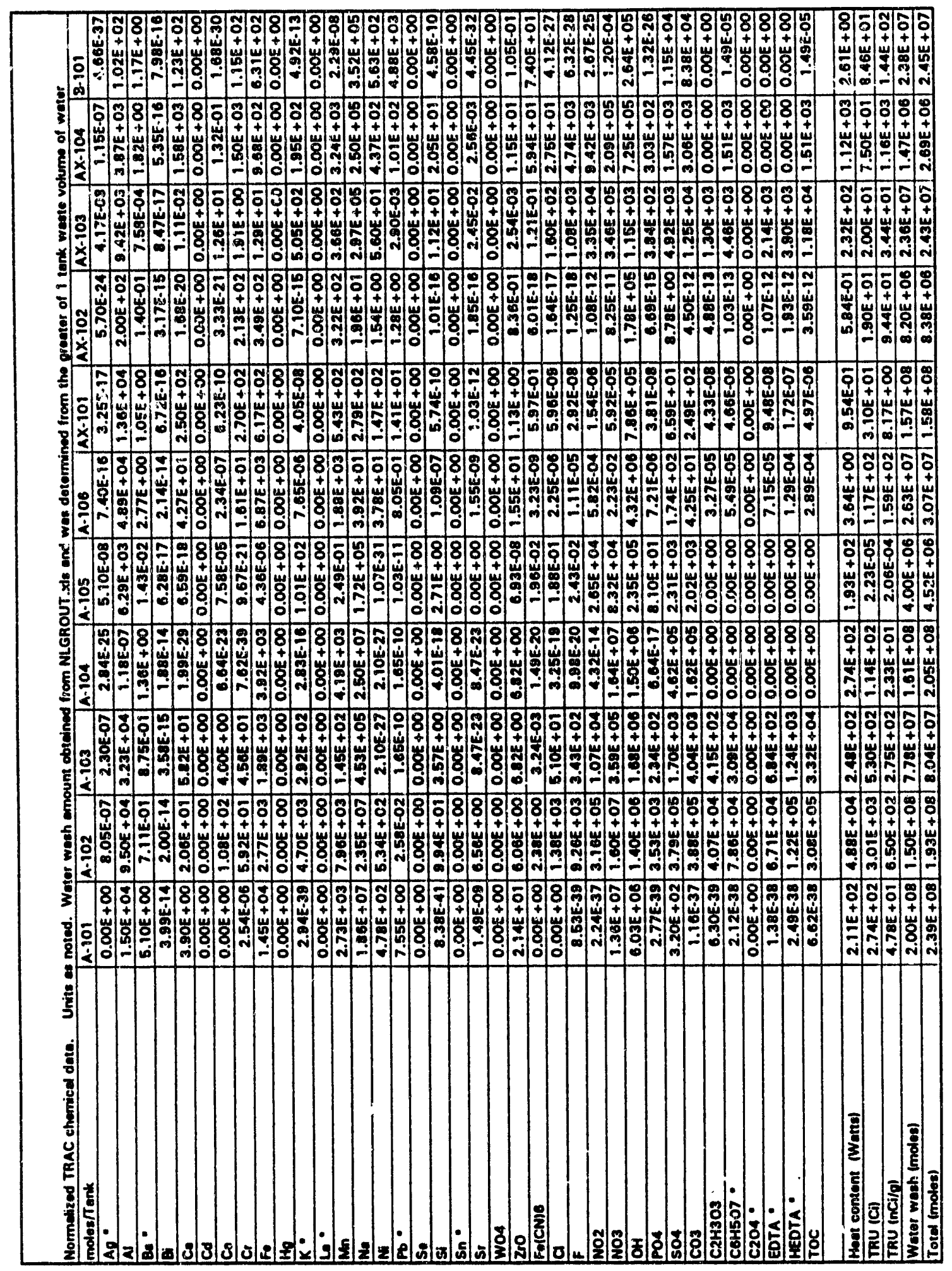

C. 1 


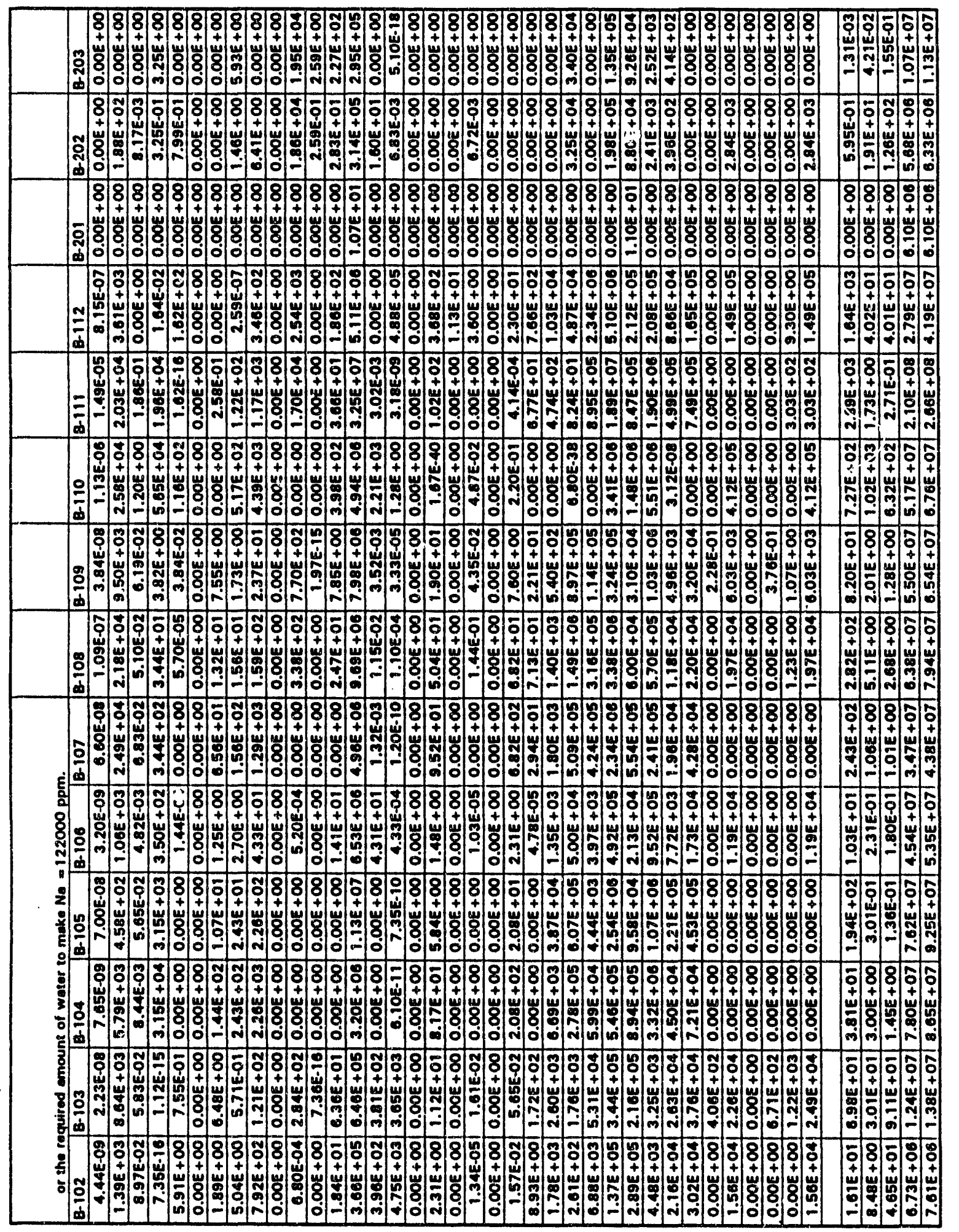




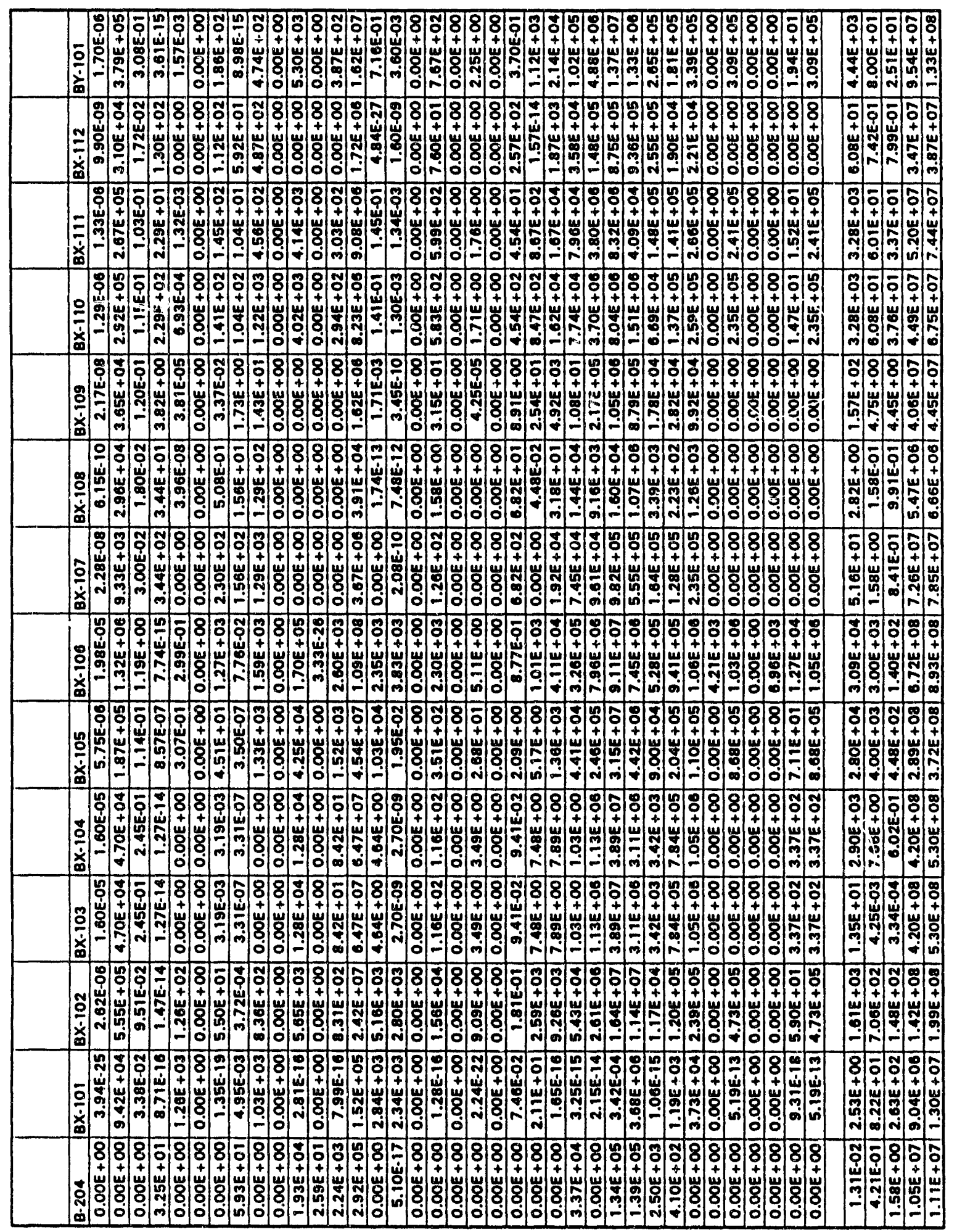

C. 3 


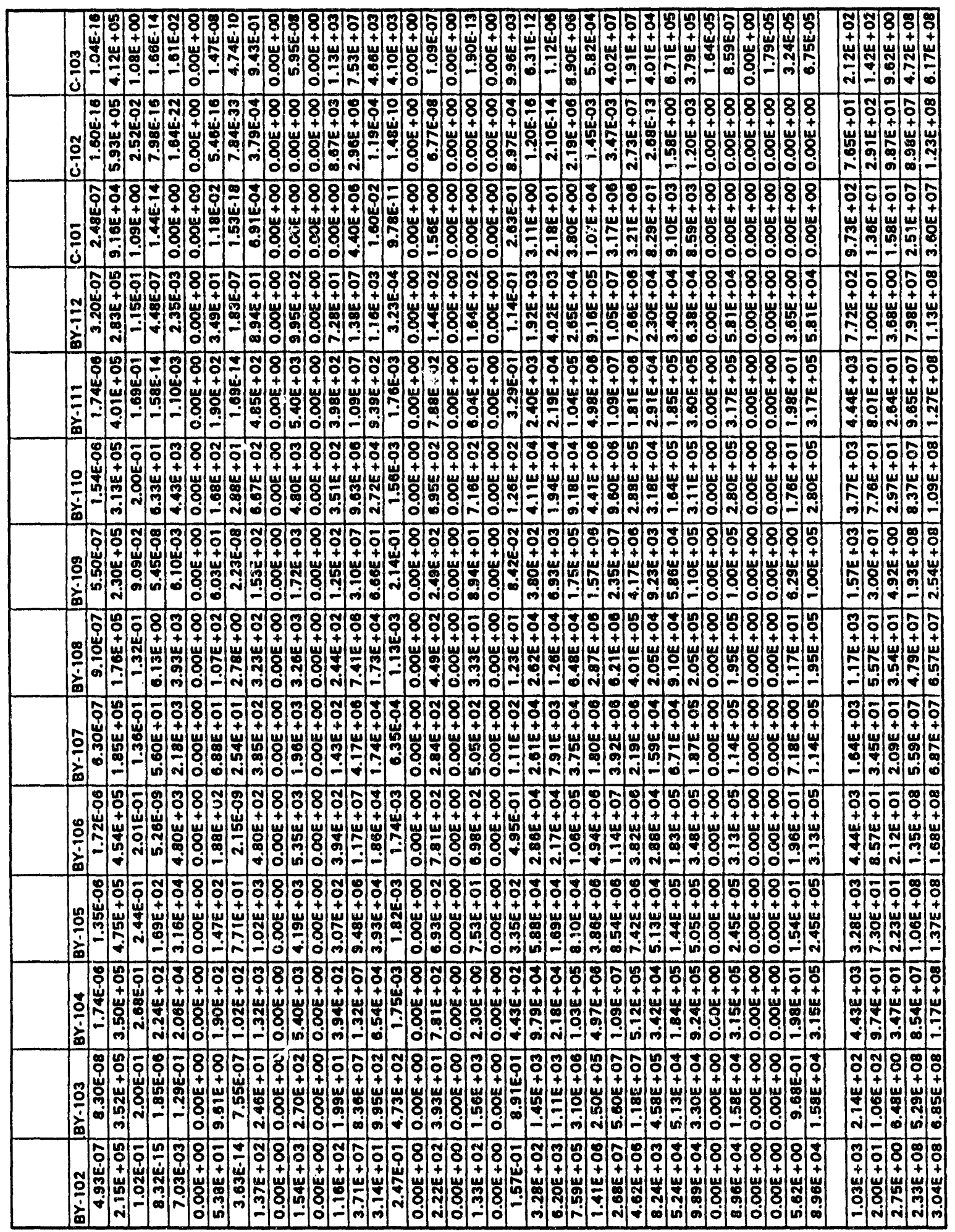

\section{4}




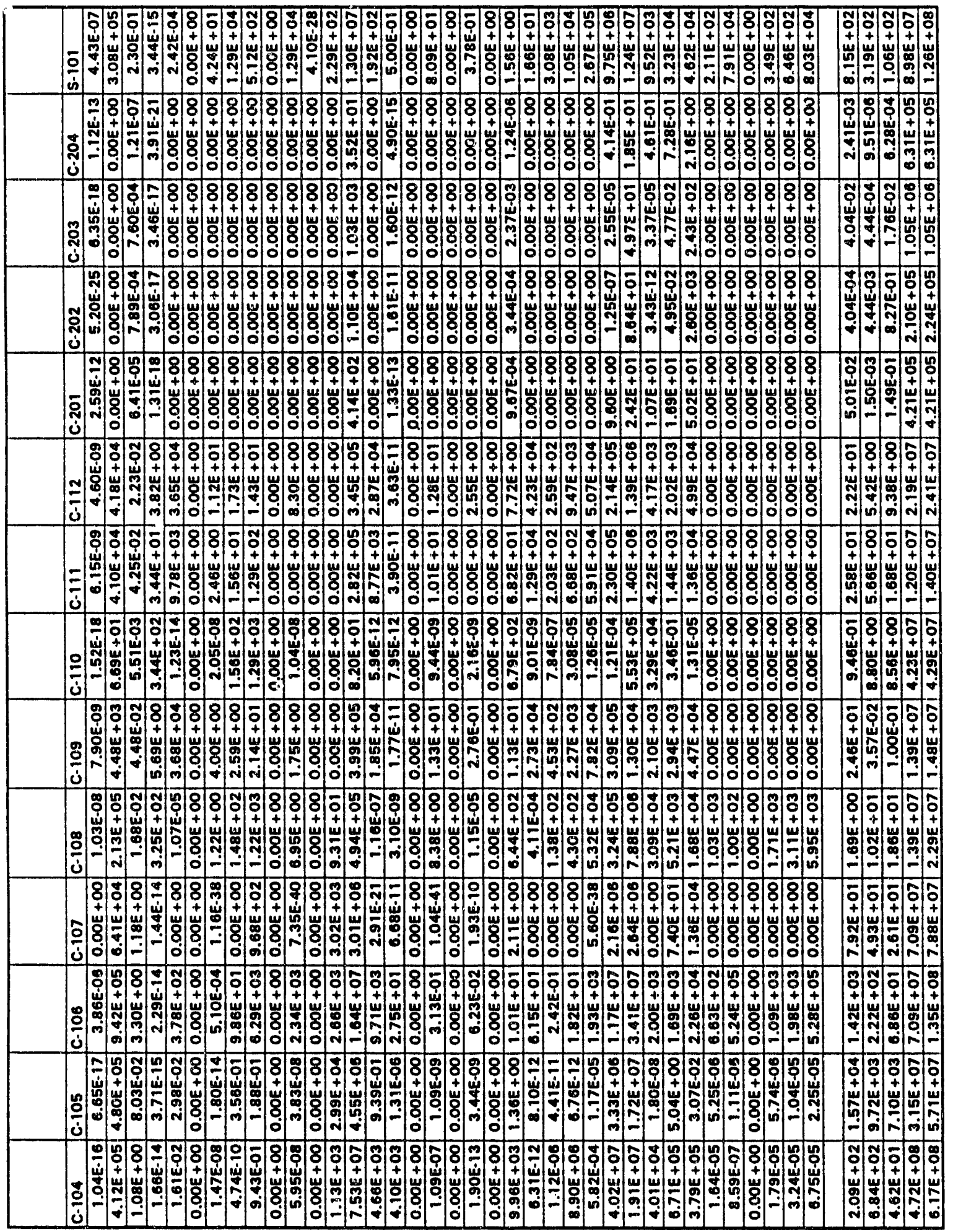




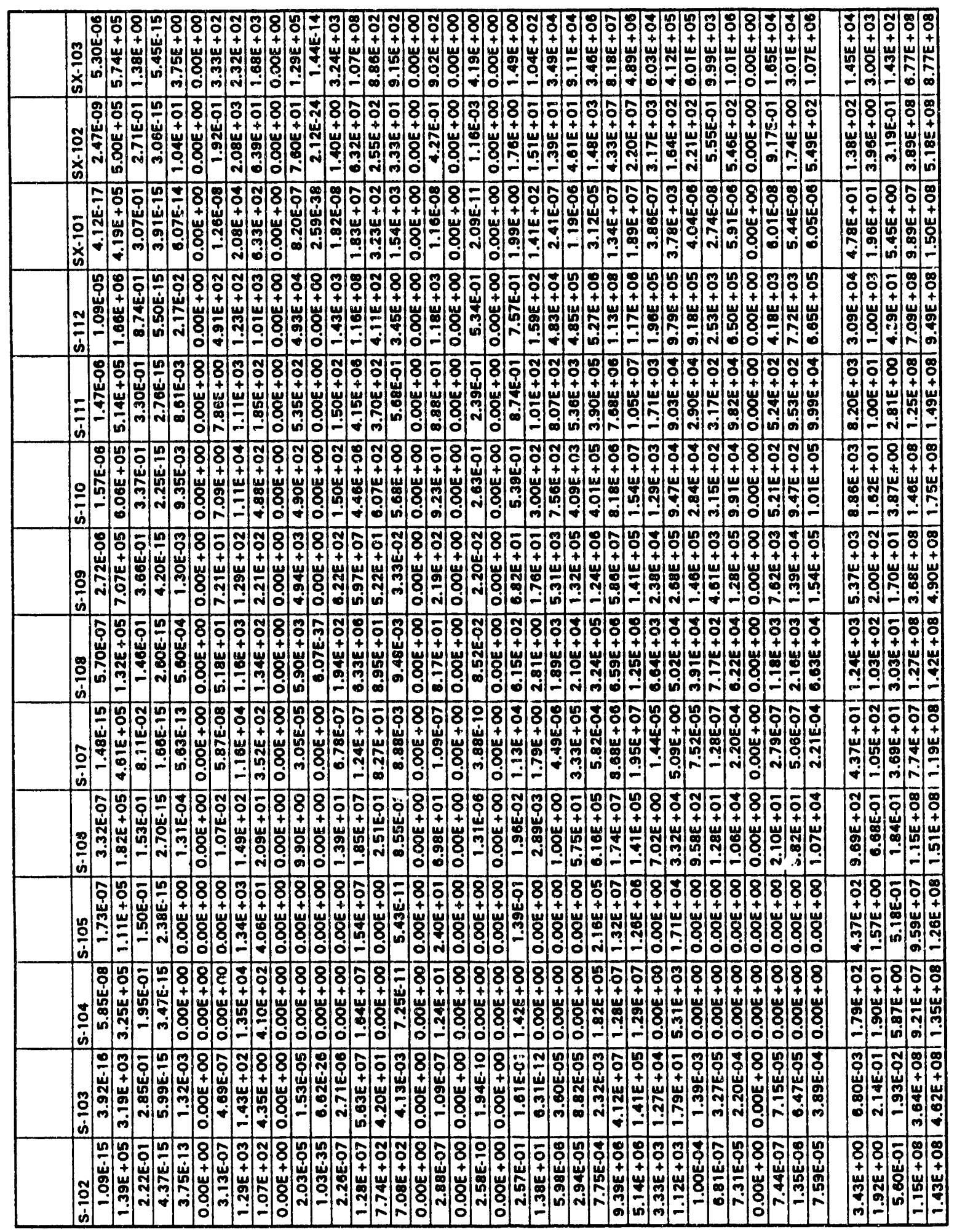




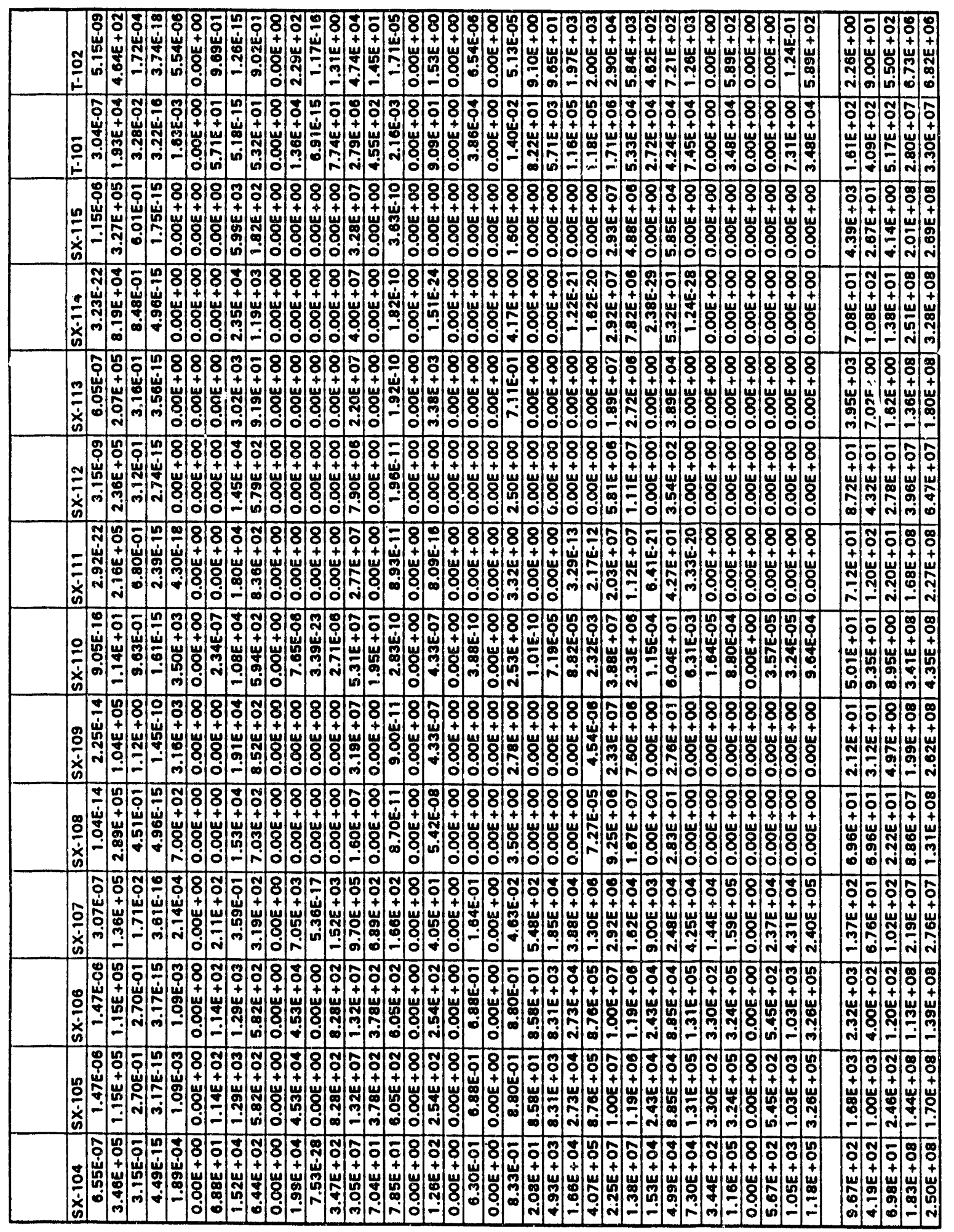

C. 7 


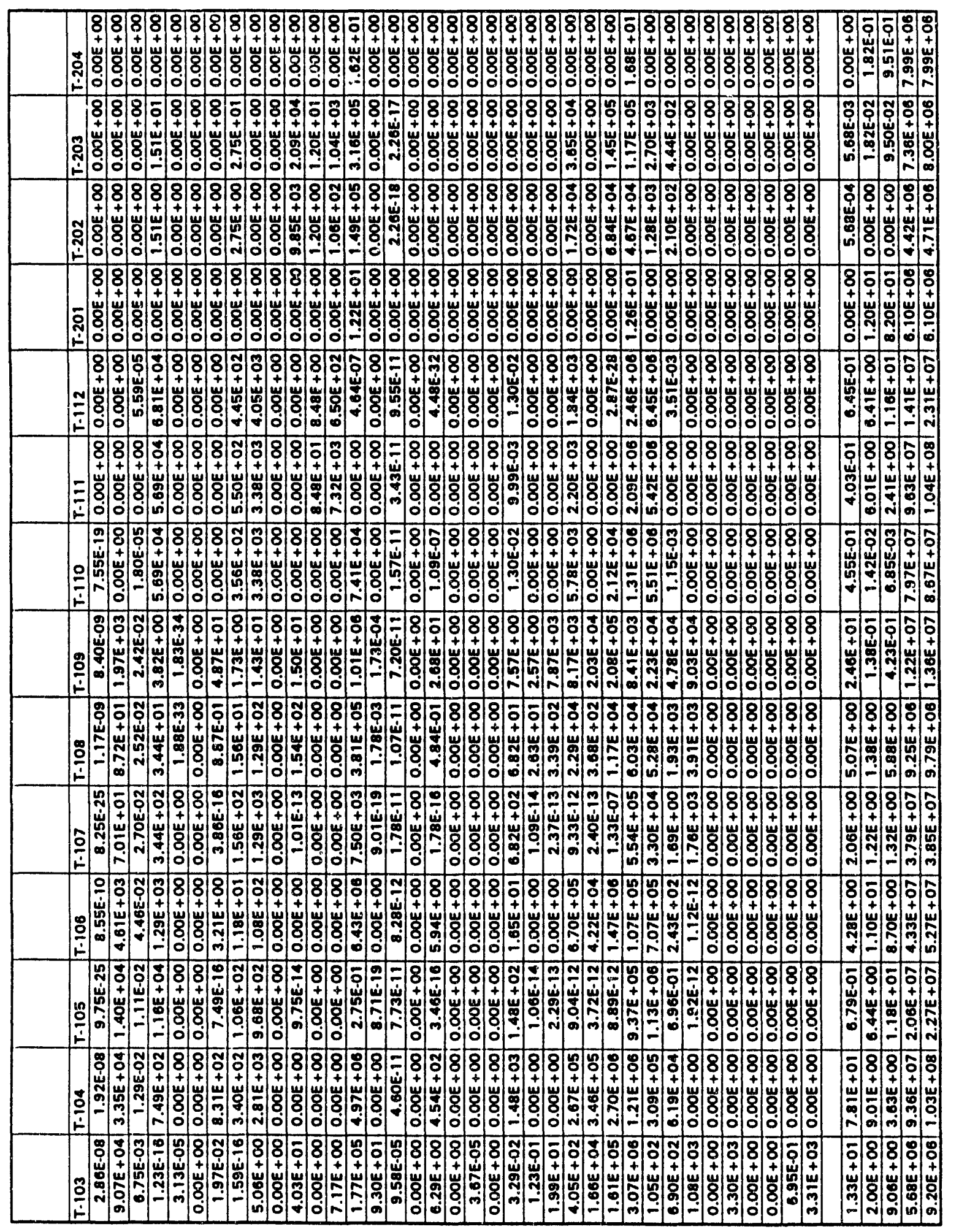




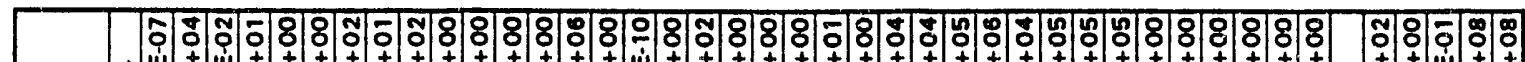

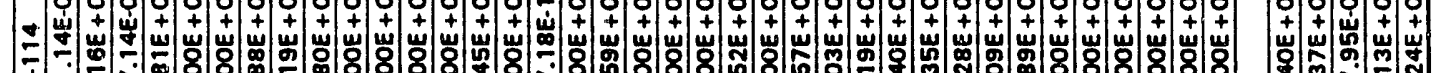

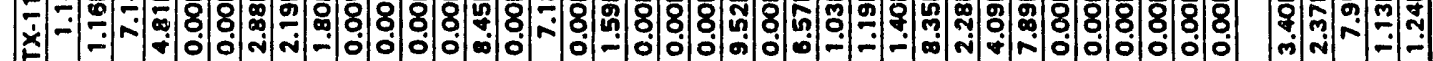
\% $\cong$ 岕 文

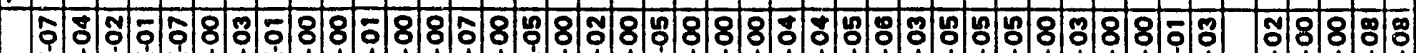

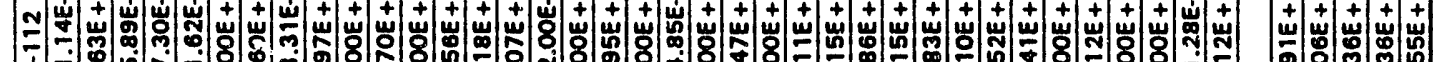
×े

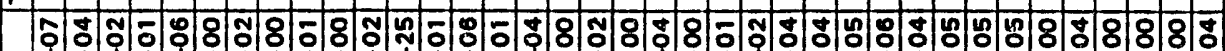

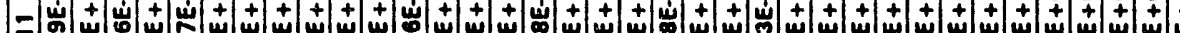

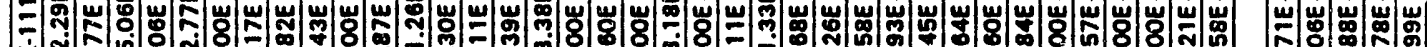
文 N

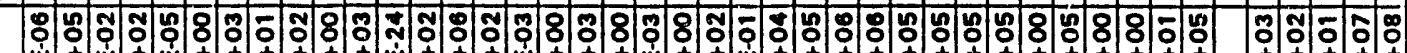
의 市

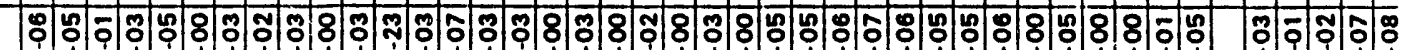

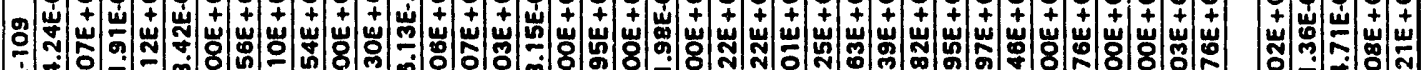

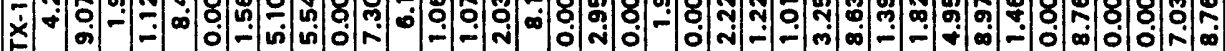

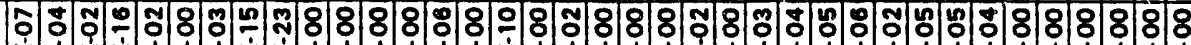

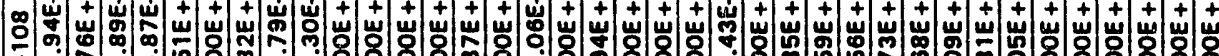
离

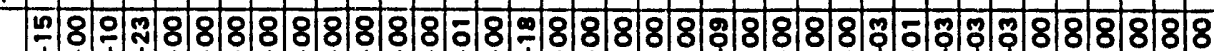

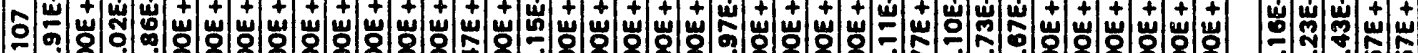
ஸे :

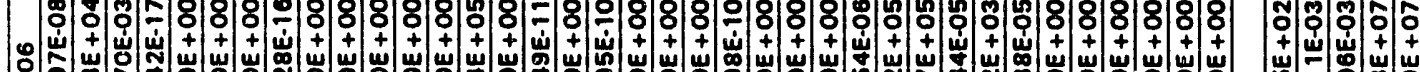
市

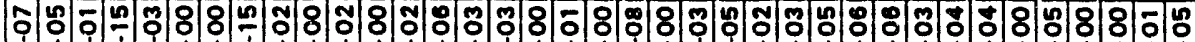
n 文 文 n

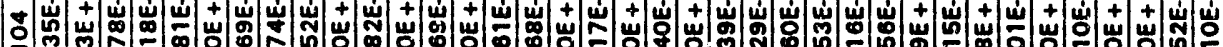

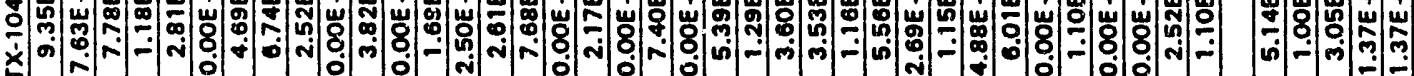

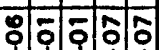

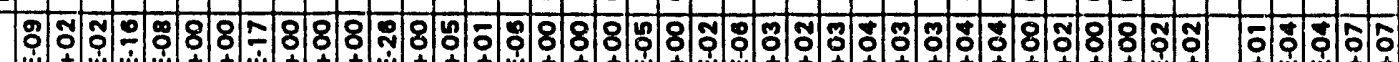

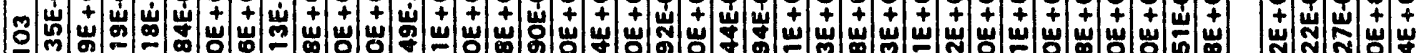
文

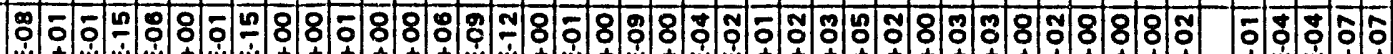

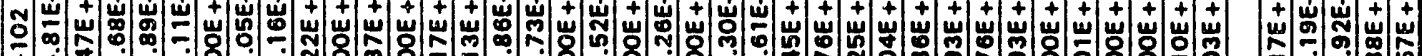

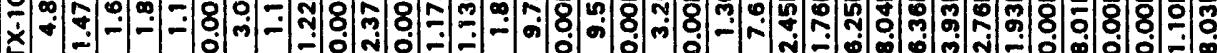

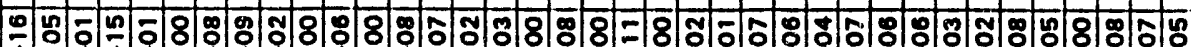
-

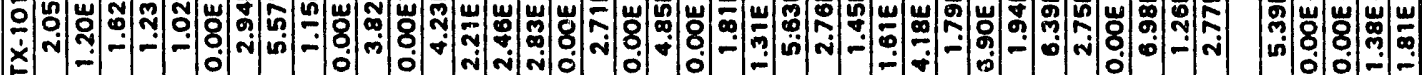




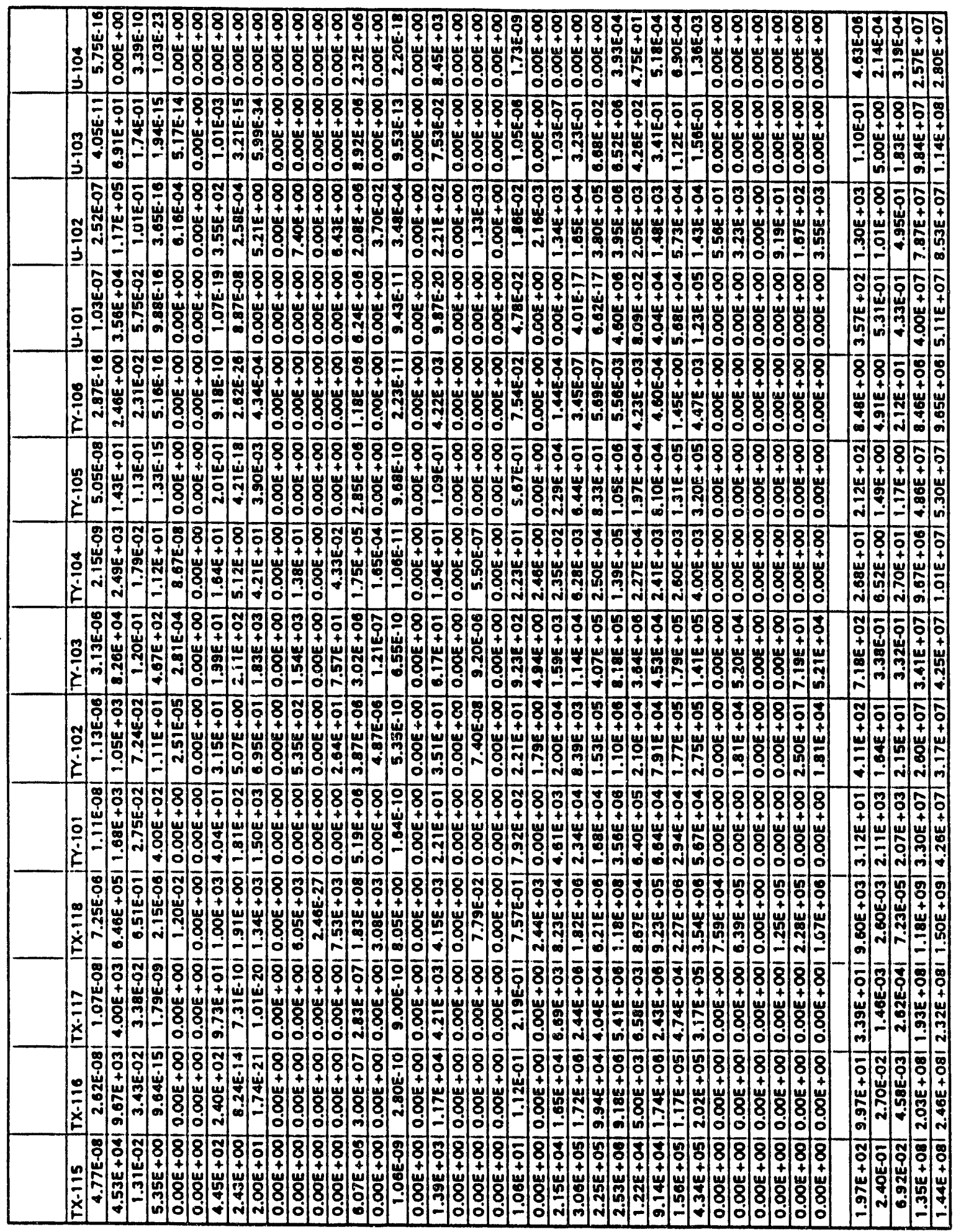




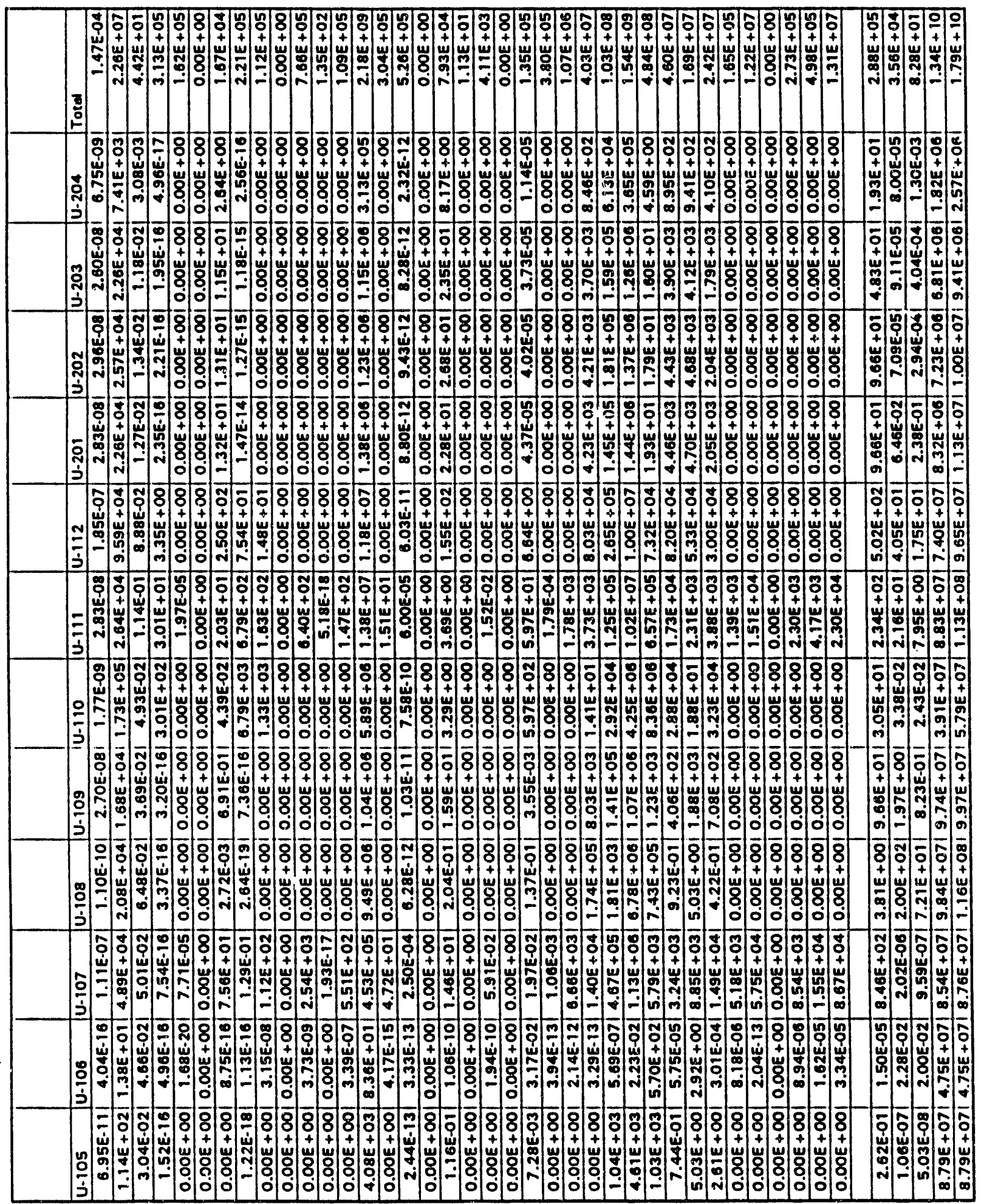


Appendix D

Sort of Tanks by HWVP Outliers 


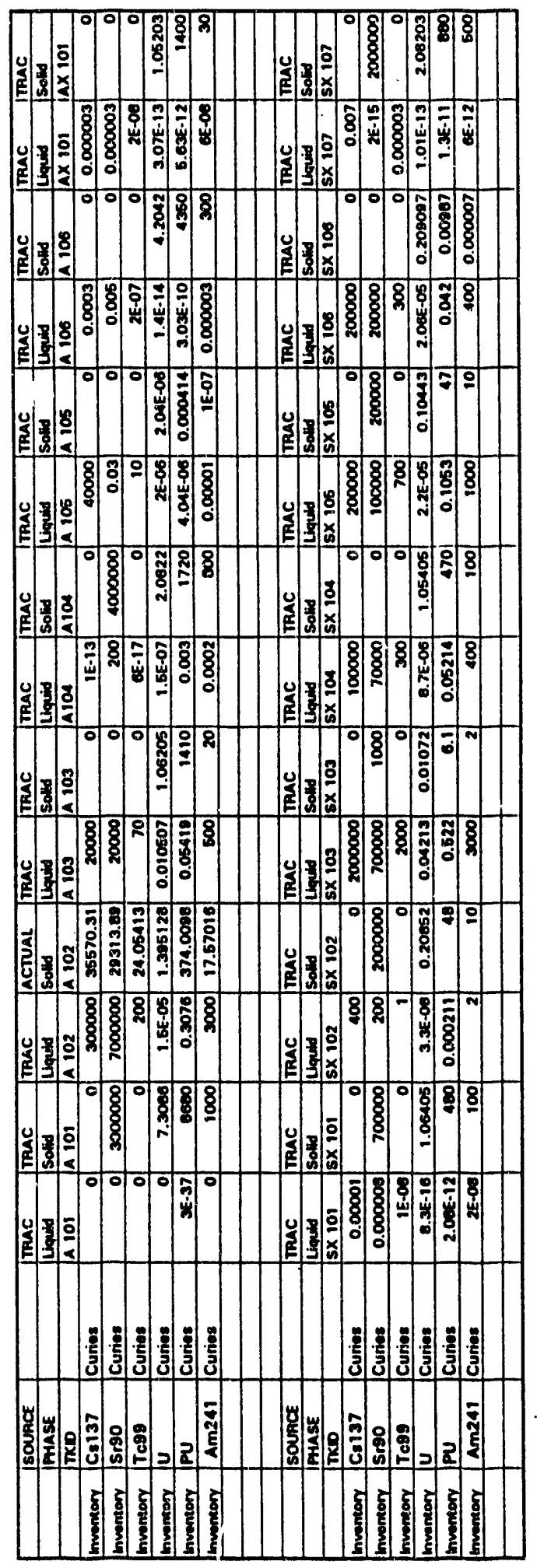

D. 1 


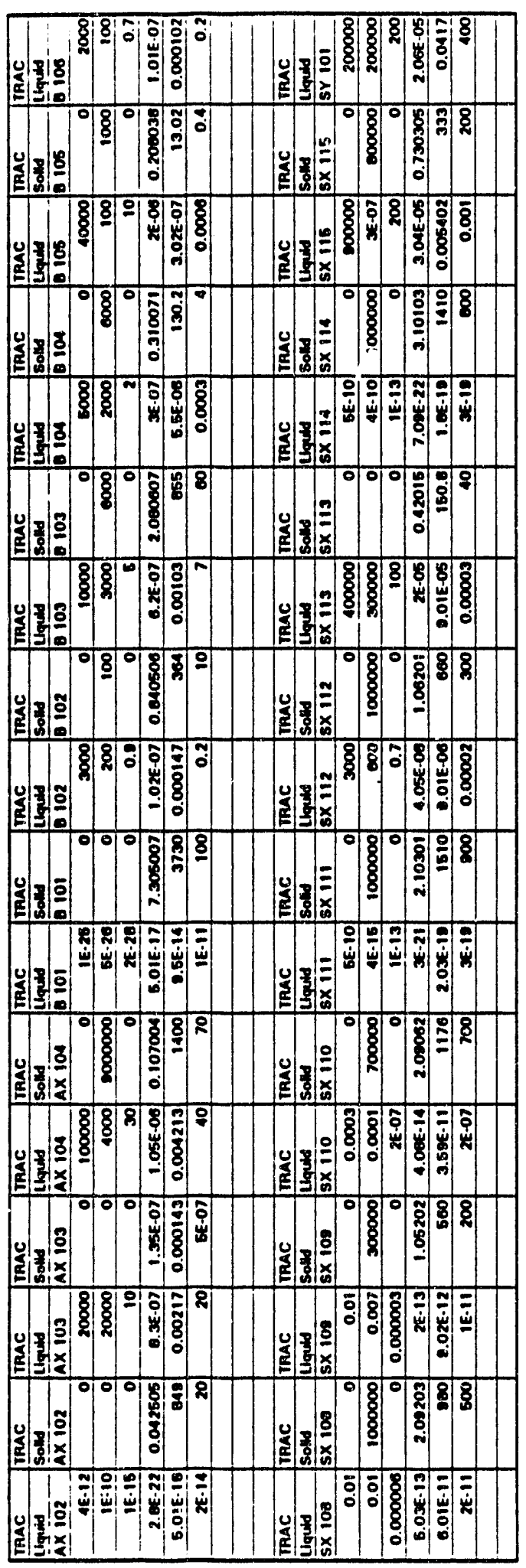

D. 2 


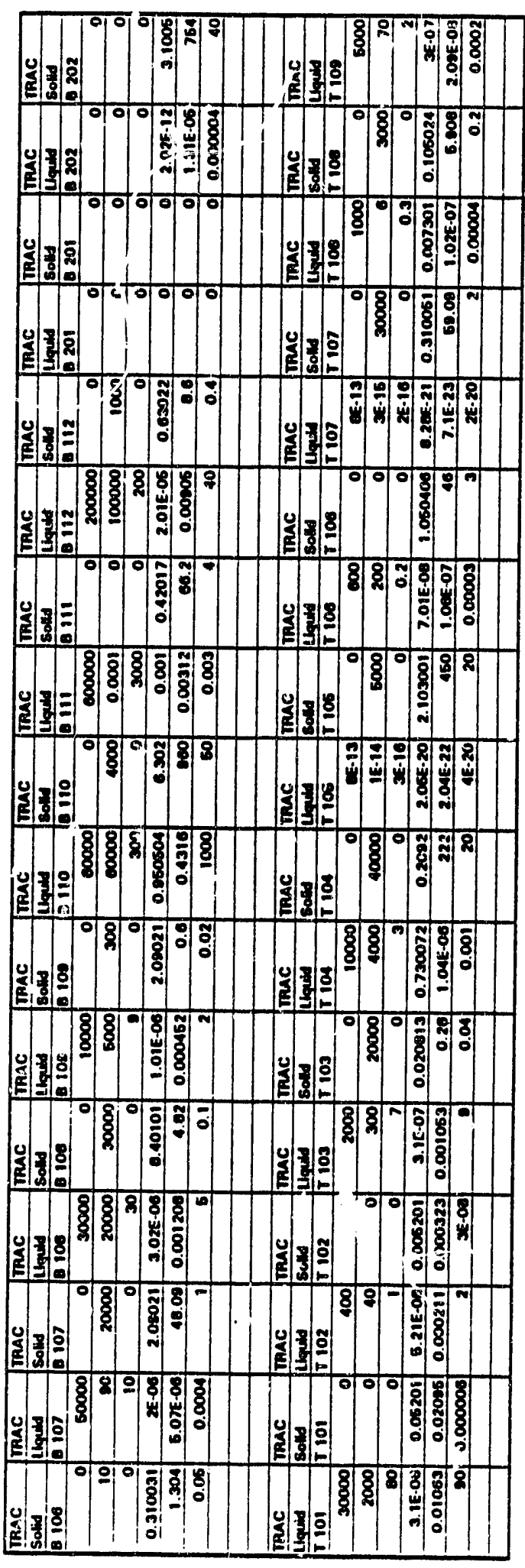

D. 3 


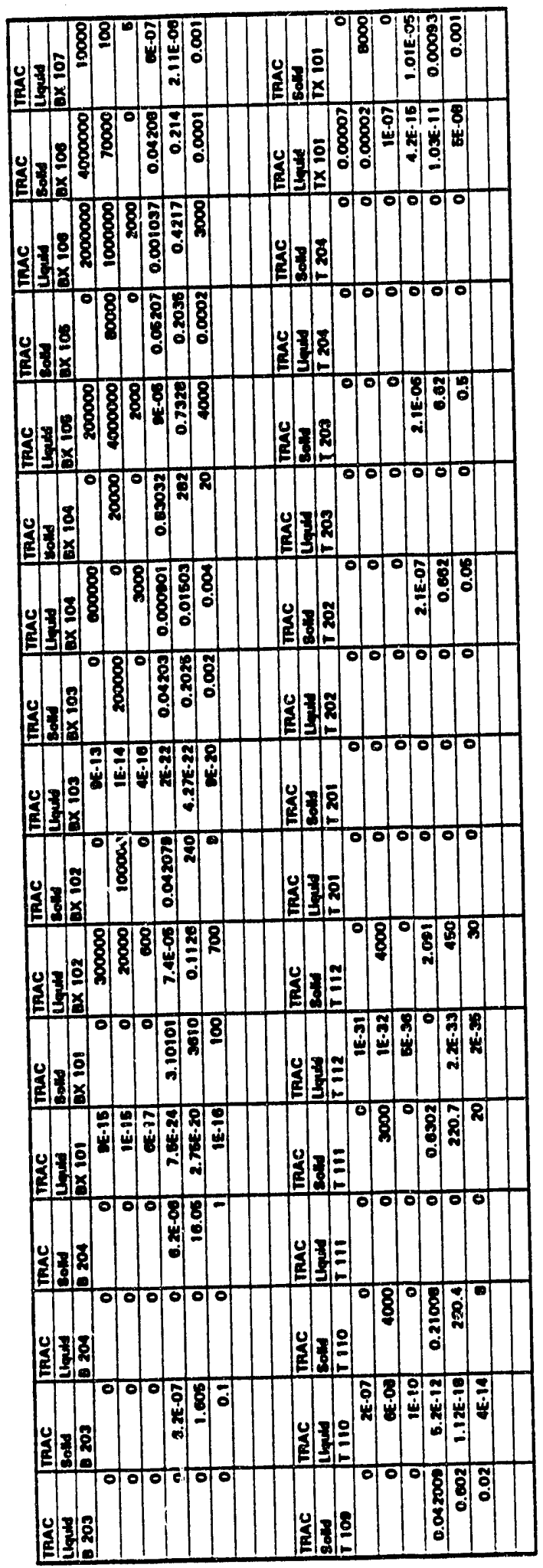

D. 4 


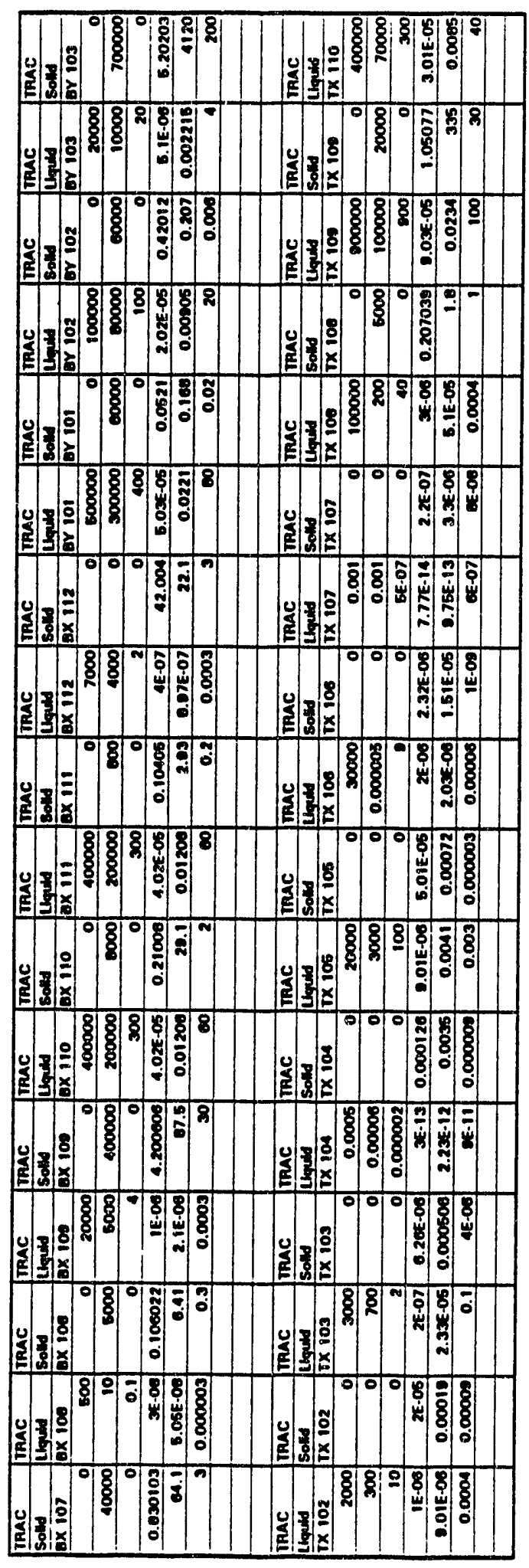

D.5 


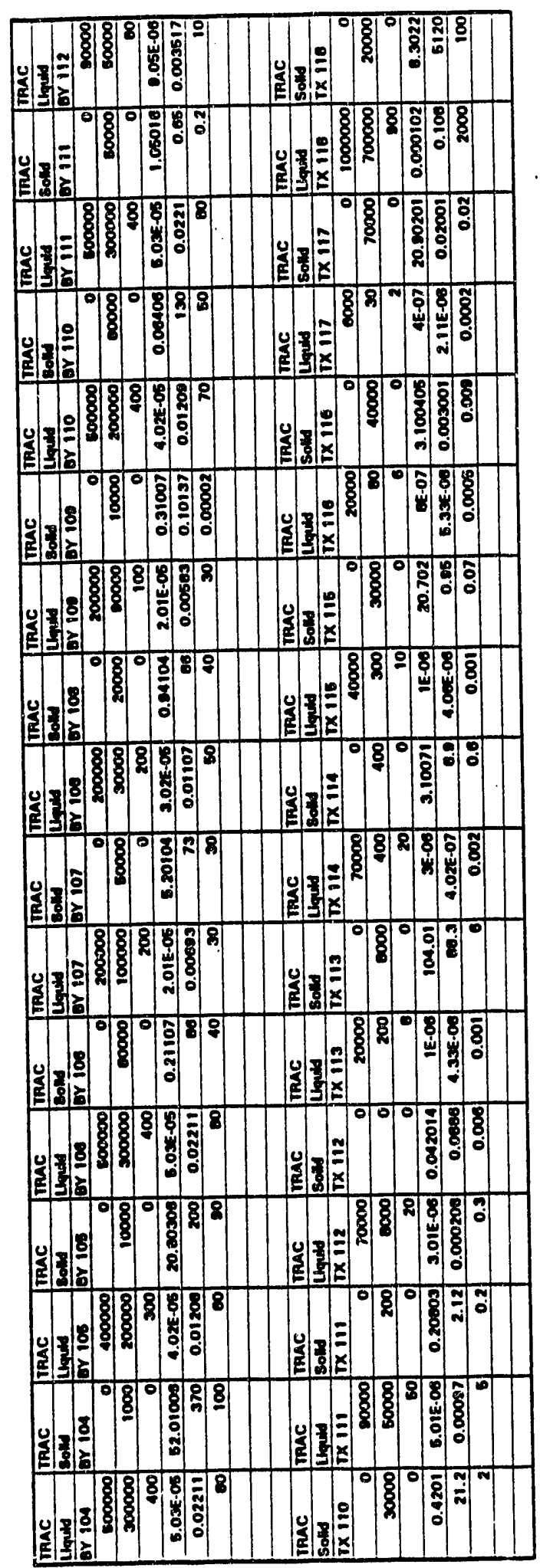

D. 6 


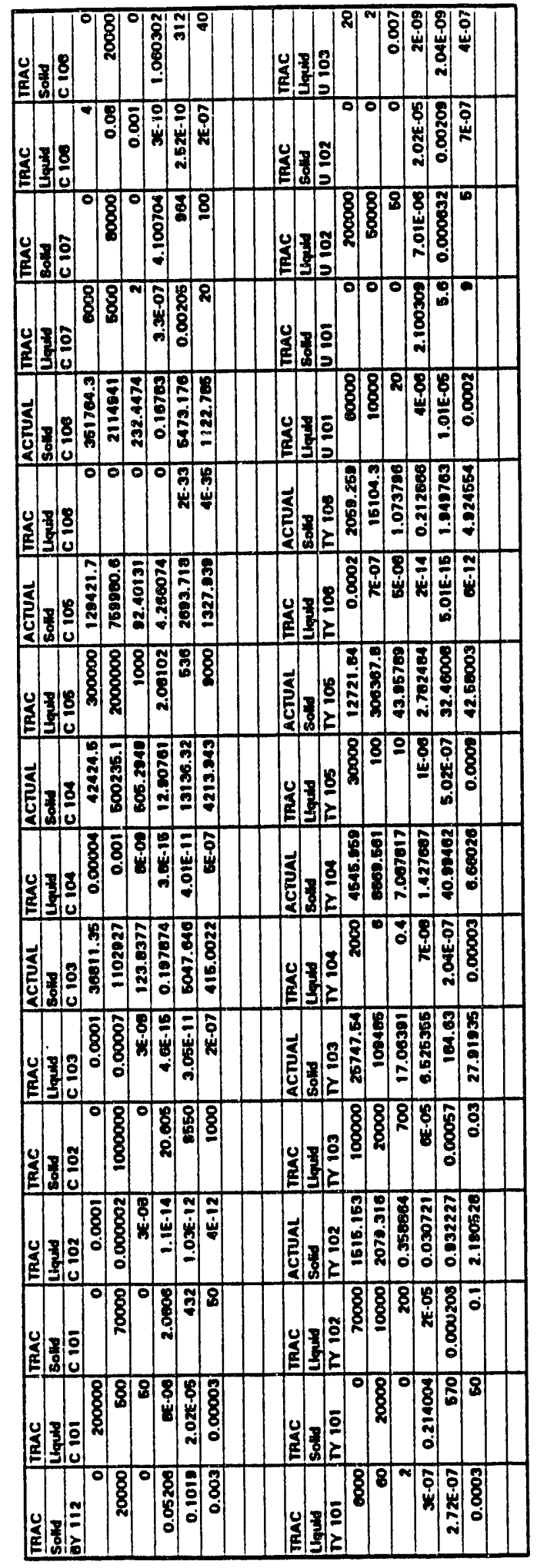

D. 7 


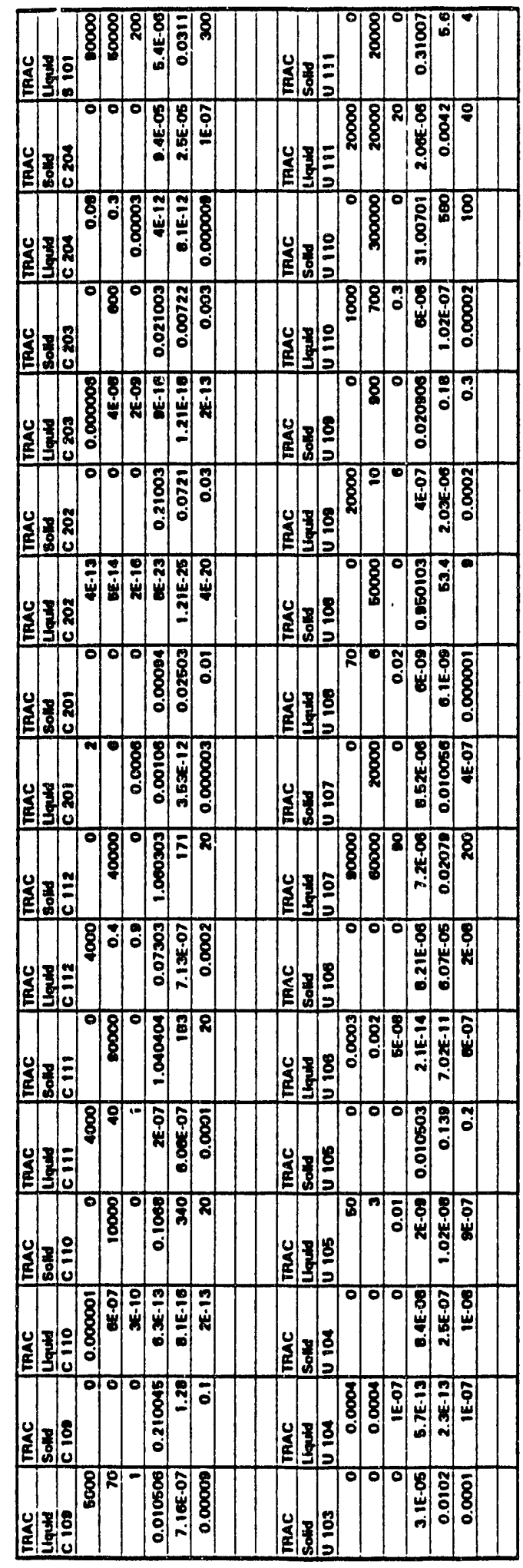

D. 8 


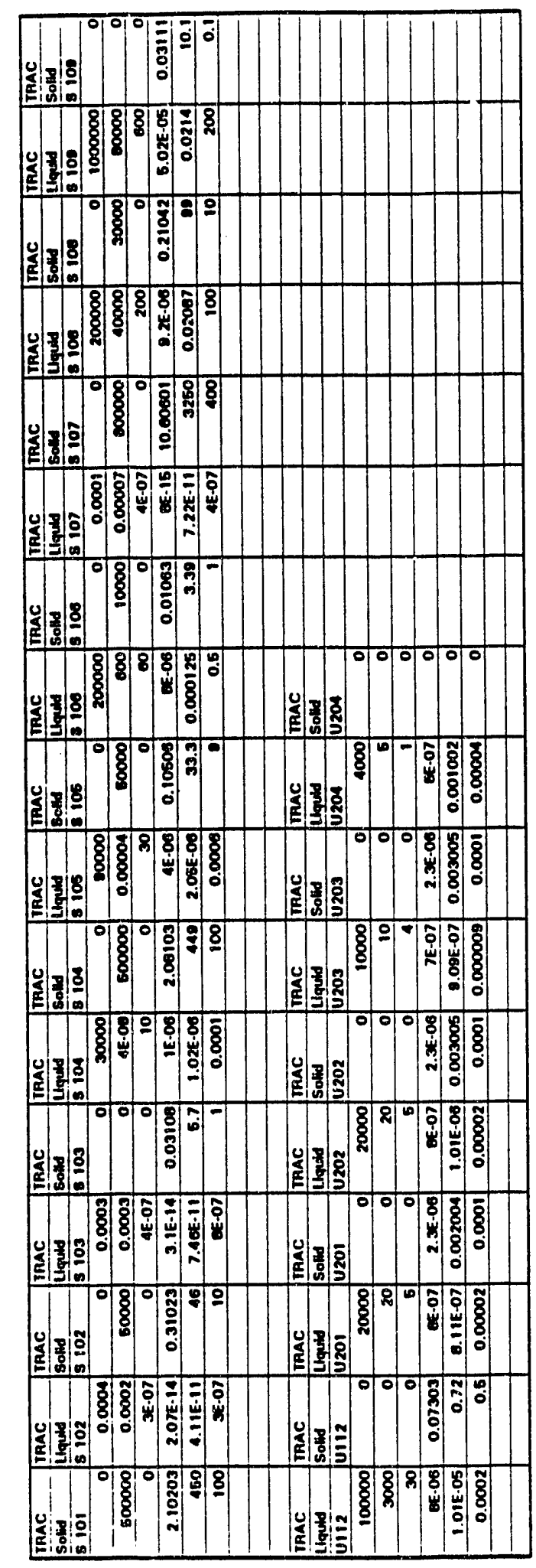

D. 9 


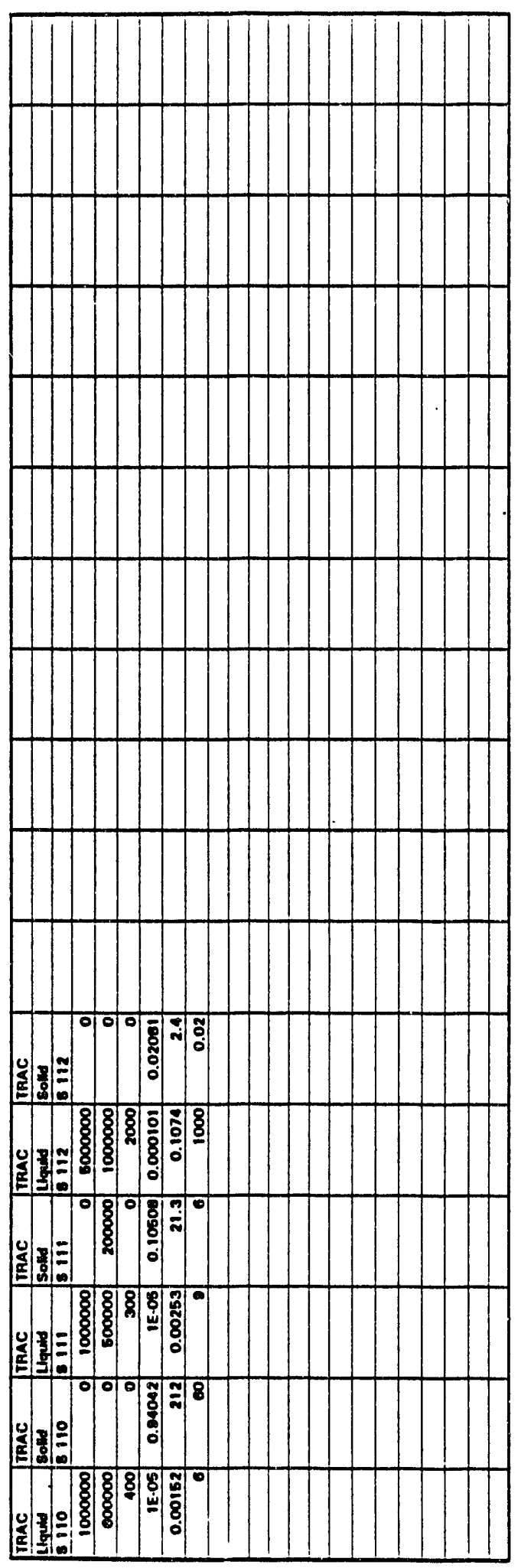

D. 10 


\section{Appendix E}

\section{GTF Grout Feed Data}




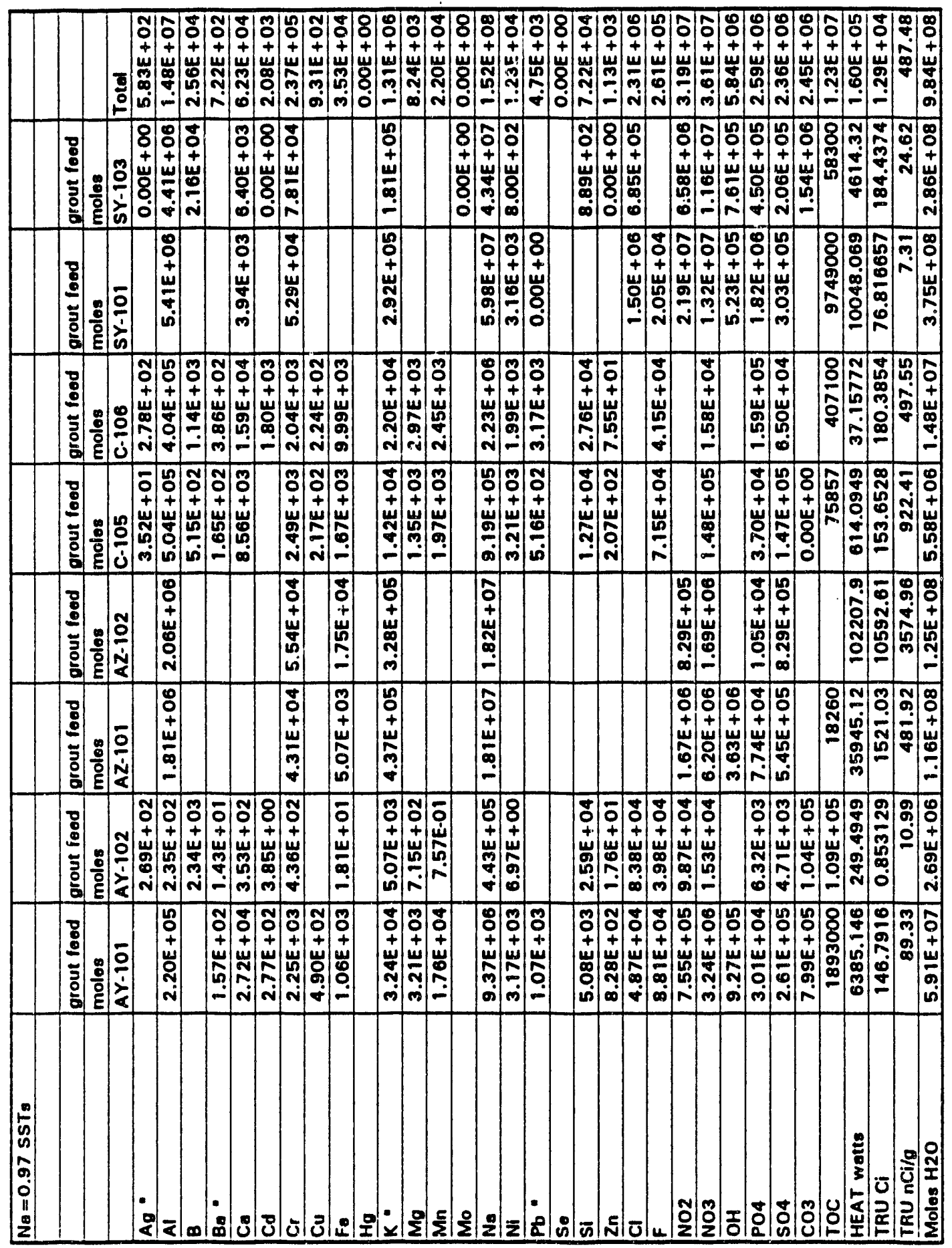

E. 1 
Appendix F

Radiochemical Data for SSTs 


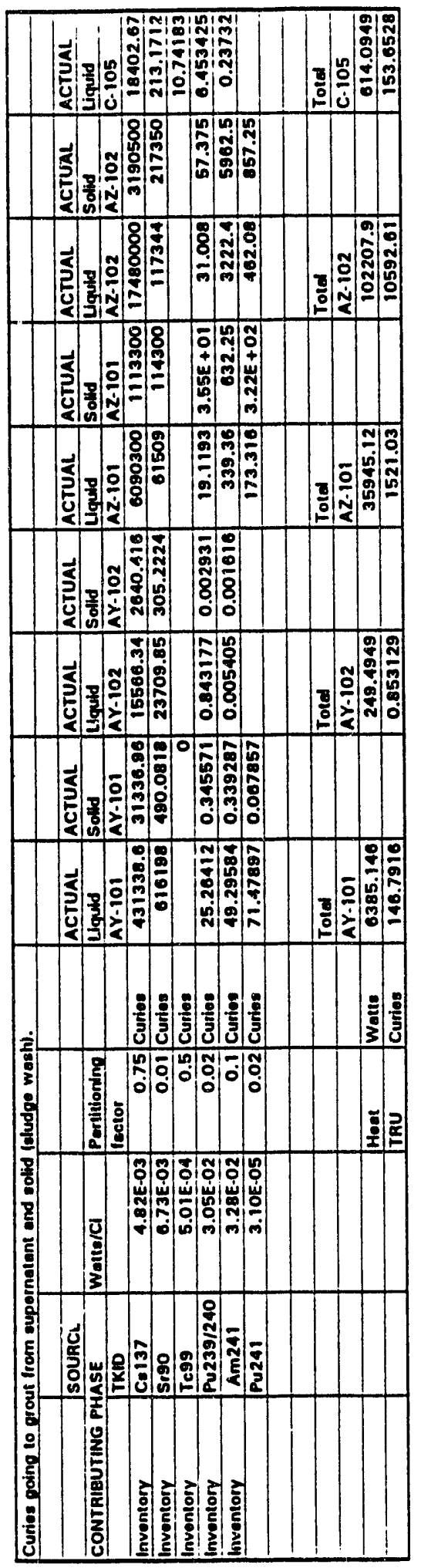

F. 1 


\begin{tabular}{|l|l|l|l|l|l|l|}
\hline & & & & & & \\
\hline & & & & & & \\
\hline ACTUAL & ACTUAL & ACTUAL & ACTUAL & ACTUAL & ACTUAL & ACTUAL \\
\hline Solld & Liquid & Sollid & Liquid & Solld & Liquid & Solid \\
\hline C-105 & C-106 & C-106 & $5 Y-101$ & $5 Y-101$ & $5 Y-103$ & SY-103 \\
\hline 97021.38 & 5050.704 & 1063.607 & 509835.5 & 1567093 & 0.000265 & 955896.3 \\
\hline 7603.308 & 299.772 & 21.11219 & 3511.931 & 1372.181 & & \\
\hline 44.00063 & 25.61688 & 0.074639 & & & & \\
\hline 14.96021 & 177.683 & 0.065043 & 0.121101 & 1.122694 & & 4.334039 \\
\hline 132.0019 & 2.525352 & 0.111959 & 0.726606 & 74.84626 & $4.57 E-09$ & 180.1034 \\
\hline & & & & & & \\
\hline & & & & & & \\
\hline & & & & & & \\
\hline & Total & & Total & & Total & \\
\hline & C-106 & & $5 Y-101$ & & $5 Y-103$ & \\
\hline & 37.15772 & & 10048.07 & & 4614.32 & \\
\hline & 180.3854 & & 76.81666 & & 184.4374 & \\
\hline
\end{tabular}


Appendix G

Case II HWVP Tank Compcsition Data 


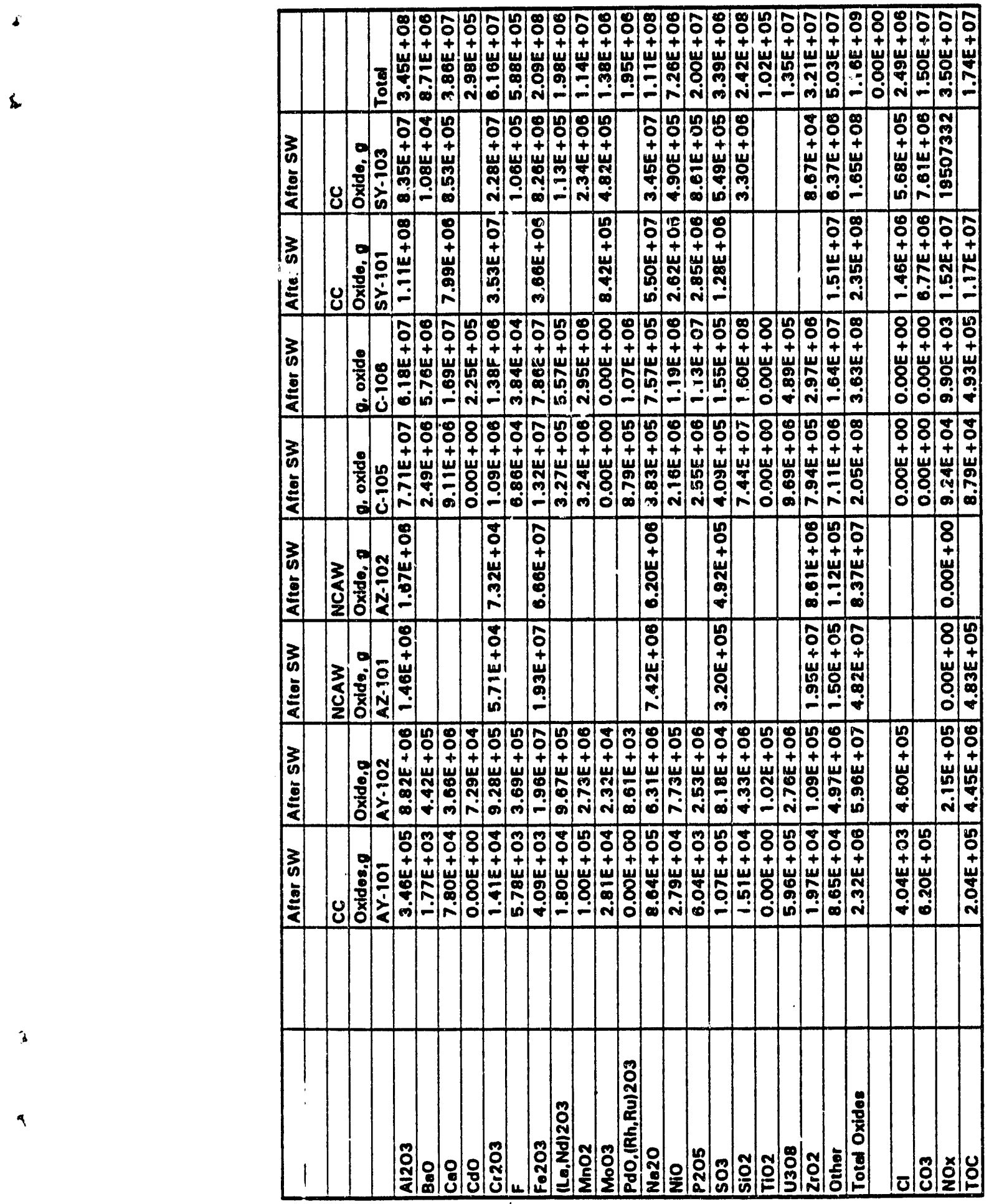

G. 1 


\section{Distribution}

No. of

Copies

12 DOE/Office of Scientific and Technical Information

5 DOE Richland Field Office

S. Burham

A5-16

L. Erickson

P. E. Lamont

C. K. Liv

J. C. Peschong

31 Westinghouse Hanford Company

J. N. Appel (10)

H. Babad

S. A. Barker

W. B. Barton

G. D. Bazinet

A. L. Boldt

J. M. Cruse

R. L. Gilchrist

G. Hansrote

H. D. Harmon

B. K. Horsager

R. A. Kirkbride

M. J. Klem

M. J. Kupfer

W. C. Miller

R. M. Orme

E. H. Randkiev

P. S. Schaus

R. A. Watrous

E. T. Weber

L. A. Wilkins

D. D. Wodrich
S4-58

A5-16

A5-16

A5-16

A5-16

R2-78

S4-58

L4-75

L4-71

A1-15

L5-63

L6-26

G6-12

R2-52

S4-57

S4-58

S4-58

H5-49

B1-58

S4-58

G6-08

B1-59

G6-08

G6-08

L4-71

B1-59
No. of

Copies

50 Pacific Northwest Laboratory

J.G.H. Geeting (10) P7-43

C. R. Allen P7-43

W. J. Apley P7-46

E. G. Baker P8-38

G. H. Beeman K6-24

K. P. Brooks P7-43

G. H. Bryan P7-25

L. R. Bunnell P8-44

C. D. Carlson P7-25

J. A. Christensen K6-43

J. M. Creer G6-01

M. J. Danielson P8-44

L. L. Fassbender K6-61

M. Hoza K7-22

P. R. Hrma P8-37

B. M. Johnson K1-78

E. O. Jones P8-38

W. L. Kuhn P8-38

D. E. Kurath (5) P7-43

D. E. Larson G6-01

G. J. Lumetta P7-25

R. J. Robertus P8-38

J. E. Rodriguez K7-73

A. J. Schmidt K2-46

L. J. Silva P8-38

L. J. Snowden-Swan P8-38

J. L. Straalsund K1-79

J. E. Surma P7-43

J. L. Swanson P7-25

C. K. Thornhill P7-43

R. E. Westerman P8-84

Publishing Coordination

Technical Report Files (5)

Distr.1 

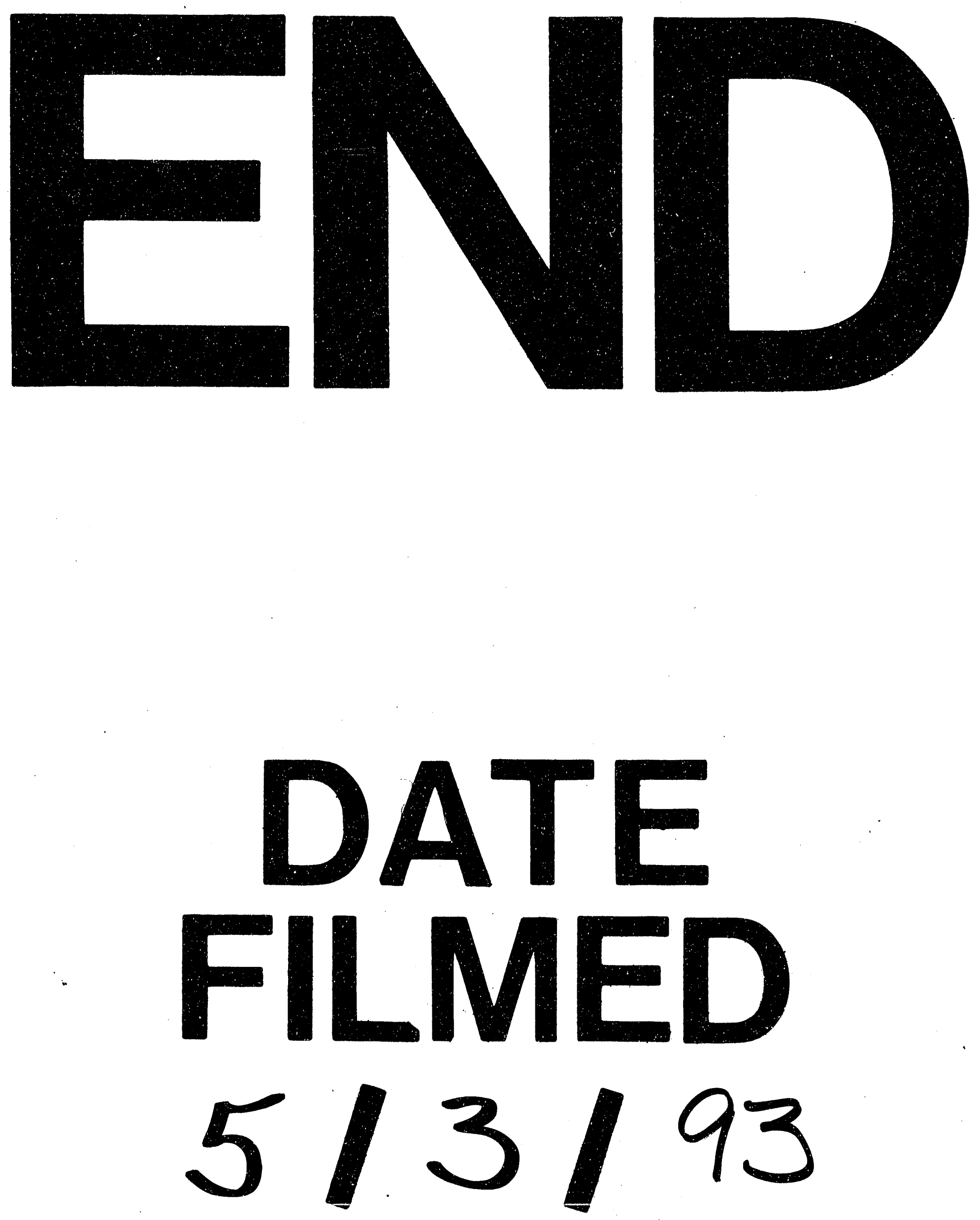
